\title{
Tianeptine induces GluA1 phosphorylation and subsequent alteration of the firing properties of CA1 neurons
}

\author{
$\mathrm{PhD}$ Thesis \\ Balázs Barkóczi \\ Zoltán Bay Nonprofit Ltd. - BAYGEN, Szeged \\ Department of Medical Chemistry, University of Szeged
}

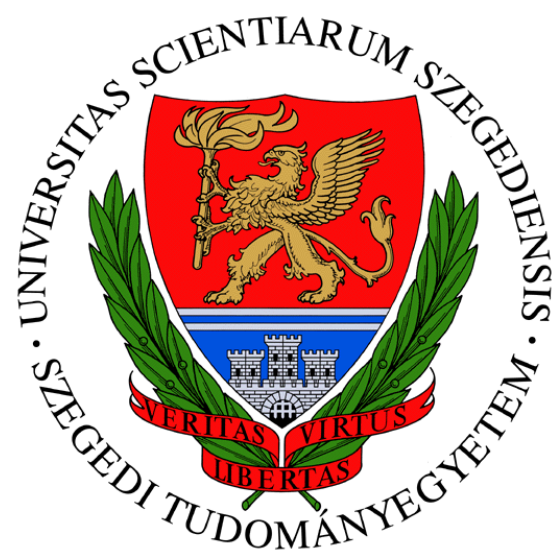

Supervisor

Viktor Szegedi PhD

Institute of Biochemistry

Biological Research Center, Hungarian Academy of Sciences, Szeged

Szeged

2012 


\section{Table of contents}

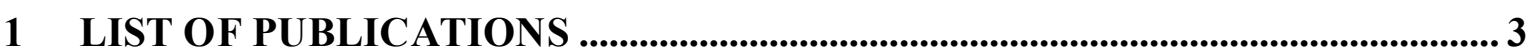

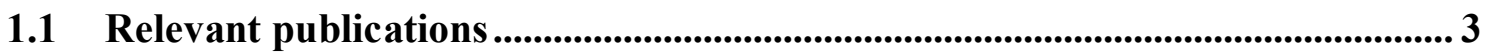

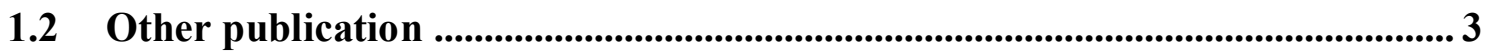

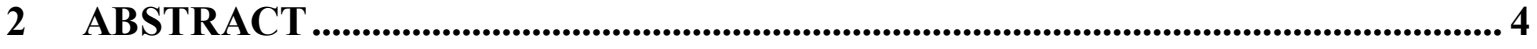

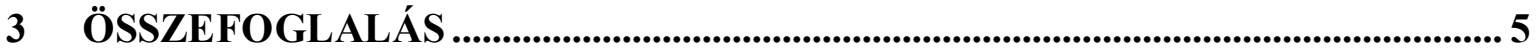

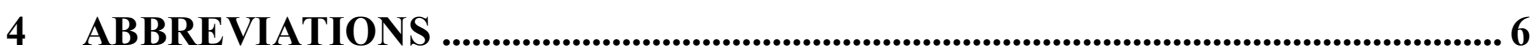

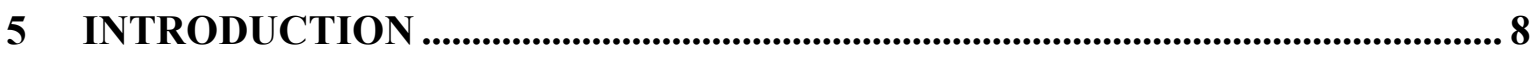

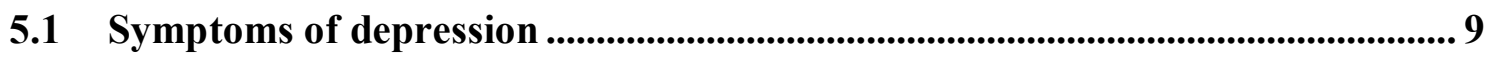

5.2 Hypotheses about the pathophysiology of depression ......................................... 11

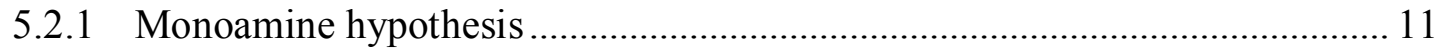

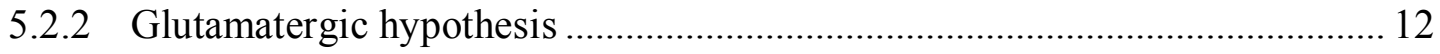

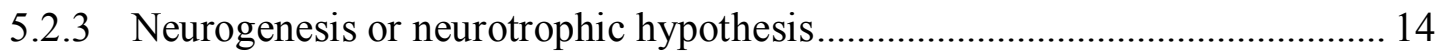

5.2.4 Alteration of information processing hypothesis ......................................... 15

5.3 Tianeptine, an atypical antidepressant ................................................................... 15

5.4 Tianeptine and AMPA receptors ............................................................. 17

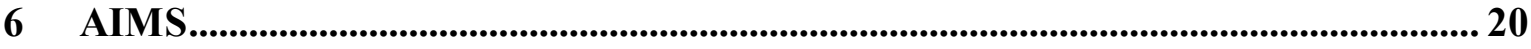

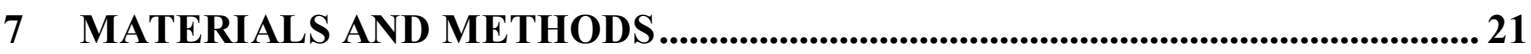

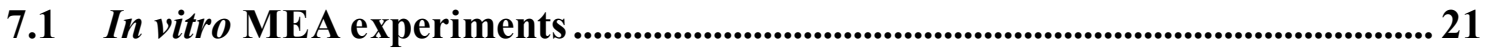

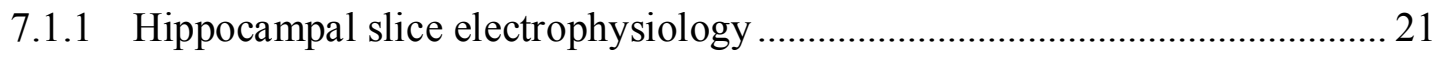

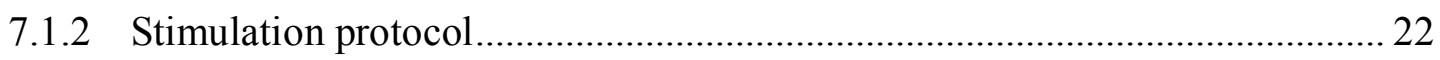

7.2 In vivo single-unit electrophysiology experiments .......................................... 22

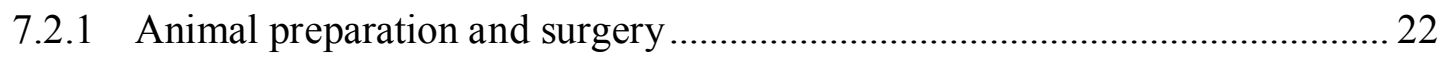

7.2.2 In vivo microiontophoresis and extracellular single-unit electrophysiology.. 22

7.3 Data analysis................................................................................................................. 23



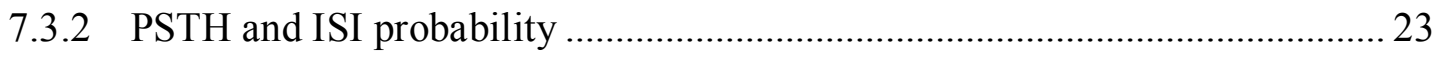

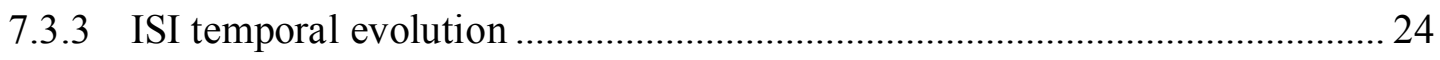

7.4 Animal care and handling .................................................................................................... 24

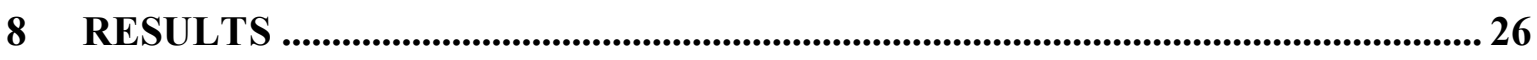

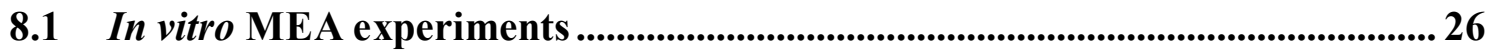

8.1.1 Tianeptine increases fEPSP amplitude in a dose-dependent manner ..............26 
8.1.2 The fEPSP amplitude enhancement is not of presynaptic origin ....................2 27

8.1.3 The effect of Tianeptine on NMDA and AMPA receptors ............................ 28

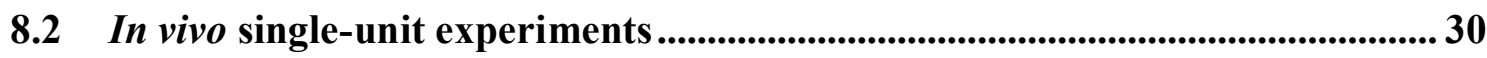

8.2.1 The effect of i.p. Tianeptine on NMDA- and AMPA-evoked neuronal firing

8.2.2 The effect of i.p. Tianeptine on the ISIs of NMDA- and AMPA-evoked

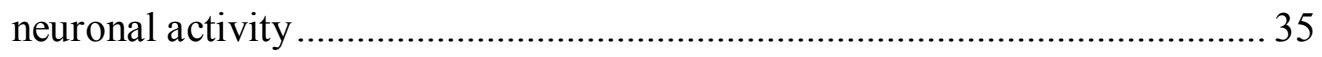

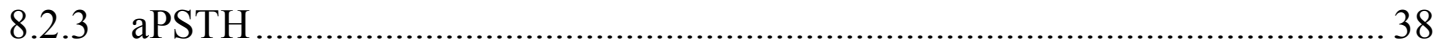

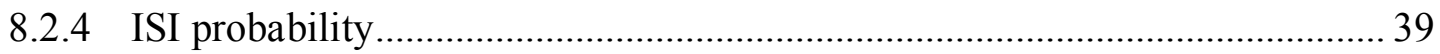

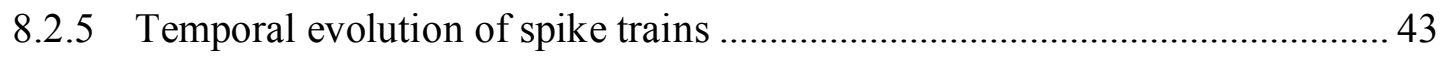

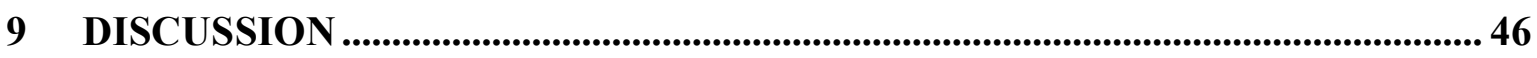

9.1 GluA1 phosphorylation alters the pattern of spiking .......................................... 48

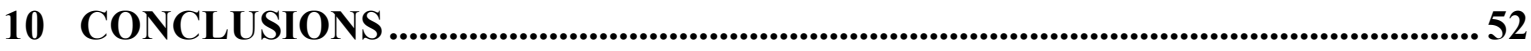

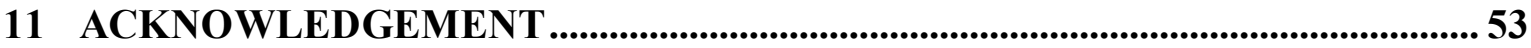

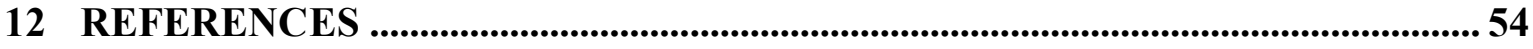

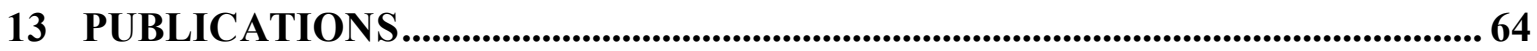

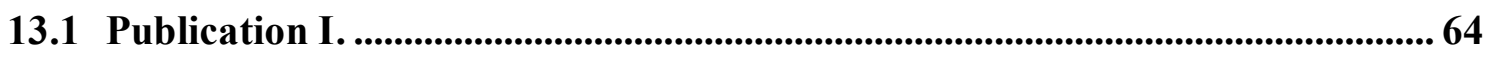

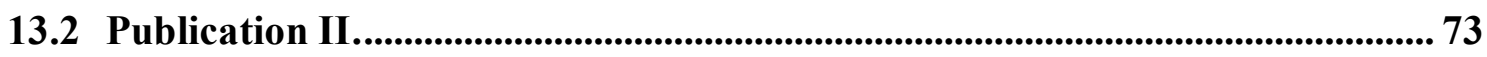

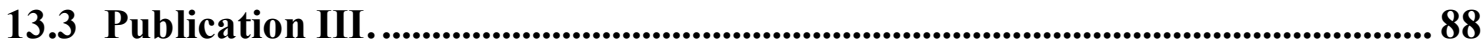




\section{List of publications}

\subsection{Relevant publications}

I. GluA1 phosphorylation alters evoked firing pattern in vivo

Balázs Barkóczi, Gábor Juhász, Robert G. Averkin, Imre Vörös, Petra Vertes, Botond Penke, Viktor Szegedi

Neural Plasticity Volume 2012, Article ID 286215, 8 pages

IF: 2.000

II. Tianeptine potentiates AMPA receptors by activating CaMKII and PKA via the p38, p42/44 MAPK and JNK pathways

Viktor Szegedi, Gábor Juhász, Xiaoqun Zhang, Balázs Barkóczi, Hongshi Qi, Alexandra Madeira, Gábor Kapus, Per Svenningsson, Michael Spedding, Botond Penke

Neurochemistry International 59:(8) pp. 1109-1122. (2011)

IF: 2.857

\subsection{Other publication}

III. Fibrillar A $\beta$ 1-42 enhances NMDA receptor sensitivity via the integrin signaling pathway

Gábor Juhász, Balázs Barkóczi, Gabriella Vass, Zsolt Datki, Ákos Hunya, Lívia Fülöp, Dénes Budai, Botond Penke, Viktor Szegedi

Journal of Alzheimer's Disease 19:(3) pp. 1055-1067. (2010)

IF: 4.261 


\section{Abstract}

Neural plasticity disturbance seems to play a crucial role in the pathophysiology of psychiatric disorders, for example in major depression. Ionotropic glutamatergic receptors such as NMDA and AMPA receptors convey fast synaptic transmission in the central nervous system, and regulate synaptic plasticity. The GluA1 subunit of AMPA receptor has central role in synaptic plasticity; moreover the elevation of phosphorylated AMPA receptor level was implicated in the antidepressant effect of various drugs. In my $\mathrm{PhD}$ thesis I investigated the effect of an atypical antidepressant, called Tianeptine, on synaptic function and GluA1 phosphorylation using in vitro murine hippocampal slice and in vivo rat single-unit electrophysiology experiments. Tianeptine increased AMPA receptormediated responses by a postsynaptic mechanism in vitro. The postsynaptic mechanism by which Tianeptine could exert its effect is the rapid phosphorylation of Ser 831 and Ser 845 amino acids of GluA1 subunit. Furthermore AMPA receptor phosphorylation alters channel properties and trafficking. Cellular plasticity requires the precise timing of action potentials within a few milliseconds, therefore it is important to understand how phosphorylation governs these events. Tianeptine was used for inducing GluA1 phosphorylation, which resulted in enhanced AMPA-evoked spiking. Similarly-enhanced responses were evoked by strong AMPA stimulation with matched firing rates. Significant differences were observed in the spike trains after Tianeptine application compared to strong AMPA stimulation. Although peristimulus time histograms (PSTH) did not show dramatic distinctions between the two groups, interspike interval (ISI) distributions and ISI temporal evolutions were significantly different, suggesting that neuronal output may differ when new inputs are activated compared to increasing the gain of previously activated receptors. Furthermore, I also show that NMDA-evoked spike trains have different patterns compared to AMPA-evoked ones. Tianeptine modulates synaptic NMDA and AMPA receptor ratio by activating several signaling cascades associated with synaptic plasticity, enhances glutamate neurotransmission via AMPA receptor phosphorylation, which mechanisms may have important role in plasticity and temporal coding. Our results suggest that the altered information coding may contribute to the development of depression. 


\section{3 Összefoglalás}

Egyre több bizonyíték utal arra, hogy a pszichiátriai megbetegedések, mint például a depresszió, kialakulásának hátterében a központi idegrendszer plaszticitásának zavara áll. Az idegsejtek gyors szinaptikus jelátvitelében résztvevő ionotróp glutamáterg receptorok a szinaptikus plaszticitást szabályzásáért is felelősek. Számos antidepresszáns jótékony hatását az AMPA receptorok foszforilációján keresztül fejtheti ki, ráadásul ezen receptorok GluA1 alegysége kitüntetett szereppel bír a szinaptikus plaszticitásban. PhD disszertációm alapját egy atípusos antidepresszáns, a Tianeptin, GluA1 alegység foszforilációjára és ezen keresztül a szinaptikus müködésre gyakorolt hatásának vizsgálata képezi. Kísérleteinket in vitro egér hippocampus szelet MEA és in vivo patkány extracelluláris egy-sejt elvezetés módszerekkel végeztük. In vitro eredményeink Tianeptin kezelést követően az AMPA receptor közvetített válaszok posztszinaptikus úton történő megnövekedését igazolták, ami a GluA1 alegység szerin 831 és 845 aminosavak gyors foszforilációjának volt köszönhető. Ezen felül a GluA1 foszforiláció képes befolyásolni az ioncsatorna vezetési tulajdonságait illetve a szinaptikus membránba történő kihelyeződés mértékét. Az idegsejtek plaszticitása az akciós potenciálok pontos időzítését feltételezi, emiatt érdemes megvizsgálni a foszforiláció időbeli kódolásra gyakorolt hatásait is. In vivo kísérleteinkben Tianeptin i.p. beadás segítségével idéztük elő a GluA1 alegység foszforilációját, ami megnövekedett AMPA kiváltott válaszokat eredményezett. Hasonlóan nagy AMPA válaszok hozhatóak létre erős AMPA ingerléssel is, azonban jelentős eltérések figyelhetőek meg a Tianeptin kezelt és az erős AMPA ingerléssel kiváltott akciós potenciál sorozatok között. Habár a peristimulus idő hisztogram (PSTH) nem mutat drasztikus különbségeket, az akciós potenciálok között eltelt idő (ISI) eloszlása és azok időbeli kifejlődése (ISI temporal evolution) jelentősen eltérőnek adódott. Eredményeink szerint az akciós potenciál sorozat kimenetek különbözőek lehetnek, ha új receptorok vannak aktiválva, illetve ha a korábban aktivált receptorok vezetését foszforiláció útján megnöveljük. Továbbá az NMDA ingerlés is különböző akciós potenciál sorozatokat eredményez, mint az AMPA ingerlés. Összességében a Tianeptin képes az NMDA és AMPA receptorok működési arányát a szinapszisban megváltoztatni, megnöveli a glutamát neurotranszmissziót az AMPA receptor foszforilációja révén, mely folyamatoknak fontos szerepe lehet az időbeli kódolásban és a plaszticitásban, illetve ezen folyamatok megváltozása a depresszió kialakulásában is szerepet játszhat. 


\section{Abbreviations}

ACSF Artificial cerebrospinal fluid

ADHD Attention deficit hyperactivity disorder

AMPA 2-amino-3-(3-hydroxy-5-methyl-isoxazol-4-yl)propanoic acid

ANOVA Analysis of variance

aPSTH Averaged peristimulus time histogram

BDNF Brain-derived neurotrophic factor

CaMKII $\mathrm{Ca}^{2+} /$ calmodulin-dependent protein kinase type II

CA1 Cornu Ammonis region 1

CA3 Cornu Ammonis region 3

CED Cambridge Electronic Design

CFLP Type of mouse outbred stock

ccPSTH Colour-coded peristimulus time histogram

CNQX 7-nitro-2,3-dioxo-1,4- dihydroquinoxaline-6-carbonitrile

DSM-IV Diagnostic and Statistical Manual of Mental Disorders IV ${ }^{\text {th }}$

EAAT-2 Excitatory amino acid transporter type 2 (also called GLT-1)

EEC European Economic Community (Council Directive 86/609/EEC)

EPSC Excitatory postsynaptic current

fEPSP Field excitatory postsynaptic potential

GABA-B Gamma-aminobutyric acid B type receptor

GluA1 AMPA receptor subunit (also called GluR1)

GLT-1 Glial glutamate transporter type 1 (also called EAAT-2)

GLT-1a Glial glutamate transporter type 1 form a

ICD-10 International Statistical Classification of Diseases and Related Health

Problems $10^{\text {th }}$

I/O Input/output

i.p. Intraperitoneal

ISI Interspike interval

JNK c-Jun N-terminal kinase

LTD Long-term depression

LTP Long-term potentiation

MAO Monoamine oxidase 
MAO-A Monoamine oxidase type A

MAO-B Monoamine oxidase type B

MAOI Monoamine oxidase inhibitor

MAPK Mitogen-activated protein kinase

MCS Multi Channel Systems

MEA Microelectrode array

MK-801 [5R,10S]-[+]-5-methyl-10,11- dihydro-5H-dibenzo[a,d]cyclohepten-5,10imine

MRI Magnetic resonance imaging

NA1 NMDA receptor subunit

NMDA N-methyl-D-aspartic acid

USA United States of America

PTSD Posttraumatic stress disorder

PKA Protein kinase type A

PPF Paired-pulse facilitation

PSTH Peristimulus time histogram

RIMA Reversible inhibitor of monoamine oxidase

ROS Reactive oxygen species

SEM Standard error of mean

Ser Serine amino acid

SSRE Selective serotonin reuptake enhancer

SSRI Selective serotonin reuptake inhibitor

STDP Spike timing-dependent plasticity

STH Stimulus time histogram

TBS Theta-burst stimulation

WHO World Health Organization

$\alpha 2$ Adrenergic receptor group $\alpha$ subtype 2

$\beta 1 \quad$ Adrenergic receptor group $\beta$ subtype 1

3D-MEA Three-dimensional microelectrode array

5-HT1 5-hydroxytryptamine (serotonin) receptor type 1

5-HT2 5-hydroxytryptamine (serotonin) receptor type 2 


\section{Introduction}

Mood disorders are among the most prevalent forms of mental illnesses, mostly because they are chronic, often recurrent, potentially life threatening due to the risk for suicide (Bostwick and Pankratz, 2000, Sartorius, 2001). Nowadays the best characterised and most researched mood disorder is major depressive disorder, because very high, in numbers approximately $20-30 \%$, is the probability, that somebody once trough his life experience some specific symptoms of the disease (Berton and Nestler, 2006). According to the most recent data there is 32.4 percent of the 12-month prevalence rate for any mental disorders or substance disorders like alcoholism or drug abuse (Kessler et al., 2005a, Kessler et al., 2005b), and interestingly the probability of major depressive disorder incidence is very high, approximately $20-30 \%$. It means that almost every third person is affected by depression in a given year. Three to five percent of the whole population suffers from such serious depression that severely disturbs the quality of life and working ability according to the estimation of the World Health Organization (WHO) (Waraich et al., 2004, Moussavi et al., 2007). It is evaluated by WHO that major depressive disorder will be the second leader of incapacity reasons for 2020 (Murray and Lopez, 1997). Even so nowadays the concerned countries spend less than $1 \%$ of the budget on appropriate treatment of depression (Thomas and Morris, 2003). From now on, I will refer to major depressive disorder as depression in my thesis.

The notion depression and depressed mood do not correspond to the same mental state. While depressed mood is a short and normally occurring state of mind, until then depression is referred to one permanent, mostly recurrent, serious disease, which has many distinctive forms. In the case of depression the feeling of sadness is much more intensive, the patients experience it very vigorously, painfully. Some of them describe this feeling, that it is far worse, than any physical pain, and would be better simply to die, than bear it. In the course of time overcomes the sense of uselessness and guilt, patients become unable to experience pleasure and to express their feelings. Moreover in the course of time the concentration ability dramatically decreases, thinking and locomotion slows down, mimics of sick people become impoverished. The expression "depression" means gloom, dejectedness. Already at 1550 B.C. an antique Egyptian record, called Ebers papyrus, mentioned the disease, although depression as a clinical term introduced in psychology since 1905 (Okasha, 1999). 
It is widely believed, that the more various are our emotions, and the many ways we can express them, the healthier is our psyche. The mood can fluctuate normally in any directions between depressed mood and exuberant happiness, but normally excursions are not so pronounced. In diseased state pathologically depressed mood called the classical depression, and the unduly overwhelming happiness called mania. Depression usually connected with anxiety, aggression, poor self-esteem, physiological stress and decrease in sexual arousal (Hammen et al., 1992, Brown, 1993, Kessler et al., 1996, Kennedy and Rizvi, 2009, Margari et al., 2012).

The disease is inheritable having a very high prevalence (40-50\%), but the genes underlie this risk have not been fully identified yet. Similarly, the environmental factors, the remaining 50-60\%, have not been defined precisely so far, and it is suggested that emotional stress, early childhood traumas, other physical illnesses, and viral infection might be involved (Fava and Kendler, 2000, Capuron and Dantzer, 2003, Caspi et al., 2003, Levinson, 2006, Irwin and Miller, 2007).

Depressive disorder is usually diagnosed in the clinic according to the Diagnostic and Statistical Manual of Mental Disorders IV ${ }^{\text {th }}$ (DSM-IV) or the International Statistical Classification of Diseases and Related Health Problems $10^{\text {th }}$ (ICD-10) guidebooks. The aetiology of the disease is less known (Kessing, 2007), hence the proper classification of the disease subtypes is not solved on the basis of pathological and molecular abnormalities, and it is not based on objective diagnostic tests such as serum chemistry, organ imaging, or biopsy examinations. Both of the classification systems set up the diagnosis on the basis of the duration of clinical symptoms, and leave out of consideration the cause and method of symptom development, which may be very important in treatment design (Wittchen et al., 2001, Andrews et al., 2008). Accordingly, depression should not be viewed as a single disease, but a heterogeneous syndrome may comprise numerous diseases of distinct causes and pathophysiologies.

\subsection{Symptoms of depression}

Depression significantly affects all aspect of life, including personal relationships, sleeping and eating habits and general health. From major depressive disorder suffering persons usually exhibit a very low mood, and an inability to experience pleasure (anhedonia), therefore persistently dominated by sad, anxious or "empty" feelings. They lose of interest in such activities or hobbies, which once induced pleasure, for example 
sexual behaviour. Depressed people suffer from thoughts and feelings of worthlessness, inappropriate guilt or regret, helplessness, hopelessness, self-hatred and pessimism. In addition depressed people are characteristically more irritable and restless, and their family and friends may notice that the depressive person's behaviour is either agitated or lethargic. In severe cases, diseased people may have symptoms of psychosis, which includes unpleasant delusions and less commonly hallucinations (Gerber et al., 1992, Baker, 1996, Cassano and Fava, 2002, Serby and Yu, 2003).

A depressed person may report multiple physical symptoms such as fatigue, decreased energy, persistent aches or pains, especially headaches, cramps, or digestive problems that do not ease even with treatment. Especially difficult to identify the illness in the case of masked depression because of the various physical symptoms. Depression and pain often co-occur, because approximately $65 \%$ of depressed patients suffer from one or more pain symptoms. Insomnia, early-morning wakefulness, or excessive sleeping (hypersomnia) very often accompanies the disease. Appetite often decreases, with results in weight loss, although increased appetite or overeating and weight gain also occur occasionally (Gerber et al., 1992, Nestler et al., 2002, Bair et al., 2003).

Major depression frequently co-occurs with other psychiatric problems such as anxiety, alcohol and drug abuse, attention deficit hyperactivity disorder (ADHD), posttraumatic stress disorder (PTSD), which complicating the diagnosis and treatment (Grant, 1995, Hirschfeld, 2001). The National Comorbidity Survey of the United States of America (USA) from 1990-92 reported that 51\% of those with major depression also suffers from chronic anxiety (Kessler et al., 1996, Kessler et al., 2008). These co-occurring illnesses may precede, cause, and/or be a consequence of depression, therefore these symptoms may have a major impact on the progression of the disease. These accompanying symptoms can delay recovery, increase risk of relapse, cause greater disability and can contribute to suicide thoughts or in more serious cases suicide attempts (Brown et al., 2001, Moussavi et al., 2007). Other symptoms of depression include concentration difficulty, poor remembering, memory impairment, inability of making decisions, withdrawal from social situations and activities. Older depressed people may have cognitive symptoms of recent onset, such as forgetfulness, and a more noticeable slowing of movements (Baker, 1996, Serby and Yu, 2003, Margari et al., 2012). 


\subsection{Hypotheses about the pathophysiology of depression}

\subsubsection{Monoamine hypothesis}

The monoamine hypothesis was postulated in the 1960's. The crucial point of this hypothesis is the malfunctioning monoamine system within the central nervous system, consequently the serotonin, dopamine, and noradrenalin transmission disturbance. The basis of this proposal makes up from the mechanism of action of early antidepressants that increase the levels of one or more of the monoamines in the synaptic cleft (Bunney and Davis, 1965, Coppen and Doogan, 1988, Nestler et al., 2002, Nutt, 2008). The monoamine systems play crucial role in almost every symptoms of depression, because numerous part of the brain such as hypothalamus, amygdala, hippocampus, cortex, basal ganglia, and brainstem are densely innervated by monoamine systems. It is believed that monoamines regulate or fine tune the function of the major neurotransmitter systems, and decreased monoamine level in the brain may cause the abnormal release of other neurotransmitters. Especially the disturbance of serotonergic system is associated with depression, therefore numerous antidepressants were developed, which can increase the serotonin level in synaptic cleft, such as selective serotonin reuptake inhibitors (SSRIs) (Goodnick and Goldstein, 1998, Berton and Nestler, 2006). Widely used SSRIs in the clinic include fluoxetine, fluvoxamine, paroxetine, sertraline and citalopram.

There is an other important drug group, which can also exert its effect on monoamine neurotransmitters called monoamine oxidase inhibitors (MAOI). Monoamine oxidases (MAO) are a family of enzymes that catalyze the oxidative deamination of monoamines, leading to the inactivation of monoamine neurotransmitters. While SSRIs decrease the reuptake of mostly serotonin, MAOIs can block MAO enzymes; therefore increasing the half-life of all monoamine neurotransmitters in the synaptic cleft. There are irreversible or reversible forms of MAOIs, nowadays the former is hardly used in clinical treatment, because of the numerous side effects involving the so called cheese reaction (Brown et al., 1989, Finberg and Gillman, 2011). Irreversible MAOIs can drastically inhibit hepatic MAO enzymes, hence can block tyramine clearance, therefore the level of tyramine can dramatically increase in the blood. Increased amount of tyramine can cause hypertensive reaction or hyperserotonemia in some patients. Because the fermented substances, especially aged cheeses, contain tyramine in high level, this side effect of irreversible MAOIs was named as cheese reaction. The most prominent representatives of irreversible MAOI are fenelzin, tranilcipromin, and there is one reversible inhibitor of 
monoamine oxidase (RIMA) used in the clinical practice, called moklobemid (Thase, 2012).

An other major group of antidepressants are the tricyclic antidepressants, which were named by the 3 ring that build up their basic structure, can exert their effects most probably by the inhibition of noradrenaline reuptake (Manji et al., 2001, Nestler et al., 2002, Morilak and Frazer, 2004). Formerly the most frequently prescribed tricyclic antidepressants were imipramin, amitriptilin, clomipramin, although these drugs have also serious side effects, such as weight gain, sedation, dizziness, and decrease in blood pressure (Roose et al., 1989). Moreover, tricyclic antidepressants are not advised to be combined with other antidepressants. Novel compounds such as nortriptilin, dezipramin have faster onsets and fewer side effects. Nevertheless, tricyclic antidepressants are not prescribed in large number nowadays; SSRIs are used more preferably because of the even less side effects (Berton and Nestler, 2006).

In spite of the clinical and preclinical observations that supported the monoamine hypothesis, it became more clear, that monoamine deficiency could not explain all aspects of the pathology of depression (Krishnan and Nestler, 2008). Recent findings have revealed multiple limitations of this hypothesis. Serotonin can be generated from the tryptophan amino acid by the tryptophan hydroxylase and amino acid decarboxilase enzymes. Therefore it was believed, that tryptophan dietary can reduce the symptoms of depression. However tryptophan rich diet cannot reduce the degree of depression. Moreover treatment of healthy people with pharmacological agents that cause the depletion of monoamines does not affect the mood regardless of reduction in the concentration of centrally available monoamines. Nevertheless there is an other interesting discrepancy in the monoamine hypothesis. Although MAOIs and SSRIs can exert its effect on neurotransmitters within hours, while the development of mood enhancing effect requires weeks of treatment. Hence it was suggested, that the monoaminergic system is not the underlying cause, but rather the consequence of the faulty alteration of other neurotransmitter systems, such as glutamatergic system.

\subsubsection{Glutamatergic hypothesis}

Being the main component of excitatory chemical transmission at chemical synapses, glutamate binds to both pre- and postsynaptic glutamate receptors, such as ionotropic N-methyl-D-aspartic acid (NMDA), 2-amino-3-(3-hydroxy-5-methyl-isoxazol- 
4-yl)propanoic acid (AMPA) and kainate receptors, and metabotropic glutamate receptors. Under chronic stress or high glucocorticoid level the extracellular glutamate level can dramatically increase in the brain, especially in the hippocampus (Lowy et al., 1993, Moghaddam et al., 1994, Lowy et al., 1995, Venero and Borrell, 1999). The pathologically high glutamate level leads to a vicious cycle known as excitotoxicity: NMDA receptor overactivation which subsequently leads to massive intracellular $\mathrm{Ca}^{2+}$ level increment, hence massive reactive oxygen species (ROS) accumulation. These processes result in dendritic spine loss, lead to dendrite shrinkage, and may start apoptosis in the long run. Chronic stress also reduces neurogenesis in the hippocampus (Lemaire et al., 2000, Van Bokhoven et al., 2011, Danzer, 2012). The increased glutamatergic activity can decrease noradrenergic locus coeruleus activity, hence causing a decline in the noradrenaline release that may have deleterious effect on serotonin and dopamine neurotransmitter systems (Andras, 2008). Under normal conditions the glutamate scavenging mechanism of glial cells is enhanced by the elevated expression of glutamate transporter (GLT-1 or EAAT-2), however this compensatory mechanism could be also easily saturated. The extreme high glutamate level can stimulate synaptic and extrasynaptic receptors that can further exacerbate depression by the reduction of synaptic plasticity and neuronal survival. Chronic stress can modify AMPA and NMDA receptor subunit ratio, which may also lead to more serious depression in the long run (Andras, 2008).

It was described, that NMDA antagonists, such as ketamine, in animal models can exert antidepressant-like effects. Group I metabotropic glutamate receptor (mGluR1 and mGluR5) antagonists, as well as positive modulators of AMPA receptors have also antidepressant-like activity (Paul and Skolnick, 2003). AMPA receptor activation leads to the enhancement of brain-derived neurotrophic factor (BDNF) expression, and subsequent neurogenesis in the hippocampus (Duman, 2004, Duman and Monteggia, 2006). AMPA receptor agonists have beneficial effect in the forced swim and tail suspension tests, behavioural assays used for assessing the level of depression in rodents; moreover the onset of antidepressant effect arises with shorter latency than in the case of SSRIs. The focus of my dissertation, Tianeptine, an atypical antidepressant can also act on the glutamatergic system: we (Szegedi et al., 2011) have described that Tianeptine enhances the phosphorylation level of AMPA receptor GluA1 subunit by activating $\mathrm{Ca}^{2+}$ / calmodulin-dependent protein kinase type II (CaMKII) and protein kinase type A (PKA) via the pathways of p38, p42/44 mitogen-activated protein kinase (MAPK) and c-Jun N- 
terminal kinase (JNK). Increasing the gain of the AMPA receptor by phosphorylation seems to prevent symptoms associated with depression (Kole et al., 2002, Svenningsson et al., 2007, Qi et al., 2009, Szegedi et al., 2011, Barkoczi et al., 2012).

\subsubsection{Neurogenesis or neurotrophic hypothesis}

A series of Magnetic resonance imaging (MRI) data have provided support for the hypothesis that major depressive disorder may have neurodegenerative components (Drevets, 2000, 2001). MRI experiments revealed that the volume of cortex and white matter of depressive patients decreased in the frontal lobe, and in the hippocampus. In contrast, hypertrophy and volume increment is observable in the amygdaloid region. Sheline et al. (Sheline et al., 1999, Sheline et al., 2003) have shown that the depressive episode length and number correlate with the degree of atrophy, although MacQueen and his team (MacQueen et al., 2003) established that after the first depression episode atrophy is mostly not detectable. Recent neurobiological results demonstrate that depression, especially major depressive disorder are characterised by glial cell loss, neuron dendrite shrinkage, decreased expression of synapse-related genes, loss of synapses and/or impairments in neuroplasticity, which in the long run can trigger volume loss of the brain especially in the frontal cortex and in the hippocampus (Rajkowska et al., 1999, Manji et al., 2003, McEwen and Olie, 2005, Kang et al., 2012). Decline of cognitive functions is a main symptom of major depression which consist of deficits in attention, concentration and explicit memory, which may be the consequence of hippocampal volume loss (Drevets, 2001). The length of major depressive period and the level of hippocampus-dependent cognitive performance showed significant inverse correlation. Most researchers believe that volume loss is not the root cause of depression, but the consequence of the illness, which can further strengthen depressive symptoms. According to Conrad and colleagues (Conrad et al., 1999) dendritic shrinkage observed in depression is not a form of permanent hippocampal damage, but a type of a special structural plasticity, which could be an adaptation to chronic stress.

It was described that chronic stress can reduce the BDNF level in hippocampus, which could be compensated by different antidepressant treatment (Chen et al., 2001, Duman, 2004, Li et al., 2010, Zhang et al., 2010, Masi and Brovedani, 2011, Deuschle et al., 2012, Li et al., 2012, Tamaji et al., 2012). Formerly it was believed that BDNF regulate only neural growth and differentiation during development, but recent studies demonstrated that BNDF is a potent regulator of plasticity and survival of adult neuronal 
and glial cells (Goldman, 1998, Cunha et al., 2010, Bath et al., 2012, Gray et al., 2012). Therefore deficiency in the BDNF level can contribute to hippocampal cell death and volume loss during the development of depression. Increased BDNF level can enhance long-term potentiation (LTP) and other forms of synaptic plasticity in the hippocampus, hence decrease the cognitive symptoms of depression. This hypothesis can explain the delayed beneficial responses to antidepressant treatments, because BDNF expression and accumulation to an effective concentration is a time consuming process. Currently no such compound is available, that can directly increase BDNF level.

\subsubsection{Alteration of information processing hypothesis}

The most recent theory of the underlying cause of depression does not put forward the imbalance in neurotransmitter systems, but it rather emphasizes perturbations in information processing, which can leads to the depressive symptoms (Delgado, 2000). The disease develops, if external stimuli cannot evoke proper responses. Accordingly effective antidepressants can restore adequate responses and communication between the affected brain parts, hence promote mood amelioration. The malfunctioning intracellular signalling cascades are the crucial points of this hypothesis (Czeh et al., 2001, D'Sa and Duman, 2002, Santarelli et al., 2003).

\subsection{Tianeptine, an atypical antidepressant}

The molecular structure of Tianeptine resembles to the tricyclic antidepressants (Figure 1.), but its mechanism of action, although not fully understood yet, is clearly different from those. Atypical antidepressants are clinically effective, but the exact mechanism of action has been yet unknown (Berton and Nestler, 2006). Antoine Deslandes and Michael Spedding synthesized Tianeptine first in 1981. Tianeptine is produced as a racemate compound; interestingly the L-isomer form is therapeutically more effective. It was believed that Tianeptine is an activator of monoamine reuptake, especially serotonin, therefore it was defined as a selective serotonin reuptake enhancer (SSRE) (Mennini et al., 1987, Fattaccini et al., 1990). This proposal was based on one preclinical experiment, where Tianeptine and fluoxetine, an SSRE and SSRI respectively, coadministration had cancellative effects on serotonin reuptake. Recently other groups failed to repeat this finding, and reported no effect of the compound on serotonin level (Watanabe et al., 1993, Pineyro et al., 1995, McEwen and Olie, 2005). Tianeptine has a robust antidepressant and anxiolytic activity, moreover more recent results revealed anticonvulsant and analgesic 
properties, but sedative, anticholinergic and cardiovascular adverse effects were not reported to dominate. Because of the relative lack of adverse side effects Tianeptine can be used in the elderly and in patients sensitive to certain side-effects. Although Tianeptine cannot bind to and cannot alter the state of most neurotransmitter receptors, such as $\alpha 2, \beta 1$ adrenergic, 5-HT1, 5-HT2 serotonergic, benzodiazepine and GABA-B receptors, cannot change MAO-A and MAO-B activity and has no effect on serotonin and noradrenaline reuptake, it can exert remarkable antidepressant activity (Kato and Weitsch, 1988, Watanabe et al., 1993, Pineyro et al., 1995). It was described that Tianeptine can decrease activity of glial glutamate transporter type 1 form a (GLT-1a), hence it can increase the extracellular glutamate level (McEwen and Chattarji, 2004, Reagan et al., 2004).

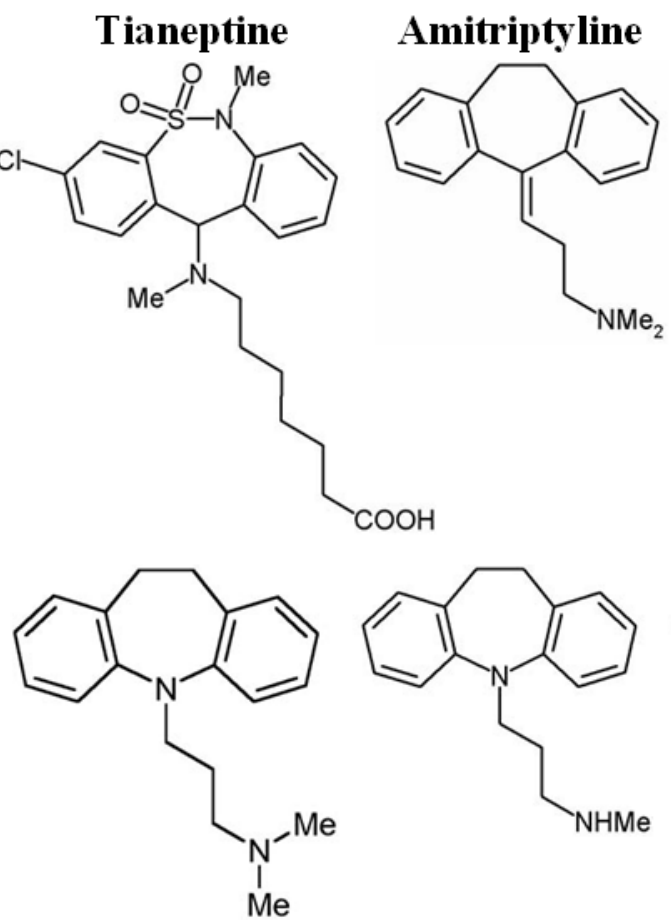

Imipramine
Desipramine<smiles>CNCC/C=C1/c2ccccc2C(C)[C@H](C)c2ccccc21</smiles><smiles>CN(C)CCCN1c2ccccc2CCc2ccc(Cl)cc21</smiles>

Clomipramine
Fluoxetine Moclobemide<smiles>CNCCC(Oc1ccc(C(F)(F)F)cc1)c1ccccc1</smiles><smiles>O=C(NCCN1CCOCC1)c1ccc(Cl)cc1</smiles>

$\mathrm{NC}$<smiles>CNCCCC1(c2ccc(F)cc2)OCc2ccccc21</smiles>

\section{Figure 1. Molecular structure of the following antidepressants:}

Atypical antidepressant: Tianeptine (Stablon)

Tricyclic antidepressants: Amitriptyline (Elavil), Nortriptyline (Aventyl, Pamelor), Imipramine (Tofranil), Desipramine (Norpamin), Clomipramine (Anafranil)

SSRIs: Fluoxetine (Prozac), Citalopram (Celexa, Cipramil)

RIMA: Moclobemide (Manerix, Aurorix)

Tianeptine can prevent structural changes induced by stress and can modify neuronal metabolism and functioning in the hippocampus. Tianeptine is able to counteract 
neuronal loss, abnormal synaptic plasticity and dendritic atrophy (McEwen and Olie, 2005, Spedding and Lestage, 2005). Accordingly Tianeptine can reverse the stress-induced decrease in hippocampal volume, can induce granule cell proliferation in the dentate gyrus, can decrease the degree of cell death and can normalise the concentrations of cerebral metabolites such as $N$-acetyl-aspartate (Czeh et al., 2001, Lucassen et al., 2001). The glucocorticoid and stress-induced shrinkage of dendrites of hippocampal Cornu Ammonis region $3(\mathrm{CA} 3)$ pyramidal cells can also be reversed by Tianeptine treatment (Magarinos et al., 1999). Lucassen and coworkers (Lucassen et al., 2004) have shown that Tianeptine may have putative cytoprotective effects in chronically stressed animals. Cognitive deficits, such as an impairment of attention, memory and problem solving, have often been reported in patients with depressive disorders (Zihl et al., 1998). Morris and coworkers (Morris et al., 2001) found that Tianeptine can enhance memory retention in the Water maze of rats with medial septum lesions. Neuroplasticity is also enhanced by Tianeptine, as was shown by a series of electrophysiological experiments. Learning and memory processes are heavily dependent on cellular forms of various neuroplasticity, and a number of studies investigated the relationship between stress and LTP, a prominent form of neuroplasticity. The group of Rocher (Rocher et al., 2004) have shown that severe acute platform stress in rats causes a long-lasting inhibition of LTP. After stress exposure, Tianeptine overcomes the block of hippocampal LTP induction in inescapable stress (Shakesby et al., 2002). Tianeptine rapidly reverses the inhibitory effects of stress on LTP at hippocampal-prefrontal synapses (Rocher et al., 2004). It was shown that chronic stress significantly elevates excitatory postsynaptic currents (EPSCs) in the CA3 of hippocampus, which can be prevented by Tianeptine treatment (Kole et al., 2002). The complex and atypical mode of action of Tianeptine may be the amelioration of neuroplasticity, hence increasing neurogenesis and inhibiting apoptosis (Czeh et al., 2001, Lucassen et al., 2004). Tianeptine may promote neuroplasticity by increasing the expression of BDNF and other nerve growth factors in the hippocampus (Alfonso et al., 2006).

\subsection{Tianeptine and AMPA receptors}

The action mechanism of Tianeptine involves the regulation of glutamatergic transmission (McEwen et al., 2010). In contrast to other antidepressants like Imipramine, Tianeptine may counteract the plasticity impairment caused by acute stress (Shakesby et al., 2002), a phenomenon which is associated with impaired BDNF/MEK/MAPK 
signalling cascade and AMPA receptor phosphorylation (Qi et al., 2009). A growing body of data suggest that the direct modulation of synaptic plasticity, by for example AMPA receptor potentiation, may overcome depressive symptoms in animal models (Alt et al., 2006). We and others have described that Tianeptine can enhance the phosphorylation state of AMPA receptors in mice (Svenningsson et al., 2007) and in rats (Qi et al., 2009, Szegedi et al., 2011). It is believed that not only AMPA receptor trafficking and synthesis but AMPA receptor phosphorylation can contribute to synaptic plasticity modulation, hence regulation of memory and learning (Malinow and Malenka, 2002).

AMPA receptors are ionotropic transmembrane glutamate receptors that mediate fast synaptic transmission in central nervous system. They can be activated by an artificial glutamate analogue called AMPA, from which the receptors name was derived. The receptor family has four subunits namely GluA1, GluA2, GluA3, and GluA4 (or GluR1-4), which can combine to form tetramers. The GluA1 subunit has two important serine (Ser) amino acids, in the 831 and in the 845 position. The 831 serine (Ser 831) can be specifically phosphorylated by protein kinase C (PKC) and CaMKII (Barria et al., 1997, Mammen et al., 1997), while serine 845 (Ser 845) can be phosphorylated by PKA. We have shown (Szegedi et al., 2011) that Tianeptine activates three distinct MAPK pathways, the JNK, p42/44 and p38 MAPK pathways, which eventually lead to enhanced AMPA receptor function through phosphorylation by CaMKII and PKA at Ser 831 and 845 respectively. GluA1 subunit phosphorylation level differently contributes to synaptic plasticity: phosphorylation of both of the former serine residues correlates with LTP, while dephosphorylation of these serines leads to long-term depression (LTD) (Lee et al., 2000). Mutant mice lacking the GluA1 subunit show impairments of LTP initial component at Cornu Ammonis region 1 (CA1) area of hippocampus (Riehle et al., 1997, Hoffman et al., 2002, Malinow and Malenka, 2002, Jensen et al., 2003), moreover these animals have robust deficit in spatial working memory (Riehle et al., 1997, Schmitt et al., 2003, Schmitt et al., 2004). Experiments with mice have mutant GluAl phosphorylation sites revealed that AMPA receptor phosphorylation mediates certain explorative and antidepressant-like actions of Tianeptine (Svenningsson et al., 2007).

Emerging evidence shows that as a rapid and short-term mechanism, dynamic protein phosphorylation directly modulates the electrophysiological properties of nerve cells, as well as the trafficking/clustering and synthesis of AMPA receptors. Therefore, it is important to investigate the differences between neuronal responses evoked either by 
stimulation of new inputs or by stimulation of already used but phosphorylated excitatory inputs. Not only the firing rate, but the temporal relationship of spikes referred to as spike timing-dependent plasticity (STDP) is also critical for information transfer (Gray and Singer, 1989, Buzsaki and Chrobak, 1995, Hopfield, 1995, Vaadia et al., 1995, Riehle et al., 1997), therefore the effect of phosphorylation on spike timing is also crucial.

In my $\mathrm{PhD}$ thesis, I chose to investigate the effect of Tianeptine on AMPA receptors. I set out to show the AMPA receptor potentiation after intraperitoneal (i.p.) administration of the drug. Moreover, I took advantage of the fact that Tianeptine induces GluA1 phosphorylation at PKA site (Ser 845) and CaMKII site (Ser 831) sites. I was interested in the effect of GluA1 phosphorylation on the spiking pattern of CA1 cells. More specifically, I aimed to investigate whether neuronal output differs when new inputs are activated compared to increasing the gain of previously activated inputs. To this end I have analyzed the spike distribution of NMDA- and AMPA-evoked spiking trains by mathematical means. 


\section{Aims}

This thesis aims to investigate the mechanism of action of Tianeptine, an atypical antidepressant. Although Tianeptine is clinically effective, its mode of action is still unknown.

I focused on the following questions:

1. What is the rapid effect of Tianeptine measured with electrophysiology on hippocampal slices?

2. Which synaptic receptor is affected by Tianeptine?

3. How Tianeptine or GluA1 phosphorylation alters the timing of neuronal activity in the CA1?

To answer these questions we used in vitro Microelectrode array (MEA) murine hippocampal slice and in vivo rat extracellular single-unit recording experiments. 


\section{$7 \quad$ Materials and Methods}

\subsection{In vitro MEA experiments}

\subsubsection{Hippocampal slice electrophysiology}

Three-month old male CFLP mice (Animal Breeding Facility at University of Szeged) were used for MEA experiments. The animals were rapidly decapitated, and the head were submerged into ice-cold water. After 1 minute, the hippocampus was taken out, and $350 \mu \mathrm{m}$ thick transverse hippocampal slices were prepared using a McIlwain tissue chopper (Campden Instruments, Loughborough, UK). Slices were incubated in standard artificial cerebrospinal fluid (ACSF) at room temperature for $60 \mathrm{~min}$, which was constantly gassed with $95 \% \mathrm{O}_{2}$ and $5 \% \mathrm{CO}_{2}$. ACSF contained the following compounds: $130 \mathrm{mM}$ $\mathrm{NaCl}, 3.5 \mathrm{mM} \mathrm{KCl}, 2 \mathrm{mM} \mathrm{CaCl} 2,2 \mathrm{mM} \mathrm{MgCl} 2,0.96 \mathrm{mM} \mathrm{NaH}_{2} \mathrm{PO}_{4}, 24 \mathrm{mM} \mathrm{NaHCO}_{3}$, and $10 \mathrm{mM}$ D-glucose. Individual slices were transferred to a three-dimensional microelectrode array (3D-MEA) chip. 3D-MEA chips enable improved and more reliable electrophysiological experimentation due to the tip-shaped microelectrodes whereby signals can be recorded from the inner layers of brain slices. One 3D-MEA chip consists of 60 tip-shaped and $60 \mu \mathrm{m}$ high electrodes in $8 \times 8$ grid shape spaced by $100 \mu \mathrm{m}$ (Ayanda Biosystems, S.A., Lausanne, Switzerland). The hippocampus slice on chip was continuously perfused with oxygenated $\operatorname{ACSF}\left(1.5 \mathrm{ml} / \mathrm{min}\right.$ at $\left.34{ }^{0} \mathrm{C}\right)$ during the whole recording session. Data were recorded by a standard, commercially available MEA setup (Multi Channel Systems [MCS] GmbH, Reutlingen, Germany). The Schaffer-collateral was stimulated by injecting a biphasic current waveform $(-100 /+100 \mu \mathrm{s})$ through one selected electrode at $0.033 \mathrm{~Hz}$, while remaining electrodes recorded field excitatory postsynaptic potentials (fEPSPs). Care was taken to choose the stimulating electrode in the same region from one slice to the other. The fEPSPs from the stratum pyramidale and stratum radiatum of CA1 were taken into consideration for analysis, and peak-to-peak amplitudes of fEPSPs were examined. After a $30 \mathrm{~min}$ incubation period, the threshold and the maximum of stimulation intensity for evoked responses was determined. For evoking responses throughout the recording, $30 \%$ of the maximal stimulation intensity was used. Statistical evaluations were made by using two-way ANOVA with post hoc Tukey's test. Asterisks denote significant differences at $\mathrm{P} \leq 0.05$ level. 


\subsubsection{Stimulation protocol}

Following a stable 30-min control sequence, input/output (I/O) curve was recorded, which means that the stimulus intensity was continuously increased from 0 to $120 \mu \mathrm{A}$ with $10 \mu \mathrm{A}$ steps. I/O curve is a measure of the sensitivity, excitability of slices. After I/O curve recording, we recorded paired-pulse facilitation (PPF). Paired-pulse protocol consisted of two stimulation pulses injected with interstimulus intervals of $50 \mathrm{~ms}$ with $0.033 \mathrm{~Hz}$. PPF is generally used for assessing the function of the presynapse. Three data points were obtained at every stimulation intensity of the I/O curve and at every interstimulus interval of the paired-pulse protocol. For the investigation of neural plasticity, a correlate of learning and memory, LTP protocol was used. LTP was induced using a theta-burst stimulation (TBS) pattern applied at the maximum stimulation intensity. TBS comprised four trains administered at $20 \mathrm{~s}$ intervals with 10 bursts given at $5 \mathrm{~Hz}$ per train and four pulses given at $100 \mathrm{~Hz}$ per burst.

\subsection{In vivo single-unit electrophysiology experiments}

\subsubsection{Animal preparation and surgery}

Extracellular single-unit recordings were taken in chloral-hydrate anesthetized (4 $\mathrm{g} / \mathrm{kg}$ initial dose i.p., supplemental doses as required) male Wistar rats (Animal Breeding Facility at University of Szeged) weighing between 300-350 g. The head of the animal was mounted in a stereotaxic frame, the skull was opened above the hippocampus (a-p: $3.8 \mathrm{~mm}$ from bregma; lat: $\pm 2 \mathrm{~mm}$ either side from the midline sulcus sagittalis), and the dura mater was carefully removed. The opening was filled with $5 \%$ agarose gel to prevent desiccation and oedema formation.

\subsubsection{In vivo microiontophoresis and extracellular single-unit electrophysiology}

Single-unit activity was extracellularly recorded by means of a low impedance $(<1$ $\mathrm{M} \Omega$ ) carbon-fiber containing multibarrel microelectrode from the hippocampus between the depths of 2 to $3 \mathrm{~mm}$, and drugs were delivered from the surrounding outer barrels. The action potentials were amplified with an ExAmp-20KB extracellular amplifier (Kation Scientific, Minneapolis, MN) and monitored with an oscilloscope. Filter bandpass frequencies were set 300 to $8000 \mathrm{~Hz}$ that allowed only action potential recording. The amplified signals were sampled and digitalized at $50 \mathrm{kHz}$ frequency towards the most accurate spike shape definition. 
In the first few in vivo experiments, where we measured the overall effect of Tianeptine on cell firing, the spikes were sorted using the SciWorks software package (DataWave, Berthoud, CO). In the latter experiments, where we analysed the spike train dynamics, spikes were sorted using the Spike2 software package (Cambridge Electronic Design [CED], Cambridge, UK). Iontophoretic drug delivery was performed by iontophoretic pumps (Minion-16 and BAB-350, Kation Scientific, Minneapolis, MN) which were controlled by a personal computer connected to Micro1401-3 data acquisition unit (CED, Cambridge, UK).

The surrounding barrels affixed to the recording electrode were used for the iontophoretic ejection of the following drugs: $100 \mathrm{mM} \mathrm{NMDA} \mathrm{Na}{ }^{+}$salt in $100 \mathrm{mM} \mathrm{NaCl}$ $(\mathrm{pH}=8)$ or $10 \mathrm{mM}$ AMPA $(\mathrm{pH}=8)$. NMDA was ejected at negative iontophoretic current ranging from 5 to $100 \mathrm{nA}$ every minute for $5 \mathrm{sec}$. AMPA was ejected every $90 \mathrm{sec}$ at negative iontophoretic current ranging from 2 to $100 \mathrm{nA}$. A retaining current of opposite direction ranging 2-21 nA was used between the receptor agonist ejections to prevent the leakage of agonists. Tianeptine was administered i.p. as a single bolus injection at a dose of $20 \mathrm{mg} / \mathrm{kg}$.

\subsection{Data analysis}

\subsubsection{Stimulus time histogram (STH) analysis}

Statistical evaluations were performed by using the total number of spikes evoked during each epoch of excitation by iontophoretic application of agonists. The background neuronal discharge was calculated by averaging a $15 \mathrm{sec}$ period of ongoing activity preceding each epoch of excitation, and this value was subtracted from all evoked responses. The total spike number during each epoch of excitation was calculated and expressed as a percentage of the mean ( \pm standard error of mean $[\mathrm{SEM}])$, and compared statistically with the data obtained after drug application by using one-way analysis of variance (ANOVA, with the Bonferroni test for post hoc analysis), unless otherwise stated. The $\mathrm{P} \leq 0.05$ was considered significant in all cases. The control level was taken as $100 \%$.

\subsubsection{PSTH and ISI probability}

In the case of peristimulus time histogram (PSTH) the number of evoked spikes per $100 \mathrm{~ms}$ was calculated during each epoch of excitation by iontophoretic application of NMDA or AMPA. These numbers were averaged within the same groups. In the case of interspike interval (ISI) spike trains were characterized by their ISI series, therefore spike 
timing was converted into digital data at $30 \mu$ s resolution. First we compared the distribution of intervals for each pair of spike trains, assuming the measured intervals to be samples of mutually independent random variables. This allowed the use of KolmogorovSmirnov tests, which compare every characteristic of the underlying probability distributions, thus requiring no further assumptions. We then charted the maximal confidence intervals of agreement between the pairs. Data were pooled and means \pm SEM of percentage values were calculated. PSTH and ISI probability profiles were evaluated by using one-way repeated measures ANOVA with post hoc Tukey's test and ANOVA with post hoc Dunnett's test, respectively. A P value of $\leq 0.05$ was considered as significant difference in all cases. Figure 2 demonstrates the schema of in vivo data analysis for PSTH and ISI probability.

\subsubsection{ISI temporal evolution}

In order to investigate the temporal evolution of spiking activity, the time course of the spiking activities were normalized, so that the first spike was taken as time 0 , while the last spike of the train was taken as 1. ISIs were plotted against this normalized spike time. To fit smooth curves to the spike trains, first we transformed them by taking their negative logarithms, which corresponds to a spiking intensity value. To compare the actual dynamics of the spike trains, we noted that ISI logarithms fit convincingly to quadratic polynomials, i.e. the ISI series itself was fitted with the dilated Gaussian $\exp (a *$ $\left.(x-a 0)^{2}+c\right)$ equation using a standard linear model. From this, we produced basic statistics of the coefficients for each group of spike trains using ANOVA with post hoc Dunnett's test. Asterisks denote significant differences at $\mathrm{P} \leq 0.05$ level. Figure 2 illustrates the schema of in vivo data analysis for ISI temporal evolution.

\subsection{Animal care and handling}

The animals were kept and the experiments were conducted in conformity with the Council Directive 86/609/EEC, the Hungarian Act of Animal Care and Experimentation (1998, XXVIII) and local regulations for the care and use of animals for research. 


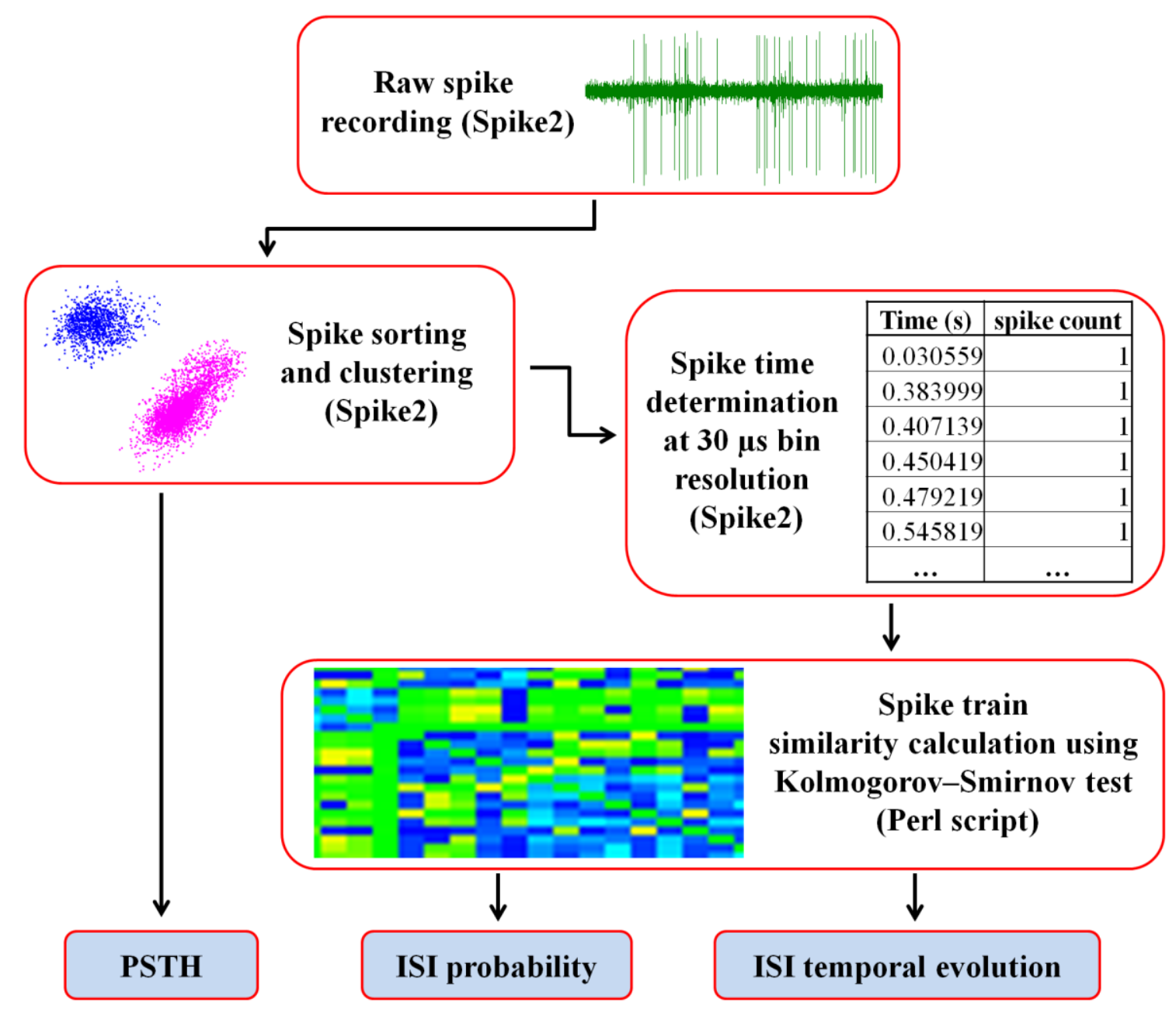

Figure 2. Schema of in vivo data analysis for PSTH, ISI probability and ISI temporal evolution:

After recording, action potentials were stored digitally, sorted and clustered offline. Inset shows the principal component plots of the spikes, probably belonging to two different cells. For ISI probability and ISI temporal evolution analysis the exact time of action potentials were determined at $30 \mu$ s bin resolution in Spike2. A Perl script was written which calculated the degree of global similarity of every spike trains using the Kolmogorov-Smirnov test, and generated a worksheet with colour-coded rates of similarity where green indicates similarity and deep blue the difference. Within groups spike trains did not differ, while distinct groups showed differences. To further examine the differences, ISI probability and ISI temporal evolution calculations were made. 


\section{Results}

\subsection{In vitro MEA experiments}

\subsubsection{Tianeptime increases fEPSP amplitude in a dose-dependent manner}

Murine hippocampal slices were continuously perfused with ACSF, and evoked fEPSPs were analyzed. After $20 \mathrm{~min}$ control level registration $100 \mu \mathrm{M}$ Tianeptine was introduced into the ACSF, which rapidly increased the peak-to-peak amplitude of evoked fEPSPs $(189 \pm 14 \%$, after $60 \mathrm{~min}, \mathrm{n}=8$ slices; $\mathrm{P} \leq 0.05$; Figure $3 \mathrm{~A}) .10 \mu \mathrm{M}$ Tianeptine could also increase significantly the fEPSP amplitudes within 60 min $(129 \pm 5 \%$, after 60 min, $\mathrm{n}=6$ slices; $\mathrm{P} \leq 0.05$; Figure $3 \mathrm{~A}$ ), although it was not so pronounced. In untreated control slices the excitability increased only to $104 \pm 1.7 \%$ (after $60 \mathrm{~min}, \mathrm{n}=4$ slices; data not shown). An inactive derivative of Tianeptine, EGIS-13217-1 had no effect on the fEPSP amplitudes $(97 \pm 2 \%$, after $60 \mathrm{~min}, \mathrm{n}=5$ slices, Figure $3 \mathrm{~A})$. Although the tricyclic antidepressant Imipramine also did not influence fEPSP amplitudes measured after $60 \mathrm{~min}$, $(103 \pm 3 \%$, after 60 min, $\mathrm{n}=4$ slices, Figure $3 \mathrm{~A})$, it caused a transient excitation which peaked at $\approx 40 \min (110 \pm 1.4 \%)$.

We also recorded I/O curves before and $60 \mathrm{~min}$ after $100 \mu \mathrm{M}$ Tianeptine wash in for assessing the rise of excitability. The I/O curves showed a clear enhancement of evoked responses (Figure 3B). Using two-way ANOVA with post hoc Tukey's test, significant differences were detected at different stimulation intensities: at $40 \mu \mathrm{A}(383 \pm 93$ vs. $624 \pm$ $61 \mu \mathrm{V}, \mathrm{P}=0.048)$, at $50 \mu \mathrm{A}(475 \pm 150$ vs. $840 \pm 80 \mu \mathrm{V}, \mathrm{P}=0.05)$ and at $60 \mu \mathrm{A}(585 \pm$ 185 vs. $1030 \pm 90 \mu \mathrm{V}, \mathrm{P}=0.048)$. 

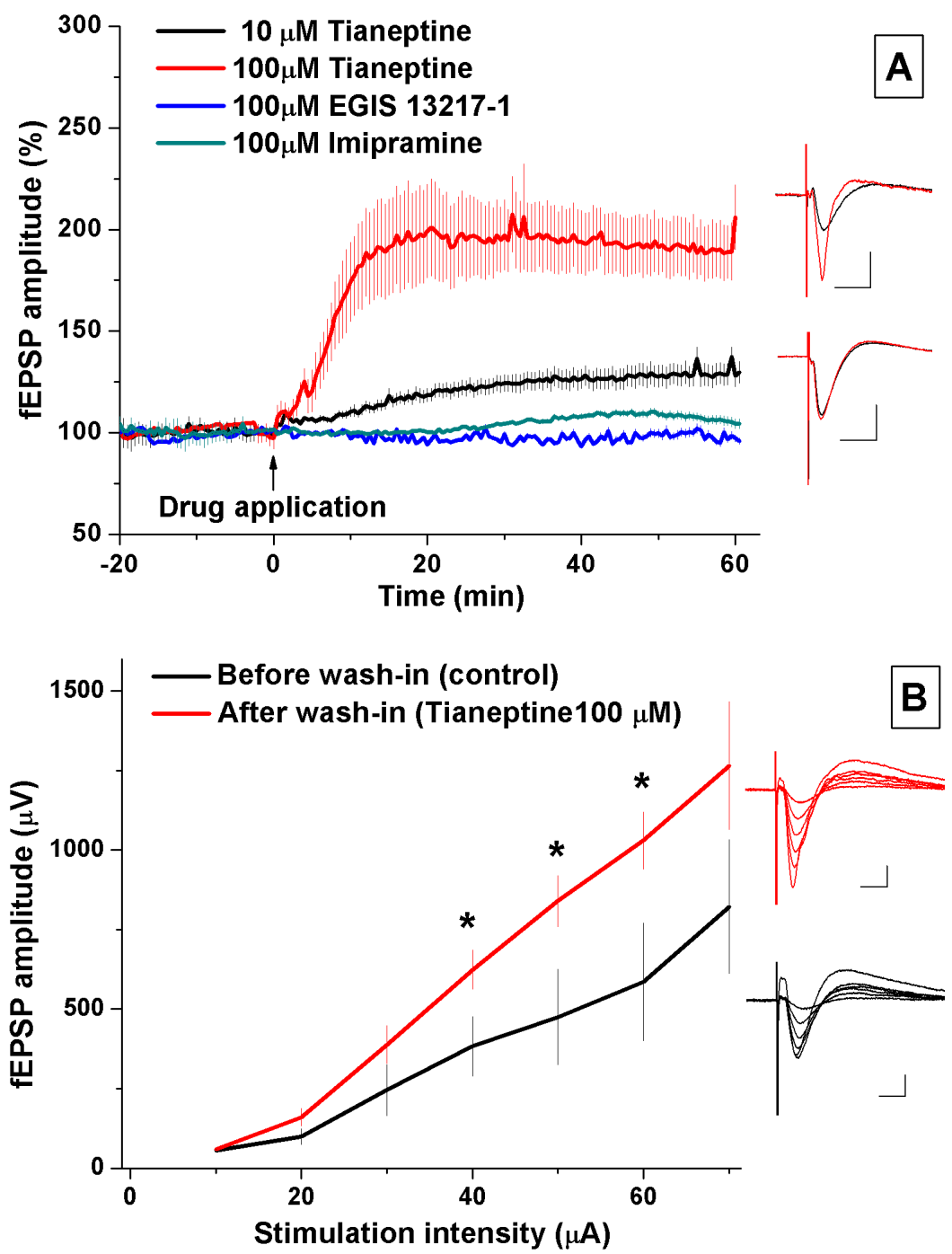

Figure 3. Tianeptine enhances the excitability of murine hippocampal slices:

Panel A shows that Tianeptine enhances fEPSP amplitude in a dose-dependent manner. $100 \mu \mathrm{M}$ Tianeptine robustly increased the fEPSP amplitude immediately after drug wash in. An inactive derivative, EGIS 13217-1 and a tricyclic antidepressant Imipramine had no effect on fEPSP amplitude. Insets show representative fEPSPs before (black) and after (red) drug application (upper $100 \mu \mathrm{M}$ Tianeptine, lower $100 \mu \mathrm{M}$ Imipramine). Panel B shows I/O curves before and after $100 \mu \mathrm{M}$ Tianeptine application. Tianeptine-treated slices had larger fEPSP amplitude values, they were more sensitive to the same stimulation intensity. Insets show representative set of evoked field potentials. Inset calibrations are $500 \mu \mathrm{V}$ and $10 \mathrm{~ms}$. ${ }^{*} \mathrm{P} \leq 0.05$, ANOVA post hoc Tukey's test

\subsubsection{The fEPSP amplitude enhancement is not of presynaptic origin}

There are two possibilities by which Tianeptine can develop its fEPSP increasing effect. First, it may act on the presynaptic site, where Tianeptine may increase somehow the vesicle release probability. Second, it may have postsynaptic effects, which can 
contribute to the fEPSP amplitude enhancement. In order to address whether Tianeptine acts on the presynapse, PPF (interstimulus interval $50 \mathrm{~ms}$ ) was recorded before and $60 \mathrm{~min}$ after Tianeptine administration. The ratio of the $2^{\text {nd }}$ and $1^{\text {st }}$ fEPSP is usually larger than 1 in the CA1 (facilitation), because the second stimulus evokes a larger fEPSP. If the second stimulating impulse closely follows a prior one (within a few $\mathrm{ms}$ ), the increased residual $\mathrm{Ca}^{2+}$ level in the presynapse may lead to increased vesicle release probability, hence higher activation in postsynaptic cell and larger amplitude of the second fEPSP. If Tianeptine exerts its effect at the presynaptic compartment, PPF change is expected.

There was no change in the ratio of $2^{\text {nd }} / 1^{\text {st }}$ fEPSP amplitude before $(1.45 \pm 0.13)$ and after Tianeptine administration (1.43 $\pm 0.04 ; \mathrm{n}=6$ slices; Figure 4), showing that Tianeptine likely has a postsynaptic site of action. Similar results were reported in the CA3 by Kole et al. (Kole et al., 2002).
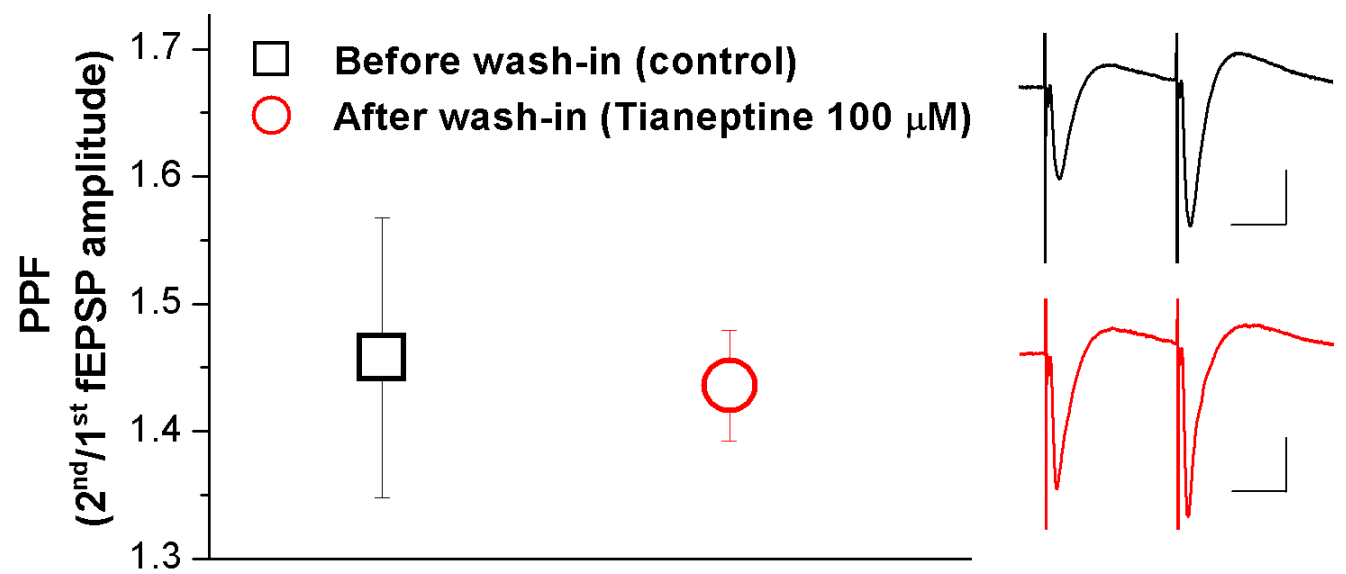

\section{Figure 4. PPF results of MEA experiments:}

There was no difference between the ratios of $2^{\text {nd }} / 1^{\text {st }}$ fEPSP amplitude before and after Tianeptine administration, which means that Tianeptine does not have any presynaptic effect. Inset curves show exemplar field potentials, where interstimulus interval is $50 \mathrm{~ms}$. Calibrations are $500 \mu \mathrm{V}$ and $25 \mathrm{~ms}$.

\subsubsection{The effect of Tianeptine on NMDA and AMPA receptors}

Tianeptine enhanced fEPSP amplitudes postsynaptically most probably by the modulation of postsynaptic excitatory ionotropic receptors. In order to reveal which receptor is affected by Tianeptine, specific receptor antagonists were used. We focused on AMPA and NMDA receptors above all, and used their specific blockers 7-nitro-2,3-dioxo1,4- dihydroquinoxaline-6-carbonitrile (CNQX), and [5R,10S]-[+]-5-methyl-10,11dihydro-5H-dibenzo[a,d]cyclohepten-5,10-imine (MK-801) respectively. Application of 50 
$\mu \mathrm{M}$ of the AMPA receptor antagonist CNQX caused a rapid and dramatic decrease in the amplitude of evoked fEPSPs (around 20\%; $n=7$ slices; Figure 5A). The remaining evoked responses were considered as NMDA receptor-mediated field potentials, because the perfusion of the NMDA receptor antagonist MK-801 completely blocked the evoked fEPSPs. $100 \mu \mathrm{M}$ Tianeptine wash in did not affect isolated NMDA receptor-mediated fEPSPs, indicating that Tianeptine cannot modify NMDA receptor function in the CA1 of hippocampal slices (Figure 5A). It is known that NMDA receptors are blocked by high $\mathrm{Mg}^{2+}$ level, therefore NMDA receptor-mediated responses should not be isolated in slices perfused by normal ACSF. However we have followed the protocol of the Lynch and Gall group (Kramar et al., 2003, Bernard-Trifilo et al., 2005), where the authors have used similar experimental setup than ours (extracellular fEPSP recordings from CA1). The authors have shown that it is indeed possible to isolate NMDA receptor-mediated fEPSPs using normal ACSF (containing $2.5 \mathrm{mM} \mathrm{Mg}^{2+}$ ) and CNQX. Similar to our findings (Figure 5A), they could also block the residual fEPSP with MK-801, strongly suggesting that the residual fEPSPs were NMDA receptor-mediated.

Next, we focused on AMPA receptors by using the non-competitive NMDA receptor antagonist $\mathrm{MK}-801$ in $50 \mu \mathrm{M}$ concentration. MK-801 alone had no significant effect on the amplitudes of evoked fEPSPs, however applying of CNQX completely diminished the evoked responses. These results showed that upon MK-801 application the fEPSPs are mostly AMPA receptor-mediated ( $n=4$ slices). The AMPA receptor-mediated fEPSPs, isolated by the MK-801 wash in, significantly increased after $100 \mu \mathrm{M}$ Tianeptine administration ( $163 \pm 4.5 \%$ after 60 min administration, $\mathrm{n}=4$ slices; $\mathrm{P} \leq 0.05$; Figure 5B), which indicates the effect of Tianeptine on AMPA receptors. Moreover, in order to test the effectiveness of the NMDA receptor antagonist, TBS was applied for inducing LTP after the 60 min Tianeptine administration period. There is NMDA receptor-dependent LTP in the CA1 region of the hippocampus, hence LTP impairment was expected after MK-801 treatment. Indeed, after TBS the amplitudes of fEPSPs remained at the pre-LTP level. The absence of LTP clearly demonstrated the blockade of NMDA receptors by MK-801 (Figure 5B). 

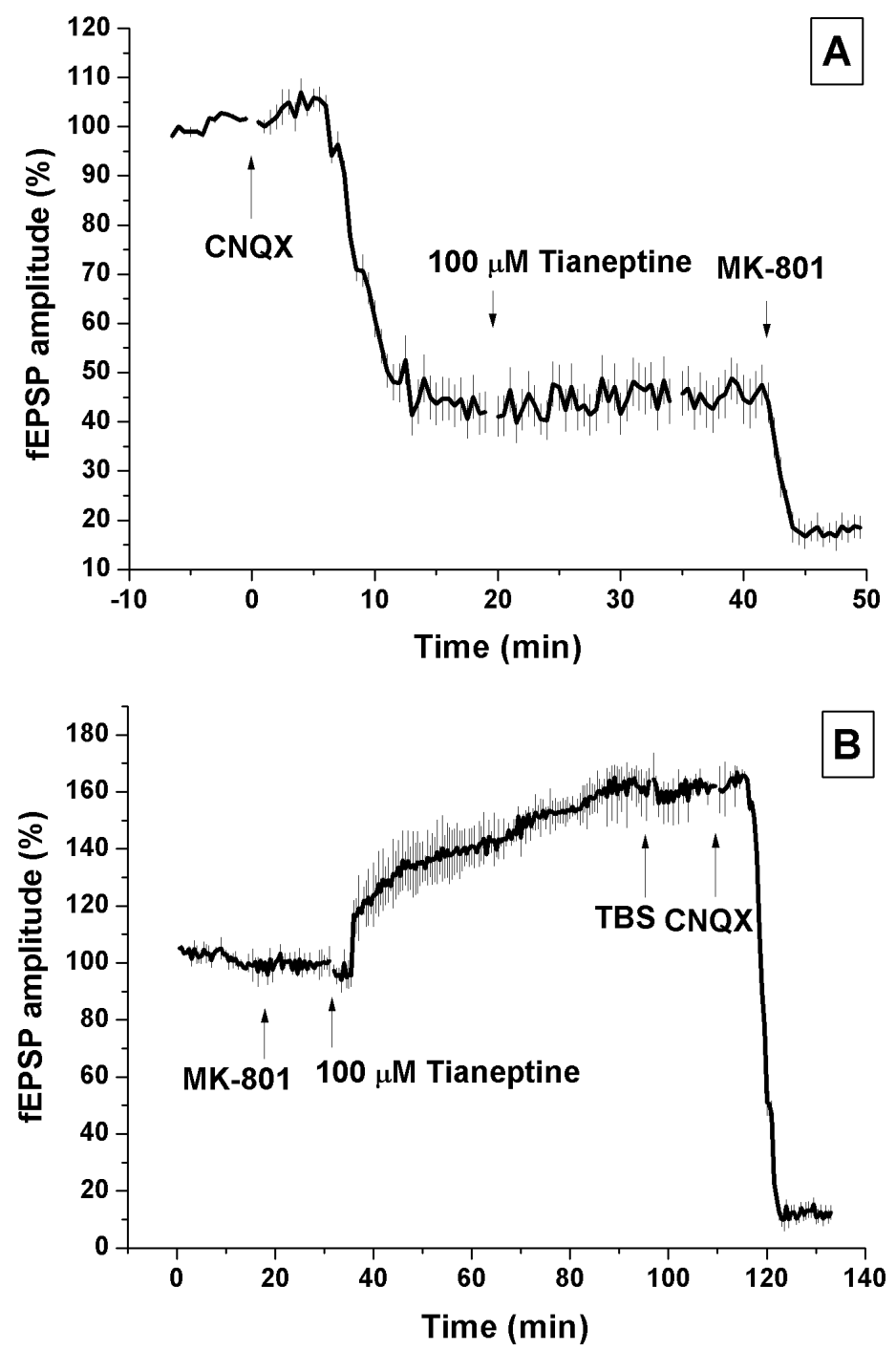

Figure 5. The fEPSP enhancement depended on the AMPA receptors:

Panel A: When AMPA receptors were blocked by CNQX, fEPSP amplitude decreased rapidly and reached a plateau level. Thereafter $100 \mu \mathrm{M}$ Tianeptine did not increase fEPSP amplitude. Applying NMDA receptor blocker MK-801 totally abolished remained evoked responses. Panel B: Blocking NMDA receptors with MK-801 prior to drug application, $100 \mu \mathrm{M}$ Tianeptine wash in dramatically enhanced AMPA-dependent fEPSP amplitude. NMDA-dependent LTP could not be evoked by TBS, which shows the blockade of NMDA receptors. Applying CNQX completely abolished field potentials. Results demonstrates that Tianeptine alters AMPA receptor functioning.

\subsection{In vivo single-unit experiments}

\subsubsection{The effect of i.p. Tianeptine on NMDA- and AMPA-evoked neuronal} firing

Based on the in vitro electrophysiology results, we aimed to investigate the effects of i.p. administered Tianeptine on NMDA- and AMPA-evoked neuronal firing in vivo. We 
recorded single-unit activity from the CA1 region of the dorsal hippocampus of chloralhydrate anesthetized rats. Spike trains were regularly evoked by applying either NMDA or AMPA, agonist of the same receptors, by the help of microiontophoresis in the very close vicinity of the recorded neuron.

In the case of NMDA, spike trains were evoked every minute while using AMPA, spike trains were evoked every 1.5 minutes. Such long interstimulus intervals allow the depletion of agonists from the vicinity of cells by reuptake or degradation; hence the consecutive stimulations can be taken into consideration as independent spike trains. We set at least 5-10 minutes long control spiking level before applying Tianeptine i.p. with no more than $15 \%$ difference in the spiking rate. After Tianeptine application we recorded the evoked responses for further 1 hour. The colour-coded peristimulus time histogram (ccPSTH) with $100 \mathrm{~ms}$ bin resolution shows evoked responses arranged in line vertically from top to bottom. The colours denote the amount of binned action potentials from cold blue to warm red.

First, we focused on NMDA-evoked single-unit firing, therefore we registered STHs containing NMDA ejections. Figure 6 consist of three panels (A-C) in order STH, ccPSTH with $100 \mathrm{~ms}$ bin, and one averaged peristimulus time histogram (aPSTH), which shows a representative recording of the effect of i.p. applied Tianeptine on NMDA-evoked neuronal activity. Evoked neuronal firing rate remained at the pre-Tianeptine level within the time frame of the recording (35-45 min), indicating that Tianeptine did not affect NMDA-evoked neuronal responses $(108 \pm 12 \% ; \mathrm{n}=6$ cells $)$.

The ccPSTH (Panel B) and the average of the firing rate of five successive trials before and 30 minute after i.p. Tianeptine application (Panel C) shows that the $5 \mathrm{sec}$ NMDA ejection (starting point marked with cyan dashed vertical line at zero sec) evoked firing rate did not change over time.

Accordingly the representative enlarged spike train insets, the evoked responses incorporate approximately the same amount of action potentials before and after Tianeptine administration and the spike train dynamics are similar. Spontaneous firing activity did not change after Tianeptine application. 


\section{Figure 6. NMDA-evoked neuronal firing}
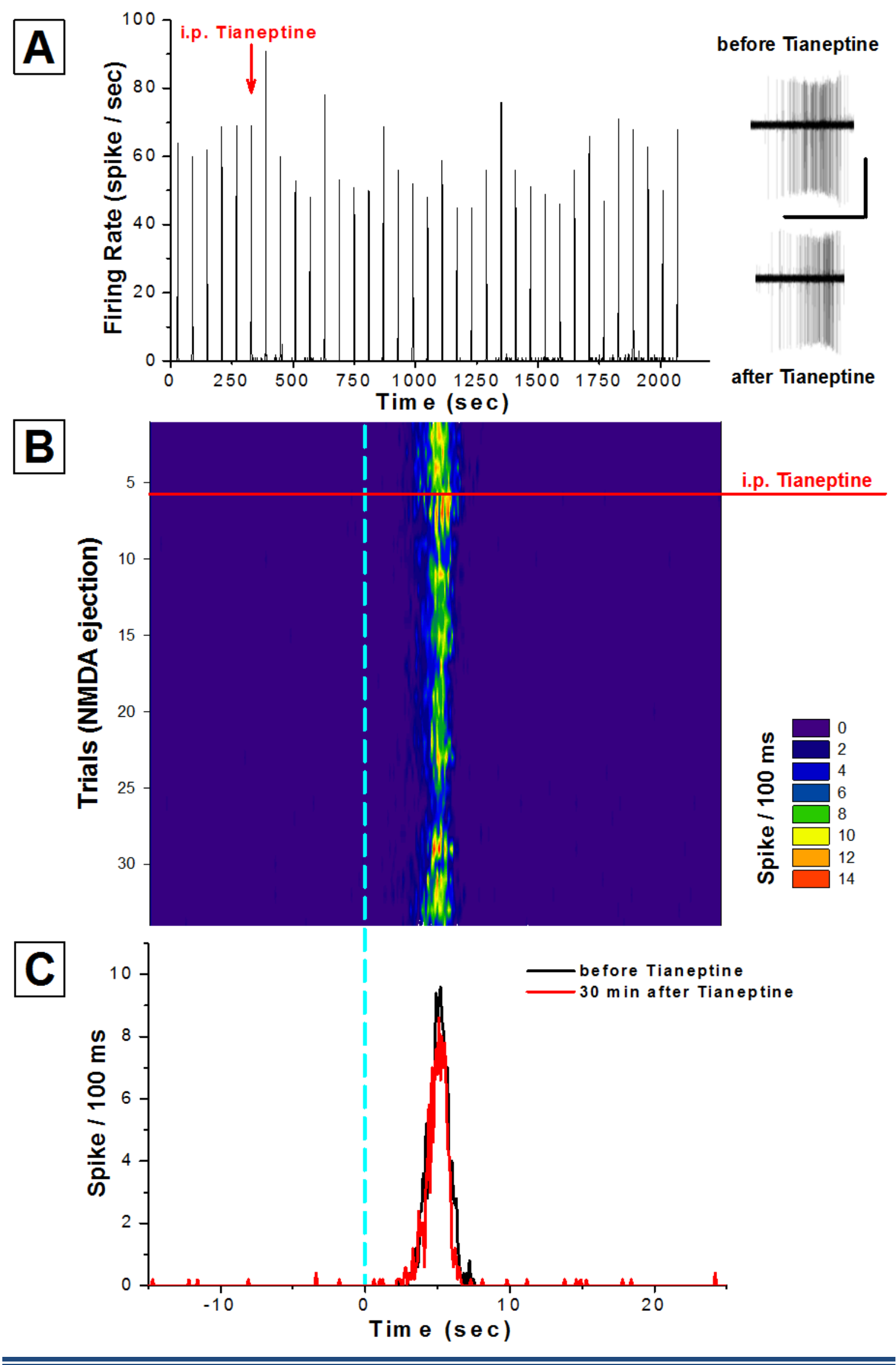
Figure 6. Representative recording of one hippocampal single-unit activity evoked by NMDA:

Panel A shows a STH, where the red arrow indicates Tianeptine administration. Two representative spike trains before and after Tianeptine treatment are enlarged, scale bars are $100 \mu \mathrm{V}$ and $5 \mathrm{sec}$. Panel B represents a ccPSTH in which cyan dashed vertical line denotes NMDA ejections, and red horizontal line denotes Tianeptine administration. Panel $\mathbf{C}$ is an aPSTH, where black curve is the averaged amount of action potentials of five spike trains before Tianeptine, red curve shows the same after Tianeptine treatment. Cyan dashed vertical line at zero second represents the starting point of NMDA ejections. The evoked responses remained unaltered after Tianeptine i.p. application, Tianeptine had no effect on NMDA-evoked firing.

Next, we investigated the effect of i.p. administered Tianeptine on AMPA-evoked neuronal firing. Figure 7 shows one representative AMPA-evoked recording. It is conspicuous that i.p. physiological saline injection only slightly increased evoked firing rate, however, following i.p. Tianeptine application the amplitude of evoked responses increased significantly. The representative enlarged spike trains denote the same increment in the number of action potentials after Tianeptine treatment. I.p. Tianeptine administration massively enhanced AMPA-elicited firing activity within $10 \mathrm{~min}$, and this effect remained within the time frame of the recordings. The average of the Tianeptine-induced effect on AMPA responses was calculated as the evoked responses of each recordings 30 minute after i.p. administration $(196 \pm 32 \% ; n=6$ cells from 6 rats; $\mathrm{P} \leq 0.05)$. Figure 8 shows the enhancing effect of Tianeptine on AMPA-evoked firings compared to NMDA-evoked firings. 


\section{Figure 7. AMPA-evoked neuronal firing}

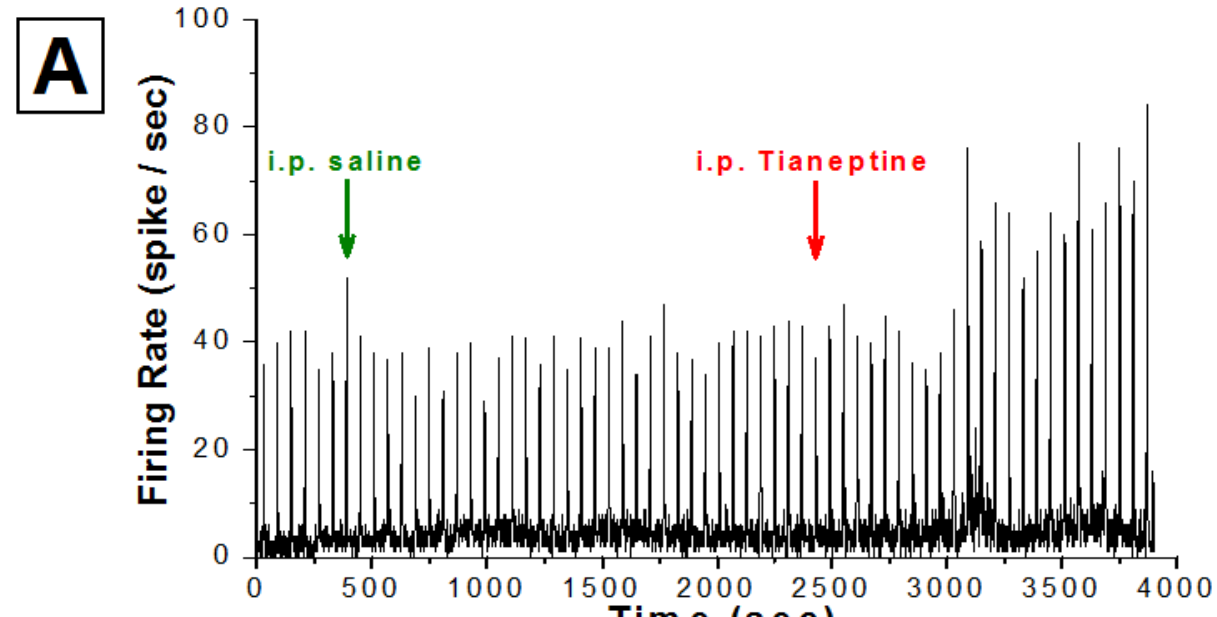

before Tianeptine

B Time (s e c)

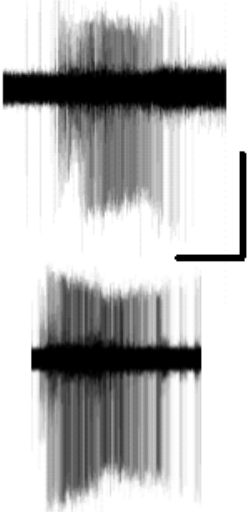

after Tianeptine

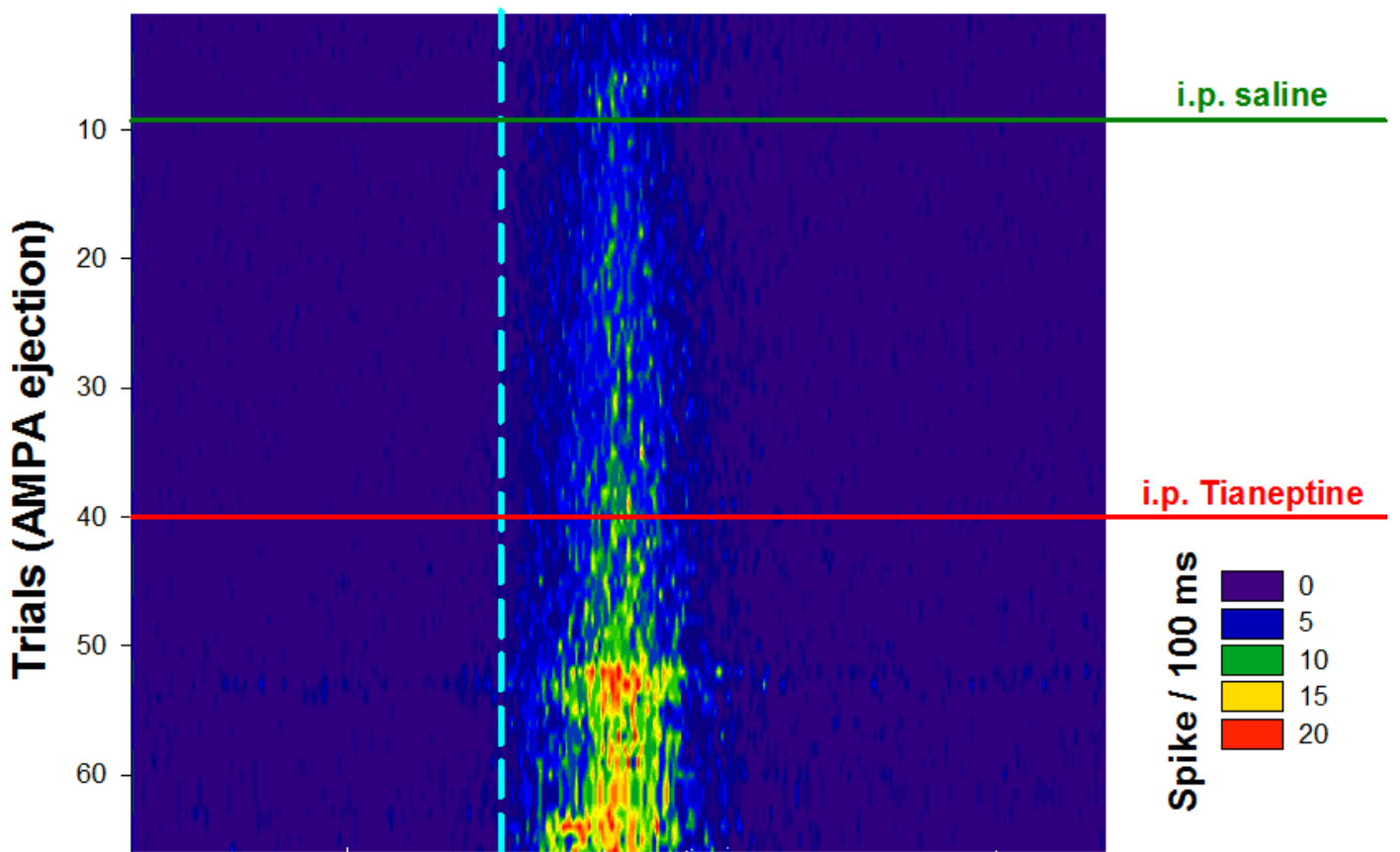

C

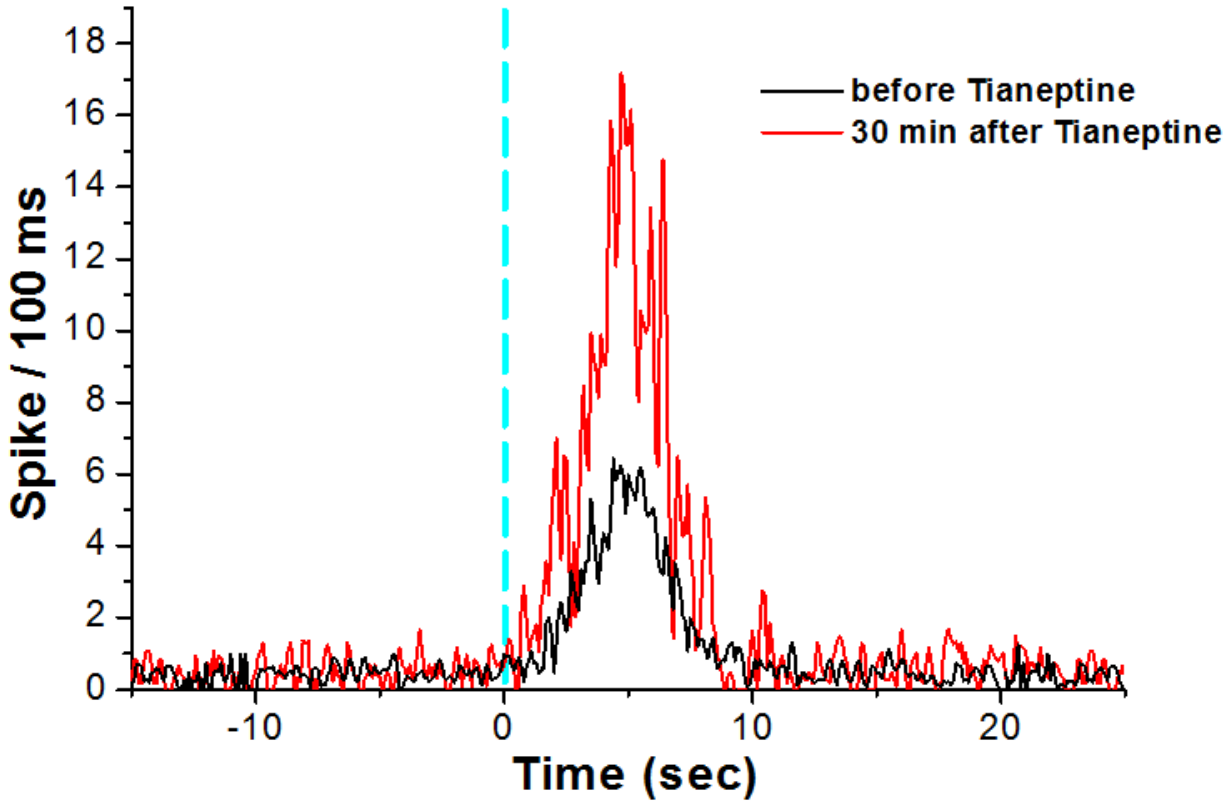


Figure 7. Representative recording illustrating AMPA-evoked neuronal firing before and after i.p. physiological saline and Tianeptine application:

Panel A: I.p. saline injection (green arrow) only slightly increased the amplitude of AMPA-evoked firing activity. In contrast, Tianeptine administration (red arrow) caused long-lasting increment of AMPA-evoked single-unit activity. Exemplar spike trains are shown before and after Tianeptine application, scale bars are $100 \mu \mathrm{V}$ and $5 \mathrm{sec}$. Panel B: In the ccPSTH more vivid colours close to red are visible after Tianeptine administration. Cyan dashed vertical line denotes AMPA ejections. Panel C: In the aPSTH containing graph the amplitude of the red curve is significantly higher, which means that Tianeptine increased AMPA-evoked firing rate.

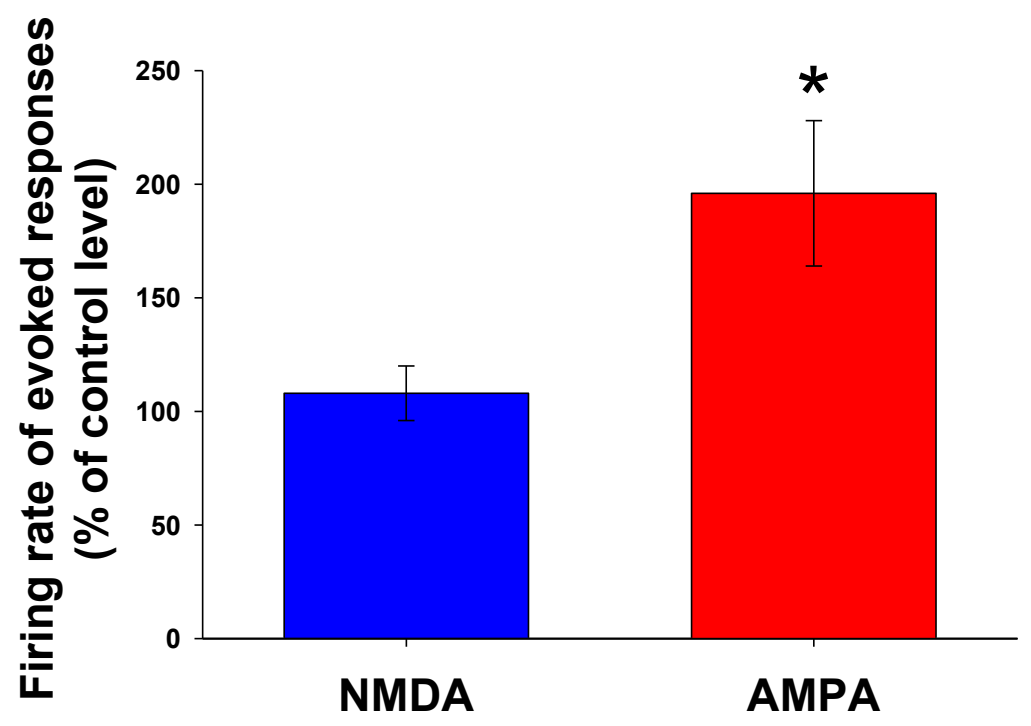

Figure 8. Summary of the effect of Tianeptine on NMDA- and AMPA-evoked responses in vivo:

NMDA-evoked responses remained at control level, but AMPA responses significantly increased after Tianeptine i.p. administration. Values are expressed in the percentage of control level. * $\mathrm{P} \leq 0.05$, ANOVA, with post hoc Bonferroni test

\subsubsection{The effect of i.p. Tianeptine on the ISIs of NMDA- and AMPA-evoked neuronal activity}

We have shown that Tianeptine elevates the phosphorylation level of AMPA receptor subunit GluA1 at Ser 831 and Ser 845 (Svenningsson et al., 2007, Qi et al., 2009, Szegedi et al., 2011). We prompted to investigate the effects of these phosphorylation events on the AMPA-evoked spike trains in vivo. We hypothesized that Tianeptine not only enhance the AMPA-evoked firing activity, but also leads to alteration of the spiking pattern and dynamics, compared to similarly-enhanced AMPA spike trains evoked by stronger AMPA stimulation. To address this point, we recorded spike trains evoked by 
weak and strong AMPA stimulation and compared to weak AMPA-evoked spike trains recorded before and after i.p. Tianeptine application. Furthermore, we compared those with NMDA-evoked spiking activity, in which Tianeptine had no effect. Ejection currents were unaltered before and after Tianeptine within an experiment.

A total of 310 spike trains from 31 single-units recorded from 21 rats were analyzed. The autocorrelogram of all units were calculated, and only units with less than $0.5 \%$ of spike intervals within the first $1 \mathrm{~ms}$ refractory period were included in the present analysis. We used spike trains for analysis only from units having high signal-to-noise ratios ( $\geq 5$-fold than noise level). These units were considered as putative pyramidal cells, based on their wider spike shapes (mean width $>400 \mu \mathrm{s}$ ).

The schema of the experimental setup is illustrated on Figure 9 which shows the 3 different stimulation protocols. Spike trains were evoked by either ejecting AMPA or NMDA, using weak or strong ejection currents. 


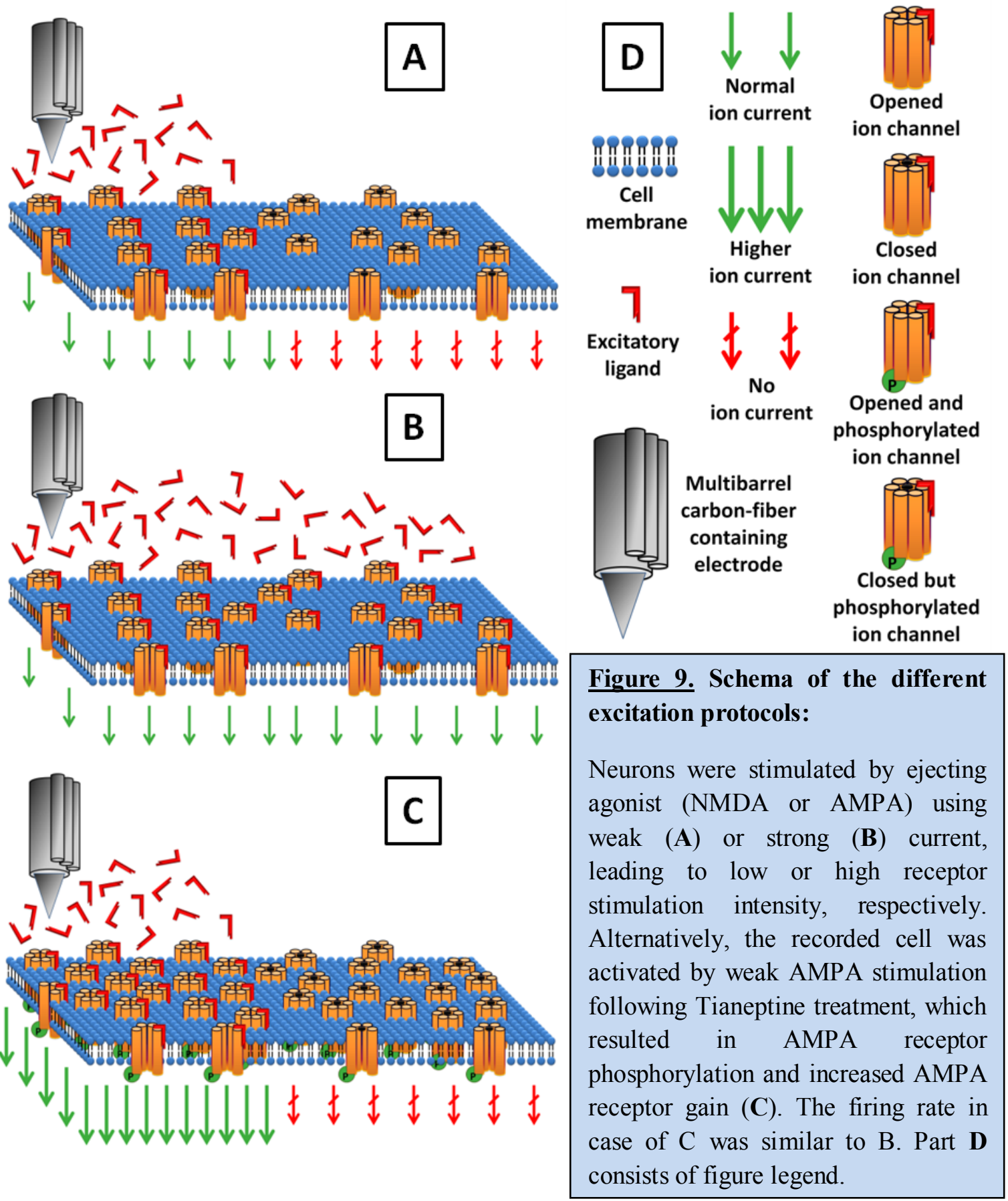

In the case of Tianeptine treatment the AMPA ejection was invariably weak along the whole registration before and after i.p. Tianeptine injection. Moreover Figure $10 \mathrm{~A}$ and B show two enlarged representative spike trains recorded before and after Tianeptine application using weak AMPA excitation, and additionally superimposed spike shapes with corresponding autocorrelograms. 


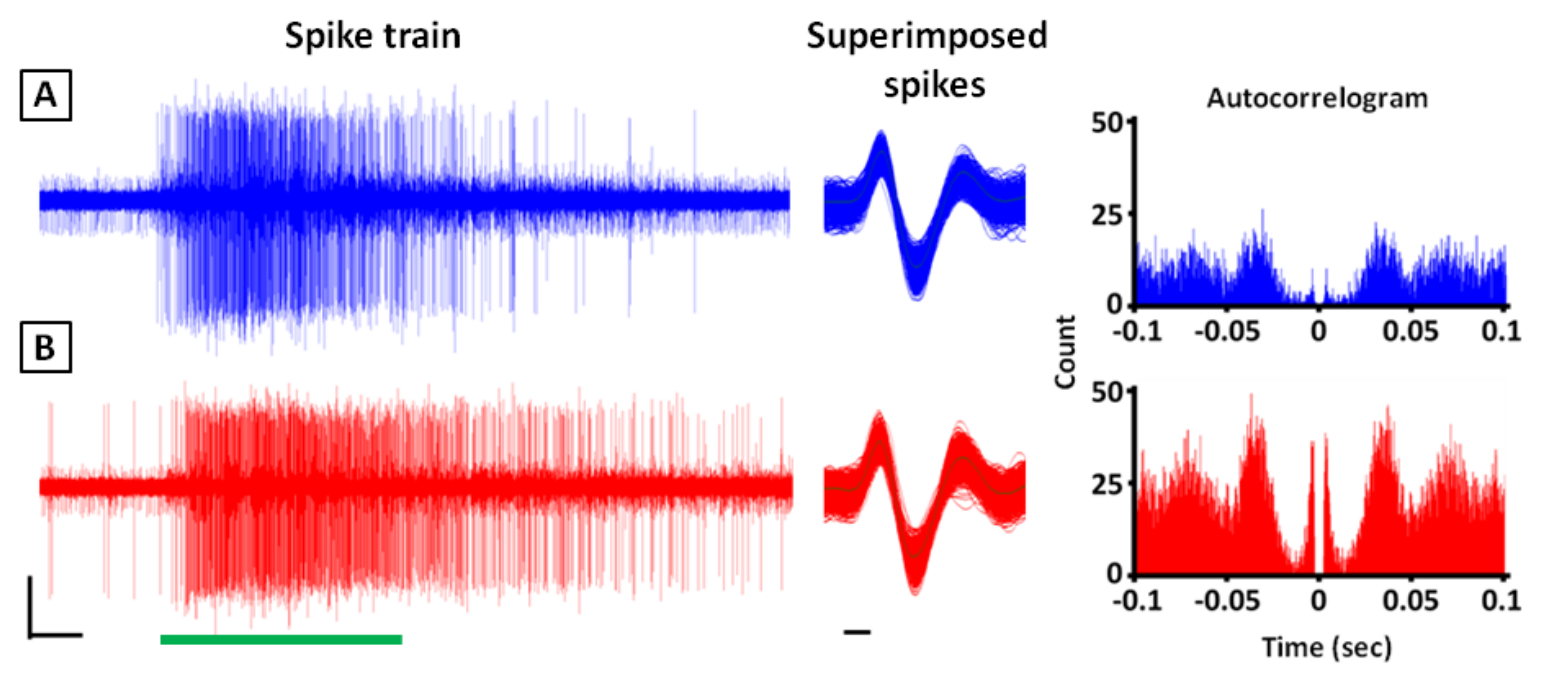

Figure 10. Representative AMPA-evoked spike trains with the appropriate spike shapes and spike autocorrelograms:

Panel A shows a spike train evoked by weak AMPA stimulation, while panel B illustrates weak AMPA-evoked spikes after Tianeptine application from the same registration. Spike shapes were unaltered throughout the recording session. Green line represents the $5 \mathrm{sec}$ AMPA ejection. Scale bars are $50 \mu \mathrm{V}$ and $1 \mathrm{sec}$ in the case of spike trains and $0.1 \mathrm{~ms}$ at the superimposed spikes. Tianeptine treatment enhanced AMPAevoked spike trains.

The level of weak excitation (ejection current) was set between 3 and 4 spike/100 ms, labeled with the following names: 'weak AMPA', 'weak NMDA', and 'AMPA before Tianeptine', whereas strong excitation was set between 6 and 8 spike/100 ms, denominated as 'strong AMPA' and 'strong NMDA'. Tianeptine i.p. application resulted in an enhancement of weak AMPA-evoked spiking activity, which reached 7-9 spike/100 ms 30 min after drug administration, such high as in the case of strong AMPA excitation, where Tianeptine treatment was otherwise absent. This group is referred as 'AMPA after Tianeptine'. Accordingly enhanced AMPA sensitivity was induced by a bolus of i.p. Tianeptine administration $(20 \mathrm{mg} / \mathrm{kg})$. Five such spike trains were analyzed from every recording in the case of weak and strong ejections, and before and after Tianeptine treatment.

\subsection{3 aPSTH}

First, we calculated the PSTHs of every spike trains, and averaged them per groups. The mean PSTH of weak/strong AMPA/NMDA stimulation and AMPA stimulation before and after Tianeptine are plotted in Figure $11 \mathrm{~A}$ and B. We compared the maximal values of 
different groups, and for this purpose a one-way repeated measures ANOVA with post hoc Tukey's test was used. We hypothesized that there should be no difference between the weak AMPA stimulation and before Tianeptine PSTH data, because the number of evoked spikes are in the same order of magnitude in both groups (the stimulation intensity was comparable). Indeed, there is no significant difference between weak AMPA, weak NMDA and AMPA before Tianeptine PSTHs (number of spike trains; $n=60,50$ and 45, respectively).
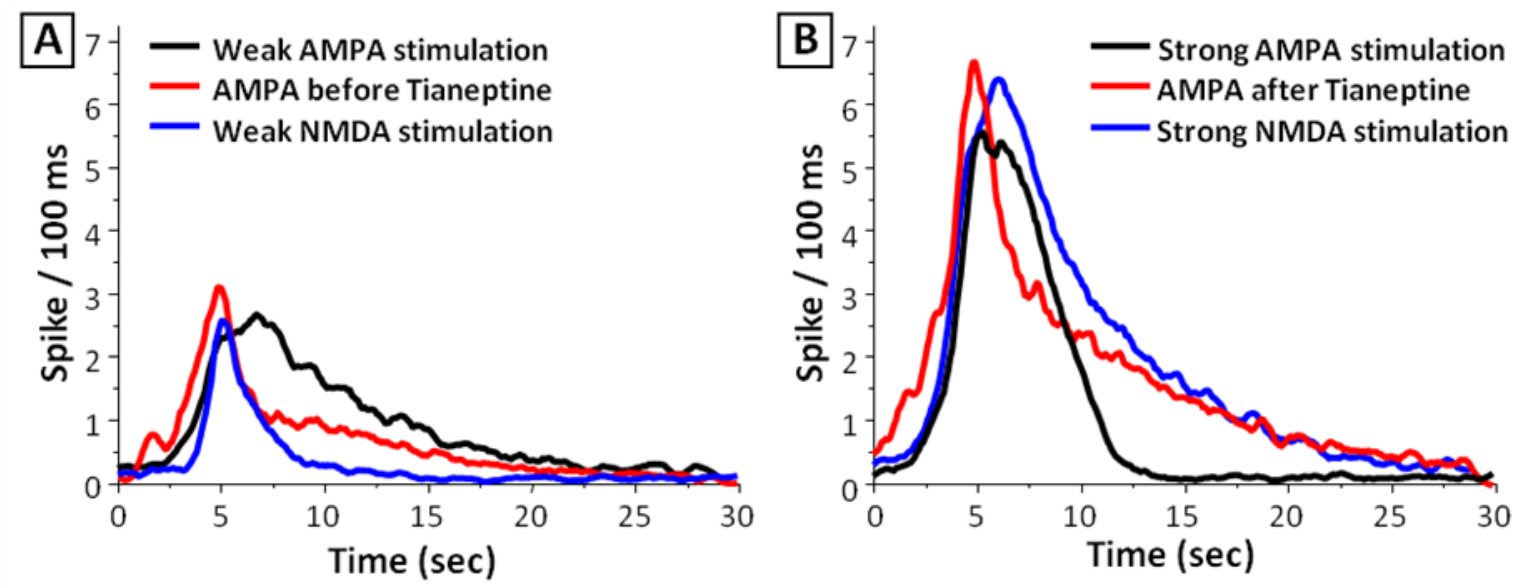

\section{Figure 11. aPSTH of registered spike trains:}

Panel A: There was no significant difference between the maxima of aPSTH curves of weak AMPA, AMPA before Tianeptine and weak NMDA groups. Panel B: Similarly, maxima of strong AMPA, AMPA after Tianeptine and strong NMDA also did not differ from each other. The effect of i. p. Tianeptine application is not manifested in the PSTH profile; although strong AMPA-evoked PSTH tend to decay faster than others.

Similarly, we found no difference between strong AMPA and AMPA after Tianeptine PSTHs ( $\mathrm{n}=60$ and 45), suggesting that the change in the AMPA-gain level after Tianeptine treatment is not manifested in the PSTH profile. In contrast, strong AMPA PSTH tended to decay faster than strong NMDA-evoked spike trains $(\mathrm{n}=50$ and $60 ; \mathrm{P} \leq$ 0.05) due to the distinct receptor kinetics.

\subsubsection{ISI probability}

The resolution of the PSTH was chosen to be $100 \mathrm{~ms}$. Although this bin value is good for finding overall global differences in the action potential trains, it is too large to detect small dissimilarities in the different action potential distribution or dynamics within 
a spike train. ISI analysis was used for analyzing the changes in firing-pattern of different units. We have used a bin value of $30 \mu$ s for determining the exact time of action potentials.

Figure 12 shows ISI probability scatter plot correlations, where ISI probability values of two different spike trains are correlated. The dots represent the ISI probability values of a spike train in queue in the function of ISI probability values of an another spike train, so the first probability value of ISI was paired with the other's first probability value, and so on. The red line denotes an ideal case of total correspondence, and the blue line shows the actual fitted line. If the spike trains contain the same ISI probability values, the blue and the red line are in cover, so there is no significant difference between the ISI probabilities of spike trains.

The blue regression line runs significantly higher in the case of before - after Tianeptine comparison than red line that indicates differences in ISI values. Tianeptine could change the ISI probability distribution of the spike trains. Contrarily, when we compared the weak AMPA before Tianeptine and weak AMPA excitations, the two regression lines are in cover marked with blue/red dashed line, which shows that there is no difference between the spike trains of the two groups. Before Tianeptine treatment the spike trains had the same ISI probability distribution than spike trains evoked by weak AMPA stimulation. Interestingly the regression lines of strong AMPA and AMPA after Tianeptine ISI probability scatter plot also runs differently, therefore ISI distribution of these evoked spike trains also includes dissimilarity in spite of similar firing rates. 


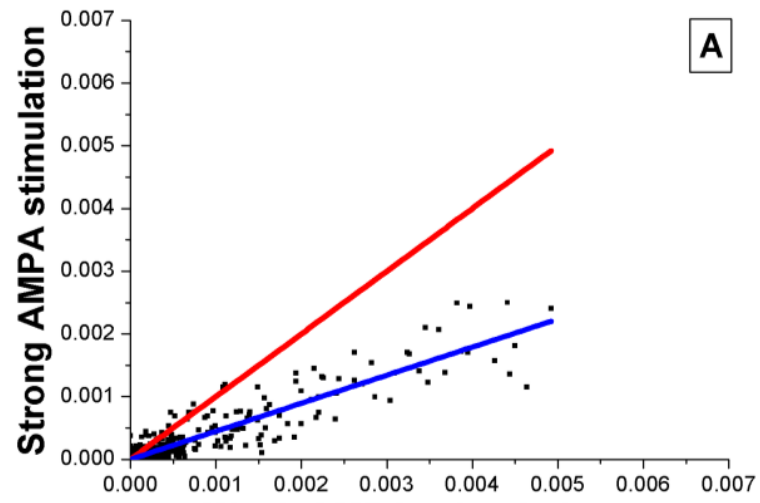

Weak AMPA stimulation

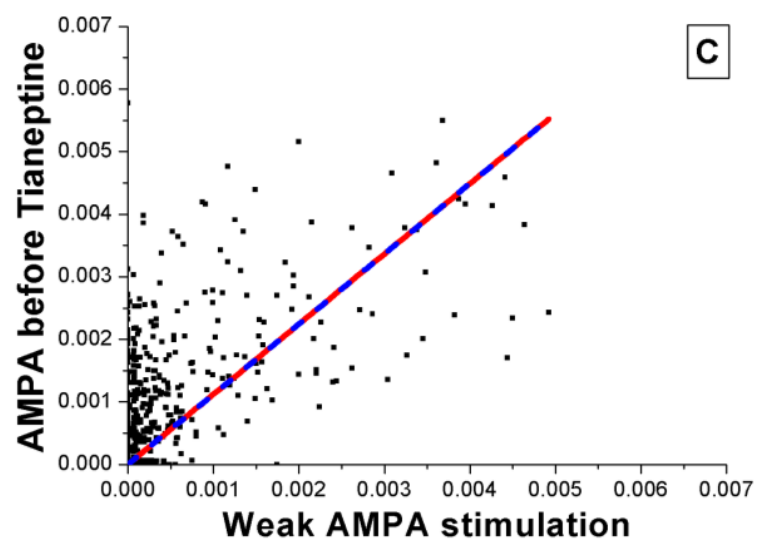

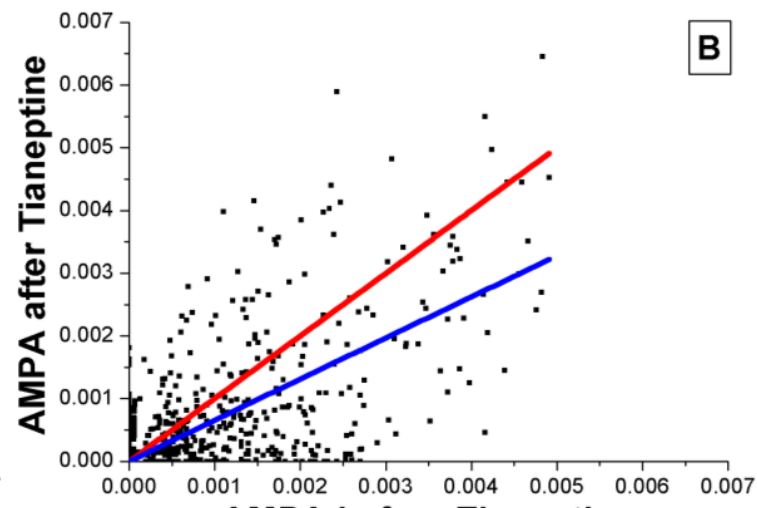

AMPA before Tianeptine

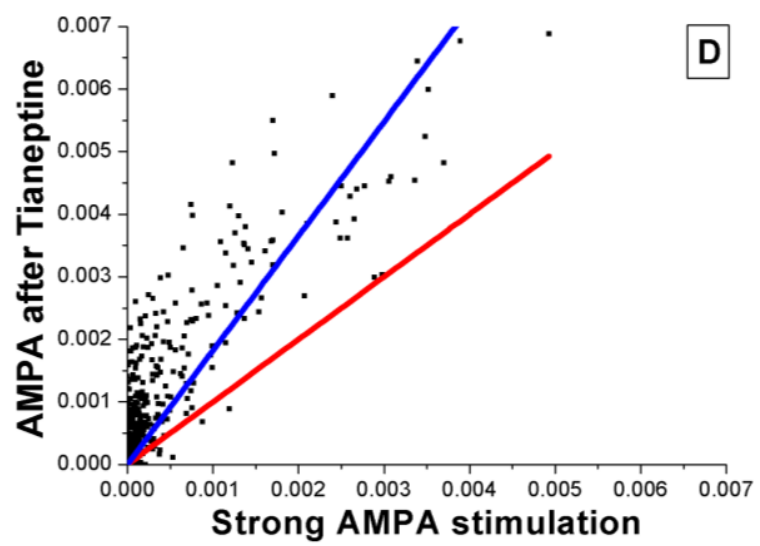

\section{Figure 12. ISI probability scatter plot correlations:}

Red line represents the total correspondence; blue line denotes the actual regression line. In the case of weak / strong AMPA (A) and AMPA before / after Tianeptine (B) the evoked responses having different magnitudes that shift the blue regression line under the red line. In contrast, in the weak AMPA and AMPA before Tianeptine (C) comparison the lines are in cover denoted with blue-red dashed line, because of evoked responses are very similar. Interestingly, the blue fitted line of the spike trains evoked by strong AMPA and AMPA after Tianeptine (D) runs appreciably different from the red correlation line in spite of the similar firing rate, which refers to dissimilarity in ISI distributions.

Subsequently, we analyzed the distribution of ISIs in the evoked spike trains and we plotted the averaged ISI probability curves (Figure 13). Significant difference was not found in the ISI probability profile of weak AMPA and before Tianeptine groups $(n=60$ and 45, respectively), where two probability peaks were seen at around 3-6 ms and 19-21 ms. Weak NMDA-evoked activity resulted in a different ISI probability pattern, also displaying two local maxima at 3-4 ms and 30-31 ms $(\mathrm{n}=50)$, but the second maximum occurs at significantly longer ISI values, although this maximum is not so pronounced. The second maxima of ISI probability curves are marked with a gray rectangle at Figure 13 panel A. Bar chart inset shows the ISI values of second maxima. The second maximum 
peak of weak NMDA ejection takes place significantly later $(\mathrm{P} \leq 0.05)$ compared to second maximum of weak AMPA- and AMPA before Tianeptine-evoked responses. Increasing the stimulation strength by applying larger ejection currents resulted in a prominent peak in the ISI probability distribution, showed in Figure 13 panel B suggesting that the spiking activity became more ordered at stronger stimulation. Moreover, in the case of weak AMPA after Tianeptine this more pronounced peak is also present in ISI probability. Spike trains of averaged ISI probability curves presented on Figure 13 panel B consisted of more action potentials and shorter ISIs than weak excitations because of higher sensitivity or the higher amount of agonist ejection.

Significant differences were observed between weak AMPA/NMDA ( $\mathrm{n}=60$ and 50) and strong AMPA/NMDA, respectively $(\mathrm{P} \leq 0.05)$. Furthermore, there was a significant difference between the strong AMPA and AMPA after Tianeptine groups, suggesting that the increase in AMPA sensitivity has an impact on ISI probability (Figure 13.B). The maximum probability for AMPA after Tianeptine was seen at 5-7 ms $(n=45)$. Also, there was difference between strong AMPA- and NMDA-evoked activity: the maximum probability was seen at 10-13 ms for strong AMPA, and 6-8 ms for strong NMDA ( $\mathrm{n}=60$ and 50; $\mathrm{P} \leq 0.05)$. In Figure 13.B bar chart inset shows the ISI values belonging to maximal probability. 

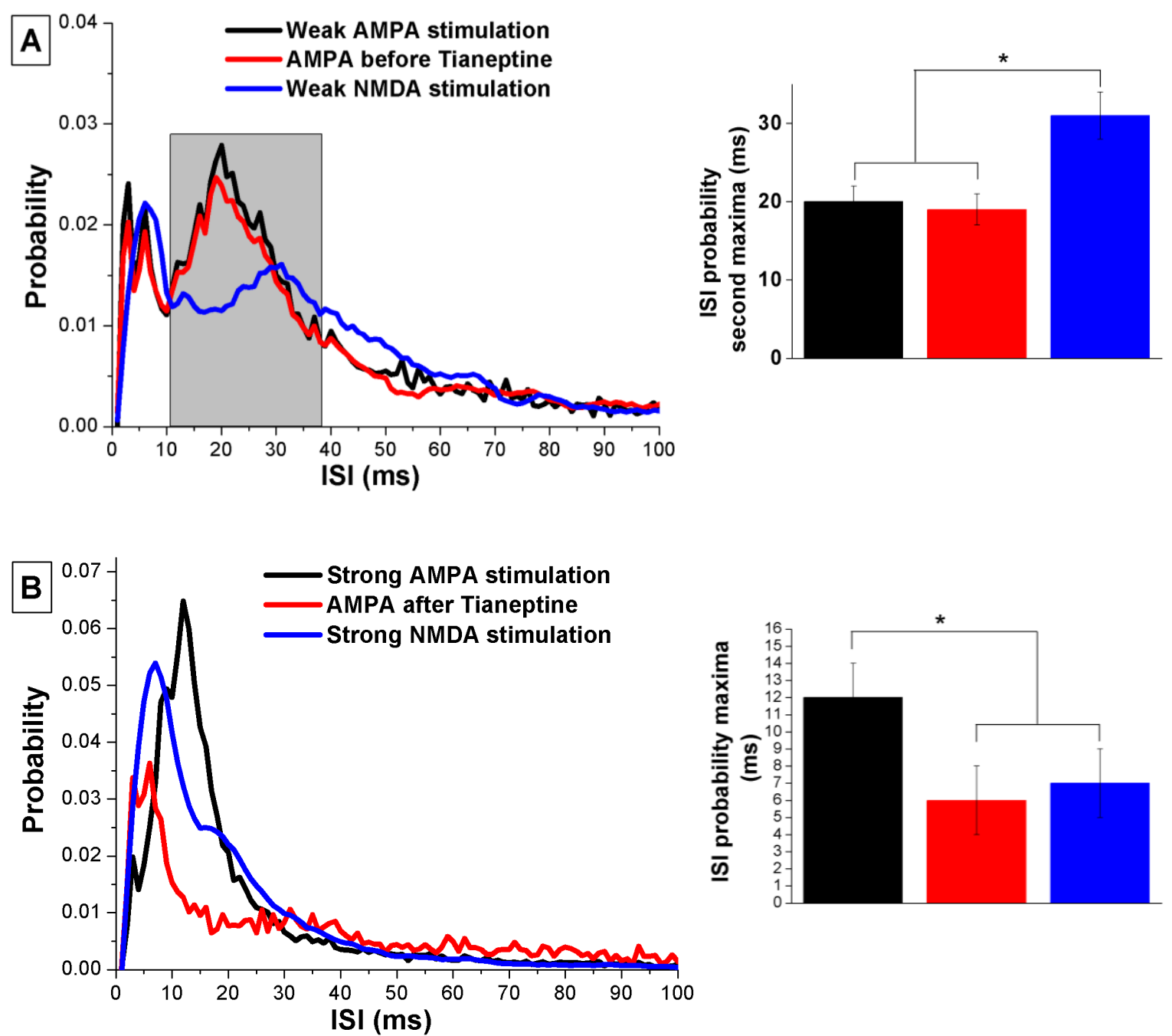

Figure 13. The averaged ISI probability profiles of different stimulation protocols:

Panel A: ISI probability distributions of weak excitation-evoked spike trains. Inset shows the ISI values for the second probability peak (marked with a grey rectangle), where there is no observable difference between weak AMPA and AMPA before Tianeptine groups. Panel B: ISI probability distributions of strong excitation-evoked and Tianeptine-treated spike trains. Inset shows the ISI values for the maximal probabilities. Note the difference between the maxima of strong AMPA and AMPA after Tianeptine groups. Colours in the insets correspond to the colours in the main figure. ${ }^{*} \mathrm{P} \leq 0.05$, ANOVA with post hoc

Dunnett's test

\subsubsection{Temporal evolution of spike trains}

Next we analyzed the temporal evolution of spiking activity within spike trains. We focused on the ISI values, and the time frame of the spike trains were set between 0 and 1 , where the first ISI value stands at zero and the last takes up 1 on the $\mathrm{x}$ scale. The ISI values follow each other in the order of its appearance. After the instantaneous frequency (1/ISI) 
data were counted, a parabola was fitted onto the 1/ISI values of spike trains with the dilated Gaussian $\exp \left(\mathrm{a} *(\mathrm{x}-\mathrm{a} 0)^{2}+\mathrm{c}\right)$ equation using a standard linear model.

Figure 14 panel A shows the averaged parabolas of different stimulation protocols. The obtained coefficients are describable by biological terms, namely the maximal instantaneous frequency exactly provides the position with highest intensity within the spike train (coefficient a), while coefficient c corresponds to the dynamism of the change in intensity. We note that the most pronounced difference lies in the time at which maximal intensity is attained (coefficient a0), which occurs significantly $(\mathrm{P} \leq 0.05)$ earlier after application of Tianeptine $(0.346 \pm 0.013)$ than on the otherwise excited cells. The values of a0 coefficients are in order $0.472 \pm 0.003$ for strong NMDA, $0.408 \pm 0.009$ for strong AMPA, $0.479 \pm 0.014$ for weak NMDA and $0.449 \pm 0.008$ for weak AMPA, respectively. We also detected significant difference between weak AMPA and strong AMPA $(\mathrm{P} \leq 0.05)$ as well as strong AMPA and strong NMDA $(\mathrm{P} \leq 0.05)$. Figure 14 panel $\mathrm{B}$ is a representative bar chart that denote the time values at which maximal intensity of averaged parabolas is attained (coefficient a0). In the case of weak AMPA after Tianeptine coefficient a0 is the smallest, because of this evoked spike trains consist of shorter ISIs hence faster dynamics. 

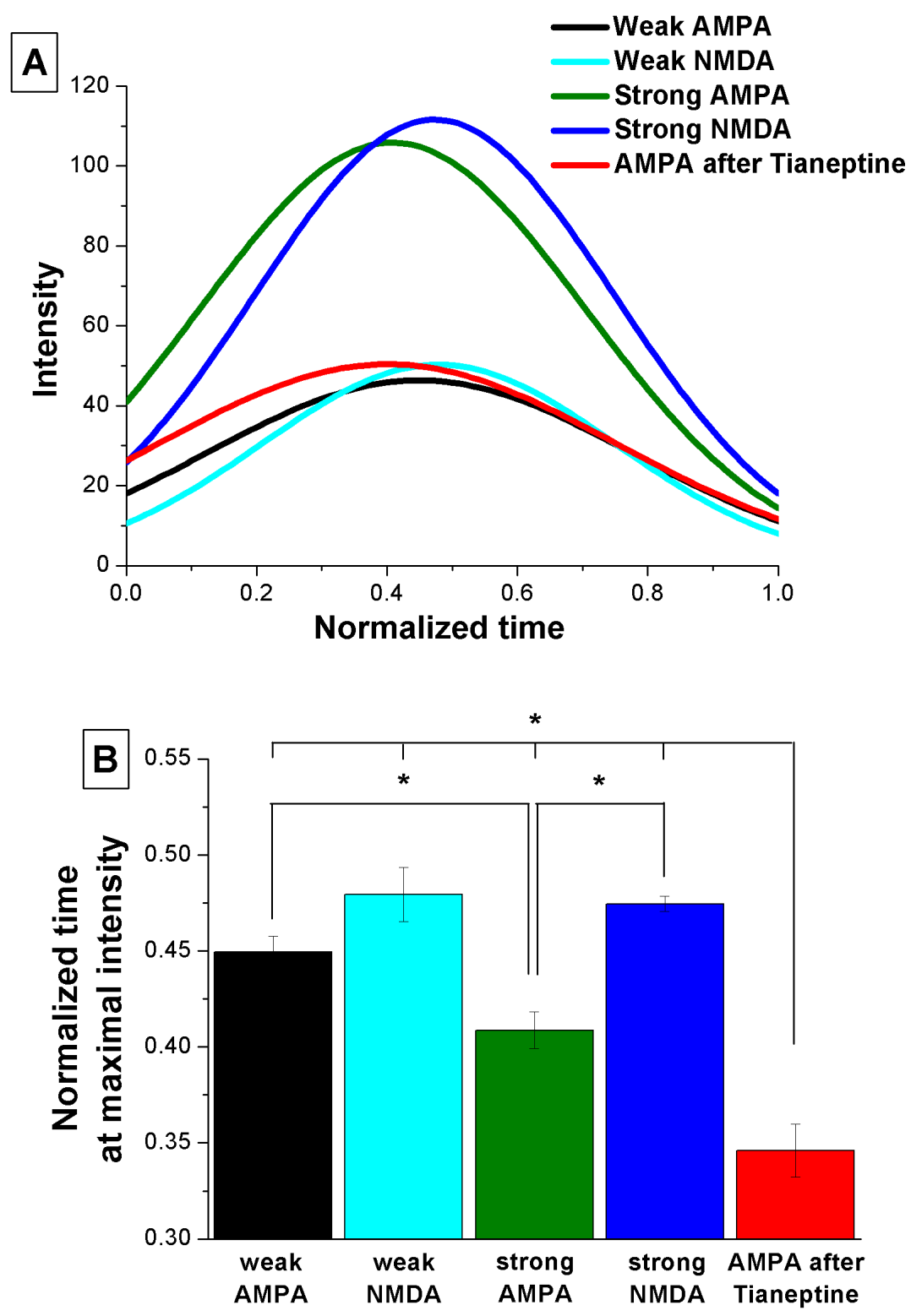

Figure 14. Averaged ISI temporal evolution of evoked spike trains:

Panel A: The instantaneous frequency (1/ISI) data were counted, and a parabola was fitted onto the 1/ISI values of spike trains with the dilated Gaussian equation. The panel shows the averaged ISI temporal evolution curves. The most pronounced difference lies in the time at which maximal intensity is reached, which occurs significantly earlier after application of Tianeptine compared to the other groups. Panel B: The bar chart represents the time belonging to maximal intensity values of differently excited cells. Notice that Tianeptine treatment significantly reduced the time requires for the reach of maximal intensity. ${ }^{*} \mathrm{P} \leq 0.05$, ANOVA, post hoc Dunnett's test 


\section{Discussion}

Better understanding of the pathophysiology of depression can lead to development of therapeutically more effective medications. The prevailing view of monoaminergic dysfunction has recently been challenged by the research of Tianeptine mechanisms of action. This widely used atypical antidepressant, sold in 80 countries, has been shown to leave the brain serotonin level unaltered (Pineyro et al., 1995, Malagie et al., 2000) in freely moving rats applied either chronically or acutely. Although it was patented as a SSRE (Mennini et al., 1987, Kato and Weitsch, 1988, Mocaer et al., 1988, Fattaccini et al., 1990, Whitton et al., 1991), recent data question this mode of action (Della et al., 2012). Instead, Tianeptine is proposed to be a neuroplasticity enhancer, representing a novel antidepressant pathway (Fuchs et al., 2002, McEwen et al., 2010, Szegedi et al., 2011). The exact underlying molecular mechanisms, however, remain to be determined. The available literature data about the effects of Tianeptine are limited. We and others (Svenningsson et al., 2007, Qi et al., 2009, Szegedi et al., 2011) showed that Tianeptine may be the only known antidepressant that can enhance phosphorylation at both Ser 831 and Ser 845 of GluA1 subunit of AMPA receptors. Accordingly, Tianeptine could enhance the amplitude of fEPSPs in murine hippocampal slices, which was blocked by different kinase inhibitors. These results pinpoint the posttranslatory modification of AMPA receptors as a highly possible target of Tianeptine. Indeed, enhancing AMPA receptor function by LY392098, a positive AMPA receptor modulator proved to have antidepressant activity in a battery of behavioral tests, which could be prevented by AMPA receptor antagonists (Li et al., 2001). In contrast, the antidepressant action of Imipramine, a classic tricyclic antidepressant was not sensitive to AMPA receptor antagonists (Li et al., 2001). Svenningsson et al. (Svenningsson et al., 2007) described that in double phospho mutant GluA1 mice in which Ser 831 and Ser 845 of AMPA GluA1 subunit were replaced by alanine amino acid which cannot be phosphorylated, Tianeptine could not develop any antidepressant effect. These data strongly suggest that Tianeptine can exert its effect via AMPA receptor potentiation, in contrast to Imipramine and fluoxetine. Kole et al. (Kole et al., 2002) reported that Tianeptine enhances AMPA receptor-mediated EPSPs in the CA3 of hippocampus via intracellular kinase cascades. The level of phosphoserines of GluA1 can rapidly increase after Tianeptine application, the phosphorylated Ser 831 reached its maximum level within 2 minutes, the phosphorylated Ser 845 within 5 minutes. The level of GluA1 in toto 
remained unaltered by Tianeptine application. Moreover the experiments demonstrated no alteration in the level of phosphorylation of NA1, an NMDA receptor subunit showing a selectivity of Tianeptine towards AMPA receptors. The dual phosphorylation of AMPA receptor GluA1 is crucial in the action of Tianeptine on synaptic plasticity. Imipramine elevates only the phosphorylation level of PKA site (Ser 845) without altering the phosphorylation level of the CaMKII site (Ser 831), resulting in a transient fEPSP potentiation. Similarly, a citrus flavonoid, called nobiletin, which also causes a rise in the PKA site (Ser 845), but not in the CaMKII site (Ser 831) induces only transient potentiation lasting for about $50 \mathrm{~min}$ (Matsuzaki et al., 2008). Although the phosphorylation of GluA1 induced by Tianeptine is temporary, as shown in the Westernblot images, it leads to a long-term excitation measured in electrophysiology (Szegedi et al., 2011). The possible reason for this is discussed below:

The phosphorylation of the PKA site (Ser 845) of GluA1 can govern insertion of AMPA receptors into the neuronal membrane, while the phosphorylation of the CaMKII site (Ser 831) regulates AMPA transportation into synapses from extrasynaptic membrane areas (Hayashi et al., 2000, Lee et al., 2000). Therefore increased presence of GluA1 in synapses and more sensitive phosphorylated AMPA receptors can lead to stronger AMPA responses. If potentiating AMPA responses is antidepressant per se, then the opposite must be true in cases where pathological "feeling high" conditions should be medicated. Indeed, antimanic agents, like lithium and valproate, attenuate GluA1 phosphorylation, hence decrease the amount of AMPA receptors in synaptic membranes (Angst et al., 1978, Du et al., 2004). It was described, that Tianeptine can not only prevent but also can reverse both stress- and corticosterone-induced dendritic remodeling of hippocampal neurons (Magarinos et al., 1999, Czeh et al., 2001). The effect of Tianeptine may be region selective, because Bobula and Hess (Bobula and Hess, 2008) reported NMDA and AMPA receptor-mediated fEPSP decrement in the prefrontal cortex after chronic Tianeptine treatment in contrast with our results in hippocampus.

Nevertheless Tianeptine may have other effects as well, including other neurotransmitter systems. Others demonstrated dopaminergic transmission enhancement by a yet unknown mechanism (Invernizzi et al., 1992). Dopamine can induce the phosphorylation of GluA1 of AMPA receptors and certain NMDA receptor subunits in vitro (Sarantis et al., 2009) and in vivo (Sarantis et al., 2012). We, however, have found that a single bolus of Tianeptine injection did not enhance NMDA receptor-mediated 
responses and did not induce NA1 phosphorylation, suggesting that under our experimental conditions enhancement of dopaminergic transmission is not likely contribute to the findings reported here. Instead, we propose that the observed effects of Tianeptine are due to improving neuroplasticity by mainly increasing GluA1 phosphorylation (McEwen et al., 2010).

\subsection{GluA1 phosphorylation alters the pattern of spiking}

Being a key component in the mammalian excitatory synapses, AMPA receptor phosphorylation has remarkable influence on basic synaptic transmission and plasticity. There are numerous papers that report on the effects of GluA1 subunit phosphorylation on the single channel properties. For example, the phosphorylation at the PKA site (Ser 845) is able to increase the channel opening probability (Banke et al., 2000) and the peak amplitude of the ion current (Roche et al., 1996). Nevertheless phosphorylation at the PKC/CaMKII site (Ser 831) can enhance single channel conductance (Derkach, 2003, Kristensen et al., 2011). In addition, as discussed above, GluA1 phosphorylation promotes AMPA receptor trafficking into the postsynapse. It is noteworthy that Tianeptine can increase the phosphorylation level of GluAl at both the PKA and CaMKII sites (Svenningsson et al., 2007, Qi et al., 2009, Szegedi et al., 2011). Although, as was shown previously, $10 \mathrm{mg} / \mathrm{kg}$ Tianeptine induces a transient increase in the GluA1 phosphorylation state, we have used $20 \mathrm{mg} / \mathrm{kg}$ Tianeptine which may cause a more prolonged elevation of GluA1 phosphorylation.

It is widely accepted that neuronal discharge rates, averaged over several hundred milliseconds to several seconds, reflect the properties of cellular input, with more intense incoming stimuli resulting in enhanced firing rates. However, increasing the excitatory drive arriving onto a neuron may be achieved by either increasing the strength of excitation via the activation of new inputs, or, alternatively, by modifying the excitatory inputs already in use, mainly through phosphorylation and subsequent elevation of the number of synaptic receptors. Precise timing of spiking activity of pre- and postsynaptic neurons in the millisecond range is required for modulating synaptic strength, a phenomenon referred to as STDP. Moreover, the temporal relationship of spikes is also critical for information transfer (Gray and Singer, 1989, Buzsaki and Chrobak, 1995, Hopfield, 1995, Vaadia et al., 1995, Riehle et al., 1997). 
Here we investigated the impact of enhanced AMPA sensitivity on the AMPAevoked spiking pattern of CA1 neurons and we compare NMDA- and AMPA-evoked spike trains. Using frequency of spike discharge as an indicator of somatic depolarization, we showed that similar levels of excitation can be achieved by either raising AMPA sensitivity, or increasing the concentration of the agonist. Despite the similar firing rates, the ISI distributions are significantly different among the two groups, showing that neuronal output may differ when new inputs are activated compared to increasing the gain of previously activated inputs.

Besides AMPA receptors, NMDA receptors are also critical components of the excitatory postsynapse and information is transferred by activation of both receptor types (Daw et al., 1993, Rivadulla et al., 2001). The relative contribution of these two receptors will affect the postsynaptic transmission and temporal summation, properties which may have important consequences in circuit function. Here we have investigated whether there is a difference in NMDA- or AMPA-evoked spiking patterns of CA1 neurons. We applied stimuli with similar strengths for either AMPA or NMDA receptors, and compared the temporal patterns of evoked spike trains. AMPA receptors are regarded as rapid activating and rapid desensitizing channels (Colquhoun et al., 1992, Hestrin, 1992), whereas NMDA receptors have a much slower kinetic (McBain and Mayer, 1994). Indeed, we found shorter latency of spiking initiation for AMPA-evoked spike trains (Figure 14), however, ISI values increased quicker compared to NMDA-induced activity. This was more evident when we applied strong stimulation, and may be due to the faster desensitization of single AMPA receptors (Colquhoun et al., 1992) compared to NMDA receptors (Kussius et al., 2009). Strong NMDA activation could maintain a fast firing activation, therefore ISIs were kept at lower values for a more prolonged time. Increasing the concentration of AMPA/NMDA or increasing the gain of previously activated inputs by Tianeptine application may also trigger the activation of local inhibitory circuits, which may have an impact on the ISI profile. Keeping this in mind, it is possible, that different inhibitory circuits were activated after applying strong AMPA than AMPA after Tianeptine, which could have differently modified ISI distribution. Indeed, results show that the ISI profile and the time at max intensity was shifted to the left both at strong AMPA and AMPA after Tianeptine compared to weak AMPA. It is noteworthy, however, that spike trains after Tianeptine application had quicker onsets and more shifted-to-the left ISI distribution, that the strong AMPA group suggesting either reduced inhibition, or enhanced gain. The 
former scenario is less likely, because Tianeptine was shown to leave the concentration and affinity of GABA-A and GABA-B receptors unaffected (Kato and Weitsch, 1988, McEwen et al., 2010). The ratio of the contribution of these receptor subtypes to postsynaptic transmission may underlie specific aspects of synaptic plasticity. For example, the early phase of LTP is thought to selectively enhance AMPA currents and alter the NMDA-to-AMPA ratio (Kauer et al., 1988, Liao et al., 1995, Lu et al., 2001, Watt et al., 2004), and during homeostatic synaptic plasticity AMPA and NMDA currents are scaled up and down proportionally (Watt et al., 2000). It is noteworthy, that the peaks of ISI probability for strong AMPA (118 ms) and NMDA $(53 \mathrm{~ms})$ stimulation correspond to theta $(8-9 \mathrm{~Hz})$ and low-gamma $(18-19 \mathrm{~Hz})$ activity, respectively, suggesting that different receptors may be involved in different oscillatory patterns.

Increasing the gain of the cellular input could be achieved by either activating novel receptors (by increasing the amount of NMDA/AMPA), or alternatively, by enhancing the function of already activated inputs. Tianeptine may increase AMPA gain in two overlapping ways: either by enhancing the phosphorylation level of GluA1, as was shown by (Svenningsson et al., 2007, Qi et al., 2009, Szegedi et al., 2011), or prompting new AMPA receptor complexes to be trafficked into the synaptic membrane (Zhang et al., 2012). Both ways could lead to increased AMPA sensitivity, in turn to increased firing rate elicited by activating the previously active inputs (weak AMPA stimulation).

We found that after Tianeptine treatment, AMPA-evoked spiking with higher probability of small ISIs compared to strong AMPA stimulation in vivo. This may be due to the altered inactivation kinetics of AMPA receptors. The temporal evolution of spiking dynamics (Figure 14) shows that the relative location of the maximum intensity of discharge activity within a spike train is altered (Figure $14 \mathrm{~B}$ ) in the AMPA after Tianeptine scenario, suggesting that higher AMPA gain leads to a more sustained rapid discharge activity. In line with this, Banke et al. (Banke et al., 2000) have shown that phosphorylation of GluA1 at the PKA site (Ser 845) does not affect the rate of recovery from desensitization. Similar results were obtained for the CaMKII site (Derkach et al., 1999), thus phosphorylation of both sites, or alternatively higher AMPA receptor surface concentration may be responsible for the observed effect.

Both the rate and timing of spiking activity may be important for information coding. Numerous studies have shown that the binned spike counts (rate) encode 
information (O'Keefe and Dostrovsky, 1971, Wilson and McNaughton, 1993), a phenomenon first described by Hubel and Wiesel (Hubel and Wiesel, 1962). They discovered, that the orientation of a bar light corresponding with the measured number of spikes in the cat's visual cortex, therefore they called this phenomenon as orientation tuning. According to the temporal coding hypothesis (Singer, 1993), however, neurons encode information by the exact timing of spikes (O'Keefe and Recce, 1993, Hopfield, 1995, Skaggs et al., 1996). This was first noticed by (Optican and Richmond, 1987). They observed variations in spike rate over time which can carry information that is not obtainable from the spike count alone.

Recent reports indicate that the information about the position is coded by both the rate and timing of place-cell activity (Harris et al., 2002, Mehta et al., 2002). In the hippocampus, various physiological states, like sleep (Hagewoud et al., 2010) and learning (Uslaner et al., 2009) can alter GluA1 phosphorylation, and in turn surface AMPA receptor expression, implying that this phenomenon is dynamically regulated and may have important functions in encoding and processing of memory traces. Recently, experience was shown to be a major factor for transforming a rate code into a more reliable temporal code (Mehta et al., 2002), which, in light of our results, suggests the involvement of physiological GluA1 phosphorylation.

Taken together, our findings further support the role of the dynamic modulation of NMDA/AMPA receptor ratio and GluA1 phosphorylation in synaptic plasticity, learning and memory. The effect of Tianeptine on neuroplasticity and rate- and temporal coding and the contribution of these effects to antidepressant activity is yet unknown. Our results show that antidepressant treatment induces not only biochemical changes, but also alter the information coding. These studies might contribute to a better understanding of the effect of antidepressants and subsequently depression. 


\section{Conclusions}

The main conclusions of this dissertation are:

1. Tianeptine selectively enhances the phosphorylation level of GluA1 at Ser 845 (PKA site), and Ser 831 (CaMKII site).

2. Elevated GluA1 phosphorylation level increases AMPA receptor-mediated responses in the CA1 both in vitro and in vivo.

3. Enhanced GluA1 phosphorylation level alters the firing properties and activity patterns of individual CA1 neurons, which may be important in the antidepressant effect of Tianeptine.

4. Although PSTH do not show dramatic changes within spike trains, ISI probability distribution reveals shorter ISIs, and ISI temporal evolution represents faster spike trains after Tianeptine administration in vivo. These changes may restore the impaired STDP seen in major depressive disorder and may contribute to the antidepressant effect of Tianeptine. 


\section{Acknowledgement}

First of all, I would like to give special thanks to Dr. Viktor Szegedi for his continuous guidance and support during my student work and $\mathrm{PhD}$ training, and for providing the place, means and inspiration to carry out this research in his laboratory.

I respectfully thank to Prof. Botond Penke for the opportunity that I could join to the research group of the Department of Medical Chemistry, and for securing the background to my experiments that were the basis of this dissertation.

I greatly appreciate the helpful and instructive advises of Dr. Gábor Juhász and for his indispensable help in Multi electrode array and in vivo experiments.

I would like to express my special thanks to Robert G. Averkin for his professional technical help in in vivo experiments.

I thank all members of the lab especially to Edina Varga and Ágnes Szántai for the outstanding help in correcting my dissertation and for creating a nice working atmosphere.

I am grateful to the essential help of Drs. Imre Vörös and Petra Vertes for lending their computational and statistic experiences during the preparation of my article.

I would like to express my thanks to Drs. Stéhlik, Krisztina Boda and József Eller for the valuable help in statistical evaluations.

Last but not least, I would like to express a huge thanks to my family for the constant encouragement and furtherance to complete my dissertation. Without the enormous support of my parents, all of this work would have been impossible. 


\section{References}

Alfonso J, Frick LR, Silberman DM, Palumbo ML, Genaro AM, Frasch AC (Regulation of hippocampal gene expression is conserved in two species subjected to different stressors and antidepressant treatments. Biol Psychiatry 59:244-251.2006).

Alt A, Weiss B, Ogden AM, Li X, Gleason SD, Calligaro DO, Bleakman D, Witkin JM (In vitro and in vivo studies in rats with LY293558 suggest AMPA/kainate receptor blockade as a novel potential mechanism for the therapeutic treatment of anxiety disorders. Psychopharmacology (Berl) 185:240-247.2006).

Andras S (["Atypical" antidepressive mechanisms: glutamatergic modulation and neuroplasticity in case of tianeptine]. Neuropsychopharmacol Hung 10:305313.2008).

Andrews G, Anderson TM, Slade T, Sunderland M (Classification of anxiety and depressive disorders: problems and solutions. Depress Anxiety 25:274-281.2008).

Angst J, Felder W, Frey R, Stassen HH (The course of affective disorders. I. Change of diagnosis of monopolar, unipolar, and bipolar illness. Arch Psychiatr Nervenkr 226:57-64.1978).

Bair MJ, Robinson RL, Katon W, Kroenke K (Depression and pain comorbidity: a literature review. Arch Intern Med 163:2433-2445.2003).

Baker FM (An overview of depression in the elderly: a US perspective. J Natl Med Assoc 88:178-184.1996).

Banke TG, Bowie D, Lee H, Huganir RL, Schousboe A, Traynelis SF (Control of GluR1 AMPA receptor function by cAMP-dependent protein kinase. J Neurosci 20:89102.2000).

Barkoczi B, Juhasz G, Averkin RG, Voros I, Vertes P, Penke B, Szegedi V (GluA1 phosphorylation alters evoked firing pattern in vivo. Neural Plast 2012:286215.2012).

Barria A, Muller D, Derkach V, Griffith LC, Soderling TR (Regulatory phosphorylation of AMPA-type glutamate receptors by CaM-KII during long-term potentiation. Science 276:2042-2045.1997).

Bath KG, Akins MR, Lee FS (BDNF control of adult SVZ neurogenesis. Dev Psychobiol 54:578-589.2012).

Bernard-Trifilo JA, Kramar EA, Torp R, Lin CY, Pineda EA, Lynch G, Gall CM (Integrin signaling cascades are operational in adult hippocampal synapses and modulate NMDA receptor physiology. J Neurochem 93:834-849.2005).

Berton O, Nestler EJ (New approaches to antidepressant drug discovery: beyond monoamines. Nat Rev Neurosci 7:137-151.2006).

Bobula B, Hess G (Antidepressant treatments-induced modifications of glutamatergic transmission in rat frontal cortex. Pharmacol Rep 60:865-871.2008).

Bostwick JM, Pankratz VS (Affective disorders and suicide risk: a reexamination. Am J Psychiatry 157:1925-1932.2000).

Brown C, Taniguchi G, Yip K (The monoamine oxidase inhibitor-tyramine interaction. J Clin Pharmacol 29:529-532.1989). 
Brown GW (Life events and affective disorder: replications and limitations. Psychosom Med 55:248-259.1993).

Brown TA, Campbell LA, Lehman CL, Grisham JR, Mancill RB (Current and lifetime comorbidity of the DSM-IV anxiety and mood disorders in a large clinical sample. J Abnorm Psychol 110:585-599.2001).

Bunney WE, Jr., Davis JM (Norepinephrine in depressive reactions. A review. Arch Gen Psychiatry 13:483-494.1965).

Buzsaki G, Chrobak JJ (Temporal structure in spatially organized neuronal ensembles: a role for interneuronal networks. Curr Opin Neurobiol 5:504-510.1995).

Capuron L, Dantzer R (Cytokines and depression: the need for a new paradigm. Brain Behav Immun 17 Suppl 1:S119-124.2003).

Caspi A, Sugden K, Moffitt TE, Taylor A, Craig IW, Harrington H, McClay J, Mill J, Martin J, Braithwaite A, Poulton R (Influence of life stress on depression: moderation by a polymorphism in the 5-HTT gene. Science 301:386-389.2003).

Cassano P, Fava M (Depression and public health: an overview. J Psychosom Res 53:849857.2002).

Chen B, Dowlatshahi D, MacQueen GM, Wang JF, Young LT (Increased hippocampal BDNF immunoreactivity in subjects treated with antidepressant medication. Biol Psychiatry 50:260-265.2001).

Colquhoun D, Jonas P, Sakmann B (Action of brief pulses of glutamate on AMPA/kainate receptors in patches from different neurones of rat hippocampal slices. J Physiol 458:261-287.1992).

Conrad CD, LeDoux JE, Magarinos AM, McEwen BS (Repeated restraint stress facilitates fear conditioning independently of causing hippocampal CA3 dendritic atrophy. Behav Neurosci 113:902-913.1999).

Coppen AJ, Doogan DP (Serotonin and its place in the pathogenesis of depression. J Clin Psychiatry 49 Suppl:4-11.1988).

Cunha C, Brambilla R, Thomas KL (A simple role for BDNF in learning and memory? Front Mol Neurosci 3:1.2010).

Czeh B, Michaelis T, Watanabe T, Frahm J, de Biurrun G, van Kampen M, Bartolomucci A, Fuchs E (Stress-induced changes in cerebral metabolites, hippocampal volume, and cell proliferation are prevented by antidepressant treatment with tianeptine. Proc Natl Acad Sci U S A 98:12796-12801.2001).

D'Sa C, Duman RS (Antidepressants and neuroplasticity. Bipolar Disord 4:183-194.2002).

Danzer SC (Depression, stress, epilepsy and adult neurogenesis. Exp Neurol 233:2232.2012).

Daw NW, Stein PS, Fox K (The role of NMDA receptors in information processing. Annu Rev Neurosci 16:207-222.1993).

Delgado PL (Depression: the case for a monoamine deficiency. J Clin Psychiatry 61 Suppl 6:7-11.2000).

Della FP, Abelaira HM, Reus GZ, Ribeiro KF, Antunes AR, Scaini G, Jeremias IC, Dos Santos LM, Jeremias GC, Streck EL, Quevedo J (Tianeptine treatment induces antidepressive-like effects and alters BDNF and energy metabolism in the brain of rats. Behav Brain Res 233:526-535.2012). 
Derkach V, Barria A, Soderling TR (Ca2+/calmodulin-kinase II enhances channel conductance of alpha-amino-3-hydroxy-5-methyl-4-isoxazolepropionate type glutamate receptors. Proc Natl Acad Sci U S A 96:3269-3274.1999).

Derkach VA (Silence analysis of AMPA receptor mutated at the CaM-kinase II phosphorylation site. Biophys J 84:1701-1708.2003).

Deuschle M, Gilles M, Scharnholz B, Lederbogen F, Lang UE, Hellweg R (Changes of Serum Concentrations of Brain-Derived Neurotrophic Factor (BDNF) during Treatment with Venlafaxine and Mirtazapine: Role of Medication and Response to Treatment. Pharmacopsychiatry.2012).

Drevets WC (Neuroimaging studies of mood disorders. Biol Psychiatry 48:813-829.2000).

Drevets WC (Neuroimaging and neuropathological studies of depression: implications for the cognitive-emotional features of mood disorders. Curr Opin Neurobiol 11:240249.2001).

Du J, Gray NA, Falke CA, Chen W, Yuan P, Szabo ST, Einat H, Manji HK (Modulation of synaptic plasticity by antimanic agents: the role of AMPA glutamate receptor subunit 1 synaptic expression. J Neurosci 24:6578-6589.2004).

Duman RS (Role of neurotrophic factors in the etiology and treatment of mood disorders. Neuromolecular Med 5:11-25.2004).

Duman RS, Monteggia LM (A neurotrophic model for stress-related mood disorders. Biol Psychiatry 59:1116-1127.2006).

Fattaccini CM, Bolanos-Jimenez F, Gozlan H, Hamon M (Tianeptine stimulates uptake of 5-hydroxytryptamine in vivo in the rat brain. Neuropharmacology 29:1-8.1990).

Fava M, Kendler KS (Major depressive disorder. Neuron 28:335-341.2000).

Finberg JP, Gillman K (Selective inhibitors of monoamine oxidase type B and the "cheese effect". Int Rev Neurobiol 100:169-190.2011).

Fuchs E, Czeh B, Michaelis T, de Biurrun G, Watanabe T, Frahm J (Synaptic plasticity and tianeptine: structural regulation. Eur Psychiatry 17 Suppl 3:311-317.2002).

Gerber PD, Barrett JE, Barrett JA, Oxman TE, Manheimer E, Smith R, Whiting RD (The relationship of presenting physical complaints to depressive symptoms in primary care patients. J Gen Intern Med 7:170-173.1992).

Goldman SA (Adult neurogenesis: from canaries to the clinic. J Neurobiol 36:267286.1998).

Goodnick PJ, Goldstein BJ (Selective serotonin reuptake inhibitors in affective disorders-I. Basic pharmacology. J Psychopharmacol 12:S5-20.1998).

Grant BF (Comorbidity between DSM-IV drug use disorders and major depression: results of a national survey of adults. J Subst Abuse 7:481-497.1995).

Gray CM, Singer W (Stimulus-specific neuronal oscillations in orientation columns of cat visual cortex. Proc Natl Acad Sci U S A 86:1698-1702.1989).

Gray JD, Milner TA, McEwen BS (Dynamic plasticity: The role of glucocorticoids, brainderived neurotrophic factor and other trophic factors. Neuroscience.2012).

Hagewoud R, Havekes R, Novati A, Keijser JN, Van der Zee EA, Meerlo P (Sleep deprivation impairs spatial working memory and reduces hippocampal AMPA receptor phosphorylation. J Sleep Res 19:280-288.2010). 
Hammen C, Davila J, Brown G, Ellicott A, Gitlin M (Psychiatric history and stress: predictors of severity of unipolar depression. J Abnorm Psychol 101:45-52.1992).

Harris KD, Henze DA, Hirase H, Leinekugel X, Dragoi G, Czurko A, Buzsaki G (Spike train dynamics predicts theta-related phase precession in hippocampal pyramidal cells. Nature 417:738-741.2002).

Hayashi Y, Shi SH, Esteban JA, Piccini A, Poncer JC, Malinow R (Driving AMPA receptors into synapses by LTP and CaMKII: requirement for GluR1 and PDZ domain interaction. Science 287:2262-2267.2000).

Hestrin S (Activation and desensitization of glutamate-activated channels mediating fast excitatory synaptic currents in the visual cortex. Neuron 9:991-999.1992).

Hirschfeld RM (The Comorbidity of Major Depression and Anxiety Disorders: Recognition and Management in Primary Care. Prim Care Companion J Clin Psychiatry 3:244-254.2001).

Hoffman DA, Sprengel R, Sakmann B (Molecular dissection of hippocampal theta-burst pairing potentiation. Proc Natl Acad Sci U S A 99:7740-7745.2002).

Hopfield JJ (Pattern recognition computation using action potential timing for stimulus representation. Nature 376:33-36.1995).

Hubel DH, Wiesel TN (Receptive fields, binocular interaction and functional architecture in the cat's visual cortex. J Physiol 160:106-154.1962).

Invernizzi R, Pozzi L, Garattini S, Samanin R (Tianeptine increases the extracellular concentrations of dopamine in the nucleus accumbens by a serotonin-independent mechanism. Neuropharmacology 31:221-227.1992).

Irwin MR, Miller AH (Depressive disorders and immunity: 20 years of progress and discovery. Brain Behav Immun 21:374-383.2007).

Jensen V, Kaiser KM, Borchardt T, Adelmann G, Rozov A, Burnashev N, Brix C, Frotscher M, Andersen P, Hvalby O, Sakmann B, Seeburg PH, Sprengel R (A juvenile form of postsynaptic hippocampal long-term potentiation in mice deficient for the AMPA receptor subunit GluR-A. J Physiol 553:843-856.2003).

Kang HJ, Voleti B, Hajszan T, Rajkowska G, Stockmeier CA, Licznerski P, Lepack A, Majik MS, Jeong LS, Banasr M, Son H, Duman RS (Decreased expression of synapse-related genes and loss of synapses in major depressive disorder. Nat Med.2012).

Kato G, Weitsch AF (Neurochemical profile of tianeptine, a new antidepressant drug. Clin Neuropharmacol 11 Suppl 2:S43-50.1988).

Kauer JA, Malenka RC, Nicoll RA (A persistent postsynaptic modification mediates longterm potentiation in the hippocampus. Neuron 1:911-917.1988).

Kennedy SH, Rizvi S (Sexual dysfunction, depression, and the impact of antidepressants. J Clin Psychopharmacol 29:157-164.2009).

Kessing LV (Epidemiology of subtypes of depression. Acta Psychiatr Scand Suppl 85 89.2007).

Kessler RC, Berglund P, Demler O, Jin R, Merikangas KR, Walters EE (Lifetime prevalence and age-of-onset distributions of DSM-IV disorders in the National Comorbidity Survey Replication. Arch Gen Psychiatry 62:593-602.2005a). 
Kessler RC, Chiu WT, Demler O, Merikangas KR, Walters EE (Prevalence, severity, and comorbidity of 12-month DSM-IV disorders in the National Comorbidity Survey Replication. Arch Gen Psychiatry 62:617-627.2005b).

Kessler RC, Gruber M, Hettema JM, Hwang I, Sampson N, Yonkers KA (Co-morbid major depression and generalized anxiety disorders in the National Comorbidity Survey follow-up. Psychol Med 38:365-374.2008).

Kessler RC, Nelson CB, McGonagle KA, Liu J, Swartz M, Blazer DG (Comorbidity of DSM-III-R major depressive disorder in the general population: results from the US National Comorbidity Survey. Br J Psychiatry Suppl 17-30.1996).

Kole MH, Swan L, Fuchs E (The antidepressant tianeptine persistently modulates glutamate receptor currents of the hippocampal CA3 commissural associational synapse in chronically stressed rats. Eur J Neurosci 16:807-816.2002).

Kramar EA, Bernard JA, Gall CM, Lynch G (Integrins modulate fast excitatory transmission at hippocampal synapses. J Biol Chem 278:10722-10730.2003).

Krishnan V, Nestler EJ (The molecular neurobiology of depression. Nature 455:894902.2008).

Kristensen AS, Jenkins MA, Banke TG, Schousboe A, Makino Y, Johnson RC, Huganir R, Traynelis SF (Mechanism of Ca2+/calmodulin-dependent kinase II regulation of AMPA receptor gating. Nat Neurosci 14:727-735.2011).

Kussius CL, Kaur N, Popescu GK (Pregnanolone sulfate promotes desensitization of activated NMDA receptors. J Neurosci 29:6819-6827.2009).

Lee HK, Barbarosie M, Kameyama K, Bear MF, Huganir RL (Regulation of distinct AMPA receptor phosphorylation sites during bidirectional synaptic plasticity. Nature 405:955-959.2000).

Lemaire V, Koehl M, Le Moal M, Abrous DN (Prenatal stress produces learning deficits associated with an inhibition of neurogenesis in the hippocampus. Proc Natl Acad Sci U S A 97:11032-11037.2000).

Levinson DF (The genetics of depression: a review. Biol Psychiatry 60:84-92.2006).

Li LF, Lu J, Li XM, Xu CL, Deng JM, Qu R, Ma SP (Antidepressant-like Effect of Magnolol on BDNF Up-regulation and Serotonergic System Activity in Unpredictable Chronic Mild Stress Treated Rats. Phytother Res 26:11891194.2012).

Li N, He X, Qi X, Zhang Y, He S (The mood stabilizer lamotrigine produces antidepressant behavioral effects in rats: role of brain-derived neurotrophic factor. J Psychopharmacol 24:1772-1778.2010).

Li X, Tizzano JP, Griffey K, Clay M, Lindstrom T, Skolnick P (Antidepressant-like actions of an AMPA receptor potentiator (LY392098). Neuropharmacology 40:1028 1033.2001).

Liao D, Hessler NA, Malinow R (Activation of postsynaptically silent synapses during pairing-induced LTP in CA1 region of hippocampal slice. Nature 375:400404.1995).

Lowy MT, Gault L, Yamamoto BK (Adrenalectomy attenuates stress-induced elevations in extracellular glutamate concentrations in the hippocampus. J Neurochem 61:19571960.1993). 
Lowy MT, Wittenberg L, Yamamoto BK (Effect of acute stress on hippocampal glutamate levels and spectrin proteolysis in young and aged rats. J Neurochem 65:268274.1995).

Lu W, Man H, Ju W, Trimble WS, MacDonald JF, Wang YT (Activation of synaptic NMDA receptors induces membrane insertion of new AMPA receptors and LTP in cultured hippocampal neurons. Neuron 29:243-254.2001).

Lucassen PJ, Fuchs E, Czeh B (Antidepressant treatment with tianeptine reduces apoptosis in the hippocampal dentate gyrus and temporal cortex. Biol Psychiatry 55:789796.2004).

Lucassen PJ, Muller MB, Holsboer F, Bauer J, Holtrop A, Wouda J, Hoogendijk WJ, De Kloet ER, Swaab DF (Hippocampal apoptosis in major depression is a minor event and absent from subareas at risk for glucocorticoid overexposure. Am J Pathol 158:453-468.2001).

MacQueen GM, Campbell S, McEwen BS, Macdonald K, Amano S, Joffe RT, Nahmias C, Young LT (Course of illness, hippocampal function, and hippocampal volume in major depression. Proc Natl Acad Sci U S A 100:1387-1392.2003).

Magarinos AM, Deslandes A, McEwen BS (Effects of antidepressants and benzodiazepine treatments on the dendritic structure of CA3 pyramidal neurons after chronic stress. Eur J Pharmacol 371:113-122.1999).

Malagie I, Deslandes A, Gardier AM (Effects of acute and chronic tianeptine administration on serotonin outflow in rats: comparison with paroxetine by using in vivo microdialysis. Eur J Pharmacol 403:55-65.2000).

Malinow R, Malenka RC (AMPA receptor trafficking and synaptic plasticity. Annu Rev Neurosci 25:103-126.2002).

Mammen AL, Kameyama K, Roche KW, Huganir RL (Phosphorylation of the alphaamino-3-hydroxy-5-methylisoxazole4-propionic acid receptor GluR1 subunit by calcium/calmodulin-dependent kinase II. J Biol Chem 272:32528-32533.1997).

Manji HK, Drevets WC, Charney DS (The cellular neurobiology of depression. Nat Med 7:541-547.2001).

Manji HK, Quiroz JA, Sporn J, Payne JL, Denicoff K, N AG, Zarate CA, Jr., Charney DS (Enhancing neuronal plasticity and cellular resilience to develop novel, improved therapeutics for difficult-to-treat depression. Biol Psychiatry 53:707-742.2003).

Margari F, Sicolo M, Spinelli L, Mastroianni F, Pastore A, Craig F, Petruzzelli MG (Aggressive behavior, cognitive impairment, and depressive symptoms in elderly subjects. Neuropsychiatr Dis Treat 8:347-353.2012).

Masi G, Brovedani P (The hippocampus, neurotrophic factors and depression: possible implications for the pharmacotherapy of depression. CNS Drugs 25:913-931.2011).

Matsuzaki K, Miyazaki K, Sakai S, Yawo H, Nakata N, Moriguchi S, Fukunaga K, Yokosuka A, Sashida Y, Mimaki Y, Yamakuni T, Ohizumi Y (Nobiletin, a citrus flavonoid with neurotrophic action, augments protein kinase A-mediated phosphorylation of the AMPA receptor subunit, GluR1, and the postsynaptic receptor response to glutamate in murine hippocampus. Eur J Pharmacol 578:194200.2008). 
McBain CJ, Mayer ML (N-methyl-D-aspartic acid receptor structure and function. Physiol Rev 74:723-760.1994).

McEwen BS, Chattarji S (Molecular mechanisms of neuroplasticity and pharmacological implications: the example of tianeptine. Eur Neuropsychopharmacol $14 \mathrm{Suppl}$ 5:S497-502.2004).

McEwen BS, Chattarji S, Diamond DM, Jay TM, Reagan LP, Svenningsson P, Fuchs E (The neurobiological properties of tianeptine (Stablon): from monoamine hypothesis to glutamatergic modulation. Mol Psychiatry 15:237-249.2010).

McEwen BS, Olie JP (Neurobiology of mood, anxiety, and emotions as revealed by studies of a unique antidepressant: tianeptine. Mol Psychiatry 10:525-537.2005).

Mehta MR, Lee AK, Wilson MA (Role of experience and oscillations in transforming a rate code into a temporal code. Nature 417:741-746.2002).

Mennini T, Mocaer E, Garattini S (Tianeptine, a selective enhancer of serotonin uptake in rat brain. Naunyn Schmiedebergs Arch Pharmacol 336:478-482.1987).

Mocaer E, Rettori MC, Kamoun A (Pharmacological antidepressive effects and tianeptineinduced 5-HT uptake increase. Clin Neuropharmacol 11 Suppl 2:S32-42.1988).

Moghaddam B, Bolinao ML, Stein-Behrens B, Sapolsky R (Glucocorticoids mediate the stress-induced extracellular accumulation of glutamate. Brain Res 655:251 254.1994).

Morilak DA, Frazer A (Antidepressants and brain monoaminergic systems: a dimensional approach to understanding their behavioural effects in depression and anxiety disorders. Int J Neuropsychopharmacol 7:193-218.2004).

Morris RG, Kelly S, Burney D, Anthony T, Boyer PA, Spedding M (Tianeptine and its enantiomers: effects on spatial memory in rats with medial septum lesions. Neuropharmacology 41:272-281.2001).

Moussavi S, Chatterji S, Verdes E, Tandon A, Patel V, Ustun B (Depression, chronic diseases, and decrements in health: results from the World Health Surveys. Lancet 370:851-858.2007).

Murray CJ, Lopez AD (Alternative projections of mortality and disability by cause 1990 2020: Global Burden of Disease Study. Lancet 349:1498-1504.1997).

Nestler EJ, Barrot M, DiLeone RJ, Eisch AJ, Gold SJ, Monteggia LM (Neurobiology of depression. Neuron 34:13-25.2002).

Nutt DJ (Relationship of neurotransmitters to the symptoms of major depressive disorder. $\mathrm{J}$ Clin Psychiatry 69 Suppl E1:4-7.2008).

O'Keefe J, Dostrovsky J (The hippocampus as a spatial map. Preliminary evidence from unit activity in the freely-moving rat. Brain Res 34:171-175.1971).

O'Keefe J, Recce ML (Phase relationship between hippocampal place units and the EEG theta rhythm. Hippocampus 3:317-330.1993).

Okasha A (Mental health in the Middle East: an Egyptian perspective. Clin Psychol Rev 19:917-933.1999).

Optican LM, Richmond BJ (Temporal encoding of two-dimensional patterns by single units in primate inferior temporal cortex. III. Information theoretic analysis. J Neurophysiol 57:162-178.1987). 
Paul IA, Skolnick P (Glutamate and depression: clinical and preclinical studies. Ann N Y Acad Sci 1003:250-272.2003).

Pineyro G, Deveault L, Blier P, Dennis T, de Montigny C (Effect of acute and prolonged tianeptine administration on the 5-HT transporter: electrophysiological, biochemical and radioligand binding studies in the rat brain. Naunyn Schmiedebergs Arch Pharmacol 351:111-118.1995).

Qi H, Mailliet F, Spedding M, Rocher C, Zhang X, Delagrange P, McEwen B, Jay TM, Svenningsson $\mathrm{P}$ (Antidepressants reverse the attenuation of the neurotrophic MEK/MAPK cascade in frontal cortex by elevated platform stress; reversal of effects on LTP is associated with GluA1 phosphorylation. Neuropharmacology 56:37-46.2009).

Rajkowska G, Miguel-Hidalgo JJ, Wei J, Dilley G, Pittman SD, Meltzer HY, Overholser JC, Roth BL, Stockmeier CA (Morphometric evidence for neuronal and glial prefrontal cell pathology in major depression. Biol Psychiatry 45:1085-1098.1999).

Reagan LP, Rosell DR, Wood GE, Spedding M, Munoz C, Rothstein J, McEwen BS (Chronic restraint stress up-regulates GLT-1 mRNA and protein expression in the rat hippocampus: reversal by tianeptine. Proc Natl Acad Sci U S A 101:21792184.2004).

Riehle A, Grun S, Diesmann M, Aertsen A (Spike synchronization and rate modulation differentially involved in motor cortical function. Science 278:1950-1953.1997).

Rivadulla C, Sharma J, Sur M (Specific roles of NMDA and AMPA receptors in directionselective and spatial phase-selective responses in visual cortex. J Neurosci 21:17101719.2001).

Roche KW, O'Brien RJ, Mammen AL, Bernhardt J, Huganir RL (Characterization of multiple phosphorylation sites on the AMPA receptor GluR1 subunit. Neuron 16:1179-1188.1996).

Rocher C, Spedding M, Munoz C, Jay TM (Acute stress-induced changes in hippocampal/prefrontal circuits in rats: effects of antidepressants. Cereb Cortex 14:224-229.2004).

Roose SP, Glassman AH, Dalack GW (Depression, heart disease, and tricyclic antidepressants. J Clin Psychiatry 50 Suppl:12-16; discussion 17.1989).

Santarelli L, Saxe M, Gross C, Surget A, Battaglia F, Dulawa S, Weisstaub N, Lee J, Duman R, Arancio O, Belzung C, Hen R (Requirement of hippocampal neurogenesis for the behavioral effects of antidepressants. Science 301:805809.2003).

Sarantis K, Antoniou K, Matsokis N, Angelatou F (Exposure to novel environment is characterized by an interaction of D1/NMDA receptors underlined by phosphorylation of the NMDA and AMPA receptor subunits and activation of ERK1/2 signaling, leading to epigenetic changes and gene expression in rat hippocampus. Neurochem Int 60:55-67.2012).

Sarantis K, Matsokis N, Angelatou F (Synergistic interactions of dopamine D1 and glutamate NMDA receptors in rat hippocampus and prefrontal cortex: involvement of ERK1/2 signaling. Neuroscience 163:1135-1145.2009). 
Sartorius N (The economic and social burden of depression. J Clin Psychiatry 62 Suppl 15:8-11.2001).

Schmitt WB, Arianpour R, Deacon RM, Seeburg PH, Sprengel R, Rawlins JN, Bannerman DM (The role of hippocampal glutamate receptor-A-dependent synaptic plasticity in conditional learning: the importance of spatiotemporal discontiguity. J Neurosci 24:7277-7282.2004).

Schmitt WB, Deacon RM, Seeburg PH, Rawlins JN, Bannerman DM (A within-subjects, within-task demonstration of intact spatial reference memory and impaired spatial working memory in glutamate receptor-A-deficient mice. J Neurosci 23:39533959.2003).

Serby M, Yu M (Overview: depression in the elderly. Mt Sinai J Med 70:38-44.2003).

Shakesby AC, Anwyl R, Rowan MJ (Overcoming the effects of stress on synaptic plasticity in the intact hippocampus: rapid actions of serotonergic and antidepressant agents. J Neurosci 22:3638-3644.2002).

Sheline YI, Gado MH, Kraemer HC (Untreated depression and hippocampal volume loss. Am J Psychiatry 160:1516-1518.2003).

Sheline YI, Sanghavi M, Mintun MA, Gado MH (Depression duration but not age predicts hippocampal volume loss in medically healthy women with recurrent major depression. J Neurosci 19:5034-5043.1999).

Singer W (Synchronization of cortical activity and its putative role in information processing and learning. Annu Rev Physiol 55:349-374.1993).

Skaggs WE, McNaughton BL, Wilson MA, Barnes CA (Theta phase precession in hippocampal neuronal populations and the compression of temporal sequences. Hippocampus 6:149-172.1996).

Spedding M, Lestage P ([Synaptic plasticity and neuropathology: new approaches in drug discovery]. Med Sci (Paris) 21:104-109.2005).

Svenningsson P, Bateup H, Qi H, Takamiya K, Huganir RL, Spedding M, Roth BL, McEwen BS, Greengard P (Involvement of AMPA receptor phosphorylation in antidepressant actions with special reference to tianeptine. Eur J Neurosci 26:35093517.2007).

Szegedi V, Juhasz G, Zhang X, Barkoczi B, Qi H, Madeira A, Kapus G, Svenningsson P, Spedding M, Penke B (Tianeptine potentiates AMPA receptors by activating CaMKII and PKA via the p38, p42/44 MAPK and JNK pathways. Neurochem Int 59:1109-1122.2011).

Tamaji A, Iwamoto K, Kawamura Y, Takahashi M, Ebe K, Kawano N, Kunimoto S, Aleksic B, Noda Y, Ozaki N (Differential effects of diazepam, tandospirone, and paroxetine on plasma brain-derived neurotrophic factor level under mental stress. Hum Psychopharmacol 27:329-333.2012).

Thase ME (MAOIs and depression treatment guidelines. J Clin Psychiatry 73:e24.2012).

Thomas CM, Morris S (Cost of depression among adults in England in 2000. Br J Psychiatry 183:514-519.2003).

Uslaner JM, Parmentier-Batteur S, Flick RB, Surles NO, Lam JS, McNaughton CH, Jacobson MA, Hutson PH (Dose-dependent effect of CDPPB, the mGluR5 positive allosteric modulator, on recognition memory is associated with GluR1 and CREB 
phosphorylation in the prefrontal cortex and hippocampus. Neuropharmacology 57:531-538.2009).

Vaadia E, Haalman I, Abeles M, Bergman H, Prut Y, Slovin H, Aertsen A (Dynamics of neuronal interactions in monkey cortex in relation to behavioural events. Nature 373:515-518.1995).

Van Bokhoven P, Oomen CA, Hoogendijk WJ, Smit AB, Lucassen PJ, Spijker S (Reduction in hippocampal neurogenesis after social defeat is long-lasting and responsive to late antidepressant treatment. Eur J Neurosci 33:1833-1840.2011).

Venero C, Borrell J (Rapid glucocorticoid effects on excitatory amino acid levels in the hippocampus: a microdialysis study in freely moving rats. Eur J Neurosci 11:24652473.1999).

Waraich P, Goldner EM, Somers JM, Hsu L (Prevalence and incidence studies of mood disorders: a systematic review of the literature. Can J Psychiatry 49:124-138.2004).

Watanabe Y, Sakai RR, McEwen BS, Mendelson S (Stress and antidepressant effects on hippocampal and cortical 5-HT1A and 5-HT2 receptors and transport sites for serotonin. Brain Res 615:87-94.1993).

Watt AJ, Sjostrom PJ, Hausser M, Nelson SB, Turrigiano GG (A proportional but slower NMDA potentiation follows AMPA potentiation in LTP. Nat Neurosci 7:518524.2004).

Watt AJ, van Rossum MC, MacLeod KM, Nelson SB, Turrigiano GG (Activity coregulates quantal AMPA and NMDA currents at neocortical synapses. Neuron 26:659-670.2000).

Whitton PS, Sarna GS, O'Connell MT, Curzon G (The effect of the novel antidepressant tianeptine on the concentration of 5-hydroxytryptamine in rat hippocampal dialysates in vivo. Neuropharmacology 30:1-4.1991).

Wilson MA, McNaughton BL (Dynamics of the hippocampal ensemble code for space. Science 261:1055-1058.1993).

Wittchen HU, Hofler M, Meister W (Prevalence and recognition of depressive syndromes in German primary care settings: poorly recognized and treated? Int Clin Psychopharmacol 16:121-135.2001).

Zhang H, Etherington LA, Hafner AS, Belelli D, Coussen F, Delagrange P, Chaouloff F, Spedding M, Lambert JJ, Choquet D, Groc L (Regulation of AMPA receptor surface trafficking and synaptic plasticity by a cognitive enhancer and antidepressant molecule. Mol Psychiatry.2012).

Zhang Y, Gu F, Chen J, Dong W (Chronic antidepressant administration alleviates frontal and hippocampal BDNF deficits in CUMS rat. Brain Res 1366:141-148.2010).

Zihl J, Gron G, Brunnauer A (Cognitive deficits in schizophrenia and affective disorders: evidence for a final common pathway disorder. Acta Psychiatr Scand 97:351 357.1998). 


\section{Publications}

13.1 Publication I.

\section{Publication}

I. 
13.2 Publication II.

\section{Publication}

II. 
13.3 Publication III.

\section{Publication}

III. 


\title{
GluA1 Phosphorylation Alters Evoked Firing Pattern In Vivo
}

\author{
Balázs Barkóczi, ${ }^{1}$ Gábor Juhász, ${ }^{2}$ Robert G. Averkin,, ${ }^{3,4}$ Imre Vörös, ${ }^{5}$ Petra Vertes, ${ }^{6}$ \\ Botond Penke, ${ }^{1,2}$ and Viktor Szegedi ${ }^{1}$
}

${ }^{1}$ Bay Zoltán Foundation for Applied Research, BAYGEN, Közép Fasor 41, Szeged 6727, Hungary

${ }^{2}$ Department of Medical Chemistry, University of Szeged, Szeged, Hungary

${ }^{3}$ Research Group for Cortical Microcircuits of the Hungarian Academy of Sciences, University of Szeged, Közép Fasor 52, Szeged 6726, Hungary

${ }^{4}$ Department of Physiology, Anatomy and Neuroscience, University of Szeged, Közép Fasor 52, Szeged 6726, Hungary

${ }^{5}$ St John's Collage, University of Oxford, Oxford, UK

${ }^{6}$ Behavioural \& Clinical Neuroscience Institute, University of Cambridge, Cambridge, UK

Correspondence should be addressed to Viktor Szegedi, szegediv@baygen.hu

Received 7 November 2011; Revised 13 January 2012; Accepted 4 February 2012

Academic Editor: Maurizio Popoli

Copyright ( 2012 Balázs Barkóczi et al. This is an open access article distributed under the Creative Commons Attribution License, which permits unrestricted use, distribution, and reproduction in any medium, provided the original work is properly cited.

\begin{abstract}
AMPA and NMDA receptors convey fast synaptic transmission in the CNS. Their relative contribution to synaptic output and phosphorylation state regulate synaptic plasticity. The AMPA receptor subunit GluAl is central in synaptic plasticity. Phosphorylation of GluA1 regulates channel properties and trafficking. The firing rate averaged over several hundred ms is used to monitor cellular input. However, plasticity requires the timing of spiking within a few ms; therefore, it is important to understand how phosphorylation governs these events. Here, we investigate whether the GluA1 phosphorylation (p-GluA1) alters the spiking patterns of CA1 cells in vivo. The antidepressant Tianeptine was used for inducing p-GluA1, which resulted in enhanced AMPA-evoked spiking. By comparing the spiking patterns of AMPA-evoked activity with matched firing rates, we show that the spike-trains after Tianeptine application show characteristic features, distinguishing from spike-trains triggered by strong AMPA stimulation. The interspike-interval distributions are different between the two groups, suggesting that neuronal output may differ when new inputs are activated compared to increasing the gain of previously activated receptors. Furthermore, we also show that NMDA evokes spiking with different patterns to AMPA spike-trains. These results support the role of the modulation of NMDAR/AMPAR ratio and p-GluA1 in plasticity and temporal coding.
\end{abstract}

\section{Introduction}

Alpha-amino-3-hydroxyl-5-methyl-4-isoxazole-propionate (AMPA) and N-methyl-D-aspartic acid (NMDA) type ionotropic glutamate receptors mediate fast neuronal excitatory transmission and play key roles in various forms of hippocampal synaptic plasticity. AMPARs comprise four subunits-GluA1, GluA2, GluA3, and GluA4 (or GluR14) - that combine to form tetramers. GluA1 is critical in several forms of hippocampal synaptic plasticity, correlates of learning, and memory. Mutant mice lacking the GluA1 subunit display impairments of the initial component of long-term potentiation (LTP) at CA1 in the hippocampus [1-4]. Moreover, these animals exhibit a robust spatial deficit in working memory [5-7]. Emerging evidence shows that as a rapid and short-term mechanism, dynamic protein phosphorylation directly modulates the electrophysiological properties of cells, as well as the trafficking/clustering and synthesis of AMPA receptors. The phosphorylation state of GluA1 has been demonstrated to be actively involved in regulating synaptic plasticity and, consequently, learning and memory processes. Phosphorylation of serine 831 and dephosphorylation of serine 845 are differentially involved in the modulation of LTP and LTD, respectively. The former serine is specifically phosphorylated by protein kinase C (PKC) and $\mathrm{Ca}^{2+} /$ calmodulin-dependent protein kinase II (CaMKII) $[8,9]$, whereas the latter serine is specifically phosphorylated by protein kinase A (PKA). 
It is widely accepted that neuronal discharge rates, averaged over several hundred milliseconds to several seconds, reflect the properties of cellular input, with more intense incoming stimuli resulting in enhanced firing rates. However, increasing the excitatory drive arriving onto a neuron may be achieved by either increasing the strength of excitation via the activation of new inputs or, alternatively, by modifying the excitatory inputs already in use, mainly through phosphorylation. In this paper, we test the hypothesis that these two scenarios may result in different spiking patterns. Precise timing of spiking activity of pre- and postsynaptic neurons in the millisecond range is required for modulating synaptic strength, a phenomenon referred to as spike timing synaptic plasticity. Moreover, the temporal relationship of spikes is also critical for information transfer [5, 10-13]. It is therefore crucial to understand the physiological mechanisms that can generate precise spike-timing in vivo.

Tianeptine, an antidepressant with distinct pharmacology to the tricyclic antidepressant agents, has been shown to increase the phosphorylation level of GluA1 on both the CaMKII and PKA site, which in turn renders the cell more sensitive to AMPA [14]. We have shown previously that intraperitoneal tianeptine administration results in an increased AMPA-evoked spiking rate in vivo [15]. Here, we investigate the impact of enhanced AMPA sensitivity on the AMPA-evoked spiking pattern of CA1 neurons, and we compare NMDA and AMPA-evoked spike trains. Using frequency of spike discharge as an indicator of somatic depolarization, we show that similar levels of excitation can be achieved by either raising AMPA sensitivity or increasing the concentration of the agonist. Despite the similar firing rates, the interspike interval distributions are significantly different among the two groups, showing that neuronal output may differ when new inputs are activated compared to increasing the gain of previously activated inputs.

\section{Experimental Procedures}

2.1. Animal Care and Handling. The animals were kept, and the experiments were conducted in conformity with Council Directive 86/609/EEC, the Hungarian Act of Animal Care and Experimentation (1998, XXVIII), and local regulations for the care and use of animals for research.

\subsection{In Vivo Microiontophoresis and Single-Unit Electrophys- iology. Extracellular single-unit recordings were taken in chloral-hydrate-anesthetized ( $4 \mathrm{~g} / \mathrm{kg}$ initial dose, i.p., supple- mental doses as required) male Wistar rats weighing between 300 and $350 \mathrm{~g}$. The head of the animal was mounted in a stereotaxic frame, the skull was opened above the hippocam- pus (a-p: $-3.8 \mathrm{~mm}$ from bregma; lat: $\pm 2 \mathrm{~mm}$ either side from the midline), and the dura mater was carefully removed.}

\subsection{Extracellular Recordings and Iontophoresis. Single-unit} activity was extracellularly recorded by means of a low impedance $(<1 \mathrm{M} \Omega) 7 \mu \mathrm{m}$ carbon fiber-containing microelectrode from the hippocampus between the depths of 2 to $3 \mathrm{~mm}$, and drugs were delivered from the surrounding outer barrels. The action potentials were amplified with an
ExAmp-20KB extracellular amplifier (Kation Scientific, Minneapolis, MN) and monitored with an oscilloscope. Filter bandpass frequencies were 300 to $8000 \mathrm{~Hz}$. The amplified signals were sampled and digitalized at $50 \mathrm{kHz}$ frequency. Spikes were sorted using the Spike2 software package (CED, Cambridge, UK). Iontophoretic drug delivery was performed by iontophoretic pumps (Minion-16 and BAB-350, Kation Scientific). A multibarrel electrode affixed to the recording electrode was used for the iontophoretic ejection of the following drugs: $100 \mathrm{mM} \mathrm{NMDA} \mathrm{Na}{ }^{+}$salt in $100 \mathrm{mM} \mathrm{NaCl}$ $(\mathrm{pH}=8)$ or $10 \mathrm{mM}$ AMPA ( $\mathrm{pH}=8)$. NMDA was ejected at negative iontophoretic current ranging from 5 to $100 \mathrm{nA}$ every minute for $5 \mathrm{sec}$. AMPA was ejected every $90 \mathrm{sec}$ at negative iontophoretic current ranging from 2 to $100 \mathrm{nA}$. A retaining current of opposite direction between 2 and $21 \mathrm{nA}$ was used. Tianeptine was administered as a single bolus intraperitoneal injection at a dose of $20 \mathrm{mg} / \mathrm{kg}$.

2.4. Data Analysis. Spike timing was converted into numerical data at $30 \mu$ s resolution. Spike trains were characterized by their interspike interval (ISI) series and compared. First, we compared the distribution of intervals for each pair of spike trains, assuming the measured intervals to be samples of mutually independent random variables. This allowed the use of Kolmogorov-Smirnov tests, which compare every characteristic of the underlying probability distributions, thus requiring no further assumptions. We then charted the maximal confidence intervals of agreement between the pairs. Data were pooled, and means \pm SEM of percentage values were calculated. PSTH and ISI probability profiles were evaluated by using ANOVA with post hoc Dunnett's test. A $P$ value of $\leq 0.05$ was considered as significant difference in all cases.

In order to investigate the temporal evolution of spiking activity, the time course of the spiking activities was normalized, so that the first spike was taken as time 0 , while the last spike of the train was taken as 1. ISIs were plotted against this normalized time. To fit smooth curves to the spike trains, first we transformed them by taking their negative logarithms, which corresponds to a spiking intensity value. To compare the actual dynamics of the spike trains, we noted that ISI logarithms fit convincingly to quadratic polynomials, that is, the ISI series itself was fitted with the dilated Gaussian $\exp \left(a *(x-a 0)^{2}+c\right)$ equation using a standard linear. From this, we produced basic statistics of the coefficients for each group of spike trains.

\section{Results}

Tianeptine has been shown to increase the phosphorylation level of AMPA receptor subunit GluA1 at Ser 831 and Ser $845[14,16]$. This effect results in increased AMPAevoked spiking activity in vivo after intraperitoneal (i.p.) tianeptine application. We hypothesized that this effect also leads to alternation of the spiking pattern evoked by AMPA. To address this point, we have recorded spike trains evoked by weak and strong AMPA stimulation and compared the data to AMPA-evoked spike trains recorded before and after i.p. tianeptine application. Furthermore, 
we compared those with NMDA-evoked spiking activity. Ejection currents were unaltered before and after tianeptine within an experiment. The outline of the experimental setup is indicated in Figure 1. A total of 310 spike trains from 31 single neurons recorded from 21 rats were analyzed. The autocorrelogram of all units were calculated, and only units with less than $0.5 \%$ of spike intervals within a $1 \mathrm{~ms}$ refractory period were included in the present analysis. We used spike trains only from units having high signal-to-noise ratios ( $\geq 5$ fold noise level). These units were considered as putative pyramidal cells, based on their wider spike shapes (mean width, $>400 \mu \mathrm{s})$. Figures $1(\mathrm{e})$ and $1(\mathrm{f})$ show a representative unit recorded before and after tianeptine application using AMPA excitation. Spike trains were evoked by either ejecting AMPA or NMDA, using weak or strong ejection currents. For representative recordings (see Supplementary Figures 1-3 in available online at doi: 10.1155/2012/286215). The level of weak excitation (ejection current) was set between 3 and 4 spike/100 ms, whereas strong excitation was set between 6 and 8 spike/100 ms. Intraperitoneal tianeptine application resulted in an enhancement of AMPAevoked spiking activity, which reached 7-9 spike/100 ms, $30 \mathrm{~min}$ after drug administration. Five such spike trains were analyzed from every recording. This group will be referred to as "AMPA after tianeptine." Accordingly enhanced AMPA sensitivity was induced by a bolus of intraperitoneal tianeptine administration $(20 \mathrm{mg} / \mathrm{kg}$, described elsewhere).

First, we compared the mean poststimulus time histogram (PSTH) of weak-strong AMPA/NMDA stimulation and AMPA stimulation before and after tianeptine (Figures 2(a) and 2(b)). A one-way repeated measure analysis of variance (ANOVA) with post hoc Tukey's test was used for this purpose. We hypothesized that there should be no difference between the weak AMPA stimulation and before tianeptine PSTH data, because no phosphorylation occurred, and the number of evoked spikes is in the same order of magnitude in both groups (the stimulation intensity was comparable). Indeed, there was no difference between weak AMPA, weak NMDA, and AMPA before tianeptine PSTHs (number of spike trains; $n=60,50$ and 45 , resp.). Similarly, we found no difference between strong AMPA and AMPA after tianeptine PSTHs ( $n=60$ and 45), suggesting that the change in the AMPA gain level is not manifested in the PSTH profile. In contrast, strong AMPA PSTH tended to decay faster than strong NMDA-evoked spike trains $(n=50$ and 60; $P \leq 0.05)$.

Next, we analyzed the distribution of interspike intervals (ISI) in the evoked spike trains (Figure 2). No significant difference was found in the ISI probability profile of weak AMPA and before tianeptine groups $(n=60$ and 45). Two probability peaks were seen at around 3-6 ms and 19$21 \mathrm{~ms}$. Weak NMDA-evoked activity resulted in a different ISI probability pattern, also displaying two local maxima (at 3-4 ms and 30-31 ms), although the latter is smaller (marked with a gray rectangle at Figure 2(c); $n=50$ and $60 ; P \leq 0.05$ compared to weak AMPA and before tianeptine).

Increasing the stimulation strength by applying larger ejection currents resulted in a prominent peak in the ISI probability distribution, suggesting that the spiking activity became more ordered at stronger stimulation. Significant differences were observed between weak AMPA/NMDA $(n=60$ and 50) and strong AMPA/NMDA, respectively $(P \leq 0.05)$. Furthermore, there was a significant difference between the "strong AMPA" and "AMPA after tianeptine" groups, suggesting that the increase in AMPA sensitivity has an impact on ISI probability (Figure 2(d)). The maximum probability for AMPA after tianeptine was seen at 5-7 ms $(n=45)$. Also, there was difference between strong AMPA and NMDA-evoked activity: the maximum probability was seen at $10-13 \mathrm{~ms}$ for strong AMPA, and 6-8 $\mathrm{ms}$ for strong NMDA ( $n=60$ and 50; $P \leq 0.05)$.

3.1. Temporal Evolution of Spike Trains. Next we analyzed the temporal pattern of spiking activity. First, we focused on the temporal evolution of ISIs. A parabola was fitted onto the instantaneous frequency (1/ISI) data (Figure 3(a)). The obtained coefficients are describable by biological terms, namely, the maximal instantaneous frequency exactly provides the position with highest intensity within the spike train $(a)$, while $c$ corresponds to the dynamism of the change in intensity. We note that the most pronounced difference lies in the time at which maximal intensity is attained $(a 0)$, which occurs significantly $(P \leq 0.05)$ earlier after application of tianeptine $(0.346 \pm 0.013)$ than on the otherwise excited cells $(0.472 \pm 0.003$ for strong NMDA, $0.408 \pm 0.009$ for strong AMPA, $0.479 \pm 0.014$ for weak NMDA, and $0.449 \pm 0.008$ for weak AMPA, resp.). We also detected significant difference between weak AMPA and strong AMPA $(P \leq 0.05)$ as well as strong AMPA and strong NMDA $(P \leq 0.05)$.

\section{Discussion}

AMPA and NMDA receptors (AMPAR and NMDAR, resp.) are the main contributors to excitatory synaptic function, and information is transferred by activation of both receptor types $[17,18]$. The relative contribution of these two receptors will affect the postsynaptic transmission and temporal summation, properties which may have important consequences in circuit function. However, posttranslational modifications can alter single-channel properties and postsynaptic function without affecting the ratio of expressed channels. Here, we have investigated whether there is a difference in NMDA or AMPA-evoked spiking patterns of CA1 neurons. We also addressed whether there is a difference in AMPA-evoked firing activity between increasing the gain of previously activated inputs and activating new inputs. By using somatic discharge as an indirect measure of depotentiation, we applied stimuli with similar strengths for either AMPA or NMDA receptors and compared the temporal patterns of evoked spike trains.

AMPA receptors are regarded as rapid activating and rapid desensitizing channels $[19,20]$, whereas NMDARs have a much slower kinetic [21]. Indeed, we found shorter latency of spiking initiation for AMPA-evoked spike trains (Figure 3(a)) however, ISI values increased quicker compared to NMDA-induced activity. This was more evident when we applied strong stimulation and may be due to the faster desensitization of single-AMPA receptors [19] 
(a)

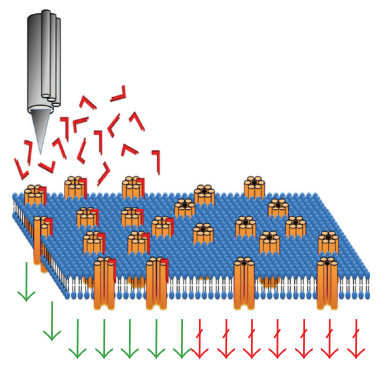

(b)

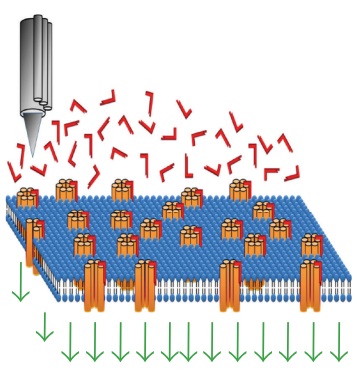

(c)

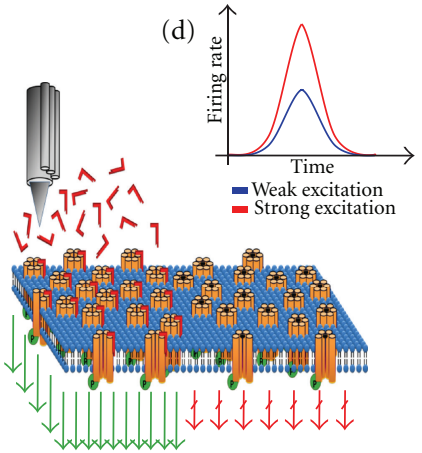

(e)

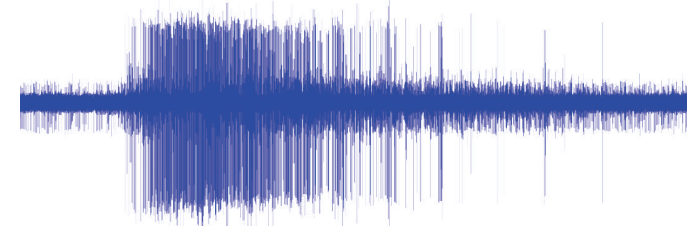

(f)

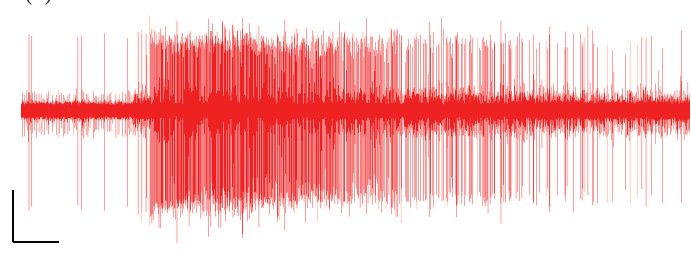

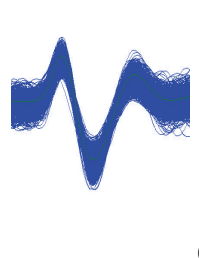
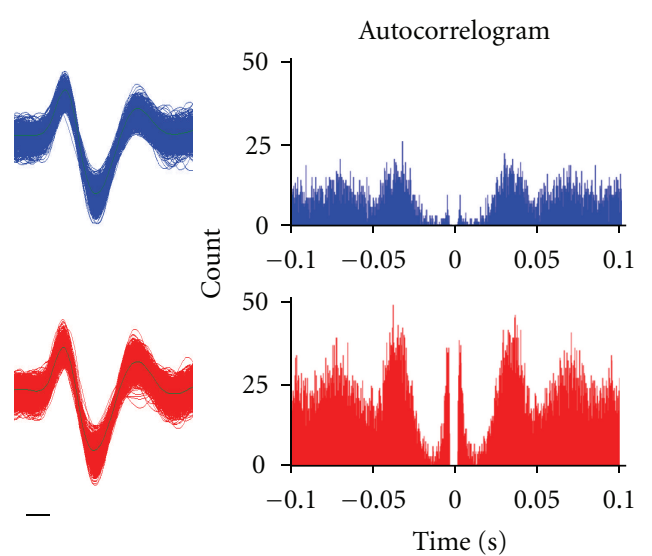

FIgURE 1: Schematic outline of the experiment. CA1 cells were excited by a small (a) or large (b) dose of excitatory compound (AMPA or NMDA). In a second set of experiments, AMPA receptor phosphorylation (GluA1 subunit), which might lead to increased AMPA receptor surface expression and subsequent rise in AMPA-evoked firing rate, was induced by an intraperitoneal tianeptine injection (c). Strong excitations triggered larger firing rates than weak excitations (d). Representative spike trains, superimposed spikes, and autocorrelograms of the same unit before (e) and $15 \mathrm{~min}$ after tianeptine injection (f). Red line marks the ejection event. Scale bars are $50 \mu \mathrm{V}$ and 1 sec and $0.1 \mathrm{~ms}$.

compared to NMDARs [22]. Strong NMDA activation could maintain a fast firing activation; therefore, ISIs were kept at lower values for a more prolonged time. Increasing the concentration of AMPA/NMDA or increasing the gain of previously activated inputs by tianeptine application may also trigger the activation of local inhibitory circuits, which may have an impact on the ISI profile. Keeping this in mind, it is possible that different inhibitory circuits were activated after applying stronger AMPA than AMPA after tianeptine, which could have differently modified ISI distribution. Indeed, results show that the ISI profile and the time at max intensity was shifted to the left both at strong AMPA and AMPA after tianeptine compared to weak AMPA. It is noteworthy, however, that spike trains after tianeptine application had quicker onsets and more shifted-to-the-left ISI distribution, that the strong AMPA group suggesting either reduced inhibition, or enhanced gain. The former scenario is less likely, because tianeptine was shown to leave the concentration and affinity of GABA-A and GABA-B receptors unaffected $[23,24]$. The ratio of the contribution of these receptor subtypes to postsynaptic transmission may underlie specific aspects of synaptic plasticity. For example, the early phase of long-term potentiation (LTP) is thought to selectively enhance AMPA currents and alter the NMDAto-AMPA ratio [25-28], and during homeostatic synaptic plasticity, AMPA and NMDA currents are scaled up and down proportionally [29]. It is noteworthy that the peaks of ISI probability for strong AMPA (118 ms) and NMDA $(53 \mathrm{~ms})$ stimulation correspond to theta- $(8-9 \mathrm{~Hz})$ and lowgamma $(18-19 \mathrm{~Hz})$ activity, respectively, suggesting that different receptors may be involved in different oscillatory patterns.

Increasing the gain of the cellular input could be achieved by either activating novel receptors (by increasing the amount of NMDA/AMPA), or alternatively, by enhancing the function of already activated inputs. Tianeptine may increase AMPA gain in two overlapping ways: either by enhancing the phosphorylation level of GluA1, as was shown by [1416], or prompting new AMPA receptor complexes to be trafficked into the synaptic membrane. Both ways could lead to increased AMPA sensitivity, in turn to increased firing rate elicited by activating the previously active inputs 
PSTH

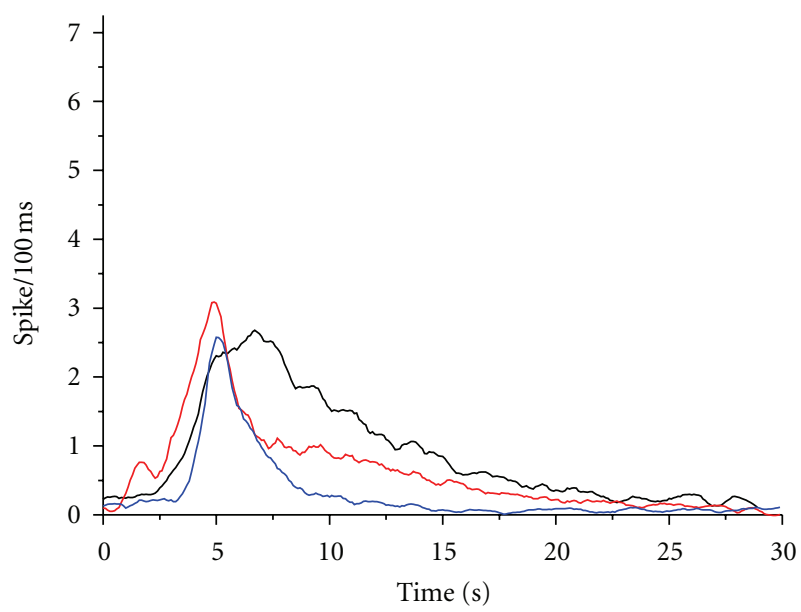

— Weak AMPA stimulation
— AMPA before tianeptine
— Weak NMDA stimulation

(a)

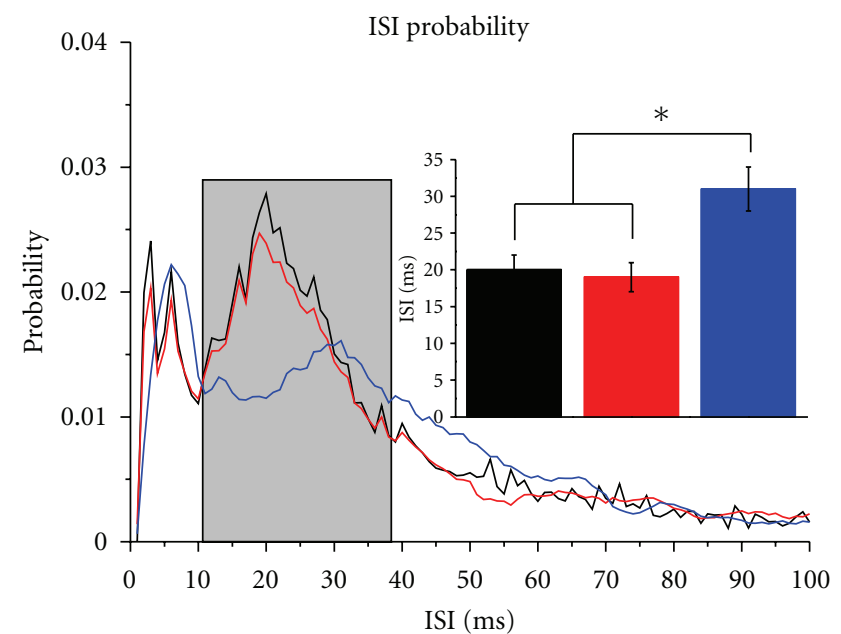

- Weak AMPA stimulation
_ AMPA before tianeptine
Weak NMDA stimulation

(c)

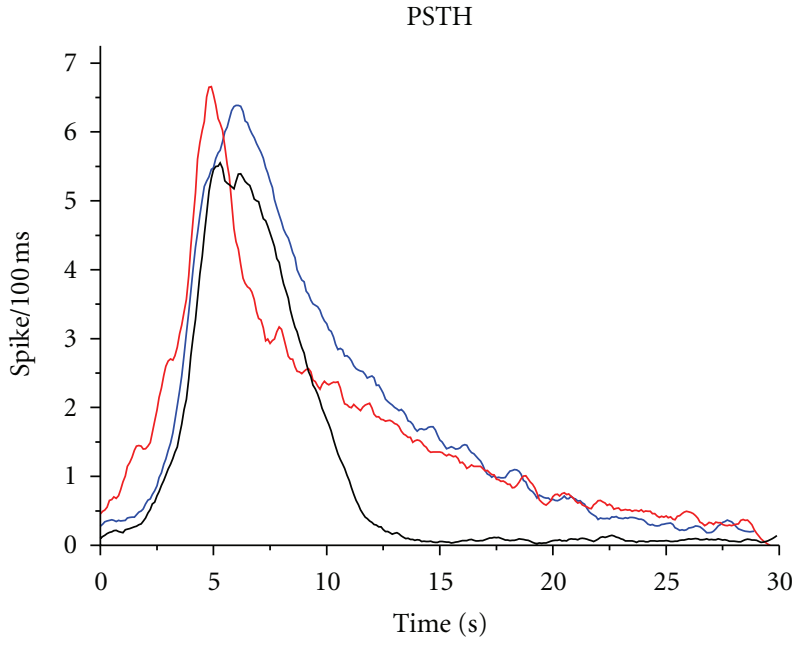

- Strong AMPA stimulation

- AMPA after tianeptine

— Strong NMDA stimulation

(b)

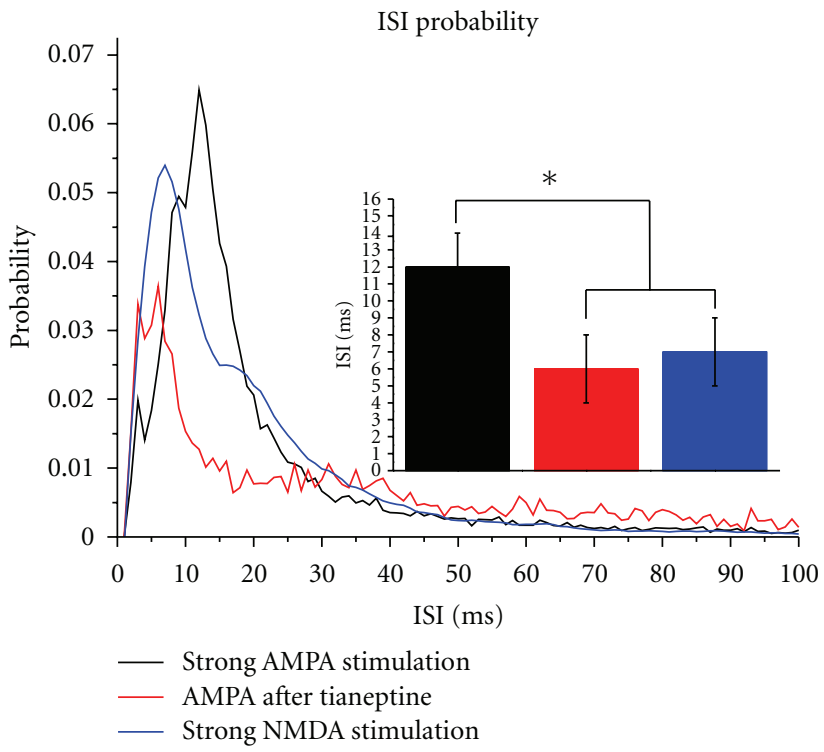

(d)

FIGURE 2: PSTH and ISI probability profiles of different spike trains. There is no difference between the PSTHs of spike trains evoked by weak excitation (a); in contrast, strong AMPA-evoked spiking activity decayed faster than strong NMDA or AMPA after tianeptine spike trains (b). ISI probability distributions of weak excitation evoked spike trains (c). Inset shows the ISI values for the second probability peak (marked with a grey rectangle). ISI probability distributions of strong excitation evoked spike trains (d). Inset shows the ISI values for the maximal probabilities. Note the difference between strong AMPA and AMPA after tianeptine. Colors in the insets correspond to the colors in the main figure. Asterisks denote significant differences at $P \leq 0.05$.

(weak AMPA stimulation). Here, we examined the relative contribution of the modified channel properties versus activation of new inputs to the enhanced synaptic strength. There is considerable evidence that GluAl phosphorylation alters the single-channel properties of the AMPA receptor complex. By using patch clamp techniques, it was shown that phosphorylation of the GluA1 subunit increases AMPAR complex efficiency. Phosphorylation at the PKA site (serine 845 ) is known to increase the channel opening probability
[30] and the peak amplitude of the current [31], while phosphorylation at the PKC/CaMKII site (serine 831) increases the single-channel conductance [32]. Moreover, GluA1 phosphorylation may induce the expression of novel AMPA receptors into the synapse, resulting in higher AMPAR concentration on the cellular surface $[33,34]$.

In order to induce GluA1 phosphorylation, we applied tianeptine, an antidepressant, which, although transiently, was shown to enhance the phosphorylation level of GluA1 at 


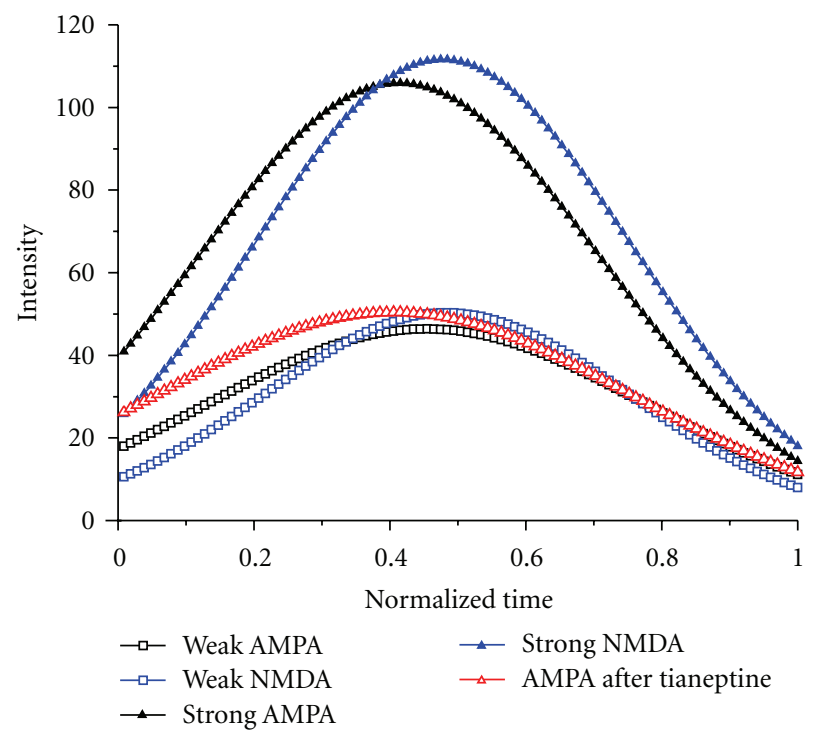

(a)

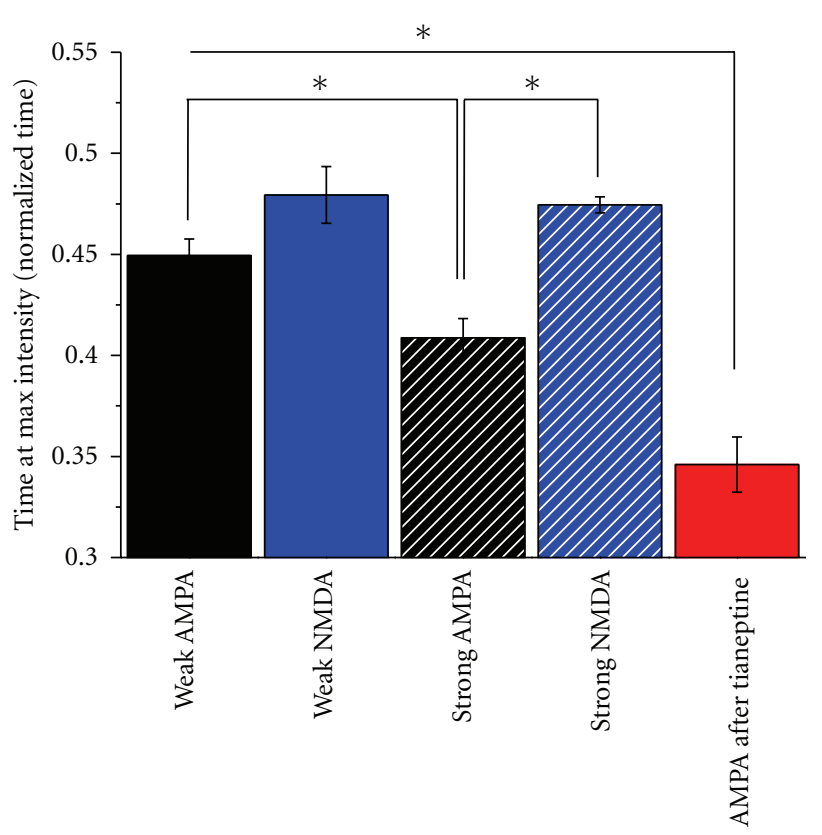

(b)

FIgURE 3: Temporal evolution of spiking dynamics. The time courses of discharge trains were normalized, and a parabola was fitted onto the 1/ISI values (a). Note that the maximal intensity is attained for both AMPA and NMDA excitation regardless of the strength, which happens later than in the AMPA after tianeptine scenario (b). Asterisks denote significant differences at $P \leq 0.05$.

both the PKA and CaMKII sites $[14,16]$. We, however, have used a higher tianeptine concentration $(20 \mathrm{mg} / \mathrm{kg}$ instead of $10 \mathrm{mg} / \mathrm{kg}$ ), which may induce a more long-lasting increase of p-GluA1. In keeping with this, we found that after tianeptine treatment, AMPA-evoked spiking with higher probability of small ISIs was compared to strong AMPA stimulation in vivo. This may be due to the altered inactivation kinetics of AMPARs. The temporal evolution of spiking dynamics (Figure 3) shows that the relative location of the maximum intensity of discharge activity within a spike train is altered (Figure 3(b)) in the AMPA after tianeptine scenario, suggesting that higher AMPA gain leads to a more sustained rapid discharge activity. In line with this, Banke et al. [30] have shown that phosphorylation of GluA1 at the PKA site does not affect the rate of recovery from desensitization. Similar results were obtained for the CaMK-II site [35], thus phosphorylation of both sites or alternatively higher AMPAR surface concentration may be responsible for the observed effect.

Tianeptine may have other mechanisms of action as well. Although originally it was thought to be a selective serotonin reuptake enhancer, recent studies demonstrated that acute and chronic application of tianeptine does not modify the extracellular concentration of serotonin in freely moving rats $[36,37]$. Other data suggest that tianeptine enhances dopaminergic transmission by a yet unknown mechanism [38]. The effects of dopamine in the hippocampus include phosphorylation of GluA1 and certain NMDAR subunits in vitro [39] and in vivo [40]. We, however, have found that a single bolus of tianeptine injection did not enhance NMDA receptor-mediated responses [15], suggesting that under our experimental conditions, enhancing dopaminergic transmission are not likely to contribute to the findings reported here. Instead, we propose that the observed effects of tianeptine are due to improving neuroplasticity by mainly increasing GluA1 phosphorylation [24].

Both the rate and timing of spiking activity may be important for information coding. Numerous studies have shown that the binned spike counts (rate) encode information [41, 42]. According to the temporal coding hypothesis [43], however, neurons encode information by the exact timing of spikes $[12,44,45]$. Recent reports indicate that the information about the position is coded by both the rate and timing of place-cell activity $[46,47]$. In the hippocampus, various physiological states, like sleep [48], and learning [49] can alter GluA1 phosphorylation, and in turn surface AMPAR expression, implying that this phenomenon is dynamically regulated and may have important functions in encoding and processing of memory traces. Recently, experience was shown to be a major factor for transforming a rate code into a more reliable temporal code [47], which, in light of our result, suggests the involvement of physiological GluA1 phosphorylation.

Taken together, our findings further support the role of the dynamic modulation of NMDAR/AMPAR ratio and GluA1 phosphorylation in synaptic plasticity, learning, and memory. 


\section{Author's Contribution}

B. Barkóczi, G. juhász, R. G. Averkin, and V. Szegedi did the experimentation; B. Barkóczi, I. Vörös, P. Vertes, and V. Szegedi analyzed the data. B. Barkóczi, G. Juhász, R. G. Averkin, I. Vörös, P. Vertes, B. Penke, and V. Szegedi wrote the paper.

\section{Acknowledgments}

This work was supported by the following Grants: NAP BIO Teller and GVOP3.3.1-0141/3.0 by the National Office for Research and Technology, Hungary, NKTH project EGISPSYCH, and OTKA PD 83581. The research leading to these results has received funding from the EC's 7th Framework Programme (FP7/2007-2013) under the Grant agreements nos. 211699 and 201159.

\section{References}

[1] D. A. Hoffman, R. Sprengel, and B. Sakmann, "Molecular dissection of hippocampal theta-burst pairing potentiation," Proceedings of the National Academy of Sciences of the United States of America, vol. 99, no. 11, pp. 7740-7745, 2002.

[2] V. Jensen, K. M. M. Kaiser, T. Borchardt et al., "A juvenile form of postsynaptic hippocampal long-term potentiation in mice deficient for the AMPA receptor subunit GluR-A," The Journal of Physiology, vol. 553, part 3, pp. 843-856, 2003.

[3] R. Malinow and R. C. Malenka, "AMPA receptor trafficking and synaptic plasticity," Annual Review of Neuroscience, vol. 25, pp. 103-126, 2002.

[4] D. Zamanillo, R. Sprengel, O. Hvalby et al., "Importance of AMPA receptors for hippocampal synaptic plasticity but not for spatial learning," Science, vol. 284, no. 5421, pp. 1805-1811, 1999.

[5] A. Riehle, S. Grun, M. Diesmann, and A. Aertsen, "Spike synchronization and rate modulation differentially involved in motor cortical function," Science, vol. 278, no. 5345, pp. 19501953, 1997.

[6] W. B. Schmitt, R. Arianpour, R. M. J. Deacon et al., "The role of hippocampal glutamate receptor-A-dependent synaptic plasticity in conditional learning: the importance of spatiotemporal discontiguity," Journal of Neuroscience, vol. 24, no. 33, pp. 7277-7282, 2004.

[7] W. B. Schmitt, R. M. J. Deacon, P. H. Seeburg, J. N. P. Rawlins, and D. M. Bannerman, "A within-subjects, withintask demonstration of intact spatial reference memory and impaired spatial working memory in glutamate receptor-Adeficient mice," Journal of Neuroscience, vol. 23, no. 9, pp. 3953-3959, 2003.

[8] A. Barria, D. Muller, V. Derkach, L. C. Griffith, and T. R. Soderling, "Regulatory phosphorylation of AMPA-type glutamate receptors by CaM-KII during long-term potentiation," Science, vol. 276, no. 5321, pp. 2042-2045, 1997.

[9] A. L. Mammen, K. Kameyama, K. W. Roche, and R. L. Huganir, "Phosphorylation of the $\alpha$-amino-3-hydroxy-5methylisoxazole-4-propionic Acid receptor GluR1 subunit by calcium/calmodulin-dependent kinase II," The Journal of Biological Chemistry, vol. 272, no. 51, pp. 32528-32533, 1997.

[10] G. Buzsaki and J. J. Chrobak, "Temporal structure in spatially organized neuronal ensembles: a role for interneuronal networks," Current Opinion in Neurobiology, vol. 5, no. 4, pp. 504-510, 1995.

[11] C. M. Gray and W. Singer, "Stimulus-specific neuronal oscillations in orientation columns of cat visual cortex," Proceedings of the National Academy of Sciences of the United States of America, vol. 86, no. 5, pp. 1698-1702, 1989.

[12] J. J. Hopfield, "Pattern recognition computation using action potential timing for stimulus representation," Nature, vol. 376, no. 6535 , pp. 33-36, 1995.

[13] E. Vaadia, I. Haalman, M. Abeles et al., "Dynamics of neuronal interactions in monkey cortex in relation to behavioural events," Nature, vol. 373, no. 6514, pp. 515-518, 1995.

[14] H. Qi, F. Mailliet, M. Spedding et al., "Antidepressants reverse the attenuation of the neurotrophic MEK/MAPK cascade in frontal cortex by elevated platform stress; reversal of effects on LTP is associated with GluA1 phosphorylation," Neuropharmacology, vol. 56, no. 1, pp. 37-46, 2009.

[15] V. Szegedi, G. Juhasz, X. Zhang et al., “Tianeptine potentiates AMPA receptors by activating CaMKII and PKA via the p38, p42/44 MAPK and JNK pathways," Neurochemistry International, vol. 59, no. 8, pp. 1109-1122, 2011.

[16] P. Svenningsson, H. Bateup, H. Qi et al., "Involvement of AMPA receptor phosphorylation in antidepressant actions with special reference to tianeptine," European Journal of Neuroscience, vol. 26, no. 12, pp. 3509-3517, 2007.

[17] N. W. Daw, P. S. G. Stein, and K. Fox, "The role of NMDA receptors in information processing," Annual Review of Neuroscience, vol. 16, pp. 207-222, 1993.

[18] C. Rivadulla, J. Sharma, and M. Sur, "Specific roles of NMDA and AMPA receptors in direction-selective and spatial phaseselective responses in visual cortex," Journal of Neuroscience, vol. 21, no. 5, pp. 1710-1719, 2001.

[19] D. Colquhoun, P. Jonas, and B. Sakmann, "Action of brief pulses of glutamate on AMPA/kainate receptors in patches from different neurones of rat hippocampal slices," The Journal of Physiology, vol. 458, pp. 261-287, 1992.

[20] S. Hestrin, "Activation and desensitization of glutamateactivated channels mediating fast excitatory synaptic currents in the visual cortex," Neuron, vol. 9, no. 5, pp. 991-999, 1992.

[21] C. J. McBain and M. L. Mayer, "N-methyl-D-aspartic acid receptor structure and function," Physiological Reviews, vol. 74, no. 3, pp. 723-760, 1994.

[22] C. L. Kussius, N. Kaur, and G. K. Popescu, "Pregnanolone sulfate promotes desensitization of activated NMDA receptors," Journal of Neuroscience, vol. 29, no. 21, pp. 6819-6827, 2009.

[23] G. Kato and A. F. Weitsch, "Neurochemical profile of tianeptine, a new antidepressant drug," Clinical Neuropharmacology, vol. 11, supplement 2, pp. S43-S50, 1988.

[24] B. S. McEwen, S. Chattarji, D. M. Diamond et al., "The neurobiological properties of tianeptine (Stablon): from monoamine hypothesis to glutamatergic modulation," Molecular Psychiatry, vol. 15, no. 3, pp. 237-249, 2010.

[25] J. A. Kauer, R. C. Malenka, and R. A. Nicoll, "A persistent postsynaptic modification mediates long-term potentiation in the hippocampus," Neuron, vol. 1, no. 10, pp. 911-917, 1988.

[26] D. Liao, N. A. Hessler, and R. Malinow, "Activation of postsynaptically silent synapses during pairing-induced LTP in CA1 region of hippocampal slice," Nature, vol. 375, no. 6530, pp. 400-404, 1995.

[27] W. Y. Lu, H. Y. Man, W. Ju, W. S. Trimble, J. F. MacDonald, and Y. T. Wang, "Activation of synaptic NMDA receptors induces membrane insertion of new AMPA receptors and LTP in cultured hippocampal neurons," Neuron, vol. 29, no. 1, pp. 243-254, 2001. 
[28] A. J. Watt, P. J. Sjostrom, M. Hausser, S. B. Nelson, and G. G. Turrigiano, "A proportional but slower NMDA potentiation follows AMPA potentiation in LTP," Nature Neuroscience, vol. 7, no. 5, pp. 518-524, 2004.

[29] A. J. Watt, M. C. W. van Rossum, K. M. MacLeod, S. B. Nelson, and G. G. Turrigiano, "Activity coregulates quantal AMPA and NMDA currents at neocortical synapses," Neuron, vol. 26, no. 3, pp. 659-670, 2000.

[30] T. G. Banke, D. Bowie, H. K. Lee, R. L. Huganir, A. Schousboe, and S. F. Traynelis, "Control of GluR1 AMPA receptor function by cAMP-dependent protein kinase," Journal of Neuroscience, vol. 20, no. 1, pp. 89-102, 2000.

[31] K. W. Roche, R. J. O’Brien, A. L. Mammen, J. Bernhardt, and R. L. Huganir, "Characterization of multiple phosphorylation sites on the AMPA receptor GluR1 subunit," Neuron, vol. 16, no. 6, pp. 1179-1188, 1996.

[32] V. A. Derkach, "Silence analysis of AMPA receptor mutated at the CAM-kinase II phosphorylation site," Biophysical Journal, vol. 84, no. 3, pp. 1701-1708, 2003.

[33] Y. Hayashi, S. H. Shi, J. A. Esteban, A. Piccini, J. C. Poncer, and R. Malinow, "Driving AMPA receptors into synapses by LTP and CaMKII: requirement for GluR1 and PDZ domain interaction," Science, vol. 287, no. 5461, pp. 2262-2267, 2000.

[34] H. K. Lee, M. Barbarosie, K. Kameyama, M. F. Bear, and R. L. Huganir, "Regulation of distinct AMPA receptor phosphorylation sites during bidirectional synaptic plasticity," Nature, vol. 405, no. 6789, pp. 955-959, 2000.

[35] V. Derkach, A. Barria, and T. R. Soderling, " $\mathrm{Ca}^{2+} /$ calmodulinkinase II enhances channel conductance of $\alpha$-amino3-hydroxy-5-methyl-4-isoxazolepropionate type glutamate receptors," Proceedings of the National Academy of Sciences of the United States of America, vol. 96, no. 6, pp. 3269-3274, 1999.

[36] I. Malagie, A. Deslandes, and A. M. Gardier, "Effects of acute and chronic tianeptine administration on serotonin outflow in rats: comparison with paroxetine by using in vivo microdialysis," European Journal of Pharmacology, vol. 403, no. 1-2, pp. 55-65, 2000.

[37] G. Pineyro, L. Deveault, C. de Montigny, and P. Blier, "Effect of prolonged administration of tianeptine on 5-HT neurotransmission: an electrophysiological study in the rat hippocampus and dorsal raphe," Naunyn-Schmiedeberg's Archives of Pharmacology, vol. 351, no. 2, pp. 119-125, 1995.

[38] R. Invernizzi, L. Pozzi, S. Garattini, and R. Samanin, “Tianeptine increases the extracellular concentrations of dopamine in the nucleus accumbens by a serotonin-independent mechanism," Neuropharmacology, vol. 31, no. 3, pp. 221-227, 1992.

[39] K. Sarantis, N. Matsokis, and F. Angelatou, "Synergistic interactions of dopamine D1 and glutamate NMDA receptors in rat hippocampus and prefrontal cortex: involvement of ERK1/2 signaling," Neuroscience, vol. 163, no. 4, pp. 1135$1145,2009$.

[40] K. Sarantis, K. Antoniou, N. Matsokis, and F. Angelatou, "Exposure to novel environment is characterized by an interaction of D1/NMDA receptors underlined by phosphorylation of the NMDA and AMPA receptor subunits and activation of ERK1/2 signaling, leading to epigenetic changes and gene expression in rat hippocampus," Neurochemistry International, vol. 60, no. 1, pp. 55-67, 2012.

[41] J. O'Keefe and J. Dostrovsky, “The hippocampus as a spatial map. Preliminary evidence from unit activity in the freelymoving rat," Brain Research, vol. 34, no. 1, pp. 171-175, 1971.
[42] M. A. Wilson and B. L. McNaughton, "Dynamics of the hippocampal ensemble code for space," Science, vol. 261, no. 5124, pp. 1055-1058, 1993.

[43] W. Singer, "Synchronization of cortical activity and its putative role in information processing and learning," Annual Review of Physiology, vol. 55, pp. 349-374, 1993.

[44] J. O'Keefe and M. L. Recce, "Phase relationship between hippocampal place units and the EEG theta rhythm," Hippocampus, vol. 3, no. 3, pp. 317-330, 1993.

[45] W. E. Skaggs, B. L. McNaughton, M. A. Wilson, and C. A. Barnes, "Theta phase precession in hippocampal neuronal populations and the compression of temporal sequences," Hippocampus, vol. 6, no. 2, pp. 149-172, 1996.

[46] K. D. Harris, D. A. Henze, H. Hirase et al., "Spike train dynamics predicts theta-related phase precession in hippocampal pyramidal cells," Nature, vol. 417, no. 6890, pp. 738-741, 2002.

[47] M. R. Mehta, A. K. Lee, and M. A. Wilson, "Role of experience and oscillations in transforming a rate code into a temporal code," Nature, vol. 417, no. 6890, pp. 741-746, 2002.

[48] R. Hagewoud, R. Havekes, A. Novati, J. N. Keijser, E. A. van der Zee, and P. Meerlo, "Sleep deprivation impairs spatial working memory and reduces hippocampal AMPA receptor phosphorylation," Journal of Sleep Research, vol. 19, no. 2, pp. 280-288, 2010.

[49] J. M. Uslaner, S. Parmentier-Batteur, R. B. Flick et al., "Dosedependent effect of CDPPB, the mGluR5 positive allosteric modulator, on recognition memory is associated with GluR1 and CREB phosphorylation in the prefrontal cortex and hippocampus," Neuropharmacology, vol. 57, no. 5-6, pp. 531$538,2009$. 


\title{
Tianeptine potentiates AMPA receptors by activating CaMKII and PKA via the p38, p42/44 MAPK and JNK pathways
}

\author{
Viktor Szegedi a,*, Gábor Juhász ${ }^{\mathrm{b}}$, Xiaoqun Zhang ${ }^{\mathrm{c}}$, Balázs Barkóczi ${ }^{\mathrm{a}}$, Hongshi Qi ${ }^{\mathrm{c}}$, Alexandra Madeira ${ }^{\mathrm{c}}$, \\ Gábor Kapus $^{\mathrm{d}}$, Per Svenningsson ${ }^{\mathrm{c}}$, Michael Spedding ${ }^{\mathrm{e}}$, Botond Penke ${ }^{\mathrm{a}, \mathrm{b}}$ \\ a Bay Zoltán Foundation for Applied Research - BAYGEN Institute, Derkovits Avenue 2, Szeged H-6726, Hungary \\ ${ }^{\mathrm{b}}$ Department of Medical Chemistry, University of Szeged, Dóm Square 8, Szeged H-6725, Hungary \\ ${ }^{c}$ Center for Molecular Medicine, Department of Clinical Neuroscience, Karolinska Institute, 17177 Stockholm, Sweden \\ ${ }^{\mathrm{d}}$ Division of Preclinical Research, EGIS Pharmaceutical Plc, 10, P.O. Box 100, Budapest H-1475, Hungary \\ e Institut de Rescherches Internationales Servier (IRIS), Suresnes 92150, France
}

\section{A R T I C L E I N F O}

\section{Article history:}

Received 25 July 2011

Received in revised form 21 September

2011

Accepted 17 October 2011

Available online 25 October 2011

\section{Keywords:}

Antidepressant

Glutamate receptors

Synaptic plasticity

NMDA

Phosphorylation

Signaling pathway

\begin{abstract}
A B S T R A C T
Impairments of cellular plasticity appear to underlie the pathophysiology of major depression. Recently, elevated levels of phosphorylated AMPA receptor were implicated in the antidepressant effect of various drugs. Here, we investigated the effects of an antidepressant, Tianeptine, on synaptic function and GluA1 phosphorylation using murine hippocampal slices and in vivo single-unit recordings. Tianeptine, but not imipramine, increased AMPA receptor-mediated neuronal responses both in vitro and in vivo, in a staurosporine-sensitive manner. Paired-pulse ratio was unaltered by Tianeptine, suggesting a postsynaptic site of action. Tianeptine, $10 \mu \mathrm{M}$, enhanced the GluA1-dependent initial phase of LTP, whereas $100 \mu \mathrm{M}$ impaired the latter phases, indicating a critical role of GluA1 subunit phosphorylation in the excitation. Tianeptine rapidly increased the phosphorylation level of $S^{831}{ }^{83}-G l u A 1$ and Ser ${ }^{845}$-GluA1. Using H-89 and KN-93, we show that the activation of both PKA and CaMKII is critical in the effect of Tianeptine on AMPA responses. Moreover, the phosphorylation states of $\mathrm{Ser}^{217 / 221}$-MEK and $\mathrm{Thr}^{183} / \mathrm{Tyr}^{185}$-p42MAPK were increased by Tianeptine and specific kinase blockers of the MAPK pathways (PD 98095, SB 203580 and SP600125) prevented the effects of Tianeptine. Overall these data suggest that Tianeptine potentiates several signaling cascades associated with synaptic plasticity and provide further evidence that a major mechanism of action for Tianeptine is to act as an enhancer of glutamate neurotransmission via AMPA receptors.
\end{abstract}

(C) 2011 Elsevier B.V. All rights reserved.

\section{Introduction}

A common form of treatment of major depression, the most common form of disease burden in Western countries (Mathers and Loncar, 2006), is to target the imbalance of monoamine neurotransmission (Coppen and Doogan, 1988). Most antidepressants alter the availability of serotonin, noradrenalin and other biogenic amines in the brain; however, this effect is unlikely to be the sole cause of the antidepressant action, but rather initiates cellular adaptations that ultimately lead to an antidepressant action (Berton and Nestler, 2006; Coyle and Duman, 2003; Manji et al., 2001). There is now considerable evidence that the glutamatergic system may play a central role in depressive disorders. Glutamate, the major excitatory neurotransmitter in the CNS, regulates synaptic plasticity, mainly via three major classes of ionotropic receptors,

* Corresponding author. Address: Bay Zoltán Foundation for Applied Research BAYGEN Institute, Közép fasor 41, Szeged H-6726, Hungary.

E-mail address: szegediv@baygen.hu (V. Szegedi). including $\alpha$-amino-3-hydroxyl-5-methyl-4-isoxazole-propionate (AMPA), kainate, and $N$-methyl-D-aspartic acid (NMDA) receptors. AMPA receptors are the predominant mediator of the ionotropic response to synaptically released glutamate in the brain; the channel is composed of a tetrameric combination of glutamate receptor A1 (GluA1), GluA2, GluA3, and GluA4 subunits. Modification of the AMPA receptor subunits by phosphorylation is critical in mediating synaptic plasticity and neuronal network responses (Malinow and Malenka, 2002). The phosphorylation state of GluA1 subunits is in direct correlation with synaptic efficiency: naïve synapses have mainly GluA1 phosphorylated at $\operatorname{Ser}^{845}$ by protein kinase A (PKA), while potentiation induces GluA1 phosphorylation at $\operatorname{Ser}^{831}$ by calcium/calmodulin-dependent kinase II (CaMKII) (Lee et al., 2000).

A growing body of data suggests that the direct modulation of synaptic plasticity, by for example AMPA receptor potentiation, may overcome depressive symptoms in animal models (Alt et al., 2006). A clinically effective antidepressant Tianeptine (Stablon ${ }^{\circledR}$ ), a compound with distinct pharmacology to the tricyclic antidepressant agents, shows no affinity for neurotransmitter receptors 
and does not inhibit the uptake of serotonin or noradrenaline in the central nervous system (Kato and Weitsch, 1988; Svenningsson et al., 2007). Tianeptine is able to counteract neuronal loss, abnormal synaptic plasticity and dendritic atrophy (McEwen and Olie, 2005; Spedding and Lestage, 2005). The mechanism of action of Tianeptine involves the regulation of glutamatergic transmission (McEwen et al., 2010). Using whole animals, we have previously found that Tianeptine increases the phosphorylation level of GluA1 subunit in the AMPA receptor complex in mice (Svenningsson et al., 2007) and rats (Qi et al., 2009), implicating that this effect is involved in the antidepressant activity. Using mice having mutations in GluA1 phosphorylation sites, we found that AMPA receptor phosphorylation mediates certain explorative and antidepressantlike actions of Tianeptine (Svenningsson et al., 2007). In contrast to other antidepressants like imipramine, Tianeptine is also unique in that it may counteract the plasticity impairment caused by acute stress (Shakesby et al., 2002), a phenomenon which is associated with impaired BDNF/MEK/MAPK signaling cascade and AMPA receptor phosphorylation (Qi et al., 2009).

In the present study we investigated the pathways involved in the AMPA receptor modifying action of Tianeptine. Preclinical and clinical evidence suggests that hippocampus may be relevant in research on the cellular mechanisms of antidepressants, because of its integrative function during the stress response, an important constituent of the depressive syndrome (McEwen, 2000; Sheline, 1996). Therefore, we used murine hippocampal slices for electrophysiological and subsequent biochemical experiments, and anaesthetized rats for recording hippocampal single-unit activity. It was found that Tianeptine activates three distinct mitogen-activated protein kinase (MAPK) pathways, the c-Jun N-terminal kinase (JNK), p42/44 and p38 MAPK pathways, which eventually lead to enhanced AMPA receptor function through phosphorylation by $\mathrm{Ca}^{2+} /$ calmodulin-dependent protein kinase II (CaMKII) and protein kinase $\mathrm{A}$ (PKA).

\section{Materials and methods}

\subsection{Animal care and handling}

The animals were kept and the experiments were conducted in conformity with Council Directive 86/609/EEC, the Hungarian Act of Animal Care and Experimentation (1998, XXVIII) and local regulations for the care and use of animals for research at Karolinska Institutet (N283/06).

\subsection{Hippocampal slice electrophysiology}

Using standard procedures, $350 \mu \mathrm{m}$ thick transverse hippocampal slices were prepared from the brain of 3 months old mice (CFLP, Animal Breeding Facility, University of Szeged) using a McIlwain tissue chopper (Campden Instruments, Loughborough, UK). Slices were incubated in standard artificial cerebrospinal fluid (ACSF) at ambient temperature for $60 \mathrm{~min}$, which was constantly gassed with $95 \% \mathrm{O}_{2}-5 \% \mathrm{CO}_{2}$. ACSF contained $(\mathrm{mM})$ : $\mathrm{NaCl}, 130 ; \mathrm{KCl}, 3.5$; $\mathrm{CaCl}_{2}, 2 ; \mathrm{MgCl}_{2}, 2 ; \mathrm{NaH}_{2} \mathrm{PO}_{4}, 0.96 ; \mathrm{NaHCO}_{3}, 24 ;$ D-glucose, $10(\mathrm{pH}$ 7.4). Individual slices were transferred to a 3D-MEA chip with 60 tip-shaped and 60- $\mu \mathrm{m}$-high electrodes spaced by $100 \mu \mathrm{m}$ (Ayanda Biosystems, S.A., Lausanne, Switzerland). The slice was continuously perfused with oxygenated $\operatorname{ACSF}\left(1.5 \mathrm{ml} / \mathrm{min}\right.$ at $\left.34^{\circ} \mathrm{C}\right)$ during the whole recording session. Data were recorded by a standard, commercially available MEA setup (Multi Channel Systems MCS $\mathrm{GmbH}$, Reutlingen, Germany). The Schaffer-collateral was stimulated by injecting a biphasic current waveform $(-100 /+100 \mu \mathrm{s})$ through one selected electrode at $0.033 \mathrm{~Hz}$. Care was taken to choose the stimulating electrode in the same region from one slice to the other. The peak-to-peak amplitudes of fEPSPs at the stratum pyramidale and stratum radiatum of CA1 were analyzed. After a 30 min incubation period, the threshold and the maximum of stimulation intensity for evoked responses was determined. For evoking responses, $30 \%$ of the maximal stimulation intensity was used.

\subsubsection{Stimulation protocol}

Following a stable 30 -min control sequence, the stimulus intensity was continuously increased from 0 to $120 \mu \mathrm{A}$ with $10 \mu \mathrm{A}$ steps (Input/Output curve). Paired-pulse protocol consisted of two stimulation pulses injected with interstimulus intervals of $50 \mathrm{~ms}$ with $0.033 \mathrm{~Hz}$. Three data points were obtained at every stimulation intensity/interstimulus intervals at the Input/Output curve and paired-pulse protocol. LTP was induced using a theta-burst stimulation (TBS) pattern applied at the maximum stimulation intensity. TBS comprised four trains administered at $20 \mathrm{~s}$ intervals with 10 bursts given at $5 \mathrm{~Hz}$ per train and four pulses given at $100 \mathrm{~Hz}$ per burst. LTD was induced with low-frequency stimulation: $3 \mathrm{~Hz}$ for 5 min at maximum intensity.

\subsection{In vivo microiontophoresis and single unit electrophysiology}

Extracellular single-unit recordings were made in chloral-hydrate anesthetized $(4 \mathrm{~g} / \mathrm{kg}$ initial dose, i.p., supplemental doses as required) male Wistar rats weighing between 250 and $330 \mathrm{~g}$. The head of the animal was mounted in a stereotaxic frame, the skull was opened above the hippocampus (a-p: $-3.8 \mathrm{~mm}$ from bregma; lat: $\pm 2 \mathrm{~mm}$ either side from the midline), and the dura mater was carefully removed. Extracellular recordings and iontophoresis: single unit activity was extracellularly recorded by means of a low impedance $(<1 \mathrm{M} \Omega) 7 \mu \mathrm{m}$ carbon fiber-containing microelectrode from the hippocampus between the depths of $2-4 \mathrm{~mm}$, and drugs were delivered from the surrounding outer barrels. The action potentials were amplified by ExAmp-20 KB extracellular amplifier (Kation Scientific, Minneapolis, MN) and monitored with an oscilloscope. Filter bandpass frequencies were $300-8000 \mathrm{~Hz}$. The amplified signals were sampled and digitalized at $50 \mathrm{kHz}$ frequency. Spikes were sorted using the SciWorks software package (DataWave, Berthoud, CO). The number of action potentials per second was counted by the computer and peristimulus time histograms were calculated and displayed in line. Iontophoretic drug delivery and collection of experimental data were performed by a multifunction instrument control and data acquisition board ( $\mathrm{Na}-$ tional Instruments PCI-1200) installed in a personal computer programmed in LabVIEW 6, and by iontophoretic pumps (Minion-16 and BAB-350, Kation Scientific). A multibarrel electrode affixed to the recording electrode was used for the iontophoretic ejection of the following drugs: $100 \mathrm{mM}$ NMDA Na in $100 \mathrm{mM} \mathrm{NaCl}(\mathrm{pH} \mathrm{8})$ or $10 \mathrm{mM}$ AMPA (pH8). NMDA was ejected at negative iontophoretic current ranging from 2 to $100 \mathrm{nA}$ every minute for $5 \mathrm{~s}$. AMPA was ejected every $90 \mathrm{~s}$ at negative iontophoretic current ranging from 2 to $100 \mathrm{nA}$. Retaining current of opposite direction between 2 and $21 \mathrm{nA}$ was used. Tianeptine was administered as a single bolus intraperitoneal injection at a dose of $20 \mathrm{mg} / \mathrm{kg}$.

\subsection{In vitro brain slice experiments to measure protein phosphorylation}

Adult male C57BL/6 wild-type mice were decapitated. Their brains were rapidly removed, hippocampi dissected out and placed in ice-cold, oxygenated $\left(95 \% \mathrm{O}_{2}+5 \% \mathrm{CO}_{2}\right)$ artificial cerebrospinal fluid containing (in mM): $126 \mathrm{NaCl}, 2.5 \mathrm{KCl}, 1.2 \mathrm{NaH}_{2} \mathrm{PO}_{4}, 1.3$ $\mathrm{MgCl}_{2}, 2.4 \mathrm{CaCl}_{2}, 10$ glucose and $26 \mathrm{NaHCO}_{3}, \mathrm{pH}$ 7.4. Coronal slices (300 $\mu \mathrm{m}$ thick) were prepared using a Leica vibratome (Leica, Germany). The slices were preincubated in ACSF buffer at $30^{\circ} \mathrm{C}$ under constant oxygenation for $60 \mathrm{~min}$, with a change of buffer after 


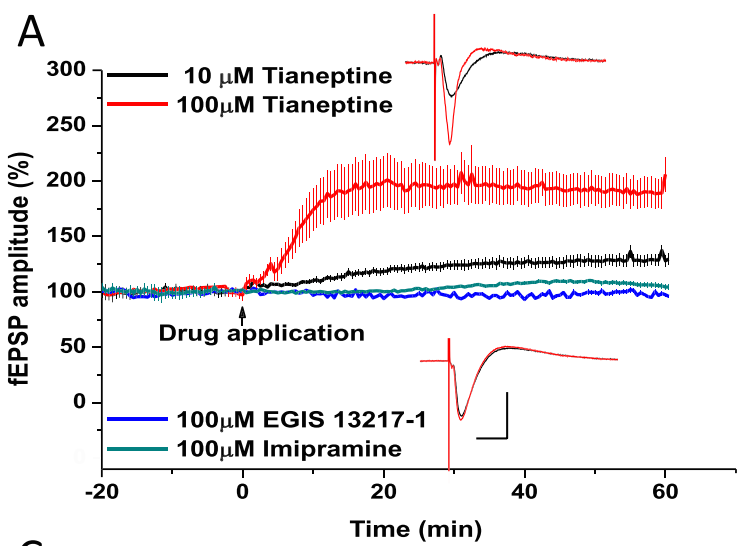

B
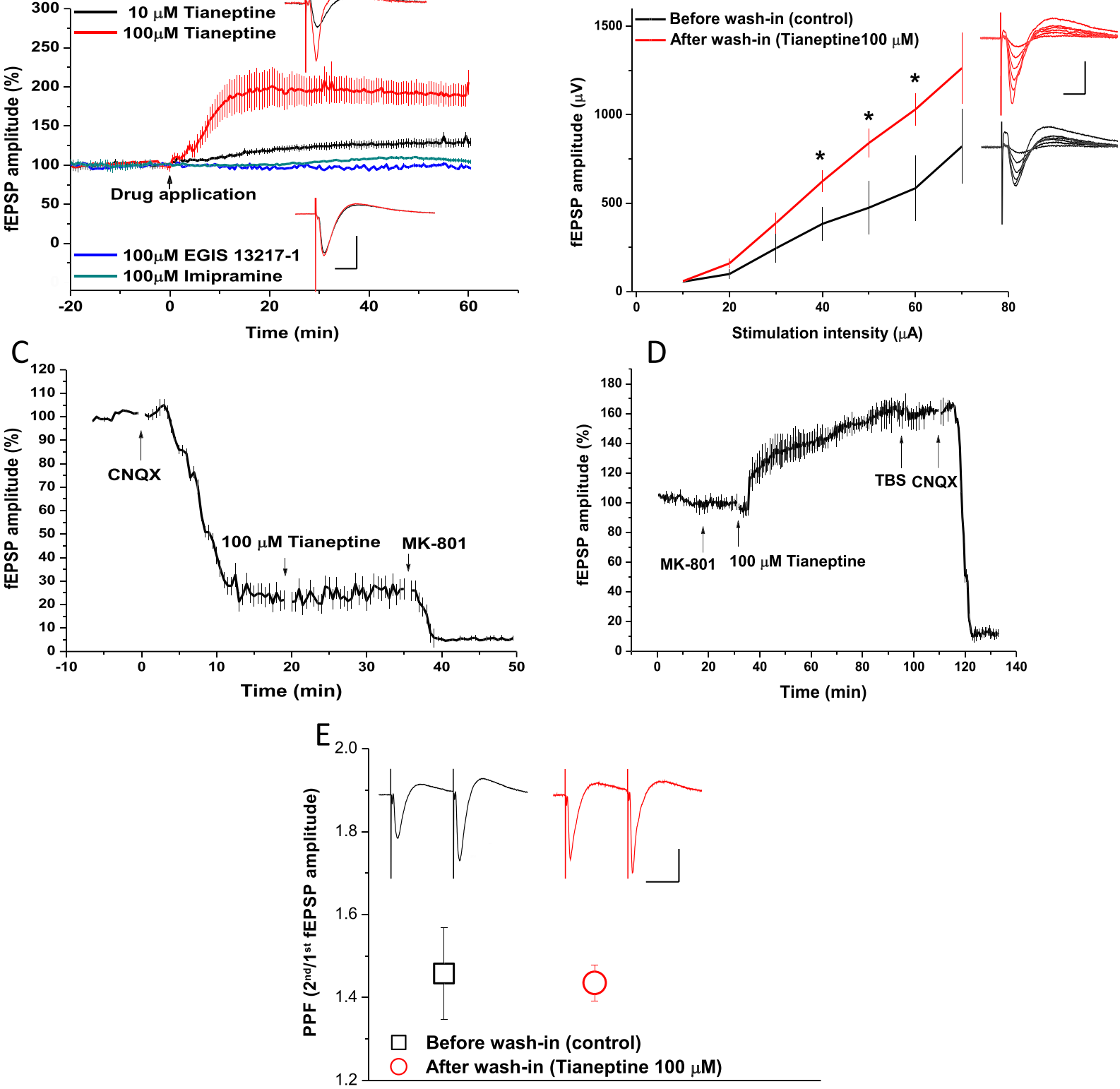

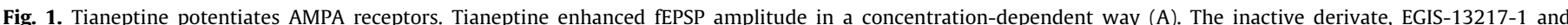

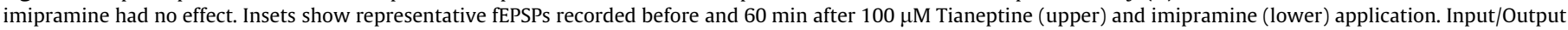

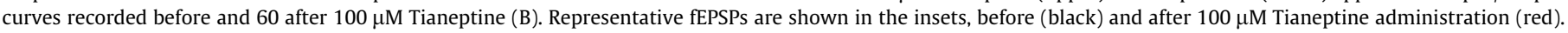

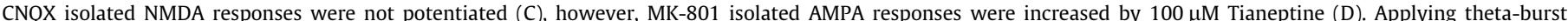

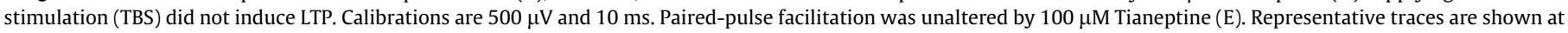

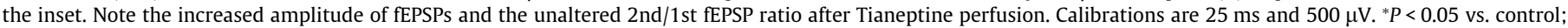
two-way ANOVA followed by Tukey's test. (For interpretation of the references to color in this figure legend, the reader is referred to the web version of this paper.)

$30 \mathrm{~min}$. In a time-course experiment, the slices were treated with Tianeptine $(50 \mu \mathrm{M})$ for $2,5,20,60,180 \mathrm{~min}$. In the dose-response experiment, the slices were treated with Tianeptine $(10,50$, $100 \mu \mathrm{M}$ ) for 2 or $5 \mathrm{~min}$. After drug treatments, the buffer was removed and the slices were rapidly frozen on dry ice and stored at $-80{ }^{\circ} \mathrm{C}$ until assayed.

\subsubsection{Immunoblotting}

Frozen tissue samples from the in vitro experiments were sonicated in $1 \%$ SDS and boiled for $10 \mathrm{~min}$. The protein concentration in each sample was thereafter determined with a BCA-based kit (Pierce, Stockholm, Sweden). Each sample $(25 \mu \mathrm{g})$ was re-suspended in sample buffer and separated by SDS-PAGE using a 12\% running gel and transferred to a PVDF transfer membrane (Sigma, Stockholm,
Sweden). The membranes were incubated for $1 \mathrm{~h}$ at room temperature with $5 \%(\mathrm{w} / \mathrm{v})$ dry milk in TBS-Tween20. Immunoblotting was performed with phosphorylation state-specific antibodies against Ser ${ }^{831}$-GluA1 (UBI, Hauppauge, NY, USA), Ser ${ }^{845}$-GluA1 (UBI), Ser $^{896}$-NA1 (UBI), Ser ${ }^{897}$-NA1 (UBI), Ser ${ }^{217 / 221}$-MEK (Cell Signaling, Piscataway, NJ, USA), $\mathrm{Thr}^{183} / \mathrm{Tyr}^{185}$-p42MAPK (Cell Signaling), $\mathrm{Thr}^{202} / \mathrm{Tyr}^{204}$-p44MAPK (Cell Signaling), Thr ${ }^{286}$-CaMKII alpha (UBI), and $\mathrm{Thr}^{286}$-CaMKII beta (UBI). Immunoblotting was also carried out with antibodies that are not phosphorylation-state-specific against total GluA1 (UBI), NA1 (UBI), MEK (Cell Signaling), p42/44MAPK (Cell Signaling), CaMKII (UBI) in 5\% dry milk dissolved in TBS-Tween20. Membranes were washed three times with TBS-Tween 20 and incubated with secondary HRP anti-rabbit antibody for $1 \mathrm{~h}$ at room temperature. At the end of the incubation, 
A
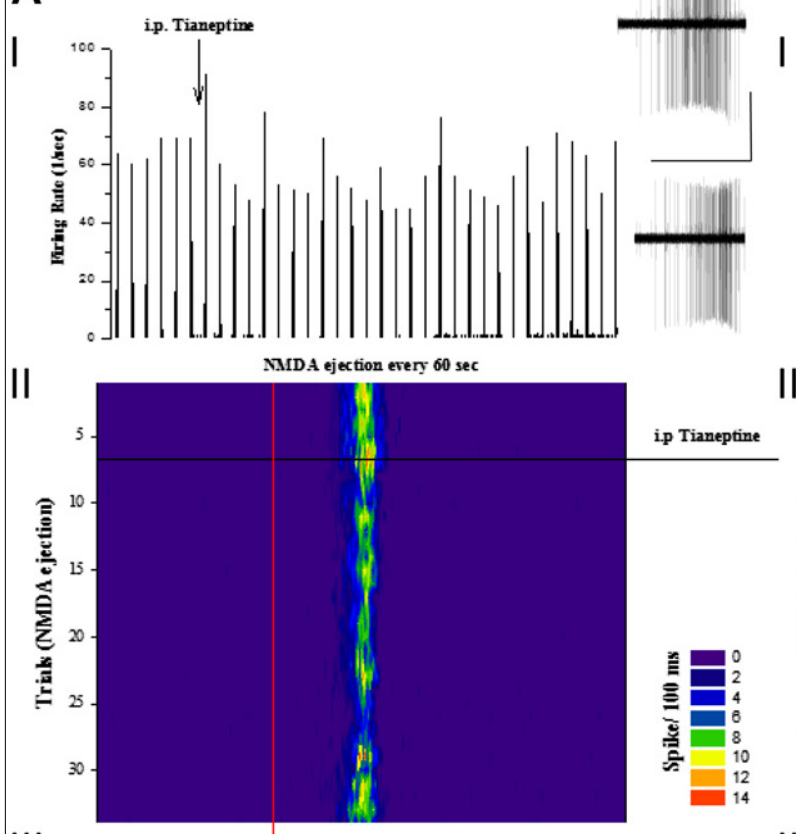

III

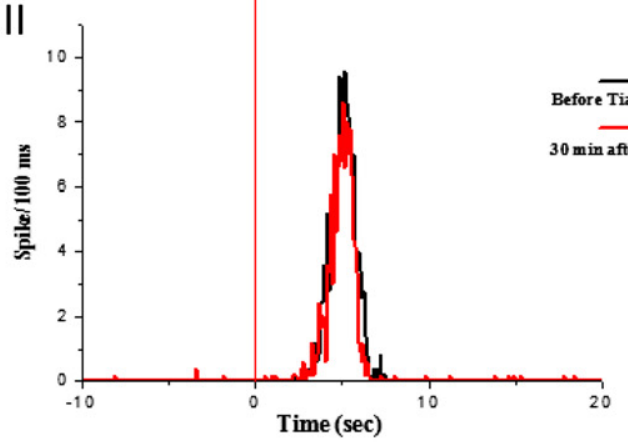

C

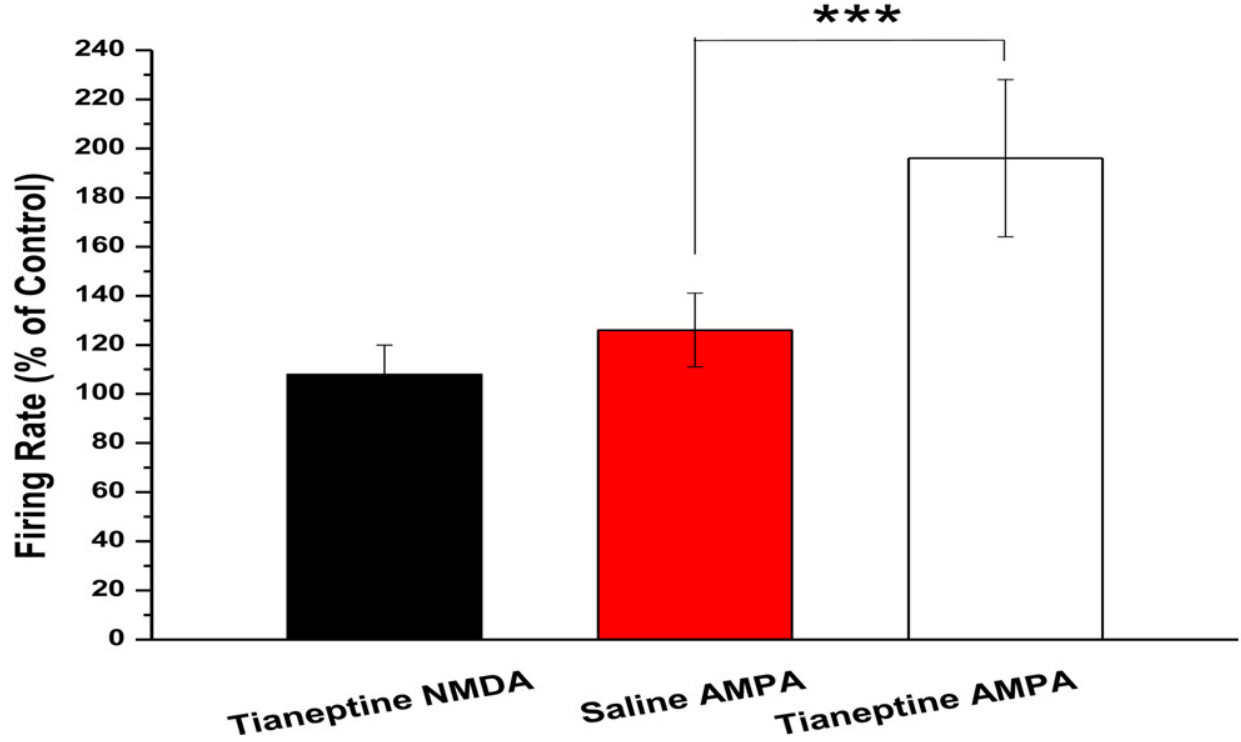

B

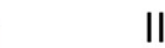

ip Tianeptine

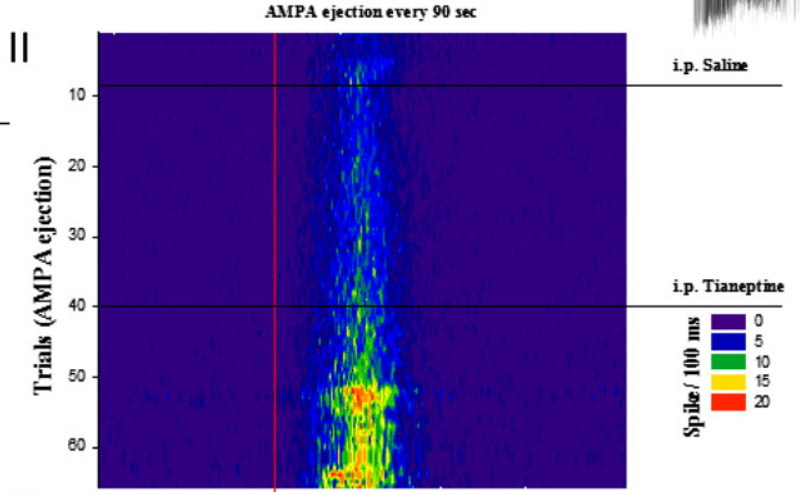

III
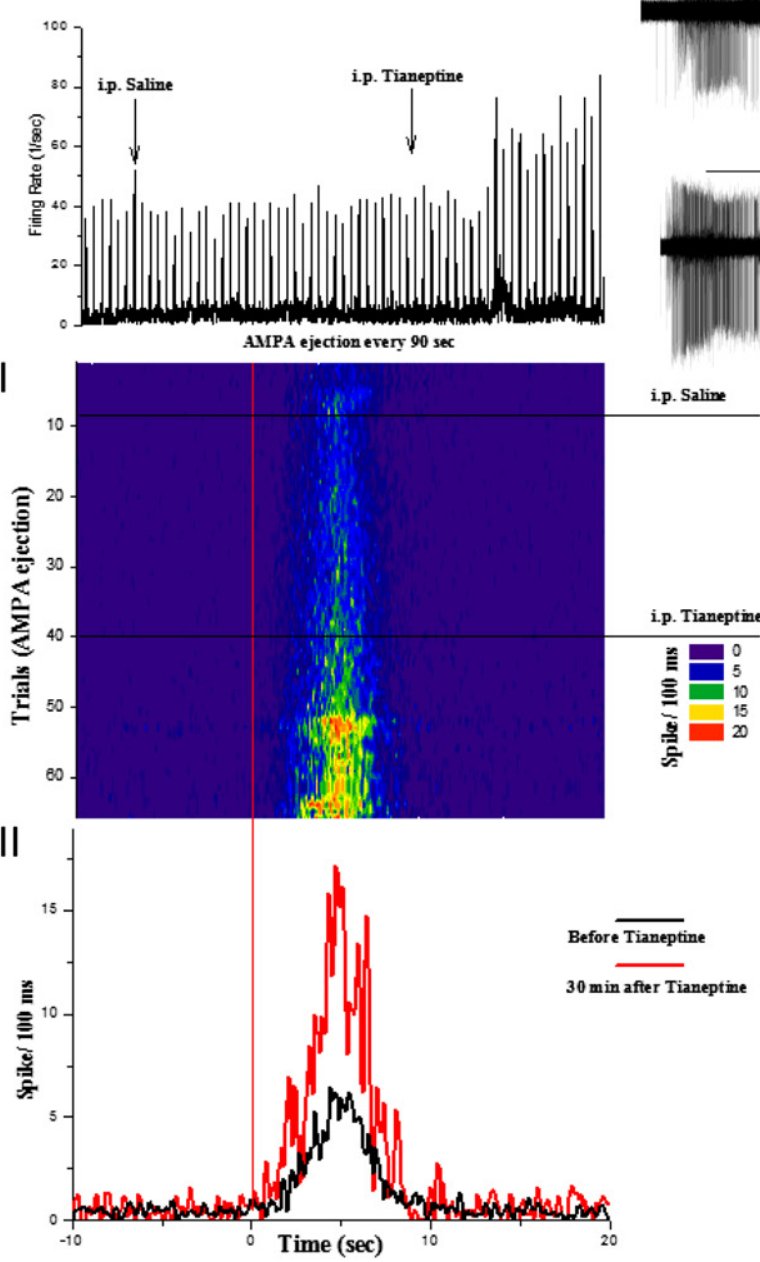

Lirimili

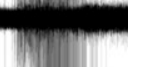

(N)
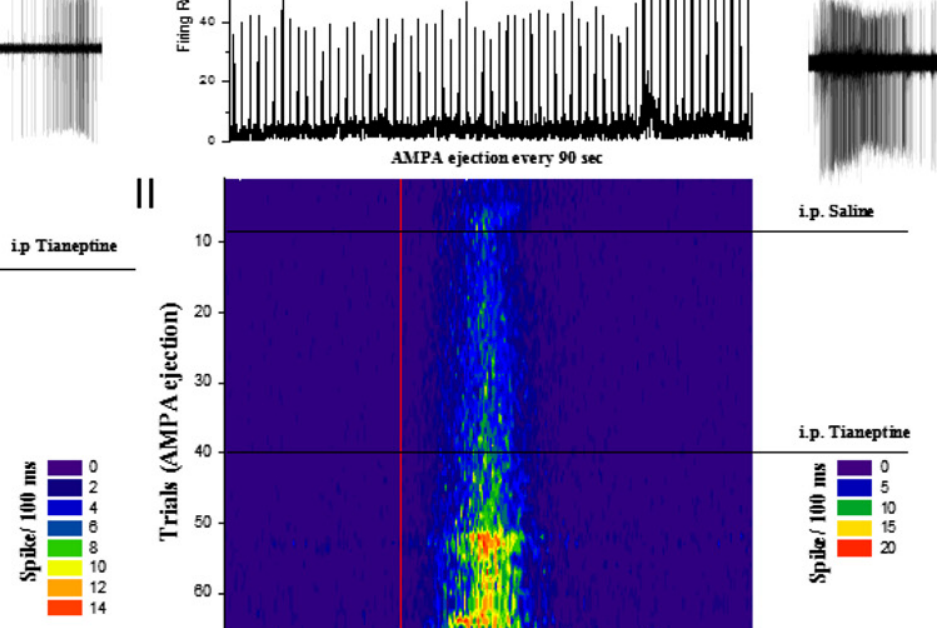

0
5

10
15
$-\quad 10$ 

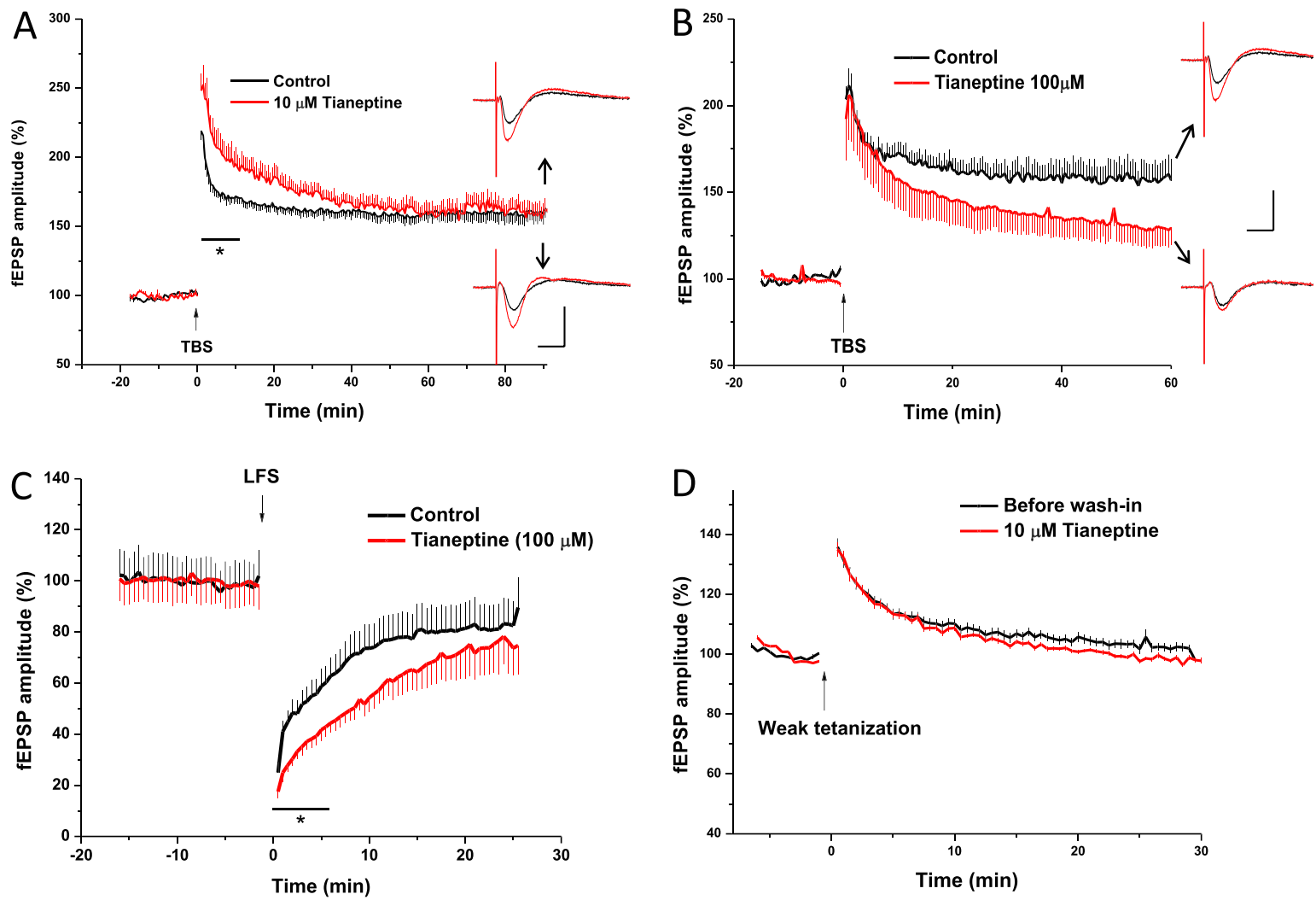

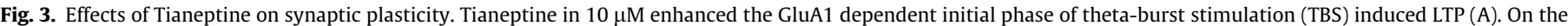

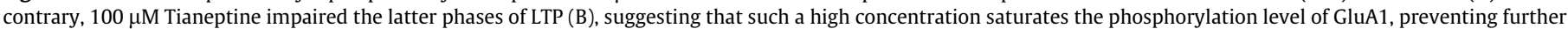

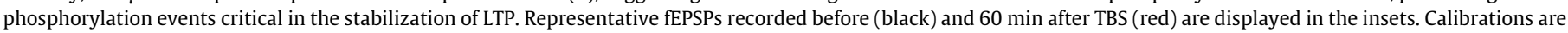

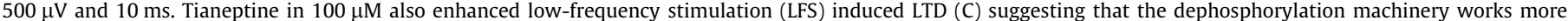

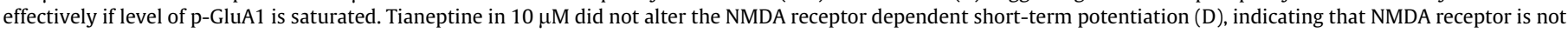

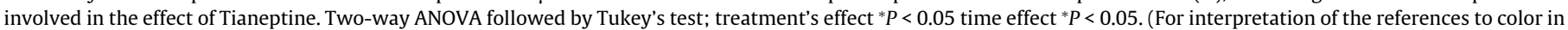
this figure legend, the reader is referred to the web version of this paper.)

phosphorylated proteins were normalized to total (phosphorylated and non-phosphorylated) levels.

\subsection{Data analysis}

For in vivo recordings, statistical evaluations were performed by using the total number of spikes evoked during each epoch of excitation by iontophoretic application of NMDA. The background neuronal discharge was calculated by averaging a 15-s period of ongoing activity preceding each epoch of excitation, and this value was subtracted from all evoked responses. The total spike number during each epoch of excitation was calculated and expressed as a percentage of the mean $( \pm S E M)$, and compared statistically with the data obtained after drug application by using one-way analysis of variance (ANOVA, with the Bonferroni test for post hoc analysis), unless otherwise stated. A $P$ value of less than 0.05 was considered significant in all cases. For the Western blot studies, the data from the time course experiment was analyzed with one-way ANOVA followed by Dunnett's test.

\section{Results}

\subsection{Electrophysiology}

\subsubsection{Tianeptine increases fEPSP amplitude in a dose-dependent} manner

Murine hippocampal slices were continuously perfused with ACSF, and evoked fEPSPs were analyzed. Introducing $100 \mu \mathrm{M}$
Tianeptine into the perfused ACSF rapidly increased the peak-topeak amplitude of evoked fEPSPs ( $189 \pm 14 \%$, after $60 \mathrm{~min}, n=8$ slices; $P \leq 0.05$; Fig. $1 \mathrm{~A}$ ). The $\mathrm{I} / \mathrm{O}$ curves taken before and $60 \mathrm{~min}$ after Tianeptine administration showed a clear enhancement of evoked responses (Fig. 1B). Using two-way ANOVA with post hoc Tukey's test, significant differences were detected at stimulation intensities of $40 \mu \mathrm{A}$ ( $383 \pm 93$ vs. $624 \pm 61 \mu \mathrm{V}, P=0.048), 50 \mu \mathrm{A}$ $(475 \pm 150$ vs. $840 \pm 80 \mu \mathrm{V}, P=0.05)$ and $60 \mu \mathrm{A}(585 \pm 185$ vs. $1030 \pm 90 \mu \mathrm{V}, P=0.048)$. Tianeptine, $10 \mu \mathrm{M}$, also significantly enhanced the amplitude of fEPSPs $(129 \pm 5 \%$, after $60 \mathrm{~min}, n=6$ slices; $P \leq 0.05$; Fig. $1 \mathrm{~A}$ ). In control slices the excitability increased only to $104 \pm 1.7 \%$ (after $60 \mathrm{~min}, n=4$ slices; data not shown). An inactive derivative of Tianeptine, EGIS-13217-1 had no effect on the fEPSPs ( $97 \pm 2 \%$, after $60 \mathrm{~min}, n=5$ slices, Fig. $1 \mathrm{~A}$ ). Although imipramine, a tricyclic antidepressant was also without any effect after $60 \mathrm{~min}$, (103 $\pm 3 \%$, after $60 \mathrm{~min}, n=4$ slices, Fig. $1 \mathrm{~A}$ ), it caused a transient excitation which peaked at $\approx 40 \mathrm{~min}(110 \pm 1.4 \%)$.

\subsubsection{The increase in evoked responses is not of presynaptic origin}

The enhancement of evoked responses could be due to presynaptic increase in vesicle release rate, and/or to postsynaptic effect. In order to address whether Tianeptine acts on the presynapse, we recorded paired pulse stimulations (interstimulus interval $50 \mathrm{~ms}$ ) before and $60 \mathrm{~min}$ after administration. There was no change in the ratio of $2 \mathrm{nd} / 1 \mathrm{st}$ fEPSP amplitude before $(1.45 \pm 0.13)$ and after Tianeptine administration ( $1.43 \pm 0.04 ; n=6$ slices; Fig. 1E), showing that Tianeptine likely has a postsynaptic site of action. Similar results were reported in the CA3 by Kole et al. (2002). 

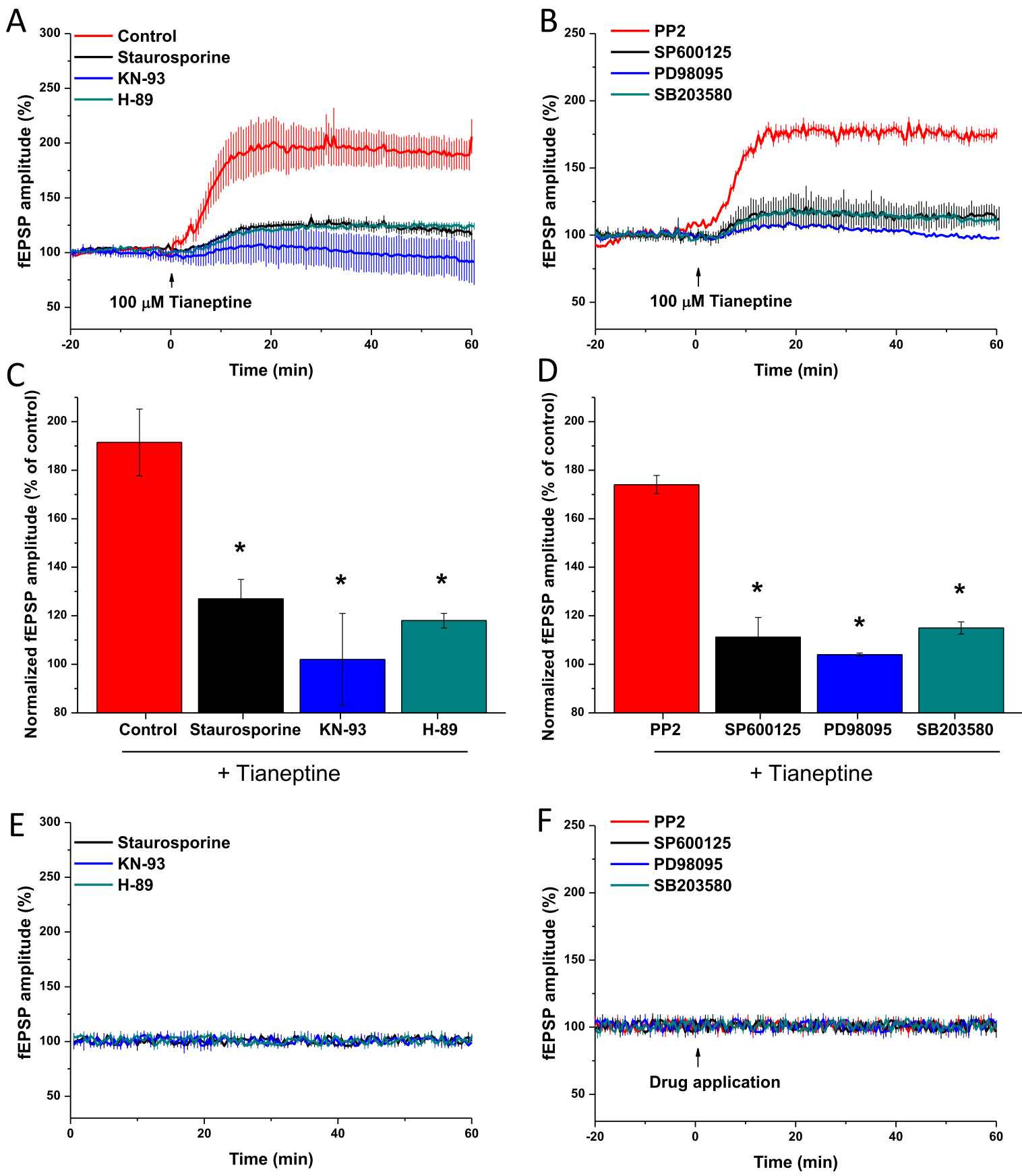

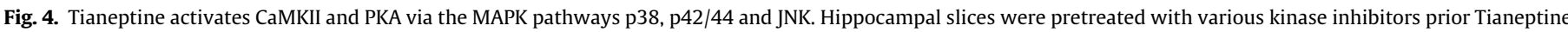

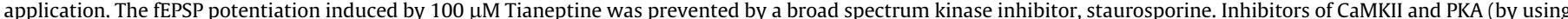

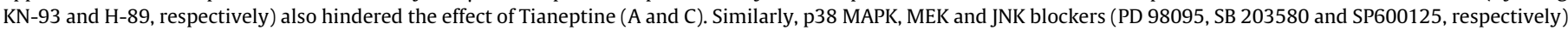

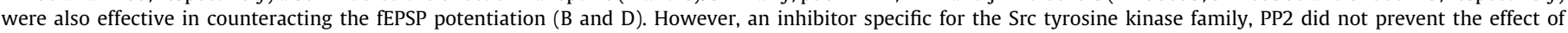
Tianeptine. Inhibitors alone did not have any effect on the fEPSP (E and F). ${ }^{*} P<0.05$ vs. control; one-way ANOVA followed by Dunnett's test.

\subsubsection{The effect of Tianeptine on NMDA and AMPA receptors}

Tianeptine enhances fEPSPs most probably via the modulation of postsynaptic excitatory ionotropic receptors, thus next we asked which receptor is affected by Tianeptine. We focused on NMDA and AMPA receptors by using specific antagonists. Application of $50 \mu \mathrm{M}$ of the AMPA receptor antagonist CNQX (6-cyano-7-nitroquixaline-2,3-dione) caused a rapid and dramatic reduction in the amplitude of evoked fEPSPs (around 20\%; $n=7$ slices; Fig. 1C). The remaining evoked responses were considered to be NMDA receptor-mediated, because perfusion of an antagonist of the NMDA receptor completely blocked this fEPSP. Applying $100 \mu \mathrm{M}$
Tianeptine did not affect isolated NMDA receptor mediated fEPSPs, indicating that Tianeptine does not modify NMDA receptor function in the CA1 (Fig. 1C).

Next we investigated the effects of Tianeptine on isolated AMPA responses. We applied the non-competitive NMDA receptor antagonists MK-801 ((+)-5-methyl-10,11-dihydro-5H-dibenzo[a,d]cyclo hepten-5,10-imine maleate) in a concentration of $50 \mu \mathrm{M}$. Perfusion of the drug onto slices had no significant effect on the amplitudes of evoked fEPSPs. However, applying CNQX completely diminished the evoked responses showing that upon MK-801 application, the fEPSPs are AMPA receptor mediated ( $n=4$ slices). We applied 
A
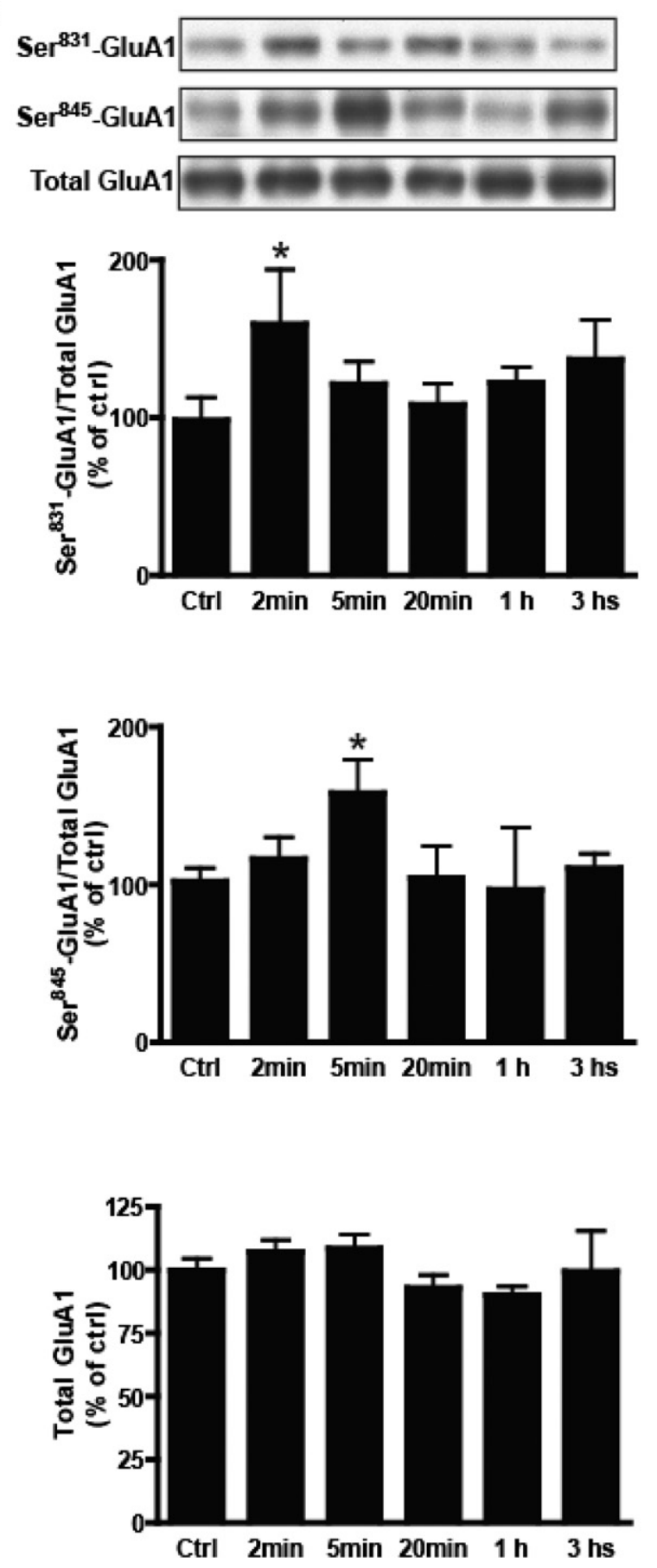
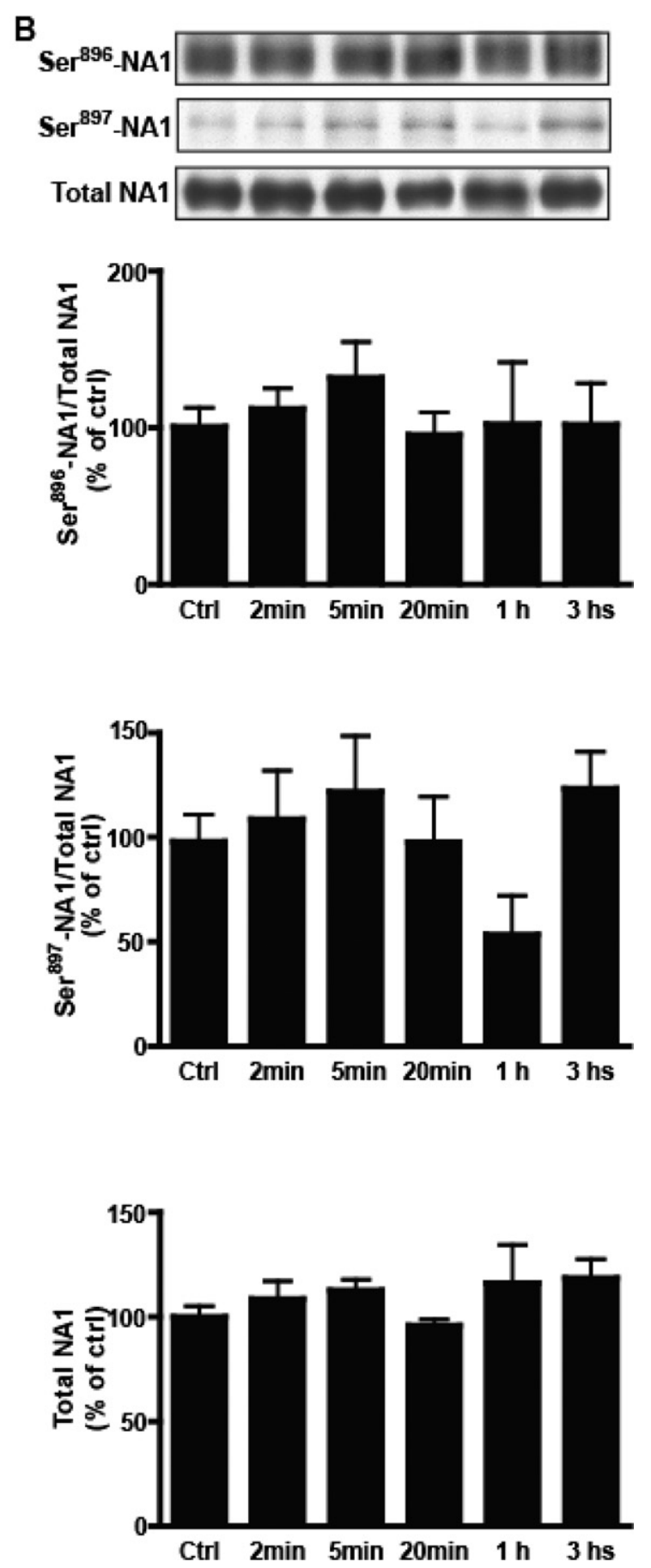

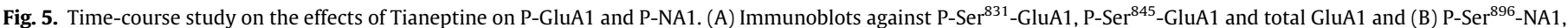

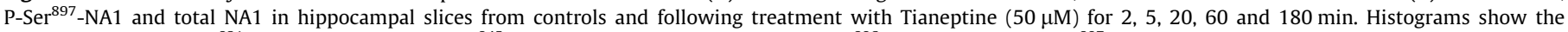

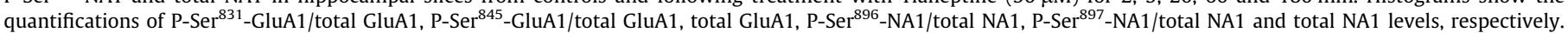
Data were normalized to total levels for each of these proteins. ${ }^{*} P<0.05,{ }^{* *} P<0.01$ vs. control; one-way ANOVA followed by Dunnett's test.

$100 \mu \mathrm{M}$ Tianeptine, which significantly increased the amplitude of the isolated AMPA receptor mediated fEPSPs ( $163 \pm 4.5 \%$ after 60 min administration, $n=4$ slices; $P \leq 0.05$; Fig. 1D) indicating that Tianeptine enhances AMPA receptor mediated responses. Moreover, in order to test the effect of the NMDA receptor antagonist, we applied theta-burst stimulation (TBS) for inducing LTP after the 60 min Tianeptine administration period. Long-term potentiation in the CA1 region of the hippocampus was shown to be NMDA receptor dependent, thus we expected to detect impairment in LTP.
Indeed, after TBS the amplitudes of fEPSPs remained at the pre-LTP level, even the first phase of LTP was impaired, clearly showing the blockade of NMDA receptors (Fig. 1D).

\subsubsection{The effect of intraperitoneal Tianeptine on NMDA and AMPA} evoked neuronal firing

Based on the in vitro electrophysiology results, we aimed to investigate the effects of i.p. administered Tianeptine on NMDA and AMPA evoked neuronal firing in vivo. We recorded single-unit 
A
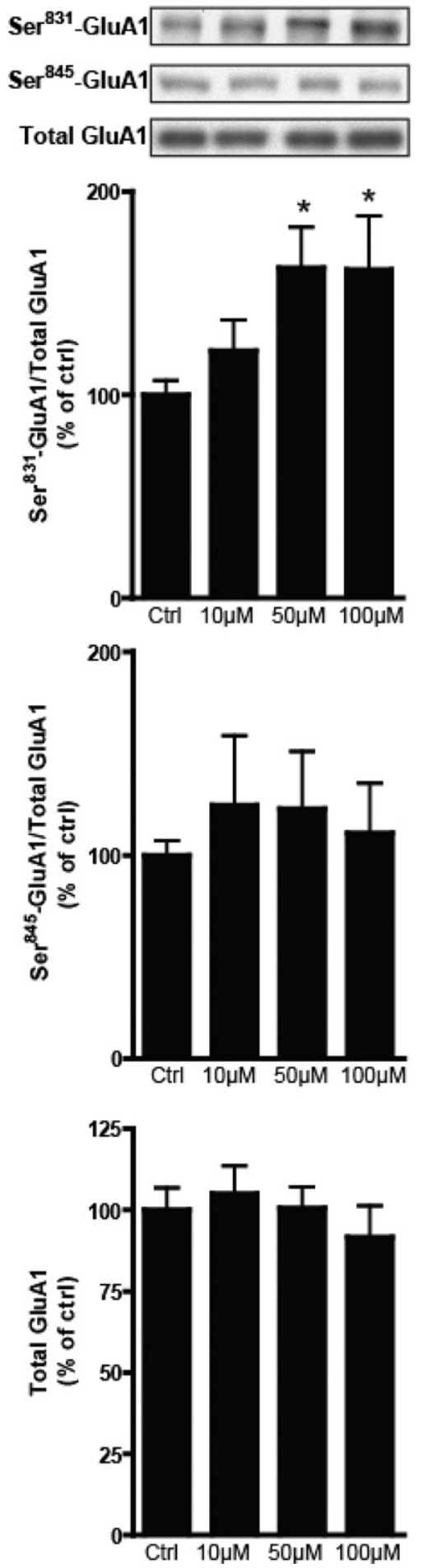

B
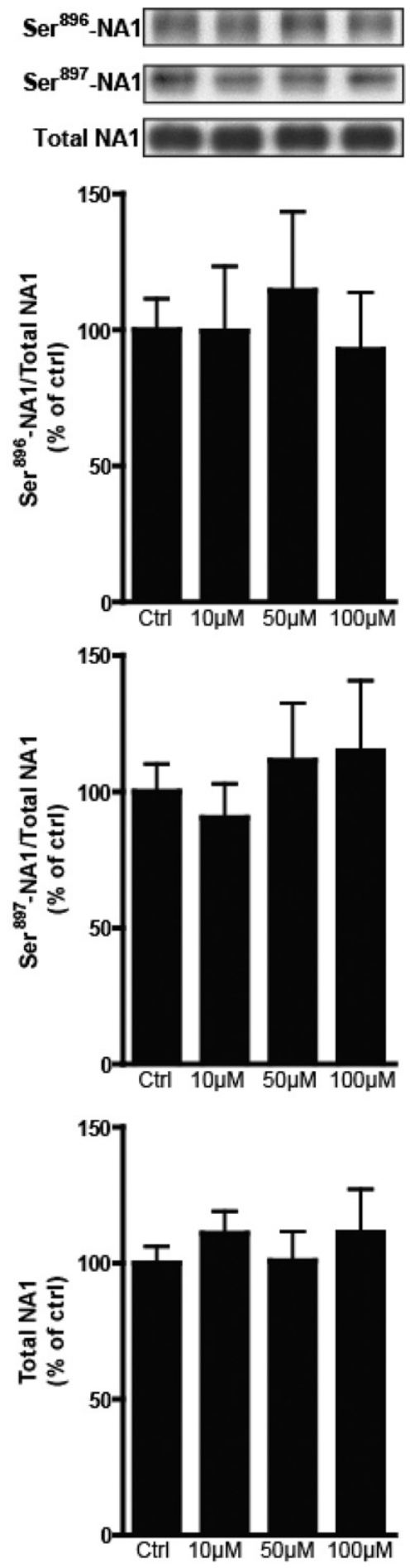

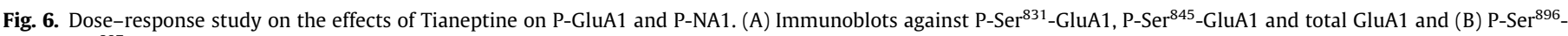

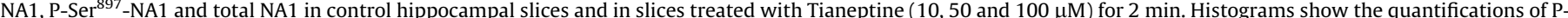

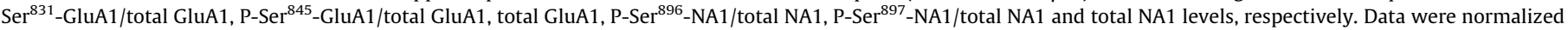
to total levels for each of these proteins. ${ }^{*} P<0.05$ vs. control; one-way ANOVA followed by Dunnett's test.

activity from the dorsal CA1. Spike trains were evoked by applying either NMDA or AMPA by means of microiontophoresis in the very close vicinity of the recorded neuron.

First, we focused on NMDA evoked neuronal firing. Tianeptine was administered following at least five successive NMDA ejection epochs which triggered firing activity with no more than $15 \%$ difference in the spiking rate. Evoked neuronal firing rate remained at the pre-Tianeptine level within the time frame of the recording (35-45 min), indicating that Tianeptine did not affect NMDA evoked neuronal responses ( $108 \pm 12 \% ; n=6$ cells from five rats; Fig. 2III). Panel A of Fig. 2I shows a representative peristimulus histogram of the effect of i.p. applied Tianeptine on NMDA evoked 
A
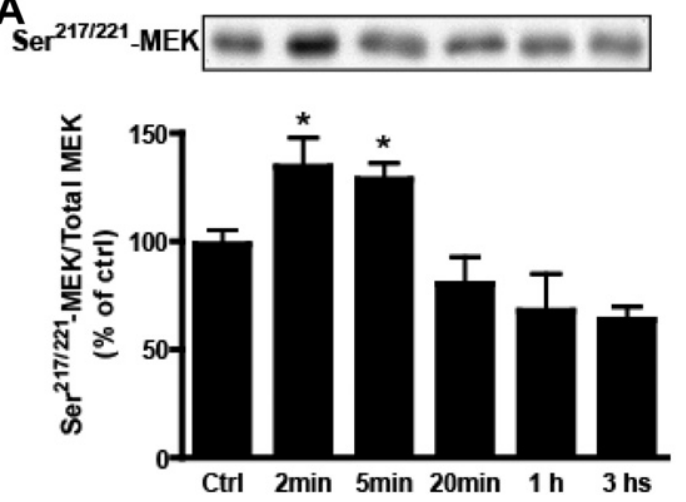

$B_{\text {P.p42MAPK }-\cdots \cdots \cdots}$

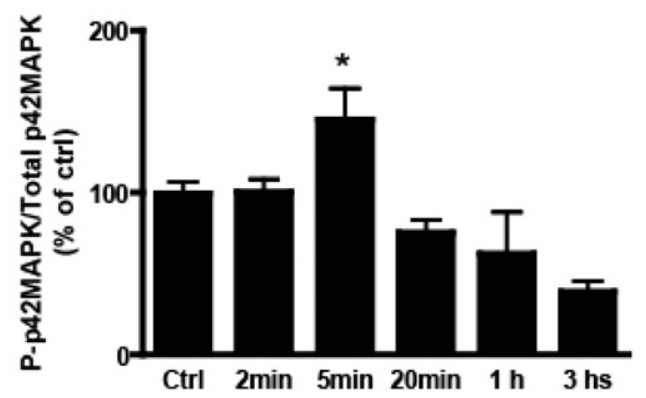

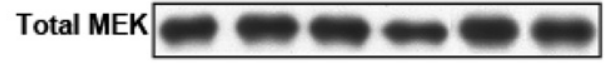

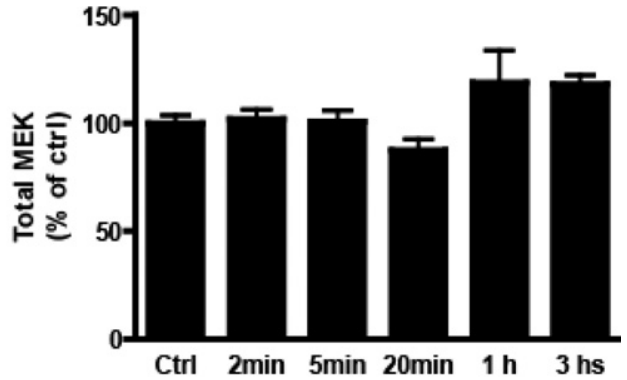

Total p42MAPK $\mathrm{em}=\mathrm{sen}$

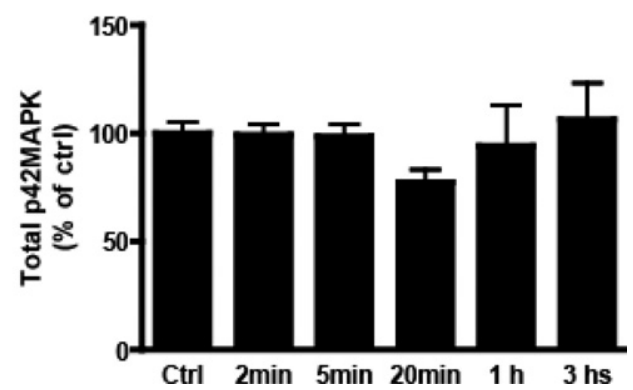

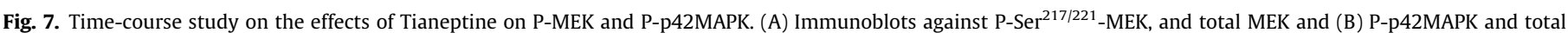

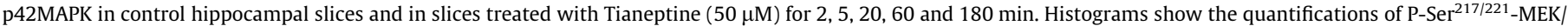

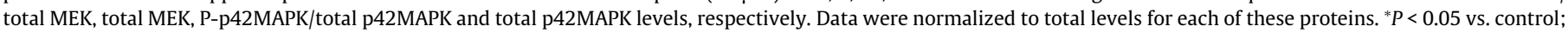
one-way ANOVA followed by Dunnett's test.

neuronal activity. The color coded peri-event time histogram with $100 \mathrm{~ms}$ bin (Panel B) and the average of the firing rate of five successive trials before and $30 \mathrm{~min}$ after i.p. Tianeptine application shows that the 5-s NMDA-ejection (marked with red line) evoked firing rate did not change over time. Spontaneous firing activity was not changed due to Tianeptine application.

Next, we investigated the effect of i.p. administered Tianeptine on AMPA evoked neuronal firing. Intraperitoneal Tianeptine administration massively enhanced AMPA elicited firing activity within $10 \mathrm{~min}$, and this effect remained within the time frame of the recordings. The average of the Tianeptine induced effect on AMPA-responses was calculated as the evoked responses of each recordings $30 \mathrm{~min}$ after i.p. administration (196 $\pm 32 \% ; n=6$ cells from 6 rats; $P \leq 0.05$; Fig. 2III). Intraperitoneal saline injection slightly increased evoked firing rate, however, following i.p. Tianeptine application evoked responses increased significantly (see Fig. 2II for a representative recording). Besides enhancing evoked firing activity, Tianeptine did not change the kinetics of the evoked spike trains, as the evoked responses returned to the basal activity in about $10 \mathrm{~s}$ following AMPA ejection both before and after Tianeptine (Fig. 2II Panel C).

\subsubsection{The effects of Tianeptine on long-term synaptic plasticity}

Modulating AMPA receptor function has been shown to be central in synaptic plasticity, thus if Tianeptine positively modulate AMPA receptors, then this may have an effect on long-term synaptic plasticity. Therefore we investigated the effects of Tianeptine on LTP and depotentiation of synaptic efficiency using murine hippocampal slices.

Following a $60 \mathrm{~min}$ Tianeptine administration period, the stimulation intensity was reduced to evoke fEPSPs similar to the pre-administration level, and LTP was evoked by theta-burst stimulation. Tianeptine, $10 \mu \mathrm{M}$, enhanced the initial phase of LTP (first 10 min; $213 \pm 21 \%, n=11$ slices; $P \leq 0.05$; Fig. $3 \mathrm{~A}$ ) compared to control slices ( $181 \pm 16 \%, n=9$ slices). Employing two-way ANOVA with post hoc Tukey's test showed that LTP after Tianeptine is significantly larger until $13 \mathrm{~min}$ after TBS $(P \leq 0.05)$. On the other hand, 90 min after TBS, the magnitude of potentiation was similar in Tianeptine treated $(163 \pm 6 \%)$ and control slices $(161 \pm 8 \%)$. In contrast, treating the slices with $100 \mu \mathrm{M}$ Tianeptine did not alter the initial phase of LTP, but it resulted in an impairment of the latter phase of potentiation ( $129 \pm 9 \%, n=6$ slices, vs. $157 \pm 12 \%, n=4$ slices; $P \leq 0.05$; Fig. 3B).

Long-term depression (LTD) is another form of persistent synaptic plasticity, where evoked fEPSPs remained depressed upon low frequency stimulation (LFS). There was a trend that Tianeptine enhances LTD: the rate of LTD 30 min after LFS was $82.5 \pm 10 \%$ 25 min after LFS in the control slices ( $n=4$ slices), while in the $100 \mu \mathrm{M}$ Tianeptine treated slices LTD was $73 \pm 11 \%$ ( $n=6$ slices; Fig. 3C). This difference was not significant, although the first 6 min of LTD were significantly enhanced by Tianeptine $(44 \pm 3 \%$ vs. $63 \pm 6 \%$ for 6 min after LFS; two-way ANOVA with post hoc Tukey's test; $P \leq 0.05)$.

If Tianeptine does not have any effect on NMDA receptors, than it will not affect a form of plasticity that is dependent on NMDA receptors. In order to address this point, we used a stimulation protocol, which evokes an NMDA receptor dependent short-term potentiation (Debanne et al., 2006; Dozmorov et al., 2004; Schulz and Fitzgibbons, 1997; Volianskis and Jensen, 2003). Before Tianeptine administration (control condition), this stimulation protocol evoked a transient fEPSP potentiation, which diminished within $30 \mathrm{~min}$. The maximum fEPSP amplitude was $136 \pm 3 \%$ ( $n=4$ slices; Fig. 3D). Following a $60 \mathrm{~min}$ administration period of $10 \mu \mathrm{M}$ Tianeptine, the level of potentiation did not differ from 
A
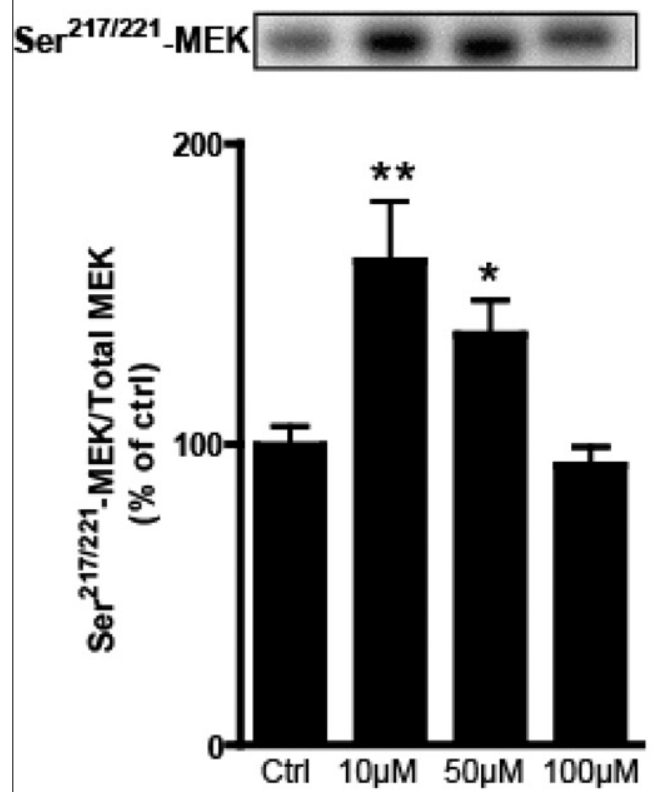

B

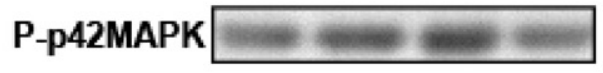

Total p42MAPK

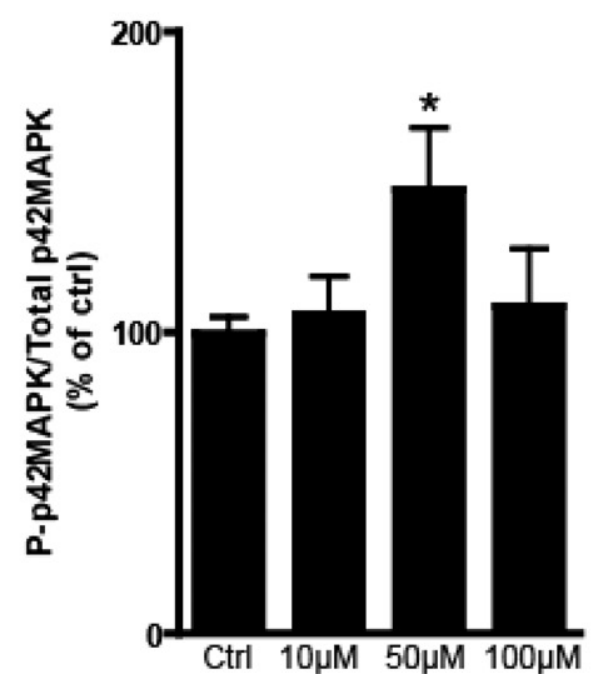

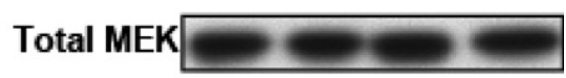

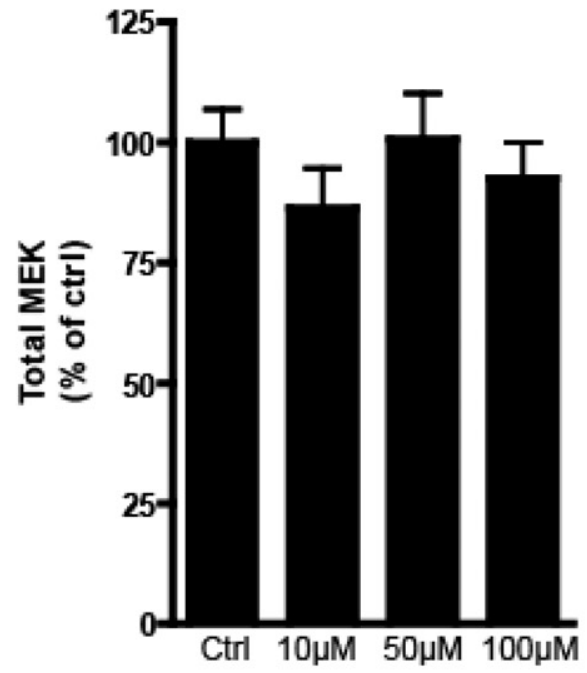

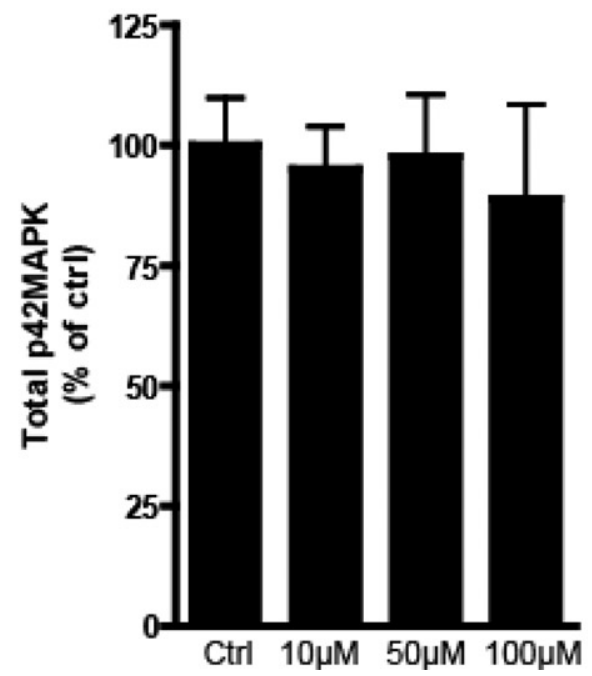

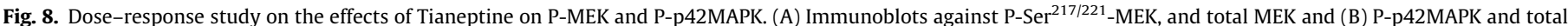

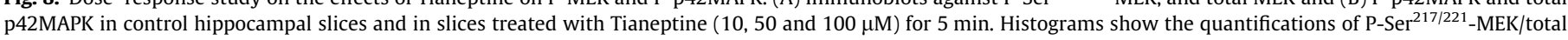

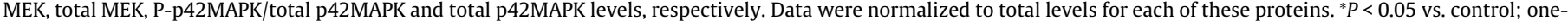
way ANOVA followed by Dunnett's test.

that of the control condition (maximum fEPSP amplitude $130 \pm 2.5 \% ; n=4$ slices; Fig. 3D). Tianeptine also did not affect the kinetics of the short-term potentiation; the fEPSP amplitude returned to $100 \%$ within $30 \mathrm{~min}$. Taken together, these results suggest that Tianeptine exerts its fEPSP potentiating effect by selectively enhancing AMPA receptor function.

\subsubsection{Tianeptine potentiates AMPA receptor via several kinases}

Tianeptine was shown to increase the phosphorylation level of GluA1 subunit, which, in turn, enhances AMPA receptor function. In order to characterize the involvement of kinases in this phenom- enon, first we perfused a broad spectrum kinase blocker, staurosporine $(10 \mu \mathrm{M})$ for $20 \mathrm{~min}$ before $100 \mu \mathrm{M}$ Tianeptine administration. Staurosporine administration slightly increased the amplitude of fEPSPs ( $109 \pm 0.8 \%$ after $20 \mathrm{~min}, n=5$ slices $)$. However, it significantly reduced the fEPSP enhancement induced by $100 \mu \mathrm{M}$ Tianeptine perfusion ( $127 \pm 8 \%$ after $60 \mathrm{~min}, n=5$ slices; $P \leq 0.05$, one-way ANOVA followed by Dunnett's test; Fig. 4A and $C$ ), suggesting that activation of kinases mediate the AMPA receptor potentiating effect of Tianeptine.

Tianeptine has been shown to increase the level of $\mathrm{p}-\mathrm{Ser}^{831}$ GluA1, at the phosphorylation site of CaMKII (Svenningsson et al., 
A
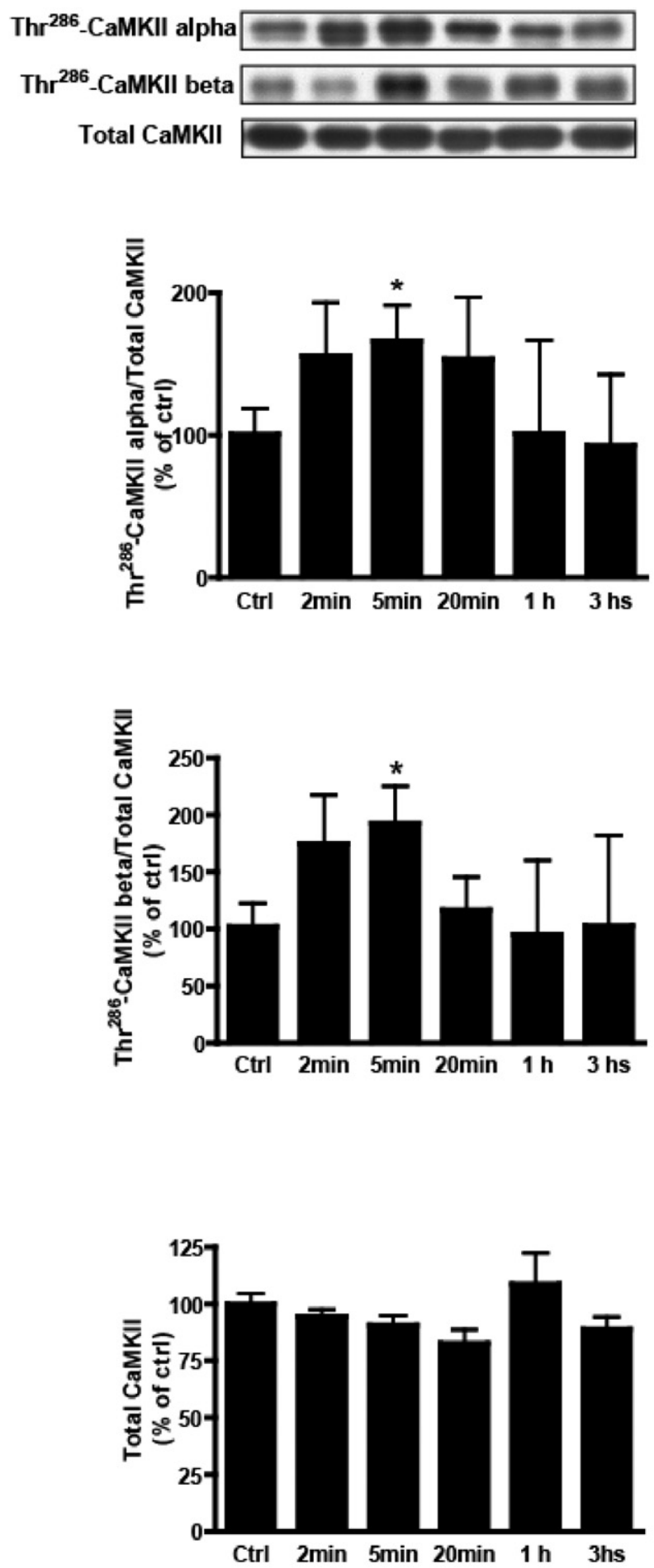

B
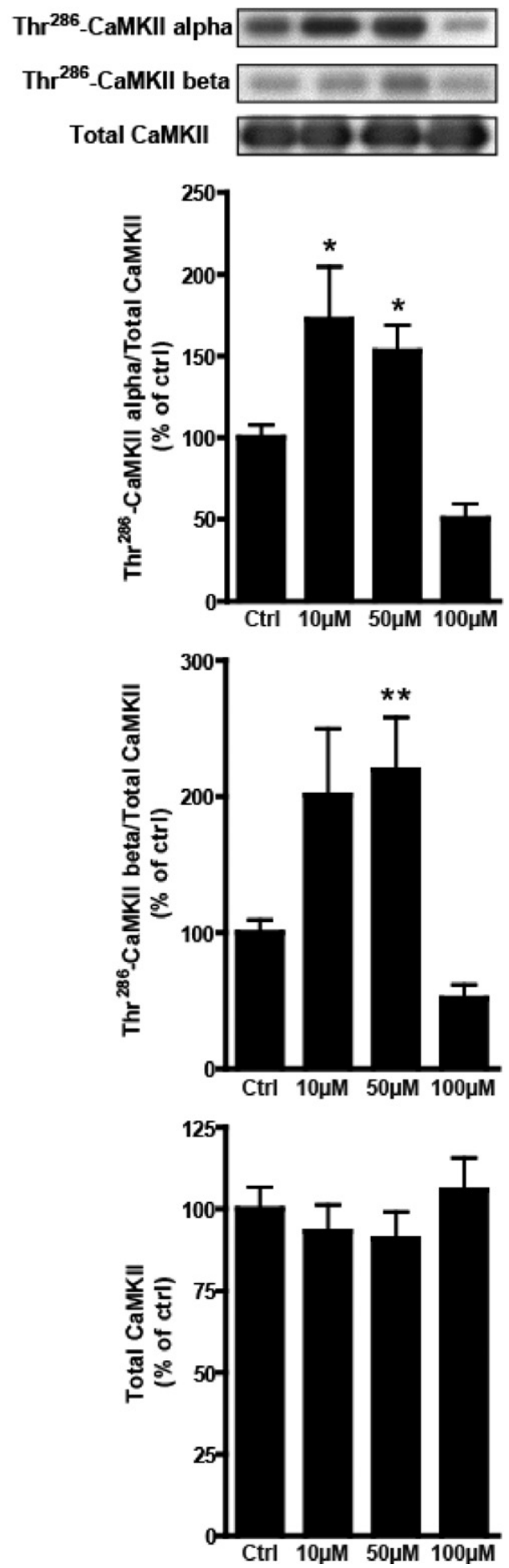

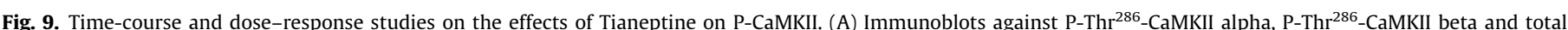

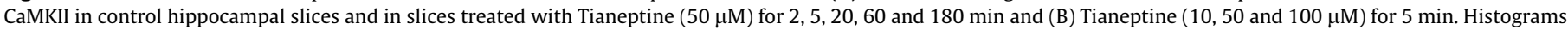

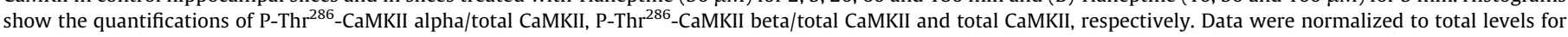
each of these proteins. ${ }^{*} P<0.05$ vs. control; one-way ANOVA followed by Dunnett's test.

2007). Thus, we investigated whether blocking CaMKII would prevent the effect of Tianeptine. Perfusing the CaMKII inhibitor KN-93 $(5 \mu \mathrm{M})$ for 20 min did not change the amplitude of fEPSPs (101 $\pm 3 \%, n=5$ slices), however, it prevented the $100 \mu \mathrm{M}$ Tianeptine induced increase in fEPSPs $(102 \pm 19 \%, n=5$ slices; Fig. $4 \mathrm{~A}$ and $\mathrm{C}$ ), suggesting that Tianeptine activates CaMKII which phosphorylates GluA1.

Tianeptine was also shown to increase the phosphorylation level of GluA1 at the protein kinase A site, $\operatorname{Ser}^{845}$. Therefore we tested a kinase blocker known to block PKA, against Tianeptine. Applying 
$\mathrm{H}-89$ in $10 \mu \mathrm{M}$ did not affect the evoked fEPSPs $(104 \pm 2 \%, n=4$ slices), but it counteracted Tianeptine induced fEPSP enhancement $(118 \pm 3 \%$; Fig. $4 \mathrm{~A}$ and $\mathrm{C})$.

In order to decide whether Tianeptine acts directly on CaMKII and on PKA or on an upstream enzyme, we investigated the possible involvement of the MAPK-MAPKK pathway in the effect of Tianeptine. We perfused the MAPKK (MEK) inhibitor PD 98095 (2'-Amino-3'-methoxyflavone, $50 \mu \mathrm{M}$ ) onto the slices, which had no effect on the basal synaptic transmission $(104 \pm 1.1 \%, n=4$ slices). Applying $100 \mu \mathrm{M}$ Tianeptine for $60 \mathrm{~min}$ did not induce any change the evoked fEPSPs (103.8 $\pm 0.7 \%, n=4$ slices; Fig. 4B and D) showing that MAPKK is involved in the effect of Tianeptine.

Next we investigated the role of an upstream kinase of MAPK by using SB 203580, a p38 MAPK inhibitor. Applying SB 203580 (4-(4fluorophenyl)-2-(4-methylsulfinylphenyl)-5-(4-pyridyl)1H-imidazole, $5 \mu \mathrm{M})$ for $20 \mathrm{~min}$ did not alter the amplitude of fEPSPs ( $97.5 \pm 4 \%, n=4$ slices). Perfusing $100 \mu \mathrm{M}$ Tianeptine only slightly increased evoked fEPSPs ( $115 \pm 2 \%, n=4$ slices; Fig. $4 \mathrm{~B}$ and D), clearly showing the involvement of p38 MAPK-MEK pathway in the action of Tianeptine.

The stress-activated MAPK pathways comprise of two distinct pathways, p38 MAPK and c-Jun N-terminal kinase (JNK) cascade. Therefore we tested an inhibitor of JNK against Tianeptine. Perfusing SP600125 (anthra[1-9cd]pyrazol-6(2H)-one, $10 \mu \mathrm{M}$ ), did not alter fEPSPs, but it prevented the effect of $100 \mu \mathrm{M}$ Tianeptine ( $111 \pm 8 \%, n=4$ slices; Fig. 4B and D).

Src kinases are shown to phosphorylate specific subunits of the NMDA receptor complex, but have no effect on AMPA receptor function (e.g. (Lin et al., 2003; Qiu et al., 2006; Uhasz et al., 2010). If Tianeptine enhanced AMPA receptor function but did not modify NMDA receptors, then inhibiting Src kinases will not have any effect on Tianeptine induced enhancement of fEPSPs. Indeed, perfusing PP2 (4-amino-5-(4-chlorophenyl)-7-(t-butyl)pyrazolo[3,4-d]pyrimidine, $10 \mu \mathrm{M}$ ), an inhibitor known to block Src kinases for $20 \mathrm{~min}$, then applying $100 \mu \mathrm{M}$ Tianeptine enhanced fEPSPs to a magnitude ( $174 \pm 4 \%, n=4$ slices; Fig. 4B and D), which did not differ significantly from the effect of Tianeptine alone.

Applying kinase inhibitors alone for $60 \mathrm{~min}$ did not change the level of fEPSPs (Fig. 4E and F).

\subsection{Western blot studies}

3.2.1. Effects of Tianeptine on phosphorylation at Ser ${ }^{831}$-GluA1, Ser $^{845}$ GluA1, Ser ${ }^{896}$-NA1 and Ser ${ }^{898}$-NA1 in hippocampal brain slices

In agreement with previous data found in whole animals (Qi et al., 2009; Svenningsson et al., 2007), we found in a time-course experiment that Tianeptine caused a rapid and significant increase in the phosphorylation of $\operatorname{Ser}^{831}$-GluA1 $(179 \pm 35 \%$ at $2 \mathrm{~min}, n=15$ slices) and Ser ${ }^{845}$-GluA1 ( $164 \pm 17 \%$ at $5 \mathrm{~min}, \quad n=19$ slices) (Fig. 5A). Meanwhile, Tianeptine had no effects on the phosphorylation state of the other major ionotropic glutamate receptor, the NMDA receptor, at the Ser ${ }^{896}$ - and $\mathrm{Ser}^{897}$-NA1 residues (Fig. 5B). Tianeptine had no effects on the levels of total GluR1 or NA1 at any of the timepoints studied (Fig. 5A and B). In the dose-response experiment, Tianeptine significantly increased the phosphorylation of Ser $^{831}$-GluA1 $(162 \pm 20 \%$ at $50 \mu \mathrm{M}, n=8$ slices and $162 \pm 27 \%$ at $100 \mu \mathrm{M}, n=6$ slices) (Fig. $6 \mathrm{~A}$ ), but had no effects on the phosphorylation state of $\mathrm{Ser}^{845}$-GluA1, Ser ${ }^{896}$ - and $\mathrm{Ser}^{897}$-NA1 residues (Fig. 6B). Tianeptine had no effects on the levels of total GluR1 or NA1 at any of the doses studied (Fig. 6A and B).

3.2.2. Effects of Tianeptine on phosphorylation at $\mathrm{Ser}^{217 / 221}-\mathrm{MEK}$, $\mathrm{Thr}^{183} / \mathrm{Tyr}^{185}$-p42MAPK, Thr ${ }^{202} / \mathrm{Tyr}^{204}$-p44MAPK and $\mathrm{Thr}^{286}$-CaMKII in hippocampal brain slices

In accordance with the data we previously found in whole rats ( $\mathrm{Qi}$ et al., 2009), Tianeptine caused rapid and significant increases in the phosphorylation of $\operatorname{Ser}^{217 / 221}$-MEK $(135 \pm 15 \%$ at 2 min, $n=15$ slices and $129 \pm 7 \%$ at $5 \mathrm{~min}, n=19$ slices) and $\mathrm{Thr}^{183} / \mathrm{Tyr}^{185}$-p42MAPK ( $145 \pm 19 \%$ at $5 \mathrm{~min}, n=19$ slices) (Fig. $7 \mathrm{~A}$ and B). In the dose-response experiment, Tianeptine significantly increased the phosphorylation of $\operatorname{Ser}^{217 / 221}$-MEK $(161 \pm 20 \%$ at $10 \mu \mathrm{M}, n=6$ slices and $136 \pm 11 \%$ at $50 \mu \mathrm{M}, n=12$ slices) and $\mathrm{Thr}^{183} / \mathrm{Tyr}^{185}$-p42MAPK ( $148 \pm 21 \%$ at $50 \mu \mathrm{M}, n=13$ slices) (Fig. $8 \mathrm{~A}$ and $\mathrm{B}$ ). In addition to GluA1 subunits and MEK/MAPK signaling, CaMKII is known to modulate synaptic plasticity. We found that Tianeptine also caused a significant increase in the phosphorylation of $\mathrm{Thr}^{286}$-CaMKII both at the alpha ( $170 \pm 16 \%$ at $5 \mathrm{~min}, n=19$ slices) and beta $(191 \pm 28 \%$ at 5 min, $n=19$ slices) subunits (Fig. 9A). In the dose-response experiment, Tianeptine also caused a significant increase in the phosphorylation of $\mathrm{Thr}^{286}$-CaMKII both at the alpha ( $172 \pm 32 \%$ at $10 \mu \mathrm{M}, n=6$ slices and $153 \pm 16 \%$ at $50 \mu \mathrm{M}, n=13$ slices $)$ and beta $(220 \pm 38 \%$ at $50 \mu \mathrm{M}, n=13$ slices) subunits (Fig. 9B). Tianeptine had no effects on the levels of total MEK, p42MAPK or CaMKII at any of the timepoints and doses studied (Figs. 7-9).

\section{Discussion}

Human imaging studies have shown that the impaired function of hippocampus in major depressive disorder could be reversed by antidepressant treatment enhancing excitability and metabolic rate (McCormick et al., 2007; McKie et al., 2005; Schaefer et al., 2006). Recently, modulating postsynaptic plasticity and AMPA receptors are in the focus of antidepressant development. Indeed, classical antidepressant compounds were found to modulate not only the level of serotonin, but the phosphorylation state of GluA1 as well, suggesting that this effect is important in the antidepressant action. Finding medications that work more directly on the therapeutic target could lead to medications with faster onset, fewer side effects and a better understanding of the pathophysiology of depression.

A clinically effective antidepressant sold in 80 countries, Tianeptine, has a different mode of action than tricyclic compounds. Tianeptine not only prevents but also reverses both stress- and corticosterone induced dendritic remodeling of hippocampal neurons (Watanabe et al., 1992) whereas fluoxetine fails to block such remodeling (Magarinos et al., 1999). We have shown previously, that similar to Tianeptine, the classical tricyclic antidepressants, imipramine and fluoxetine increase the hippocampal level of phospho-Ser ${ }^{845}$ _GluA1 (Du et al., 2004; Svenningsson et al., 2002). Tianeptine, but not imipramine, was also found to increase phosphorylation of $\mathrm{Ser}^{831}$-GluA1. Collectively, these data show that Tianeptine may be the only known antidepressant that can enhance phosphorylation at both GluA1 sites. Thus antagonizing AMPA receptors was ineffective against the antidepressant action of imipramine, but it prevented the antidepressant action of LY392098, a positive AMPA receptor modulator, measured $1 \mathrm{~h}$ after drug administration ( $\mathrm{Li}$ et al., 2001). In addition, Tianeptine failed to produce antidepressant activity in dual-phosphomutant GluA1 mice in which $\mathrm{Ser}^{831}$ - and $\mathrm{Ser}^{845}$-GluA1 had been inactivated by alanine replacements (Svenningsson et al., 2007). Taken together, these data indicate that in contrast to imipramine and fluoxetine, Tianeptine might exert its mood stabilizing effect via rapid AMPA receptor potentiation. Kole et al. have shown that Tianeptine rapidly enhances AMPA receptor mediated EPSPs in the CA3 through the involvement of kinases (Kole et al., 2002). This is in accord with our results, which show that Tianeptine, but not imipramine, enhances AMPA receptor mediated neuronal responses. This enhancement of evoked responses is probably mediated by GluA1 phosphorylation, as Tianeptine rapidly increased the level of pGluA1 subunits. Tianeptine $(50 \mu \mathrm{M})$ enhanced Ser ${ }^{831}$-GluA1 2 min, and Ser ${ }^{845}$-GluA1 5 min, after perfusion in hippocampal slices, without altering the phosphorylation state of NA1. The dual phosphory- 
lation effect is critical in AMPA response enhancement, since blocking either CaMKII or PKA prevented Tianeptine induced potentiation. The imipramine-induced PKA activation (without CaMKII activity) resulted in a transient potentiation, similar to the effect of Tianeptine in the presence of CaMKII inhibitor, showing that PKA activation alone is not sufficient to induce permanent enhancement of AMPA receptor function. Indeed, increasing GluA1 phosphorylation selectively at the PKA site by a citrus flavonoid caused only a transient, 50-min-long fEPSP enhancement (Matsuzaki et al., 2008). Tianeptine caused only a transient increase in the level of p-Ser ${ }^{831}$-GluA1 and p-Ser ${ }^{845}$-GluA1, however, the excitation of AMPAR mediated electrophysiological responses were permanent. The potentiation of synaptic GluA1 may be a two step process whereby insertion of GluA1 onto neuronal surface is governed by phosphorylation of GluA1 on the PKA site and GluA1 transportation into synapses is regulated by the activation of CaMKII (Hayashi et al., 2000; Lee et al., 2000). The total GluA1 level was unchanged, indicating that expression of the subunit was unaltered by Tianeptine. Thus, increasing the activity of PKA and CaMKII may result in enhanced GluA1 synaptic expression and increased AMPA responses. In support of this hypothesis, antimanic agents like lithium and valproate, (Angst et al., 1978), attenuate the phosphorylation level of GluA1, resulting in a decrease of the surface expressed AMPARs (Du et al., 2004). In contrast to the findings in brain slices, Tianeptine had no significant effect on the phosphorylation state of GluA1 subunits in HEK-293 cells stably expressing rat GluA1 flip receptor (see Supplementary material). These data indicate that Tianeptine only regulates the phosphorylation state of GluA1 subunits when these subunits are expressed in neurons. This effect may be region selective, because Bobula and Hess reported a decrease of NMDA and AMPA receptor mediated fEPSP after chronic Tianeptine treatment in the prefrontal cortex (Bobula and Hess, 2008).

In contrast to imipramine and fluoxetine, Tianeptine was also shown to enhance correlates of learning and to prevent stress induced memory impairment (Qi et al., 2009; Shakesby et al., 2002; Zoladz et al., 2008). The phosphorylation state of GluA1 is influenced by different forms of hippocampal long lasting synaptic plasticity. Long-term potentiation induces phosphorylation of the CaMKII site, while long-term depression dephosphorylates the PKA site (Lee et al., 2000). Hippocampal LTP consists of several, partly overlapping phases involving different molecular pathways. Besides being sensitive to kinase inhibitors (Huber et al., 1995), the initial phase is dependent on GluA1 function, as genetically modified mice lacking the GluA1 subunit (Gria1 ${ }^{-1-}$ mice) show impairment of the initial phase of LTP (Romberg et al., 2009). Moreover, an allosteric positive AMPA receptor modulator was reported to enhance approximately the first 10 min of LTP in vivo (Bernard et al., 2010), similar to our results with $10 \mu \mathrm{M}$ Tianeptine. Altogether, these data indicate that Tianeptine affects GluA1 subunit function and/or phosphorylation state. However, high concentration of the drug $(100 \mu \mathrm{M})$ caused impairment in the potentiation, suggesting that the phosphorylation level of GluA1 was saturated by Tianeptine pretreatment, preventing the stabilization of LTP. On the other hand, the same concentration of Tianeptine enhanced LTD, which could be due to the more effective dephosphorylation process of the saturated and more available PKA sites. Enhancing (even saturating) the level of key phosphorylation sites at the AMPA receptor complex might lead to improved plasticity (e.g. early phase of LTP and LTD) underlying better memory performance.

Using specific blockers and biochemical assays, we provided evidence that the AMPA receptor potentiation by Tianeptine is modulated by three distinct MAPK pathways: p42/44, JNK and p38 signaling, which subsequently activates CaMKII and PKA. Blocking any of these pathways prevents the AMPA receptor potentiation caused by Tianeptine, suggesting a cooperative and complex mechanism. Stress is an important precipitating factor of major depressive state (Caspi et al., 2003; Kessler, 1997), and is used to induce mood disorder in animal models (Agid et al., 2007; Anisman and Matheson, 2005; Henn and Vollmayr, 2005; Rocher et al., 2004; Spedding and Lestage, 2005). Various stressors modulate p38 MAPK, p42/44 MAPK and JNK signaling pathways (Lee et al., 2006; Meller et al., 2003; Shen et al., 2004; Yang et al., 2004), which mediate the activity of ion channels and ionotropic receptors (Adams and Sweatt, 2002). Thus, these pathways, in turn, may have negative impact on measures of synaptic plasticity (Gerges and Alkadhi, 2004; Qi et al., 2009; Sweatt, 2001). Interfering with the MAPK pathways and with the negative effects of stressors on synaptic plasticity may be beneficial for the treatment of depressive mood disorders (Agid et al., 2007). Indeed, various antidepressants activate MAPK pathways, such as Tianeptine and imipramine (Peng et al., 2008; Svenningsson et al., 2007), which were also shown to reverse the decrease of MAPK signaling after stress (Qi et al., 2009). Furthermore, acute administration of a blood-brain-barrier permeable MEK inhibitor, PD 184161 caused depressive-like behavior, and blocked the antidepressant-like effects of the monoamine-based antidepressants desipramine and sertraline (Duman et al., 2007), indicating a central role of this pathway in depressive symptoms. We propose that enhancement of AMPA receptor mediated transmission by MAPK pathways activation may be an important antidepressant mechanism.

\section{Conclusion}

In conclusion, this study extends the previous works by showing that Tianeptine potentiates several independent signaling cascades associated with synaptic plasticity and add further evidence that Tianeptine acts as an enhancer of AMPA receptor transmission.

\section{Acknowledgments}

This work was supported by the following Grants: OTKA NK 73672 and OTKA PD 83581 from the Hungarian National Sciences Foundation, NAP BIO Teller and EGISPSYC OM-00166/ 2008 from the National Office for Research and Technology, Hungary. Vetenskapsrådet, Söderbergs stiftelse och Kungliga Vetenskapsakademien.

\section{Appendix A. Supplementary data}

Supplementary data associated with this article can be found, in the online version, at doi:10.1016/j.neuint.2011.10.008.

\section{References}

Adams, J.P., Sweatt, J.D., 2002. Molecular psychology: roles for the ERK MAP kinase cascade in memory. Annu. Rev. Pharmacol. Toxicol. 42, 135-163.

Agid, Y., Buzsaki, G., Diamond, D.M., Frackowiak, R., Giedd, J., Girault, J.A., Grace, A., Lambert, J.J., Manji, H., Mayberg, H., Popoli, M., Prochiantz, A., Richter-Levin, G., Somogyi, P., Spedding, M., Svenningsson, P., Weinberger, D., 2007. How can drug discovery for psychiatric disorders be improved? Nat. Rev. Drug Discov. 6, 189201.

Alt, A., Weiss, B., Ogden, A.M., Li, X., Gleason, S.D., Calligaro, D.O., Bleakman, D., Witkin, J.M., 2006. In vitro and in vivo studies in rats with LY293558 suggest AMPA/kainate receptor blockade as a novel potential mechanism for the therapeutic treatment of anxiety disorders. Psychopharmacology (Berlin) 185, 240-247.

Angst, J., Felder, W., Frey, R., Stassen, H.H., 1978. The course of affective disorders. I. Change of diagnosis of monopolar, unipolar, and bipolar illness. Arch. Psychiatr. Nervenkr. 226, 57-64

Anisman, H., Matheson, K., 2005. Stress, depression, and anhedonia: caveats concerning animal models. Neurosci. Biobehav. Rev. 29, 525-546.

Bernard, K., Danober, L., Thomas, J.Y., Lebrun, C., Munoz, C., Cordi, A., Desos, P., Lestage, P., Morain, P., 2010. DRUG FOCUS: S 18986: a positive allosteric modulator of AMPA-type glutamate receptors pharmacological profile of a novel cognitive enhancer. CNS Neurosci. Ther. 16, e193-e212. 
Berton, O., Nestler, E.J., 2006. New approaches to antidepressant drug discovery: beyond monoamines. Nat. Rev. Neurosci. 7, 137-151.

Bobula, B., Hess, G., 2008. Antidepressant treatments-induced modifications of glutamatergic transmission in rat frontal cortex. Pharmacol. Rep. 60, 865-871.

Caspi, A., Sugden, K., Moffitt, T.E., Taylor, A., Craig, I.W., Harrington, H., McClay, J., Mill, J., Martin, J., Braithwaite, A., Poulton, R., 2003. Influence of life stress on depression: moderation by a polymorphism in the 5-HTT gene. Science 301, 386-389.

Coppen, A.J., Doogan, D.P., 1988. Serotonin and its place in the pathogenesis of depression. J. Clin. Psychiatry 49 (Suppl.), 4-11.

Coyle, J.T., Duman, R.S., 2003. Finding the intracellular signaling pathways affected by mood disorder treatments. Neuron 38, 157-160.

Debanne, D., Thompson, S.M., Gahwiler, B.H., 2006. A brief period of epileptiform activity strengthens excitatory synapses in the rat hippocampus in vitro. Epilepsia 47, 247-256.

Dozmorov, M., Li, R., Xu, H.P., Jilderos, B., Wigstrom, H., 2004. Slowly developing depression of N-methyl-D-aspartate receptor mediated responses in young rat hippocampi. BMC Neurosci. 5, 26.

Du, J., Gray, N.A., Falke, C.A., Chen, W., Yuan, P., Szabo, S.T., Einat, H., Manji, H.K., 2004. Modulation of synaptic plasticity by antimanic agents: the role of AMPA glutamate receptor subunit 1 synaptic expression. J. Neurosci. 24, 6578-6589.

Duman, C.H., Schlesinger, L., Kodama, M., Russell, D.S., Duman, R.S., 2007. A role for MAP kinase signaling in behavioral models of depression and antidepressant treatment. Biol. Psychiatry 61, 661-670.

Gerges, N.Z., Alkadhi, K.A., 2004. Hypothyroidism impairs late LTP in CA1 region but not in dentate gyrus of the intact rat hippocampus: MAPK involvement. Hippocampus 14, 40-45.

Hayashi, Y., Shi, S.H., Esteban, J.A., Piccini, A., Poncer, J.C., Malinow, R., 2000. Driving AMPA receptors into synapses by LTP and CaMKII: requirement for GluR1 and PDZ domain interaction. Science 287, 2262-2267.

Henn, F.A., Vollmayr, B., 2005. Stress models of depression: forming genetically vulnerable strains. Neurosci. Biobehav. Rev. 29, 799-804

Huber, K.M., Mauk, M.D., Thompson, C., Kelly, P.T., 1995. A critical period of protein kinase activity after tetanic stimulation is required for the induction of longterm potentiation. Learn Memory 2, 81-100.

Kato, G., Weitsch, A.F., 1988. Neurochemical profile of tianeptine, a new antidepressant drug. Clin. Neuropharmacol. 11 (Suppl. 2), S43-S50.

Kessler, R.C., 1997. The effects of stressful life events on depression. Annu. Rev. Psychol. 48, 191-214.

Kole, M.H., Swan, L., Fuchs, E., 2002. The antidepressant tianeptine persistently modulates glutamate receptor currents of the hippocampal CA3 commissural associational synapse in chronically stressed rats. Eur. J. NeuroSci. 16, 807-816.

Lee, H.K., Barbarosie, M., Kameyama, K., Bear, M.F., Huganir, R.L., 2000. Regulation of distinct AMPA receptor phosphorylation sites during bidirectional synaptic plasticity. Nature 405, 955-959.

Lee, E.R., McCool, K.W., Murdoch, F.E., Fritsch, M.K., 2006. Dynamic changes in histone $\mathrm{H} 3$ phosphoacetylation during early embryonic stem cell differentiation are directly mediated by mitogen- and stress-activated protein kinase 1 via activation of MAPK pathways. J. Biol. Chem. 281, 21162-21172.

Li, X., Tizzano, J.P., Griffey, K., Clay, M., Lindstrom, T., Skolnick, P., 2001. Antidepressant-like actions of an AMPA receptor potentiator (LY392098). Neuropharmacology 40, 1028-1033.

Lin, B., Arai, A.C., Lynch, G., Gall, C.M., 2003. Integrins regulate NMDA receptormediated synaptic currents. J. Neurophysiol. 89, 2874-2878.

Magarinos, A.M., Deslandes, A., McEwen, B.S., 1999. Effects of antidepressants and benzodiazepine treatments on the dendritic structure of CA3 pyramidal neurons after chronic stress. Eur. J. Pharmacol. 371, 113-122.

Malinow, R., Malenka, R.C., 2002. AMPA receptor trafficking and synaptic plasticity. Annu. Rev. Neurosci. 25, 103-126.

Manji, H.K., Drevets, W.C., Charney, D.S., 2001. The cellular neurobiology of depression. Nat. Med. 7, 541-547.

Mathers, C.D., Loncar, D., 2006. Projections of global mortality, burden of disease from 2002 to 2030. PLoS Med. 3, e442.

Matsuzaki, K., Miyazaki, K., Sakai, S., Yawo, H., Nakata, N., Moriguchi, S., Fukunaga, K., Yokosuka, A., Sashida, Y., Mimaki, Y., Yamakuni, T., Ohizumi, Y., 2008. Nobiletin, a citrus flavonoid with neurotrophic action, augments protein kinase A-mediated phosphorylation of the AMPA receptor subunit, GluR1, and the postsynaptic receptor response to glutamate in murine hippocampus. Eur. J. Pharmacol. 578, 194-200.

McCormick, L.M., Boles Ponto, L.L., Pierson, R.K., Johnson, H.J., Magnotta, V., Brumm, M.C., 2007. Metabolic correlates of antidepressant and antipsychotic response in patients with psychotic depression undergoing electroconvulsive therapy. J. Ect 23, 265-273.

McEwen, B.S., 2000. The neurobiology of stress: from serendipity to clinical relevance. Brain Res. 886, 172-189.
McEwen, B.S., Olie, J.P., 2005. Neurobiology of mood, anxiety, and emotions as revealed by studies of a unique antidepressant: tianeptine. Mol. Psychiatry 10 525-537.

McEwen, B.S., Chattarji, S., Diamond, D.M., Jay, T.M., Reagan, L.P., Svenningsson, P., Fuchs, E., 2010. The neurobiological properties of tianeptine (Stablon): from monoamine hypothesis to glutamatergic modulation. Mol. Psychiatry 15, 237249.

McKie, S., Del-Ben, C., Elliott, R., Williams, S., del Vai, N., Anderson, I., Deakin, J.F. 2005. Neuronal effects of acute citalopram detected by pharmacoMRI. Psychopharmacology (Berlin) 180, 680-686.

Meller, E., Shen, C., Nikolao, T.A., Jensen, C., Tsimberg, Y., Chen, J., Gruen, R.J., 2003 Region-specific effects of acute and repeated restraint stress on the phosphorylation of mitogen-activated protein kinases. Brain Res. 979, 57-64.

Peng, C.H., Chiou, S.H., Chen, S.J., Chou, Y.C., Ku, H.H., Cheng, C.K., Yen, C.J., Tsai, T.H., Chang, Y.L., Kao, C.L., 2008. Neuroprotection by imipramine against lipopolysaccharide-induced apoptosis in hippocampus-derived neural stem cells mediated by activation of BDNF and the MAPK pathway. Eur. Neuropsychopharmacol. 18, 128-140.

Qi, H., Mailliet, F., Spedding, M., Rocher, C., Zhang, X., Delagrange, P., McEwen, B., Jay, T.M., Svenningsson, P., 2009. Antidepressants reverse the attenuation of the neurotrophic MEK/MAPK cascade in frontal cortex by elevated platform stress reversal of effects on LTP is associated with GluA1 phosphorylation. Neuropharmacology 56, 37-46.

Qiu, S., Zhao, L.F., Korwek, K.M., Weeber, E.J., 2006. Differential reelin-induced enhancement of NMDA and AMPA receptor activity in the adult hippocampus. J. Neurosci. 26, 12943-12955.

Rocher, C., Spedding, M., Munoz, C., Jay, T.M., 2004. Acute stress-induced changes in hippocampal/prefrontal circuits in rats: effects of antidepressants. Cereb. Cortex 14, 224-229.

Romberg, C., Raffel, J., Martin, L., Sprengel, R., Seeburg, P.H., Rawlins, J.N., Bannerman, D.M., Paulsen, O., 2009. Induction and expression of GluA1 (GluR-A)-independent LTP in the hippocampus. Eur. J. NeuroSci. 29, 1141-1152.

Schaefer, H.S., Putnam, K.M., Benca, R.M., Davidson, RJ., 2006. Event-related functional magnetic resonance imaging measures of neural activity to positive social stimuli in pre- and post-treatment depression. Biol. Psychiatry 60, 974-986.

Schulz, P.E., Fitzgibbons, J.C., 1997. Differing mechanisms of expression for shortand long-term potentiation. J. Neurophysiol. 78, 321-334.

Shakesby, A.C., Anwyl, R., Rowan, M.J., 2002. Overcoming the effects of stress on synaptic plasticity in the intact hippocampus: rapid actions of serotonergic and antidepressant agents. J. Neurosci. 22, 3638-3644.

Sheline, Y.I., 1996. Hippocampal atrophy in major depression: a result of depression-induced neurotoxicity? Mol. Psychiatry 1, 298-299.

Shen, C.P., Tsimberg, Y., Salvadore, C., Meller, E., 2004. Activation of Erk and JNK MAPK pathways by acute swim stress in rat brain regions. BMC Neurosci. 5, 36

Spedding, M., Lestage, P., 2005. Synaptic plasticity and neuropathology: new approaches in drug discovery. Med. Sci. (Paris) 21, 104-109.

Svenningsson, P., Tzavara, E.T., Witkin, J.M., Fienberg, A.A., Nomikos, G.G., Greengard, P., 2002. Involvement of striatal and extrastriatal DARPP-32 in biochemical and behavioral effects of fluoxetine (Prozac). Proc. Natl. Acad. Sci. USA 99, 3182-3187.

Svenningsson, P., Bateup, H., Qi, H., Takamiya, K., Huganir, R.L., Spedding, M., Roth B.L., McEwen, B.S., Greengard, P., 2007. Involvement of AMPA receptor phosphorylation in antidepressant actions with special reference to tianeptine. Eur. J. NeuroSci. 26, 3509-3517.

Sweatt, J.D., 2001. The neuronal MAP kinase cascade: a biochemical signal integration system subserving synaptic plasticity and memory. J. Neurochem. 76, 1-10.

Uhasz, G.J., Barkoczi, B., Vass, G., Datki, Z., Hunya, A., Fulop, L., Budai, D., Penke, B., Szegedi, V., 2010. Fibrillar Abeta $\{1-42\}$ enhances NMDA receptor sensitivity via the integrin signaling pathway. J. Alzheimers Dis. 19, 1055-1067.

Volianskis, A., Jensen, M.S., 2003. Transient and sustained types of long-term potentiation in the CA1 area of the rat hippocampus. J. Physiol. 550, 459-492.

Watanabe, Y., Gould, E., Daniels, D.C., Cameron, H., McEwen, B.S., 1992. Tianeptine attenuates stress-induced morphological changes in the hippocampus. Eur. J. Pharmacol. 222, 157-162.

Yang, C.H., Huang, C.C., Hsu, K.S., 2004. Behavioral stress modifies hippocampal synaptic plasticity through corticosterone-induced sustained extracellular signal-regulated kinase/mitogen-activated protein kinase activation. J Neurosci. 24, 11029-11034.

Zoladz, P.R., Park, C.R., Munoz, C., Fleshner, M., Diamond, D.M., 2008. Tianeptine: an antidepressant with memory-protective properties. Curr. Neuropharmacol. 6, 311-321. 


\title{
Fibrillar $\mathrm{A} \beta_{1-42}$ Enhances NMDA Receptor Sensitivity via the Integrin Signaling Pathway
}

\author{
Gábor Juhász ${ }^{\mathrm{a}}$, Balázs Barkóczi ${ }^{\mathrm{b}}$, Gabriella Vass ${ }^{\mathrm{a}}$, Zsolt Datki ${ }^{\mathrm{b}}$, Ákos Hunya ${ }^{\mathrm{a}}$, Lívia Fülöp ${ }^{\mathrm{a}}$, \\ Dénes Budai ${ }^{\mathrm{c}}$, Botond Penke ${ }^{\mathrm{a}, \mathrm{b}}$ and Viktor Szegedi ${ }^{\mathrm{b}, *}$ \\ ${ }^{a}$ Department of Medical Chemistry, University of Szeged, Szeged, H-6720, Hungary \\ ${ }^{\mathrm{b}}$ Bay Zoltán Foundation of Applied Research - BAYGEN Institute, Szeged, H-6727, Hungary \\ ${ }^{\mathrm{c}}$ Department of Environmental Biology, University of Szeged, Szeged, H-6726, Hungary
}

Handling Associate Editor: Ashley Bush

Accepted 9 October 2009

\begin{abstract}
The aggregated form of amyloid- $\beta(\mathrm{A} \beta)_{1-42}$ has been shown to increase N-methyl-D-aspartic acid (NMDA) evoked neuronal activity in vivo. Here we further characterized this phenomenon by investigating the role of integrin activation and downstream Src kinase activity using in vivo electrophysiology and in vitro intracellular $\mathrm{Ca}^{2+}$ measurements. Pretreatment of differentiated SH-SY5Y cells with fibrillar $\mathrm{A} \beta_{1-42}$ markedly enhanced the intracellular calcium increases caused by NMDA receptor (NMDA-R) stimulation. Function blocking antibody against $\beta 1$ integrin depressed the facilitatory effects of $\mathrm{A} \beta_{1-42}$. Similarly, $\mathrm{A} \beta_{1-42}$ facilitated NMDA-R driven firing of hippocampal neurons in vivo, and this effect was reduced by neutralizing antibody against $\beta 1$ integrins. The positive action of $\mathrm{A} \beta_{1-42}$ on NMDA-R dependent responses was also depressed by an inhibitor known to block Src kinase. These results support the hypothesis that aggregated $\mathrm{A} \beta_{1-42}$ is recognized by the $\beta 1$ subunit containing integrins and may induce a Src kinase dependent NMDA receptor phosphorylation.
\end{abstract}

Keywords: Alzheimer's disease, amyloid- $\beta$, calcium influx, integrin, NMDA receptor, single-unit, Src kinase

\section{INTRODUCTION}

One pathological hallmark of Alzheimer's disease $(\mathrm{AD})$ is the presence of extracellular plaques in the brain, which are mainly composed of an aggregation prone peptide, amyloid- $\beta(\mathrm{A} \beta)_{1-42}$ [1]. Considerable evidence indicates that early $\mathrm{AD}$ is a synaptic disease and $\mathrm{A} \beta_{1-42}$ has a central role in the synaptotoxicity leading to cognitive dysfunction [2]. The mild cognitive impairment preceding $\mathrm{AD}$ is hypothesized to be due to synaptic dysfunction most likely caused by accumulated $\mathrm{A} \beta$ species [3]. Recently, the small molec-

*Correspondence to: Viktor Szegedi Ph.D., Bay Zoltán Foundation of Applied Research - BAYGEN Institute, Szeged, Derkovits avenue 2., H-6727, Hungary. Tel.: +36 62 546788; Fax: +36 62 546974; E-mail: szegediv@ baygen.hu. ular weight $\mathrm{A} \beta$ oligomers have gained much attention as the most likely causes for neuronal degeneration in $\mathrm{AD}$ [4-6]. However, several papers report on the harmful effects of fibrillar $\mathrm{A} \beta$ preparations: they induce neuronal dystrophy $[7,8]$, tau hyperphosphorylation [9], and neuronal death both in vitro $[10,11]$ and in vivo [12]. In addition, a recent paper by Minkeviciene and colleagues identified fibrillar $\mathrm{A} \beta$ species as the pathogenetic entities causing neuronal hyperexcitation [13]. All of these data suggest that not only do oligomers possess detrimental action, but fibrils may also induce unfavorable cellular effects.

$\mathrm{Ca}^{2+}$ influx through the N-methyl-D-aspartic acid (NMDA)-type glutamate receptor is postulated to play a central role in the pathogenesis of AD (e.g. [14]). Extracellular $\mathrm{A} \beta$ species were repeatedly shown to enhance NMDA receptor function by an unknown pathway [15-21]. Among several membrane proteins, 
$\mathrm{A} \beta_{1-42}$ binds to integrins [22-24] and activates the downstream signaling pathway, including focal adhesion protein paxillin and focal adhesion kinase, which might have a central role in the toxic effect of $\mathrm{A} \beta$ species [25-27]. Furthermore, A $\beta$-induced synaptic plasticity impairment could be prevented by integrin specific antibodies [28] suggesting an early role of this pathway in $\mathrm{AD}$. Integrins are transmembrane, heterodimeric ( $\alpha$ and $\beta$ subunit) receptors that mediate cell-extracellular matrix (ECM) connection [29]. Integrins are involved in the modulation of synaptic plasticity and memory and may affect NMDA receptor efficiency in the adult brain [30,31]. Recently, Wright and colleagues [32] have shown that $\mathrm{A} \beta$-induced neurotoxicity could be prevented by specific integrin-antibodies.

In the present study we investigated the effects of integrin blocking antibodies and a kinase inhibitor known to block Src on $\mathrm{A} \beta$-induced NMDA receptor potentiation by using an intracellular $\left[\mathrm{Ca}^{2+}\right]$ assay. Also, NMDA evoked neuronal firing was recorded by in vi$v o$ single-unit activity. In conclusion, blocking of either $\mathrm{A} \beta$-integrin interaction or integrin kinase activation prevented the excitation and the consequent enhancement of the intracellular $\left[\mathrm{Ca}^{2+}\right]$ level induced by $\mathrm{A} \beta$.

\section{MATERIALS AND METHODS}

Preparation of $A \beta_{1-42}$ fibrils

Synthesis of $\mathrm{A} \beta_{1-42}$ was performed in-house as previously reported [33]. Protected amino acids and coupling reagents were purchased from Orpegen Pharma (Heidelberg, Germany), while solvents were from Sigma-Aldrich (St. Louis, Missouri, USA). All chemicals were used without additional purification. The purified $\mathrm{A} \beta_{1-42}$ was dissolved in MilliQ water to a concentration of $500 \mu \mathrm{g} / \mathrm{ml}$ (pH of the resulting solution was 4.2 ), sonicated for $10 \mathrm{~min}$, and incubated overnight at $37^{\circ} \mathrm{C}$ to facilitate the formation of fibrils. In order to remove the insoluble pre-aggregates of $\mathrm{A} \beta_{1-42}$, the stock solution was centrifuged at $1000 \mathrm{~g}$ for $1 \mathrm{~min}$. Then the supernatant, which showed only a slight opacity, was lyophilized to dryness. Prior to the measurements, the fibrillar $\mathrm{A} \beta_{1-42}$ was resuspended in physiological salt solution.

\section{Transmission electron microscopy methodology}

Solutions of $10 \mu 1$ droplets were placed onto carbonfilm coated 400 mesh copper grids (Electron Mi- croscopy Sciences, Washington DC, USA) and incubated for $2 \mathrm{~min}$. The specimen was fixed with $0.5 \%$ (v/v) glutaraldehyde solution for $1 \mathrm{~min}$, washed 3 times with MilliQ water, and finally stained with $2 \%(\mathrm{w} / \mathrm{v})$ uranyl acetate (by incubating for $2 \mathrm{~min}$ ). Excess solution was removed by suction with filter paper. Aggregates were studied by a Philips CM 10 transmission electron microscope (FEI Company, Hillsboro, Oregon, USA) operating at $100 \mathrm{kV}$. Images were taken by a Megaview II Soft Imaging System routinely at magnifications of $\times 46,000$, and $\times 64,000$, and analyzed by an AnalySis ${ }^{\circledR} 3.2$ software package (Soft Imaging System GmbH, Münster, Germany).

\section{Cell differentiation}

Differentiated SH-SY5Y human neuroblastoma cell culture was used as previously described [34]. Briefly, cells were grown for 10 days on 96-well plates, and differentiation was initiated by the addition of $10 \mu \mathrm{M}$ retinoic acid (RA) and $16 \mathrm{nM}$ phorbol ester (TPA) dissolved in cell culture medium containing a final concentration of $0.5 \%$ dimethyl sulfoxide (DMSO). On the first day, the number of non-differentiated cells in the wells was $2.5 \times 10^{5}$ cells $/ \mathrm{ml}$ in suspension. After 10 days of differentiation, the cells were bound as a monolayer on the plate, and cell counting resulted in $3 \times$ $10^{5}$ cells $/ \mathrm{cm}^{2}$ (corresponding to $6.5 \times 10^{5}$ cells $/ \mathrm{ml}$ in suspension). Chemicals were purchased from SigmaAldrich, Budapest. A representative figure (Fig. 2) shows SH-SY5Y cells before (A) and after (B) differentiation.

\section{Intracellular $\mathrm{Ca}^{2+}$ concentration measurement}

For intracellular $\left[\mathrm{Ca}^{2+}\right]$ measurements, the Fluo-4 NW Calcium Assay Kit (Cat. No. F36206 from Invitrogen) was used. The kinetics of the change in the fluorescence intensity was measured with a 96-well plate specific NOVOstar OPTIMA plate reader (BMG Labtech). A quick well mode detection form (0.5 s/cycle) was used. The supernatant solution (growth medium) was removed from adherent SH-SY5Y cells with a pipette and a new medium (100 $\mu$ l of the dye loading Hank's solution per well), free from phenol red and differentiating agents such as RA, TPA, and DMSO, was added rapidly to each well at $37^{\circ} \mathrm{C}$. The cells were incubated for $30 \mathrm{~min}$ with a calcium specific dye Fluo-4 (Invitrogen) at $37^{\circ} \mathrm{C}$, and then incubated in ambient temperature for an additional 30 min. The cells were then treated with one of the fol- 
lowing compounds: $10 \mu \mathrm{M}$ PP2, $20 \mu \mathrm{M}$ PP3 (Calbiochem), $20 \mu \mathrm{g} / \mathrm{ml}$ anti- $\beta 1$ integrin antibody, $20 \mu \mathrm{g} / \mathrm{ml}$ anti- $\alpha 2$ integrin antibody (Chemicon), $50 \mu \mathrm{M}$ MK801, and $1 \mu \mathrm{M}$ thapsigargin (Sigma-Aldrich). Distilled water was used for diluting the compounds, thus control wells were treated with the same amount of distilled water. After 15 min incubation periods, the cells received $10 \mu \mathrm{M}$ fibrillar $\mathrm{A} \beta_{1-42}, 10 \mu \mathrm{M}$ nifedipine (Sigma-Aldrich), $30 \mu \mathrm{M}$ N,N,N',N'-Tetrakis-(2pyridylmethyl)-ethylenediamine (TPEN, SigmaAldrich), or, for control purposes, distilled water. Before each assay, the stock solution of $\mathrm{A} \beta$ peptide $(0.5 \mathrm{mM})$ was freshly prepared in bidistilled water. The cells were treated with NMDA ( $1 \mathrm{mM}$ final concentration) using the built-in liquid micro-pipettor of the plate reader, at an injection speed of $100 \mu \mathrm{l} / \mathrm{s}$. The distance between the cells in well and the end of the pipettor was consistently $3 \mathrm{~mm}$. The normalized fluorescence intensity (NFI) was calculated via the following formula: $\%\left[\left(\mathrm{~F}-\mathrm{F}_{0}\right) / \mathrm{F}_{0}\right] . \mathrm{F}_{0}$ is the initial fluorescence intensity of the dyes in the measurements before treatments. $\mathrm{F}$ is the amplitude of the fluorescence intensity caused by the intracellular $\left[\mathrm{Ca}^{2+}\right]$ rise.

\section{In vivo single-unit recordings and iontophoresis}

The previously described method was used [35]. Briefly, the head of chloral hydrate-anesthetized male Wistar rat weighing 280-330 g was mounted in a stereotaxic frame, the skull was opened above the hippocampus (antero-posterior coordinates: -2.8 to -3.8 from bregma; lateral: $2 \mathrm{~mm}$ on either side from the midline), and the dura mater was carefully removed. The location of the electrode was verified by iontophoretic Pontamine Sky Blue ejection ( $-3 \mu \mathrm{A}$ for $15 \mathrm{~min}$ ) followed by conventional histology. The principles of laboratory animal care (NIH publication No. 85-23) and the protocol for animal care was approved and followed by the Hungarian Health Committee (1998) and the European Communities Council Directive of 24 November 1986 (86/609/EEC).

Single-unit activity was recorded extracellularly by means of a low-impedance $(<1 \mathrm{M} \Omega) 7 \mu \mathrm{m}$ carbon fiber-containing microelectrode (Kation Scientific, Minneapolis, MN) [36]. The action potentials were amplified [37], filtered, and then monitored with an oscilloscope. A window discriminator was used for spike discrimination and peristimulus time histogram construction. The amplified signals were sampled and digitalized at $50 \mathrm{kHz}$. The number of action potentials per second was counted by the computer and peristimulus time histograms were calculated, displayed in line and digitally stored for off-line analysis using the DataWave SciWorks software package. Iontophoretic drug delivery and experimental data collection were performed by a multifunction instrument control and data acquisition board PCI-1200 (National Instruments, Austin, Texas, USA) placed in a computer.

The drug barrels of the combined recording/iontophoresis electrode contained one of the following freshly made solutions: $100 \mathrm{mM}$ NMDA Na salt $(\mathrm{pH} 8.0$, Sigma), $0.1 \mathrm{mg} / \mathrm{ml}$ 4-Amino-5-(4-chlorophenyl)-7-(tbutyl)pyrazolo[3,4-d]pyrimidine e(InSolution ${ }^{\circledR}$ PP2, Calbiochem), $0.1 \mathrm{mg} / \mathrm{ml}$ 4-Amino-7-phenylpyrazol pyrimidine (PP3, Calbiochem), $0.1 \mathrm{mg} / \mathrm{ml}$ anti-integrin antibodies (anti- $\beta 1$ integrin, MAB1987Z; anti- $\alpha 2$ integrin, MAB1950Z; pH 9, Chemicon), and $50 \mu \mathrm{M}$ aged $\mathrm{A} \beta_{1-42}$ sample ( $\mathrm{pH}$ 6.4). $\mathrm{A} \beta_{1-42}$ containing samples were sonicated (Merck Eurolab $120 \mathrm{~W}$ apparatus) for 15 min prior to use. NMDA was ejected with negative iontophoretic currents ranging from 10 to $100 \mathrm{nA}$. Retaining currents in the interval 2-16 nA of opposite direction were used. $\mathrm{A} \beta_{1-42}$ was ejected at $-380 \mathrm{nA}$ for $60 \mathrm{sec}$, while PP2 and PP3 were ejected at $+100 \mathrm{nA}$ for $2 \mathrm{~min}$. The anti-integrin antibodies were ejected at $-100 \mathrm{nA}$ for $2 \mathrm{~min}$. Cells were excited by the brief $(5 \mathrm{sec})$, alternating repetitive ejection of NMDA. The interval between two excitation epochs was $60 \mathrm{sec}$.

\section{Data analysis}

Statistical evaluation for the $\mathrm{Ca}^{2+}$ assay data were performed by using the sum of NMDA evoked increase in normalized fluorescence intensity. All data were compared to fA $\beta_{1-42}$ data using ANOVA with post hoc Bonferroni. Statistical evaluations for the in vivo results were performed by using the total number of spikes evoked during each excitation epoch by iontophoretic application of NMDA. The background neuronal discharge was calculated by averaging a $15 \mathrm{~s}$ period of ongoing activity preceding each excitation epoch, and this value was subtracted from all evoked responses. The total spike number during each excitation epoch was calculated and expressed as a percentage of the mean ( \pm SEM), and compared statistically with the data obtained after $\mathrm{A} \beta_{1-42}$ application by using one-way analysis of variance (ANOVA, with the Bonferroni test for post hoc analysis). A $P$ value of $\leqslant 0.05$ was considered significant.

\section{RESULTS}

Transmission electron microscopy

As we intended to study the effect of the fibrillar 


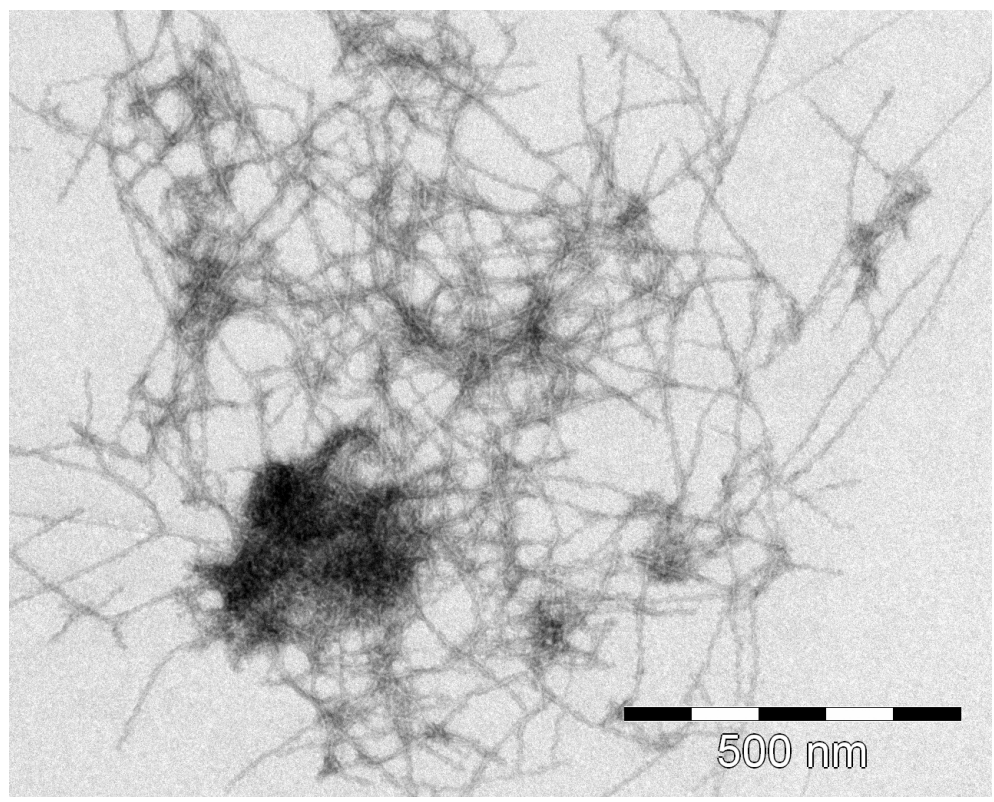

Fig. 1. Transmission electron micrograph of the sample used for the experiments. Mature $\mathrm{A} \beta_{1-42}$ fibrils can be observed with a typical average diameter of 7-10 $\mathrm{nm}$ and length of $0.5-2 \mu \mathrm{m}$

$\mathrm{A} \beta_{1-42}$ on the integrin-mediated NMDA regulation, we applied a standardized protocol to obtain a proper population of $\mathrm{A} \beta_{1-42}$ fibrils. Therefore, we conducted an elongated incubation at a slightly acidic $\mathrm{pH}$ at $37^{\circ} \mathrm{C}$. The lyophilized peptide contained mature fibrils, typically with an average diameter of $7-10 \mathrm{~nm}$, and length of $0.5-2 \mu \mathrm{m}$. After lyophilization the peptide retained its fibrillar structure by forming large bunches of mature fibrils, as represented in Fig. 1.

\section{Intracellular $\left[\mathrm{Ca}^{2+}\right]$ measurement}

$\mathrm{Ca}^{2+}$ influx through NMDA receptors are known to be crucial in $\mathrm{A} \beta_{1-42}$-mediated physiological effects. Thus, we investigated the effect of fibrillar $\mathrm{A} \beta_{1-42}$ on the $\mathrm{Ca}^{2+}$ influx evoked by NMDA-R stimulation. For this purpose, we loaded differentiated SH-SY5Y cells with Fluo-4 calcium dye. We first tested if NMDA triggers $\left[\mathrm{Ca}^{2+}\right] \mathrm{i}$ increase and if this is enhanced by fA $\beta_{1-42}$. Cells were treated with distilled water (DW, for control as the treating compounds were diluted/dissolved in DW) or $\mathrm{fA} \beta_{1-42}$ using the built-in liquid injector. The $\left[\mathrm{Ca}^{2+}\right] \mathrm{i}$ levels were monitored for $9 \mathrm{~min}$. There was no significant difference in the basal fluorescence level (before NMDA introduction) between the treatment groups, suggesting that $\mathrm{fA} \beta_{1-42}$ did not affect intracellular $\mathrm{Ca}^{2+}$ concentration. Nine minutes after DW (control) or $\mathrm{fA} \beta_{1-42}$ application, NMDA was ejected into the medium. The fluorescence intensity quickly increased to $116 \pm 0.2 \%$, (NMDA evoked $\left.\left[\mathrm{Ca}^{2+}\right] \mathrm{i}(\mathrm{NEC})\right)$ and remained at about 117$118 \%$ within the time frame of the measurement in the control wells. In contrast, fA $\beta_{1-42}$ treated cells exhibited a markedly increased NMDA evoked $\left[\mathrm{Ca}^{2+}\right] \mathrm{i}$ (NEC), reaching a maximum of $130.45 \pm 0.4 \%(n=$ $3 ; P \leqslant 0.05$; Fig. 3, Panel A). The signal was specific to NMDA, because injection of the same volume of DW did not elicit any change in fluorescence $(n=3$; Fig. 3, Panel A). Moreover, cells pretreated with $50 \mu \mathrm{M}$ MK-801, a noncompetitive NMDA receptor antagonist, showed only minute changes after NMDA injection (a maximum of $105 \pm 0.1 \%$; $n=3$; Fig. 3, Panel A).

To establish whether inhibiting the integrin-fA $\beta_{1-42}$ interaction would decrease the NEC potentiating effect of fA $\beta_{1-42}$, cells were pretreated either with function blocking anti- $\beta 1$ integrin antibody or anti- $\alpha 2$ integrin antibody for $15 \mathrm{~min}$ before $\mathrm{fA} \beta_{1-42}$ application. Interfering with the $\beta 1$ integrin pathway significantly decreased fA $\beta_{1-42}$-induced NEC increase (a maximum of $116 \pm 2.3 \% ; n=3 ; P \leqslant 0.05$; Fig. 3, Panel B) compared to $\mathrm{fA} \beta_{1-42}$-treated wells on the same plate $(130.3 \pm 0.3 \% ; n=3)$. In contrast, anti- $\alpha 2$ integrin antibody treatment had only a minute NEC decreasing effect (maximum of $125.8 \pm 1.1 \% ; n=3$; Fig. 3, Panel B).

We hypothesized that $\mathrm{fA} \beta_{1-42}$ bound to integrin activates the integrin signaling cascade which alters the phosphorylation state of different NMDA receptor sub- 

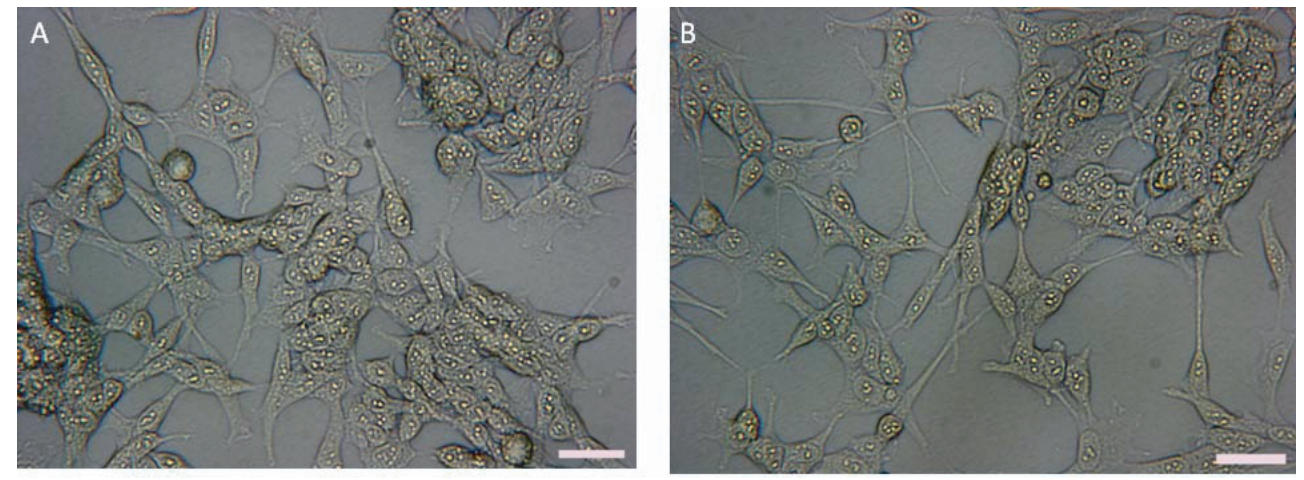

Fig. 2. Human-derived neuroblastoma SH-SY5Y cell line imaged using a phase-contrast microscope. Non-differentiated cells (A) and cells after differentiation (B). Note the long neurites of the differentiated cells. Bar $=20 \mu \mathrm{m}$.
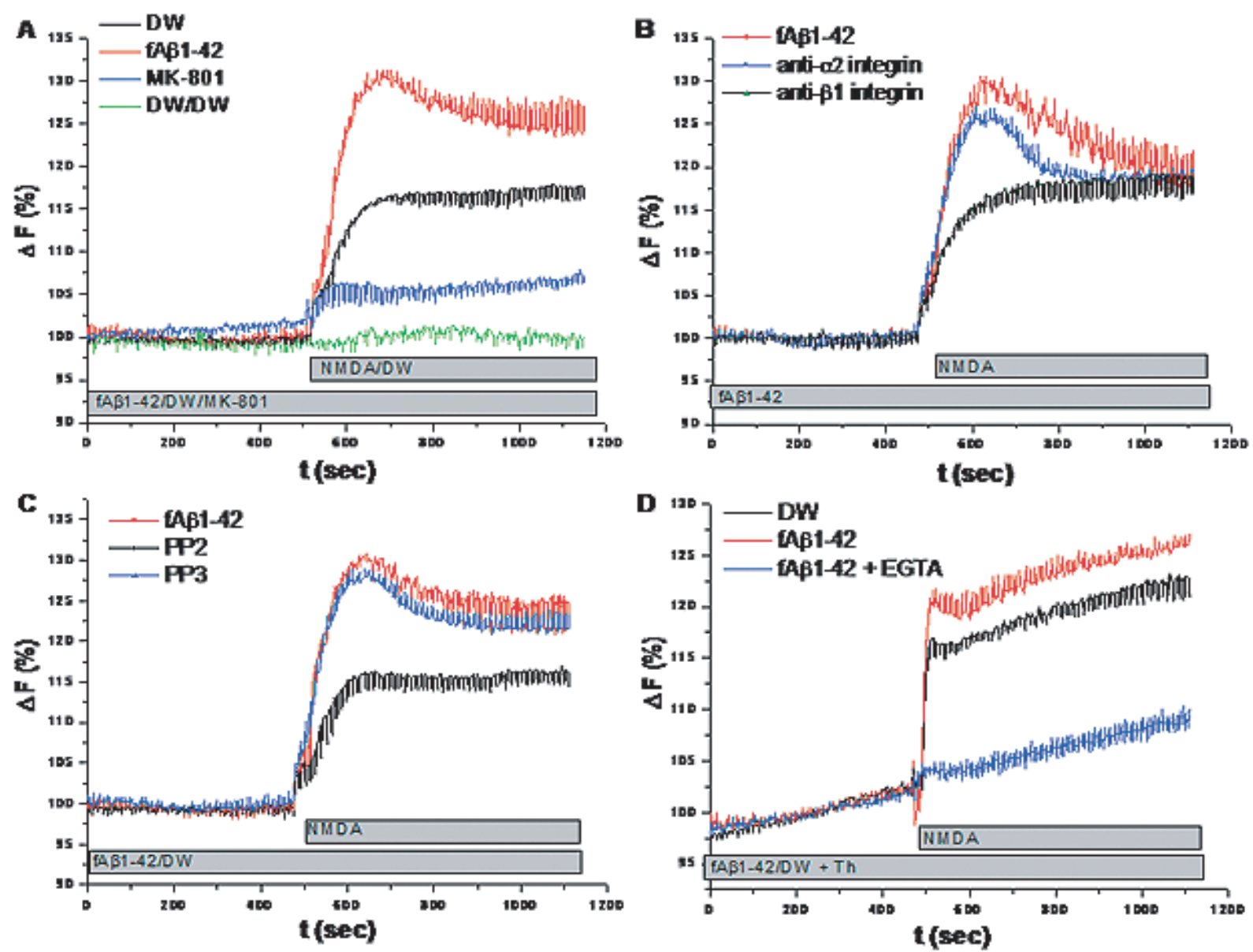

Fig. 3. NMDA evoked intracellular $\left[\mathrm{Ca}^{2+}\right]$ increase (NEC) on a population of differentiated SH-SY5Y neuroblastoma cells. Treating compounds were applied as indicated in the gray rectangles below. NMDA was applied into the medium after 9 min. Fibrillar A $\beta_{1-42}$ enhances NEC compared to control (distilled water treatment, DW, Panel A, B and C). Anti $\beta 1$-integrin antibody prevented, while anti $\alpha 2$-integrin antibody did not affect fA $\beta_{1-42}$ induced NEC increase (Panel B). Blocking the integrin-linked src tyrosine kinase family with PP2 also prevented fA $\beta_{1-42}$ induced NEC enhancement (Panel C). Panel D shows the effect of blocking the intracellular $\mathrm{Ca}^{2+}$ release by thapsigargin on NEC. Fibrillar $\mathrm{A} \beta_{1-42}$ enhanced NEC compared to control. Chelating the extracellular $\mathrm{Ca}^{2+}$ by EGTA prevented NEC. All data points are means of 3 separate measurements. 
units, leading to an increased sensitivity and enhanced NEC to NMDA application. We tested this hypothesis by administering a cell permeable tyrosine kinase family inhibitor known to be specific for Src, PP2, $15 \mathrm{~min}$ prior to $\mathrm{fA} \beta_{1-42}$ treatment. PP2 and $\mathrm{fA} \beta_{1-42}$-treated cells exhibited significantly less NEC (maximum of $116.8 \pm 1 \% ; n=3 ; P \leqslant 0.05$; Fig. 3, Panel C) than cells treated with only fA $\beta_{1-42}$ on the same plate (maximum of $130.8 \pm 0.9 \% ; n=3$ ). Conversely, pretreatment with PP3, an epidermal growth factor receptor tyrosine kinase inhibitor had no impact on the fA $\beta_{1-42^{-}}$ induced NEC increase (maximum of $128 \pm 0.6 \%$; $n=$ 3; Fig. 3, Panel C).

The increase in $\left[\mathrm{Ca}^{2+}\right] \mathrm{i}$ to NMDA injection can be due to exclusive $\mathrm{Ca}^{2+}$ influx or to evoked $\mathrm{Ca}^{2+}$ release from intracellular stores. Therefore we depleted the endoplasmic reticulum, a major source of intracellular $\mathrm{Ca}^{2+}$, by applying $1 \mu \mathrm{M}$ thapsigargin (Th). This compound was shown to specifically inhibit the sarco/endoplasmic reticulum $\mathrm{Ca}^{2+}$-ATPase [38, 39]. Thus, only the NMDA-induced $\mathrm{Ca}^{2+}$ influx is assumed to increase of the fluorescence signal. Cells treated with Th showed a sluggish, but constant rise in the fluorescence, probably due to the ongoing depletion of intracellular $\mathrm{Ca}^{2+}$. Ejection of NMDA caused a steep rise of $\left[\mathrm{Ca}^{2+}\right] \mathrm{i}$ in the control wells, reaching 117 $\pm 1.3 \%(n=3)$. Cells pretreated with fA $\beta_{1-42}$ and Th showed a significantly larger NEC (120.7 $\pm 1.2 \%$; $n=3 ; P \leqslant 0.05$; Fig. 3, Panel D). The fluorescence did not decrease over time compared to the wells which were not treated with Th. This could be due to the blockage of the $\mathrm{Ca}^{2+}$ ATPase, which pumps the cytosolic $\mathrm{Ca}^{2+}$ into the endoplasmic reticulum. In order to check the specificity of NEC in the Th treated cells, we introduced EGTA, a non-permeable specific $\mathrm{Ca}^{2+}$ chelator for binding the extracellular $\mathrm{Ca}^{2+}$. Cells treated with fA $\beta_{1-42}$, Th, and EGTA exhibited a minimal NEC (104.2 $\pm 0.5 \% ; n=3$; Fig. 3, Panel C), showing that after Th treatment, only the influx of extracellular $\mathrm{Ca}^{2+}$ contribute to NEC.

NMDA receptor activation might induce subsequent voltage-gated calcium channels (VGCC) activation, which may participate in the NMDA-induced rise in fluorescence. We pretreated the cells with $10 \mu \mathrm{M}$ nifedipine, a specific L-type VGCC blocker for $9 \mathrm{~min}$, then NMDA was introduced into the medium. The maximum of NEC was $118 \pm 0.8 \%$ ( $n=3$; data not shown), suggesting that it is NMDA receptor activation, which predominantly participates in NEC.

The calcium probe Flou-4 is sensitive to intracellu$\operatorname{lar} \mathrm{Zn}^{2+}$ level, thus we investigated whether NEC has a $\mathrm{Zn}^{2+}$ compound or not. Cells were pretreated by $30 \mu \mathrm{M}$ TPEN, a cell permeable $\mathrm{Zn}^{2+}$ chelator with low affinity for $\mathrm{Ca}^{2+}$, for 9 min before NMDA treatment. NMDA-induced NEC reached $117.17 \pm 0.9 \%(n=3$, data not shown), which is not different from the control data, suggesting that the observed NEC is mainly composed of intracellular $\mathrm{Ca}^{2+}$ rises.

\section{In vivo single-unit electrophysiology}

In order to investigate the role of the integrin pathway in the $\mathrm{fA} \beta_{1-42}$-induced increase of NMDA receptor sensitivity, an electrophysiological approach was utilized. Previously, we have described that aggregated $\mathrm{A} \beta_{1-42}$ enhances NMDA evoked neuronal firing in the CA1 region in vivo (e.g. [18,20,21]. Indeed, after ejecting fA $\beta_{1-42}$, NMDA evoked neuronal firing increased to a maximum of $248 \pm 21 \%$ in 10 recordings out of 13 (Fig. 6). Application of the anti- $\alpha 2$ integrin antibody did not prevent the NMDA triggered firing increase in 7 out of 8 recordings (maximum of $246 \pm 25 \%$; $n=7$; Fig. 6). Figure 3 shows a representative peristimulus histogram of the slowly emerging fA $\beta_{1-42}$ induced NMDA response enhancement, on which $\alpha 2$-integrin antibody did not have any effect (Panel A). A $\beta$ induced not only an increase in spiking rate, but it also caused a widening of the evoked spiketrains. The color coded peri-event time histogram with $100 \mathrm{~ms}$ bin (Panel B) and the average of the firing rate of 5 successive trials before and $30 \mathrm{~min}$ after $\mathrm{fA} \beta_{1-42}$ application shows that the responses gradually became wider and higher, suggesting that the peptide affected NMDA receptor kinetics. Interestingly, the onset of spiking did not change. The red line represents the onset of $5 \mathrm{sec}$ NMDA ejection. Interspike interval (ISI) analysis of evoked spike trains recorded before and 30 min after $\mathrm{fA} \beta_{1-42}$ ejection suggest that the recorded neuron not only fired more spikes in a given time window (see Fig. 4, Panel A), but it also fired more rapidly (data not shown). There was a shift to the left in the ISI histogram, showing that the latency between two successive spikes decreased: the maximum probability was 0.064 at $10 \mathrm{~ms}$ ISI before $\mathrm{A} \beta_{1-42}$, which changed to 0.082 at $7 \mathrm{~ms}$ after $\mathrm{A} \beta_{1-42}$.

On the contrary, single-units which were pretreated with anti- $\beta 1$ integrin antibody before $\mathrm{fA} \beta_{1-42}$ ejection showed no enhancement of NMDA induced spiking rate. Evoked responses remained at the control level, reaching a maximum of $108 \pm 11 \%$ ( $n=10$; Fig. 6 ). The kinetics of NMDA induced spike-trains also did not change during the time frame of the recordings (see 

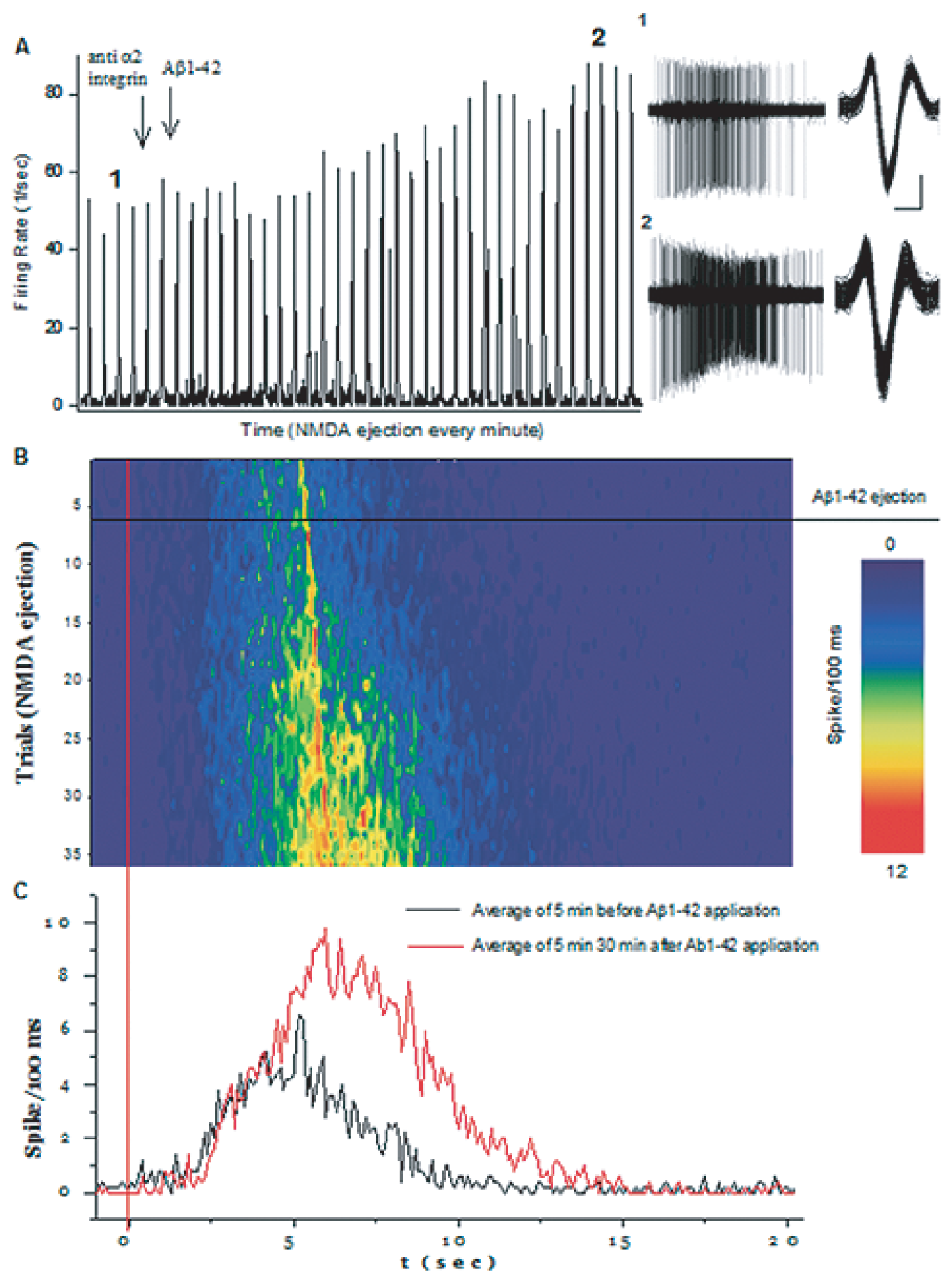

Fig. 4. Representative data of the effects of anti- $\alpha 2$ integrin pretreatment on $\mathrm{A} \beta_{1-42}$ induced enhancement of NMDA-evoked spiking activity. Peristimulus histogram (Panel A) shows the sluggish, yet significant increase of evoked spiking rate of a CA1 neuron after A $\beta_{1-42}$ application. Representative $15 \mathrm{sec}$ long spike trains and the superimposed spikes were recorded at the marked time points ( 1 and 2 on the histogram). The color-coded perievent histogram with $100 \mathrm{~ms}$ bins (Panel B) displays the widening and increase in amplitude of evoked responses. Panel C shows the mean spike number/100 ms of 5 successive NMDA evoked spike-trains before and $30 \mathrm{~min}$ after $\mathrm{A} \beta_{1-42}$ ejection. Red line denotes the onset of 5-sec NMDA ejection. Calibrations are $60 \mu \mathrm{V}$ and $0.8 \mathrm{~ms}$. 
A

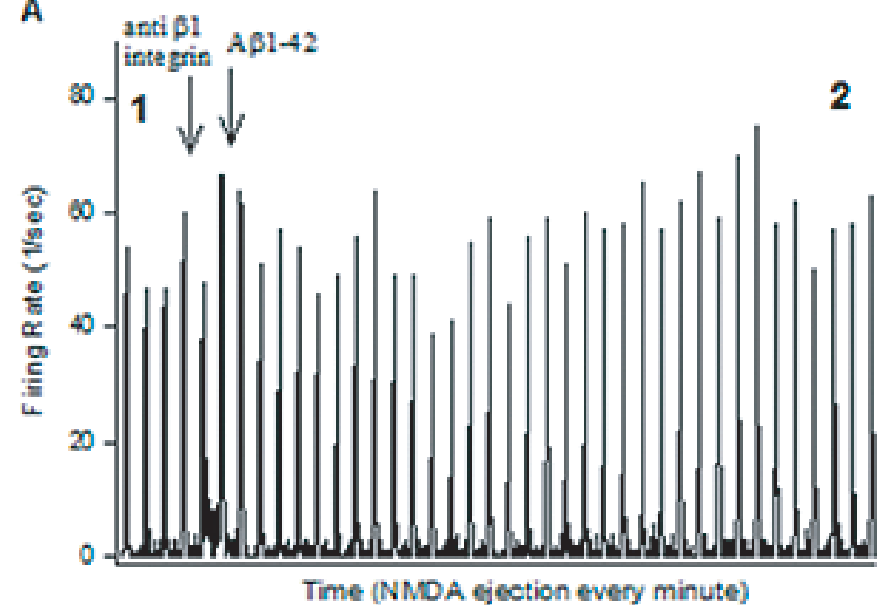

8

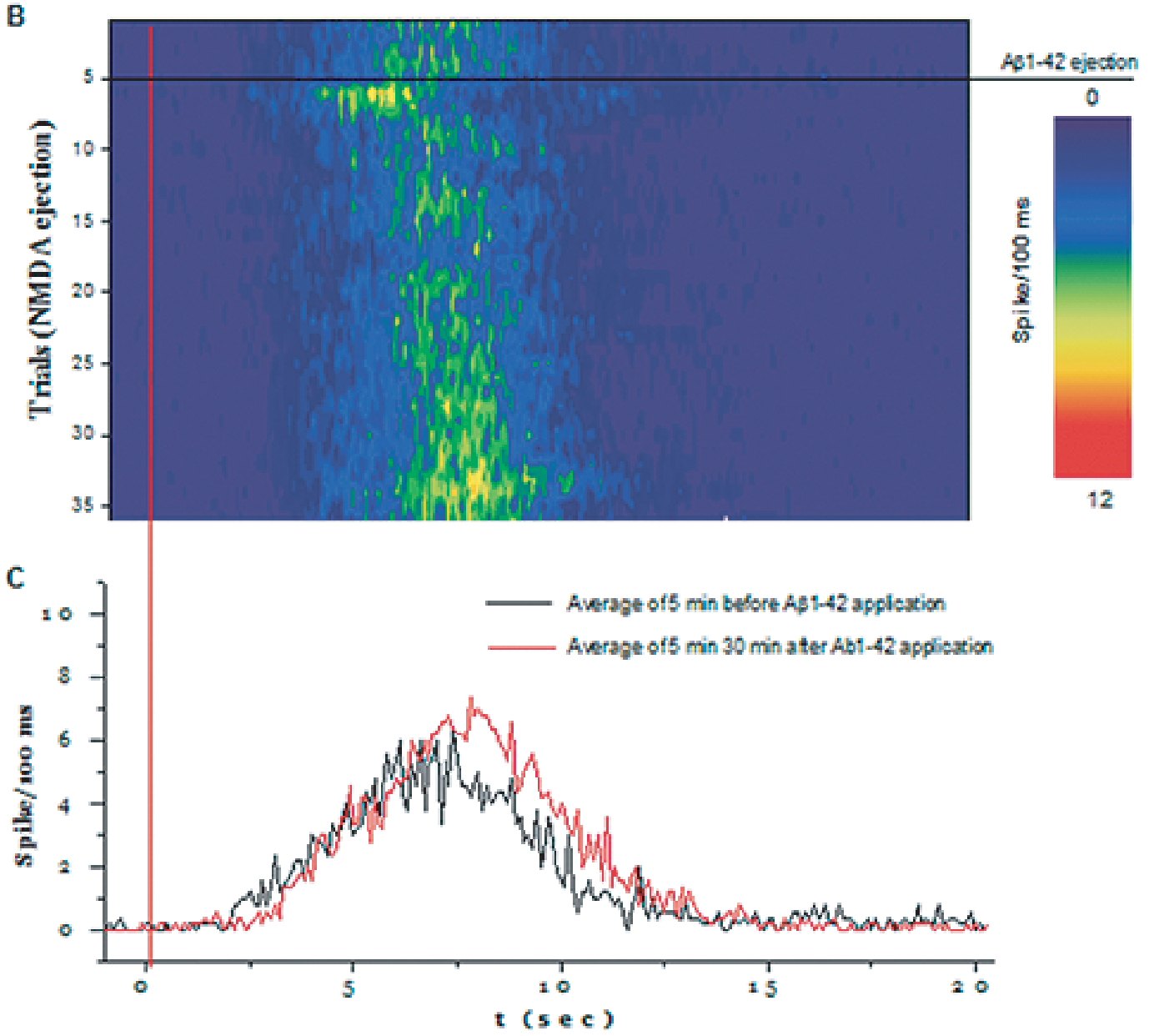

Fig. 5. Representative data of the effects of anti- $\beta 1$ integrin pretreatment on A $\beta_{1-42}$ induced enhancement of NMDA-evoked spiking activity. The peristimulus histogram (Panel A) shows the lack of increase of evoked spiking rate of a CA1 neuron after A $\beta_{1-42}$ application. Representative $15 \mathrm{sec}$ long spike trains and the superimposed spikes were recorded at the marked time points ( 1 and 2 on the histogram). The color-coded perievent histogram with $100 \mathrm{~ms}$ bins (Panel B) displays the lack of widening and increase in amplitude of evoked responses. Panel C shows the mean spike number/100 ms of 5 successive NMDA evoked spike-trains before and 30 min after $\mathrm{A} \beta_{1-42}$ ejection. Red line denotes the onset of 5-sec NMDA ejection. Calibrations are $60 \mu \mathrm{V}$ and $0.8 \mathrm{~ms}$. 


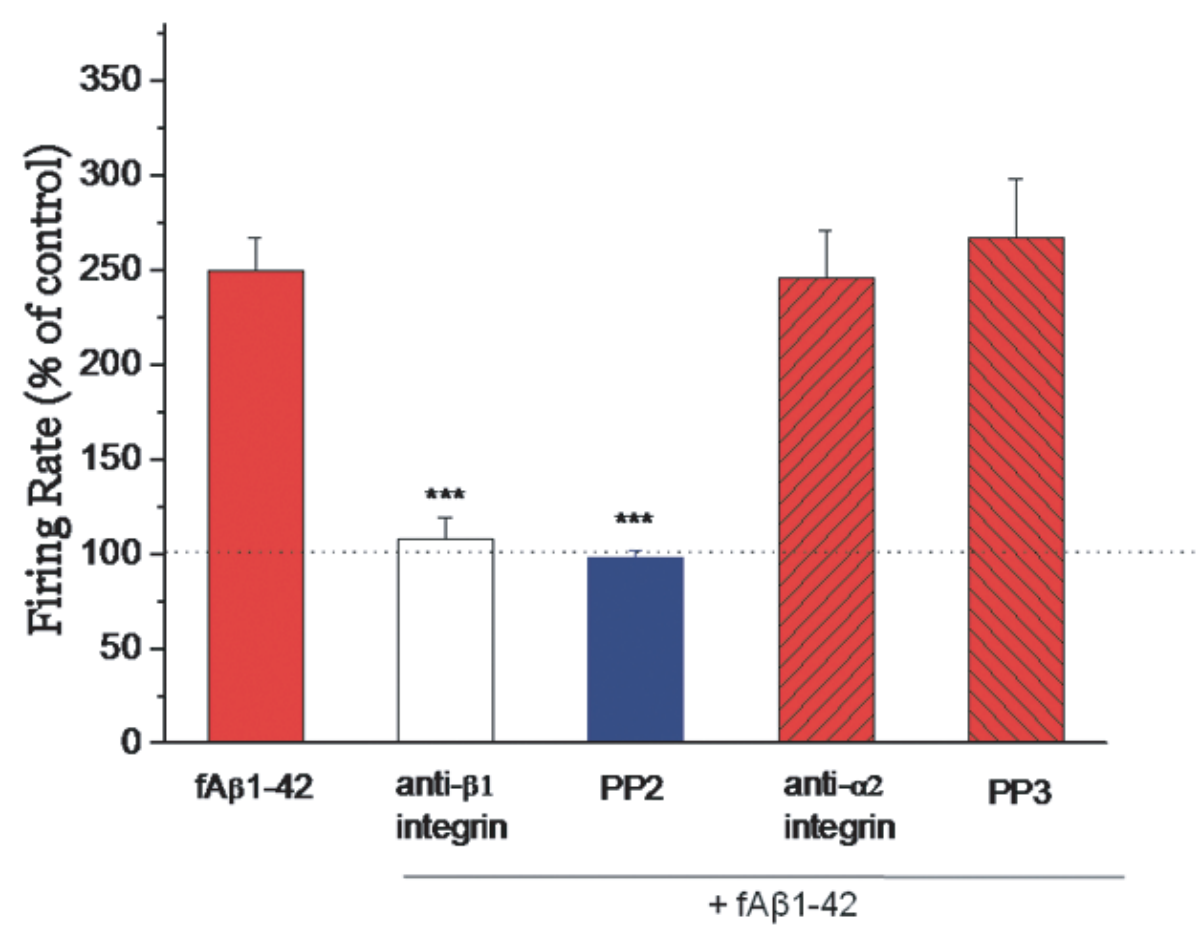

Fig. 6. Summary of the maxima of NMDA evoked spiking rate. Anti- $\beta 1$ integrin antibody and PP 2 pretreatment prevented the excitatory effect of $\mathrm{A} \beta_{1-42}$. Compounds used for control purposes (anti- $\alpha 1$ integrin antibody and PP3) were not effective in interfering with $\mathrm{A} \beta_{1-42}$ induced effect. $* * *$ denotes significant difference compared to fA $\beta_{1-42}$ data at $P \leqslant 0.001$.

Fig. 5, Panel B and C for a representative recording). Moreover, the ISI analysis of the evoked spike-trains revealed no significant difference in the pattern of spiking before (maximum probability was 0.048 at $10 \mathrm{~ms}$ ) and 30 min after $\mathrm{fA} \beta_{1-42}$ ejection (maximum probability was 0.048 at $9 \mathrm{~ms}$ ).

Next we investigated whether blocking the integrin activated src kinase family has an effect on fA $\beta_{1-42}$ induced excitation. Following a control sequence with at least 4 successive NMDA evoked spiking trains, PP2 then fA $\beta_{1-42}$ were ejected. Responses reached a maximum of $98 \pm 4 \%(n=9$; Fig. 6$)$ within 40 min: the $\mathrm{fA} \beta_{1-42}$ induced excitation was prevented. Preejecting of the control EGFR kinase inhibitor PP3 did not modify the rate of NMDA response enhancement after $\mathrm{fA} \beta_{1-42}$ ejection in 6 out of 8 recordings (a maximum of $267 \pm 31 \%$; $n=6$; Fig. 6). These compounds alone did not modify the NMDA evoked responses within the time frame of the experiments: ejecting either anti-integrin antibody had no effect on the responses (maxima of $108 \pm 11 \%$; $n=5$ for anti $\beta 1$ integrin and $98 \pm 10 \% ; n=5$ for anti $\alpha 2$-integrin antibody respectively; data not shown). Similarly, neither tyrosine-kinase inhibitor used affected NMDA re- sponses (maxima of $94 \pm 8 \% ; n=6$ for PP2 and 109 $\pm 8 \% ; n=6$ for PP3 respectively; data not shown).

\section{DISCUSSION}

A widely recognized central event of AD is the aggregation of $\mathrm{A} \beta$ peptides in the brain under which distinct aggregational structures and forms arise from small oligomeric assemblies to larger protofibrillar species [40-43]. The exact pathogenic A $\beta$ entity remains to be identified; however, recently certain oligomeric $\mathrm{A} \beta$ species were proposed to be the initiators of neuronal malfunction and degeneration [44-46]. On the other hand, aggregated $\mathrm{A} \beta$ species have been repeatedly shown to induce neuronal dysfunction and death, probably through a different mechanism than oligomers [47,48]. Recently, Martins and collaborators showed that the direction of the aggregation cycle could be reversed by membrane lipids [49]. They identified oligomers being resolubilized from $\mathrm{A} \beta$ fibrils upon fibril-lipid contact, which they called as "backward" oligomers. Under the circumstances we used for biological experiments, it cannot be excluded that these oligomeric species mediate the observed effects. How- 


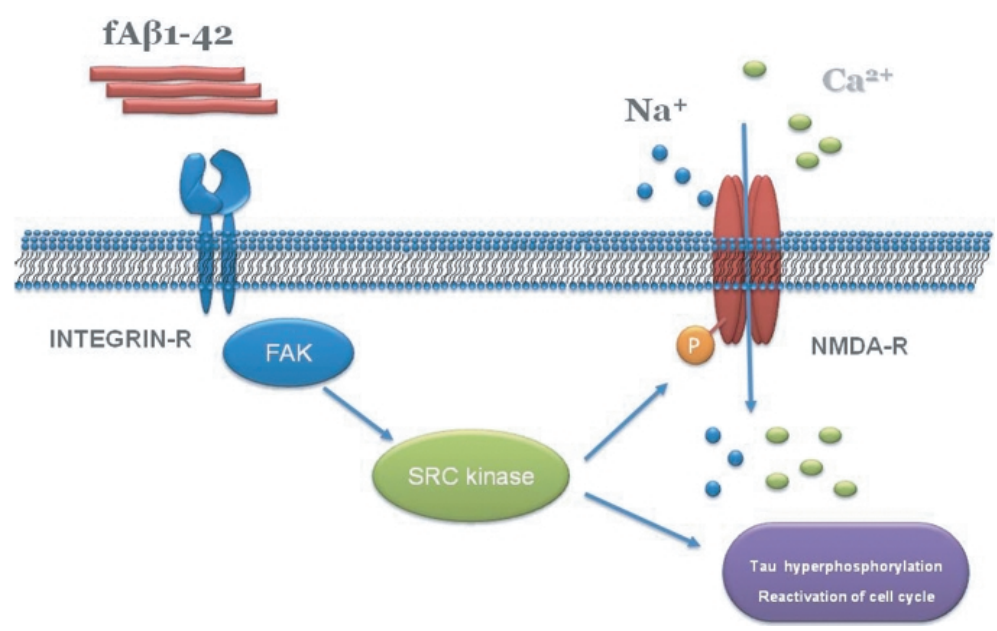

Fig. 7. Proposed mechanism of $\mathrm{fA} \beta_{1-42}$ induced NMDA receptor enhancement. Fibrillar $\mathrm{A} \beta$ is recognized as an extracellular matrix component by the $\beta 1$ subunit containing integrins. Upon binding, the integrin activated molecular cascade is initiating, which involves focal adhesion kinase (FAK), and subsequent src kinase activation, leading to the phosphorylation of NMDA receptors. Increased phosphorylation of NMDA receptors results in enhanced $\mathrm{Ca}^{2+}$ influx and eventually neuronal death. Overactivation of src kinase may cause tau hyperphosphorylation and reactivation of cell cycle.

ever, we have found that $\mathrm{A} \beta_{1-42}$ oligomers and fibrils have divergent effects on neuronal spiking (Juhasz et al, unpublished results), and, based on these data, we propose that the biological activity reported here is most likely due to $\mathrm{A} \beta_{1-42}$ fibrils.

In the present study we have shown that $\mathrm{fA} \beta_{1-42}$ may enhance NMDA receptor function as measured by NMDA evoked $\mathrm{Ca}^{2+}$ influx and NMDA triggered firing rate. Single-unit data shows that the onset of the facilitation is about 9-11 min; therefore we incubated the differentiated neuroblastoma cells in $\mathrm{fA} \beta_{1-42}$ for 9 min before evoking $\mathrm{Ca}^{2+}$ influx. This temporal frame suggests that fA $\beta_{1-42}$ does not affect NMDA-R directly, but through an intracellular signaling cascade. Indeed, blocking the fibrillar $\mathrm{A} \beta$-integrin interaction with a specific antibody or inhibiting the downstream src tyrosine kinase family prevented $\mathrm{A} \beta$ induced excitation. Using differentiated neuroblastoma cells, we also showed that NMDA induced increase in $\left[\mathrm{Ca}^{2+}\right] \mathrm{i}$ is also exacerbated by fibrillar $\mathrm{A} \beta$ and may can be prevented by inhibiting the $\mathrm{A} \beta-\beta 1$ integrin subunit interaction or blocking the src kinase family. We have used an anti- $\alpha 2$ integrin antibody as control, as this integrin subunit has been shown not to be expressed in the hippocampus [50]. Indeed, the control antibody did not prevent the NMDA receptor overexcitation and the resulting increase in $\left[\mathrm{Ca}^{2+}\right] \mathrm{i}$ induced by $\mathrm{fA} \beta_{1-42}$.

Several integrin subunits have been shown to localize in the adult hippocampus synapses [51-56], regulating NMDA receptor function [30,31,57,58], synaptic plasticity, and learning and memory processes $[55,57$,
59-62]. Among the various subunits, $\beta 1$ is expressed abundantly in the central nervous system (CNS) and was shown to be involved in the formation of synaptic plasticity $[60,63]$. Integrins recognize the consensus Arg-Gly-Asp (RGD) tripeptide sequence and have been shown to bind to $\mathrm{A} \beta$ through the similar ArgHis-Asp-Ser (RHDS, A $\beta 4-8$ ) sequence [22,64]. Also, several papers have demonstrated that CNS cells are able to bind to aggregated $\mathrm{A} \beta$ via an integrin dependent mechanism (for review, see $[65,66]$ ) and this interaction activates downstream tyrosine kinases [67]. A $\beta$ induced integrin activation also initiates several molecular pathways. Integrin modulates the activity of glycogen synthase kinase- $3 \beta$ via integrin-linked kinase [6870], which is a key enzyme in the formation of intracellular hyperphosphorylated tau tangles (for a recent review, see [71]), which is a major histological hallmark of AD. In addition, src family kinase activation per se may lead to the formation of hyperphosphorylated tau tangles [72-74]. Furthermore, fibrillar A $\beta$-integrin binding may not only induce tau hyperphosphorylation, but may reactivate the cell-cycle via an src-kinase family dependent pathway, which leads to apoptosis of the terminally differentiated neuron cells [75]. It should be noted, however, that cells with multiple chromosome number have been found in AD brains [76,77] suggesting a terminated cell cycle after the $S$ phase, presumably in the late $G_{2}$ phase [78]. The overexpression of an src-family kinase, namely fyn kinase also exacerbates synapse loss and cognitive impairment in transgenic mice modeling of AD [79]. This suggests a di- 
rect involvement of the src kinase family in the fibrillar $\mathrm{A} \beta$-induced pathological processes. In support of this hypothesis, Shirazi and Wood have demonstrated an elevated level of fyn kinase in human AD brains [80].

Why does integrin receptor bind to aggregated $\mathrm{A} \beta_{1-42}$ ? Integrins readily bind to extracellular matrix (ECM) proteins, like collagen, fibronectin, and laminin. These large proteins form a quasi-fibrillar structure, which resembles the aggregated $\mathrm{A} \beta$. This data supports the hypothesis that fibrillar $\mathrm{A} \beta$ is recognized as a fake extracellular matrix, to which CNS cells bind mainly via integrins [28,32]. In addition, a naturally globular protein albumin can trigger cell death through the integrin pathway when converted into the fibrillar form [68]. Thus, this pathway may represent a uniform signaling event activated by $\beta$-sheet rich fibrillar proteins. We postulate that aggregated misfolded proteins, like $\mathrm{A} \beta_{1-42}$, may either induce an aberrant activation of the integrin pathway, or disrupt the normal ECM-integrin binding. This abnormal ECM may reactivate the cell cycle and thereby cause NMDA receptor excitation, leading to increased $\mathrm{Ca}^{2+}$ influx and subsequent cell death (Fig. 7). Therefore, interfering with either the direct fibrillar $\mathrm{A} \beta$-integrin binding or the downstream src kinase activity may be a promising target for the treatment of $\mathrm{A} \beta$ associated diseases.

In conclusion, we have shown that fibrillar $\mathrm{A} \beta_{1-42}$ acts through the $\beta 1$ subunit containing integrins and potentiates NMDA receptor function. This pathway involves the activation of src-tyrosine kinase family, which presumably leads to the phosphorylation of the NMDA receptor subunits, causing an increased $\mathrm{Ca}^{2+}$ influx upon activation. Therefore, interfering with this pathway may have novel therapeutic relevance applications in neurodegenerative disease.

\section{ACKNOWLEDGMENTS}

This work was supported by the following grants: OTKA NK 73672 from the Hungarian National Sciences Foundation, NAP BIO Teller and EGISPSYC OM-00166/2008 from the National Office for Research and Technology and Memoload FP-7 201159 grant. L.F. acknowledges the postdoctoral grant from the Hungarian Ministry of Education (KPÖ0040/2006). L.F. wishes to thank the Hungarian Academy of Sciences for the support of the János Bolyai Research Grant.

Authors' disclosures available online (http://www.jalz.com/disclosures/view.php?id=177).

\section{REFERENCES}

[1] Berg L, McKeel DW, Jr., Miller JP, Baty J, Morris JC (1993) Neuropathological indexes of Alzheimer's disease in demented and nondemented persons aged 80 years and older. Arch Neurol 50, 349-358.

[2] Selkoe DJ (2008) Soluble oligomers of the amyloid betaprotein impair synaptic plasticity and behavior. Behav Brain Res 192, 106-113.

[3] Rowan MJ, Klyubin I, Wang Q, Hu NW, Anwyl R (2007) Synaptic memory mechanisms: Alzheimer's disease amyloid beta-peptide-induced dysfunction. Biochem Soc Trans 35, 1219-1223.

[4] Sturchler E, Galichet A, Weibel M, Leclerc E, Heizmann CW (2008) Site-specific blockade of RAGE-Vd prevents amyloidbeta oligomer neurotoxicity. J Neurosci 28, 5149-5158.

[5] De Felice FG, Wu D, Lambert MP, Fernandez SJ, Velasco PT, Lacor PN, Bigio EH, Jerecic J, Acton PJ, Shughrue PJ, Chen-Dodson E, Kinney GG, Klein WL (2008) Alzheimer's disease-type neuronal tau hyperphosphorylation induced by A beta oligomers. Neurobiol Aging 29, 1334-1347.

[6] Lacor PN, Buniel MC, Furlow PW, Clemente AS, Velasco PT, Wood M, Viola KL, Klein WL (2007) Abeta oligomer-induced aberrations in synapse composition, shape, and density provide a molecular basis for loss of connectivity in Alzheimer's disease. J Neurosci 27, 796-807.

[7] Hunya A, Foldi I, Szegedi V, Soos K, Zarandi M, Szabo A, Zadori D, Penke B, Datki ZL (2008) Differences between normal and alpha-synuclein overexpressing SH-SY5Y neuroblastoma cells after Abeta(1-42) and NAC treatment. Brain Res Bull 75, 648-654

[8] Grace EA, Rabiner CA, Busciglio J (2002) Characterization of neuronal dystrophy induced by fibrillar amyloid beta: implications for Alzheimer's disease. Neuroscience 114, 265-273.

[9] Busciglio J, Lorenzo A, Yeh J, Yankner BA (1995) betaamyloid fibrils induce tau phosphorylation and loss of microtubule binding. Neuron 14, 879-888.

[10] Mattson MP, Cheng B, Davis D, Bryant K, Lieberburg I, Rydel RE (1992) beta-Amyloid peptides destabilize calcium homeostasis and render human cortical neurons vulnerable to excitotoxicity. J Neurosci 12, 376-389.

[11] Pike CJ, Walencewicz AJ, Glabe CG, Cotman CW (1991) In vitro aging of beta-amyloid protein causes peptide aggregation and neurotoxicity. Brain Res 563, 311-314.

[12] Geula C, Wu CK, Saroff D, Lorenzo A, Yuan M, Yankner BA (1998) Aging renders the brain vulnerable to amyloid betaprotein neurotoxicity. Nat Med 4, 827-831.

[13] Minkeviciene R, Rheims S, Dobszay MB, Zilberter M, Hartikainen J, Fulop L, Penke B, Zilberter Y, Harkany T, Pitkanen A, Tanila H (2009) Amyloid beta-induced neuronal hyperexcitability triggers progressive epilepsy. J Neurosci 29, 3453-3462.

[14] Gardoni F, Di Luca M (2006) New targets for pharmacological intervention in the glutamatergic synapse. Eur J Pharmacol 545, 2-10.

[15] Brorson JR, Bindokas VP, Iwama T, Marcuccilli CJ, Chisholm JC, Miller RJ (1995) The Ca2+ influx induced by beta-amyloid peptide 25-35 in cultured hippocampal neurons results from network excitation. J Neurobiol 26, 325-338.

[16] Wu J, Anwyl R, Rowan MJ (1995) beta-Amyloid selectively augments NMDA receptor-mediated synaptic transmission in rat hippocampus. Neuroreport 6, 2409-2413.

[17] Harkany T, Abraham I, Timmerman W, Laskay G, Toth B, Sasvari M, Konya C, Sebens JB, Korf J, Nyakas C, Zarandi M, 
Soos K, Penke B, Luiten PG (2000) beta-amyloid neurotoxicity is mediated by a glutamate-triggered excitotoxic cascade in rat nucleus basalis. Eur J Neurosci 12, 2735-2745.

[18] Juhasz G, Marki A, Vass G, Fulop L, Budai D, Penke B, Falkay G, Szegedi V (2009) An intraperitoneally administered pentapeptide protects against abeta(1-42) induced neuronal excitation in vivo. J Alzheimers Dis 16, 189-196.

[19] Molnar Z, Soos K, Lengyel I, Penke B, Szegedi V, Budai D (2004) Enhancement of NMDA responses by beta-amyloid peptides in the hippocampus in vivo. Neuroreport 15, 16491652.

[20] Szegedi V, Fulop L, Farkas T, Rozsa E, Robotka H, Kis Z, Penke Z, Horvath S, Molnar Z, Datki Z, Soos K, Toldi J, Budai D, Zarandi M, Penke B (2005) Pentapeptides derived from Abeta 1-42 protect neurons from the modulatory effect of Abeta fibrils-an in vitro and in vivo electrophysiological study. Neurobiol Dis 18, 499-508.

[21] Szegedi V, Juhasz G, Rozsa E, Juhasz-Vedres G, Datki Z, Fulop L, Bozso Z, Lakatos A, Laczko I, Farkas T, Kis Z, Toth G, Soos K, Zarandi M, Budai D, Toldi J, Penke B (2006) Endomorphin-2, an endogenous tetrapeptide, protects against Abeta1-42 in vitro and in vivo. FASEB J 20, 1191-1193.

[22] Sabo S, Lambert MP, Kessey K, Wade W, Krafft G, Klein WL (1995) Interaction of beta-amyloid peptides with integrins in a human nerve cell line. Neurosci Lett 184, 25-28.

[23] Goodwin JL, Kehrli ME, Jr., Uemura E (1997) Integrin Mac-1 and beta-amyloid in microglial release of nitric oxide. Brain Res 768, 279-286.

[24] Jeon YJ, Won HY, Moon MY, Choi WH, Chang CH, Lee JY, Kim J, Kim SC, Kim YS, Park JB (2008) Interaction of microglia and amyloid-beta through beta2-integrin is regulated by RhoA. Neuroreport 19, 1661-1665.

[25] Berg MM, Krafft GA, Klein WL (1997) Rapid impact of betaamyloid on paxillin in a neural cell line. J Neurosci Res 50, 979-989.

[26] Zhang C, Qiu HE, Krafft GA, Klein WL (1996) Protein kinase $\mathrm{C}$ and $\mathrm{F}$-actin are essential for stimulation of neuronal FAK tyrosine phosphorylation by G-proteins and amyloid beta protein. FEBS Lett 386, 185-188

[27] Williamson R, Scales T, Clark BR, Gibb G, Reynolds CH, Kellie S, Bird IN, Varndell IM, Sheppard PW, Everall I, Anderton BH (2002) Rapid tyrosine phosphorylation of neuronal proteins including tau and focal adhesion kinase in response to amyloid-beta peptide exposure: involvement of Src family protein kinases. J Neurosci 22, 10-20.

[28] Wang Q, Klyubin I, Wright S, Griswold-Prenner I, Rowan MJ, Anwyl R (2008) Alpha v integrins mediate beta-amyloid induced inhibition of long-term potentiation. Neurobiol Aging 29, 1485-1493.

[29] Miranti CK, Brugge JS (2002) Sensing the environment: a historical perspective on integrin signal transduction. Nat Cell Biol 4, E83-90.

[30] Juhasz G, Vass G, Bozso Z, Budai D, Penke B, Szegedi V (2008) Integrin activation modulates NMDA and AMPA receptor function of CA1 cells in a dose-related fashion in vivo. Brain Res 1233, 20-26.

[31] Lin B, Arai AC, Lynch G, Gall CM (2003) Integrins regulate NMDA receptor-mediated synaptic currents. J Neurophysiol 89, 2874-2878

[32] Wright S, Malinin NL, Powell KA, Yednock T, Rydel RE, Griswold-Prenner I (2007) Alpha2beta1 and alphaVbeta1 integrin signaling pathways mediate amyloid-beta-induced neurotoxicity. Neurobiol Aging 28, 226-237.
[33] Zarandi M, Soos K, Fulop L, Bozso Z, Datki Z, Toth GK, Penke B (2006) Synthesis of Abeta[1-42] and its derivatives with improved efficiency. J Pept Sci 13, 94-99.

[34] Datki Z, Juhasz A, Galfi M, Soos K, Papp R, Zadori D, Penke B (2003) Method for measuring neurotoxicity of aggregating polypeptides with the MTT assay on differentiated neuroblastoma cells. Brain Res Bull 62, 223-229.

[35] Szegedi V, Juhasz G, Budai D, Penke B (2005) Divergent effects of Abeta1-42 on ionotropic glutamate receptor-mediated responses in CA1 neurons in vivo. Brain Res 1062, 120-126.

[36] Budai D, Molnar Z (2001) Novel carbon fiber microelectrodes for extracellular electrophysiology. Acta Biol Szeged 45, 6573.

[37] Budai D (2004) Ultralow-noise headstage and main amplifiers for extracellular spike recording. Acta Biol Szeged 48, 13-17.

[38] Mintz E, Guillain F (1997) Ca2+ transport by the sarcoplasmic reticulum ATPase. Biochim Biophys Acta 1318, 52-70.

[39] Lin CY, Hilgenberg LG, Smith MA, Lynch G, Gall CM (2008) Integrin regulation of cytoplasmic calcium in excitatory neurons depends upon glutamate receptors and release from intracellular stores. Mol Cell Neurosci 37, 770-780.

[40] Burdick D, Soreghan B, Kwon M, Kosmoski J, Knauer M, Henschen A, Yates J, Cotman C, Glabe C (1992) Assembly and aggregation properties of synthetic Alzheimer's A4/beta amyloid peptide analogs. J Biol Chem 267, 546-554.

[41] Hilbich C, Kisters-Woike B, Reed J, Masters CL, Beyreuther K (1991) Human and rodent sequence analogs of Alzheimer's amyloid beta A4 share similar properties and can be solubilized in buffers of $\mathrm{pH}$ 7.4. Eur J Biochem 201, 61-69.

[42] Isaacs AM, Senn DB, Yuan M, Shine JP, Yankner BA (2006) Acceleration of amyloid beta-peptide aggregation by physiological concentrations of calcium. J Biol Chem 281, 2791627923.

[43] Snyder SW, Ladror US, Wade WS, Wang GT, Barrett LW, Matayoshi ED, Huffaker HJ, Krafft GA, Holzman TF (1994) Amyloid-beta aggregation: selective inhibition of aggregation in mixtures of amyloid with different chain lengths. Biophys $J$ 67, 1216-1228.

[44] Harmeier A, Wozny C, Rost BR, Munter LM, Hua H, Georgiev O, Beyermann M, Hildebrand PW, Weise C, Schaffner W, Schmitz D, Multhaup G (2009) Role of amyloid-beta glycine 33 in oligomerization, toxicity, and neuronal plasticity. $\mathrm{J} \mathrm{Neu}$ rosci $\mathbf{2 9}, \mathbf{7 5 8 2 - 7 5 9 0 .}$

[45] Lesne S, Koh MT, Kotilinek L, Kayed R, Glabe CG, Yang A, Gallagher M, Ashe KH (2006) A specific amyloid-beta protein assembly in the brain impairs memory. Nature 440, 352-357.

[46] Hung LW, Ciccotosto GD, Giannakis E, Tew DJ, Perez K, Masters CL, Cappai R, Wade JD, Barnham KJ (2008) Amyloidbeta peptide (Abeta) neurotoxicity is modulated by the rate of peptide aggregation: Abeta dimers and trimers correlate with neurotoxicity. J Neurosci 28, 11950-11958.

[47] Dahlgren KN, Manelli AM, Stine WB, Jr., Baker LK, Krafft GA, LaDu MJ (2002) Oligomeric and fibrillar species of amyloid-beta peptides differentially affect neuronal viability. J Biol Chem 277, 32046-32053.

[48] Ye C, Walsh DM, Selkoe DJ, Hartley DM (2004) Amyloid beta-protein induced electrophysiological changes are dependent on aggregation state: N-methyl-D-aspartate (NMDA) versus non-NMDA receptor/channel activation. Neurosci Lett 366, 320-325.

[49] Martins IC, Kuperstein I, Wilkinson H, Maes E, Vanbrabant M, Jonckheere W, Van Gelder P, Hartmann D, D'Hooge R, De Strooper B, Schymkowitz J, Rousseau F (2008) Lipids revert 
inert Abeta amyloid fibrils to neurotoxic protofibrils that affect learning in mice. EMBO J 27, 224-233.

[50] Pinkstaff JK, Detterich J, Lynch G, Gall C (1999) Integrin subunit gene expression is regionally differentiated in adult brain. J Neurosci 19, 1541-1556.

[51] Bahr BA, Lynch G (1992) Purification of an Arg-Gly-Asp selective matrix receptor from brain synaptic plasma membranes. Biochem J 281 (Pt 1), 137-142.

[52] Rodriguez MA, Pesold C, Liu WS, Kriho V, Guidotti A, Pappas GD, Costa E (2000) Colocalization of integrin receptors and reelin in dendritic spine postsynaptic densities of adult nonhuman primate cortex. Proc Natl Acad Sci U S A 97, 35503555 .

[53] Einheber S, Schnapp LM, Salzer JL, Cappiello ZB, Milner TA (1996) Regional and ultrastructural distribution of the alpha 8 integrin subunit in developing and adult rat brain suggests a role in synaptic function. J Comp Neurol 370, 105-134.

[54] Nishimura SL, Boylen KP, Einheber S, Milner TA, Ramos DM, Pytela R (1998) Synaptic and glial localization of the integrin alphavbeta8 in mouse and rat brain. Brain Res 791, 271-282.

[55] Chan CS, Weeber EJ, Kurup S, Sweatt JD, Davis RL (2003) Integrin requirement for hippocampal synaptic plasticity and spatial memory. J Neurosci 23, 7107-7116.

[56] Schuster T, Krug M, Stalder M, Hackel N, Gerardy-Schahn $\mathrm{R}$, Schachner M (2001) Immunoelectron microscopic localization of the neural recognition molecules L1, NCAM, and its isoform NCAM180, the NCAM-associated polysialic acid, beta1 integrin and the extracellular matrix molecule tenascin$\mathrm{R}$ in synapses of the adult rat hippocampus. J Neurobiol 49, 142-158.

[57] Shi Y, Ethell IM (2006) Integrins control dendritic spine plasticity in hippocampal neurons through NMDA receptor and $\mathrm{Ca} 2+/$ calmodulin-dependent protein kinase II-mediated actin reorganization. J Neurosci 26, 1813-1822.

[58] Bernard-Trifilo JA, Kramar EA, Torp R, Lin CY, Pineda EA, Lynch G, Gall CM (2005) Integrin signaling cascades are operational in adult hippocampal synapses and modulate NMDA receptor physiology. J Neurochem $\mathbf{9 3}, 834-849$.

[59] Chan CS, Levenson JM, Mukhopadhyay PS, Zong L, Bradley A, Sweatt JD, Davis RL (2007) Alpha3-integrins are required for hippocampal long-term potentiation and working memory. Learn Mem 14, 606-615.

[60] Chan CS, Weeber EJ, Zong L, Fuchs E, Sweatt JD, Davis RL (2006) Beta 1-integrins are required for hippocampal AMPA receptor-dependent synaptic transmission, synaptic plasticity, and working memory. J Neurosci 26, 223-232.

[61] LeBaron RG, Hernandez RV, Orfila JE, Martinez JL, Jr. (2003) An integrin binding peptide reduces rat CA1 hippocampal long-term potentiation during the first few minutes following theta burst stimulation. Neurosci Lett 339, 199-202.

[62] Chang HP, Ma YL, Wan FJ, Tsai LY, Lindberg FP, Lee EH (2001) Functional blocking of integrin-associated protein impairs memory retention and decreases glutamate release from the hippocampus. Neuroscience 102, 289-296.

[63] Staubli U, Chun D, Lynch G (1998) Time-dependent reversal of long-term potentiation by an integrin antagonist. J Neurosci 18, 3460-3469.

[64] Ghiso J, Rostagno A, Gardella JE, Liem L, Gorevic PD, Fran- gione B (1992) A 109-amino-acid C-terminal fragment of Alzheimer's-disease amyloid precursor protein contains a sequence, -RHDS-, that promotes cell adhesion. Biochem J 288 (Pt 3), 1053-1059.

[65] Verdier Y, Penke B (2004) Binding sites of amyloid betapeptide in cell plasma membrane and implications for Alzheimer's disease. Curr Protein Pept Sci 5, 19-31.

[66] Verdier Y, Zarandi M, Penke B (2004) Amyloid beta-peptide interactions with neuronal and glial cell plasma membrane: binding sites and implications for Alzheimer's disease. J Pept Sci 10, 229-248.

[67] Bamberger ME, Harris ME, McDonald DR, Husemann J, Landreth GE (2003) A cell surface receptor complex for fibrillar beta-amyloid mediates microglial activation. J Neurosci 23, 2665-2674.

[68] Huang CY, Liang CM, Chu CL, Liang SM (2009) Albumin fibrillization induces apoptosis via integrin/FAK/Akt pathway. BMC Biotechnol 9, 2.

[69] Ho B, Hou G, Pickering JG, Hannigan G, Langille BL, Bendeck MP (2008) Integrin-linked kinase in the vascular smooth muscle cell response to injury. Am J Pathol 173, 278-288.

[70] Ishii T, Furuoka H, Muroi Y, Nishimura M (2003) Inactivation of integrin-linked kinase induces aberrant tau phosphorylation via sustained activation of glycogen synthase kinase 3beta in N1E-115 neuroblastoma cells. J Biol Chem 278, 26970-26975.

[71] Muyllaert D, Kremer A, Jaworski T, Borghgraef P, Devijver H, Croes S, Dewachter I, Van Leuven F (2008) Glycogen synthase kinase-3beta, or a link between amyloid and tau pathology? Genes Brain Behav 7 Suppl 1, 57-66.

[72] Lesort M, Jope RS, Johnson GV (1999) Insulin transiently increases tau phosphorylation: involvement of glycogen synthase kinase-3beta and Fyn tyrosine kinase. J Neurochem 72, 576-584.

[73] Lee G, Thangavel R, Sharma VM, Litersky JM, Bhaskar K, Fang SM, Do LH, Andreadis A, Van Hoesen G, KsiezakReding H (2004) Phosphorylation of tau by fyn: implications for Alzheimer's disease. J Neurosci 24, 2304-2312.

[74] Bhaskar K, Yen SH, Lee G (2005) Disease-related modifications in tau affect the interaction between Fyn and Tau. $J$ Biol Chem 280, 35119-35125.

[75] Frasca G, Carbonaro V, Merlo S, Copani A, Sortino MA (2008) Integrins mediate beta-amyloid-induced cell-cycle activation and neuronal death. J Neurosci Res 86, 350-355.

[76] Mosch B, Morawski M, Mittag A, Lenz D, Tarnok A, Arendt T (2007) Aneuploidy and DNA replication in the normal human brain and Alzheimer's disease. J Neurosci 27, 6859-6867.

[77] Yang Y, Geldmacher DS, Herrup K (2001) DNA replication precedes neuronal cell death in Alzheimer's disease. $J \mathrm{Neu}$ rosci 21, 2661-2668.

[78] Nagy Z, Esiri MM, Smith AD (1998) The cell division cycle and the pathophysiology of Alzheimer's disease. Neuroscience 87, 731-739.

[79] Chin J, Palop JJ, Puolivali J, Massaro C, Bien-Ly N, Gerstein H, Scearce-Levie K, Masliah E, Mucke L (2005) Fyn kinase induces synaptic and cognitive impairments in a transgenic mouse model of Alzheimer's disease. J Neurosci 25, 96949703.

[80] Shirazi SK, Wood JG (1993) The protein tyrosine kinase, fyn, in Alzheimer's disease pathology. Neuroreport 4, 435-437. 